\title{
Charakterisierung zellulärer Immunantworten von mit SIV immunisierten und infizierten Makaken
}

\author{
Dissertation \\ zur Erlangung des Doktorgrades \\ der Mathematisch-Naturwissenschaftlichen Fakultäten \\ der Georg-August-Universität zu Göttingen
}

\author{
vorgelegt von \\ Reiner Schulte \\ aus Arnsberg
}

Göttingen, den 18.09.2007 
D7

Referent:

Prof. Dr. H.-J. Fritz

Koreferent:

Priv.-Doz. Dr. S. Sopper

Tag der mündlichen Prüfung: $\quad$ 01.11.2007 


\section{Abkürzungsverzeichnis}

Abb.

Abbildung

ADCC engl. antibody dependent cellular cytotoxicity

$\mathrm{AID}_{50}$ $50 \%$ Affen-infektiöse Dosis

AIDS engl. acquired immunodeficiency syndrome

APC-konjugiert Allophycocyanin-konjugiert

AT2-SIV Aldrithiol-2 inaktiviertes SIV

BSA engl. bovine serum albumin

CA Kapsidprotein (engl. capsid protein)

CCR5 engl. chemokine receptor 5

CD engl. cluster of differentiation

$\mathrm{CD}^{+} 195^{+}$ CD195 exprimierende CD4 ${ }^{+}$T-Zellen

CDC engl. Centers for Disease Control and Prevention

CFSE Carboxyfluoresceindiazetatsuccinimylester

$\mathrm{CpG}$ Cytidin-phosphatidyl-Guanosin-Oligonukleotide CTL engl. cytotoxic T-lymphocyte

DMSO

Dimethylsulfoxid

DNA engl. deoxyribonucleic acid

EDTA Ethylendiamintetraessigsäure

ELISA engl. enzyme-linked immunosorbent assay ELISPOT engl. enzyme-linked immuno spot technique engl. englisch et al. und andere (lat. et alii bzw. et aliae) Env engl. envelope

FACS engl. fluorescence activated cell sorting

FCS engl. fetal calf serum

FITC Fluoresceinisothiocyanat FSC Vorwärtsstreulicht (engl. forward scatter)

g Gramm; Erdbeschleunigung

Gag Gruppenspezifisches Antigen

GALT engl. gut-associated lymphoid tissue

gp Glykoprotein

Grp Gruppe

$\mathrm{HCV}$ Hepatitis-C-Virus

HIV Humanes Immundefizienzvirus

HRPO engl. horseradish peroxidase

$I_{50}$ Interquartilabstand (mittlere $50 \%$ aller Daten)

ICS engl. intracellular cytokine staining

IFN Interferon $\lg$ Immunglobulin IL Interleukin i.m. intramuskulär 
lat. lateinisch

LCMV lymphozytäres Choriomeningitis-Virus

LTNP engl. long-term non-progressors

LTR engl. long terminal repeats

mAK monoklonaler Antikörper

Mamu Abkürzung für Macaca mulatta (Rhesusaffe)

$\mathrm{MHC}$ engl. major histocompatibility complex

MIP1a engl. macrophage inflammatory protein $1 \alpha$

MIP1 $\beta$ engl. macrophage inflammatory protein $1 \beta$

mRNA engl. messenger RNA

MUVADEN engl. Mukosal Vaccines Against Human and Simian Immunodeficiency Viruses Based on Dendritic Cells

MVA engl. modified vaccinia Ankara

Nef engl. negative factor

neg. negativ

NK-Zellen Natürliche Killerzellen

PBMC engl. peripheral blood mononuclear cells

PBS engl. phosphate buffered saline

PCR engl. polymerase chain reaction

PE Phycoerythrin

PerCP Peridinin Chlorophyll a-Protein

PFU engl. plague forming unit

$\mathrm{pH}$ $-\log \left[\mathrm{H}^{+}\right]$

PMT engl. photomultiplier tube

Pol. Polymerase

PRR engl. pattern recognition receptors

PVDF Polyvinyldifluorid

RANTES engl. regulated upon activation, normal $T$ cell expressed and presumably secreted

Rev. engl. regulator of expression of virion proteins

RNA engl. ribonucleic acid

rpm Umdrehungen pro Minute (engl. revolutions per minute)

RPM Roswell Park Memorial Institute

RT Reverse Transkriptase; real time

S.C. subkutan (engl. subcutaneous)

SCIV engl. single-cycle immunodeficiency virus

SEB Staphylococcus-Enterotoxin B

SFU engl. spot forming unit

SHIV chimäres Virus aus HIV und SIV

SSC Seitwärtsstreulicht (engl. side scatter) SIV engl. simian immunodeficiency virus

Tab Tabelle

Tat. Transaktivator der Transkription 


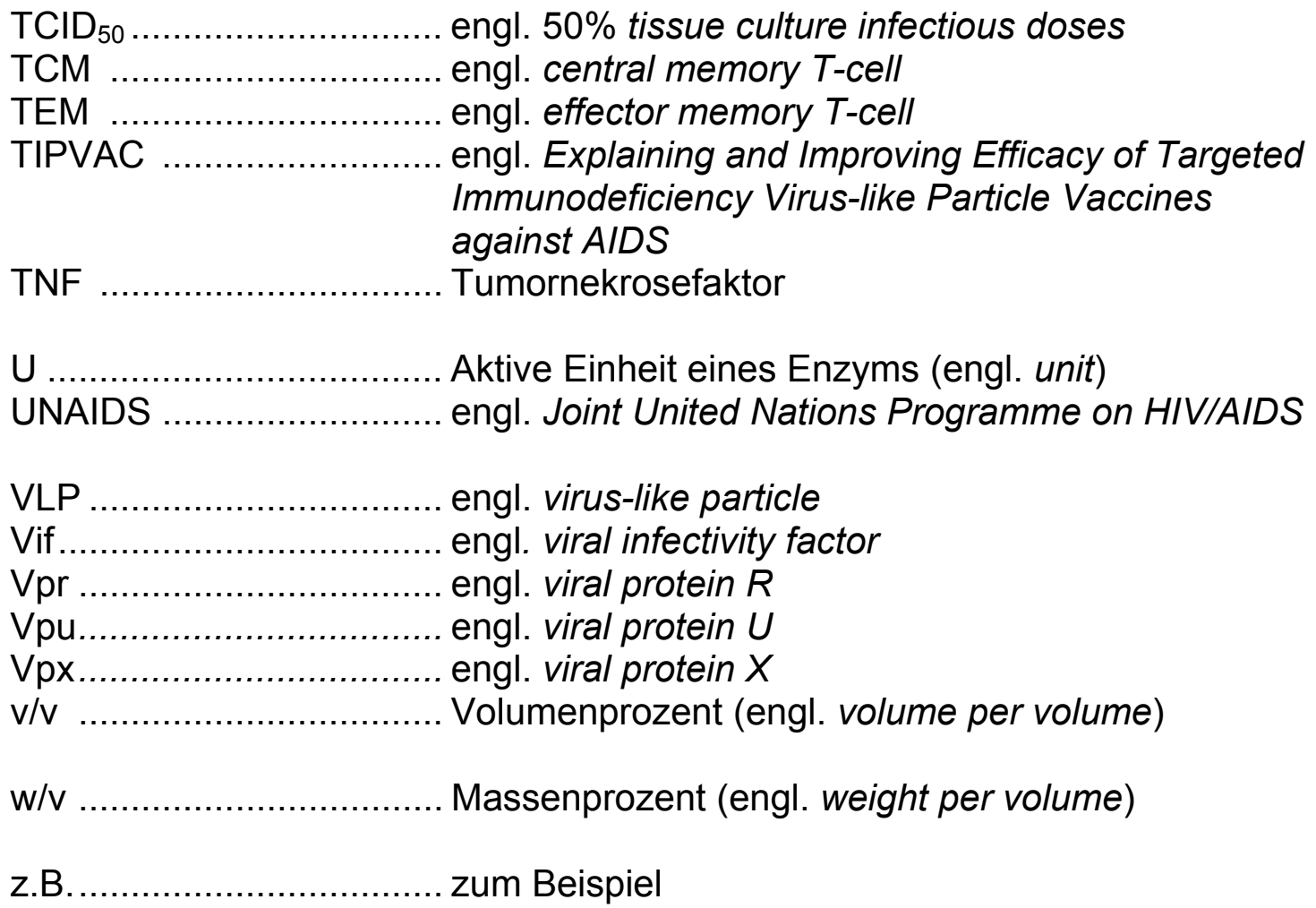




\section{Abkürzungsverzeichnis \\ Inhaltsverzeichnis}

1. EINLEITUNG 1

1.1 Das erworbene Immunschwächesyndrom (AIDS) ......................... 1

1.2 Das Simiane Immundefizienzvirus (SIV) ....................................

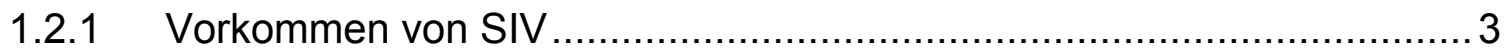

1.2.2 Struktur und Aufbau von SIV ......................................................... 3

1.2.3 Die Organisation des viralen Genoms .......................................... 4

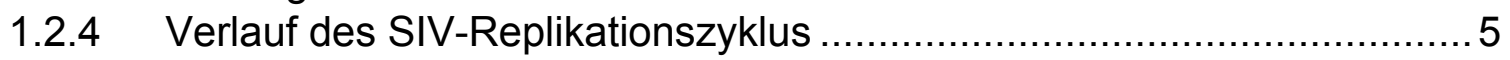

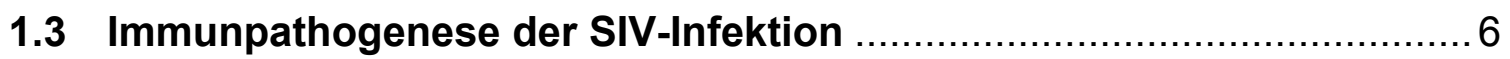

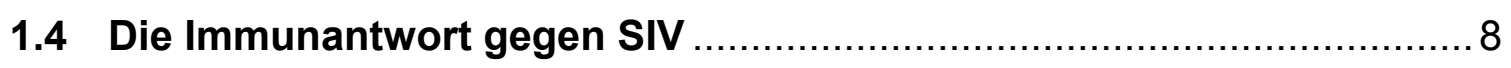

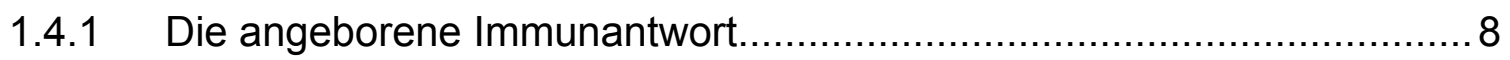

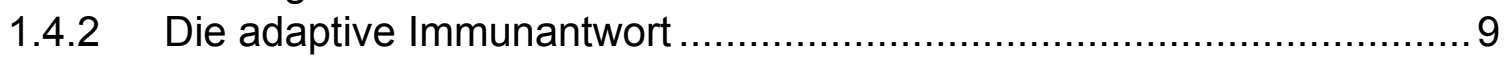

1.4.3 Die Funktion von Zytokinen bei der adaptiven Immunantwort ................ 10

1.4.4 Die Funktion von Gedächtniszellen bei der adaptiven Immunantwort .... 11

1.4.5 Die Tetramer-Technologie zur Messung der zellulären Immunantwort... 13

1.5 Die SIV-Infektion von Rhesusaffen als Tiermodell zur Erforschung der HIV-Infektion des Menschen ................................................. 14

1.6 Die Entwicklungen von Impfstoffen gegen SIV als Modell für die

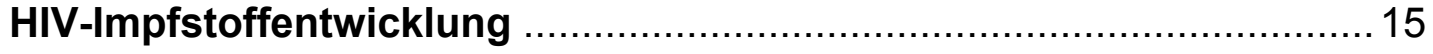

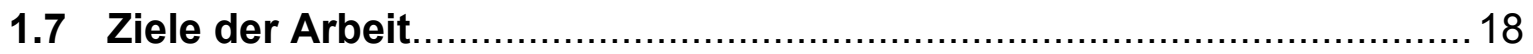

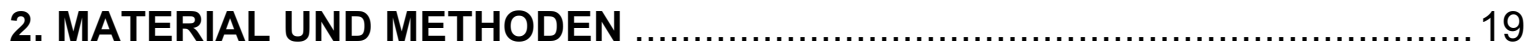

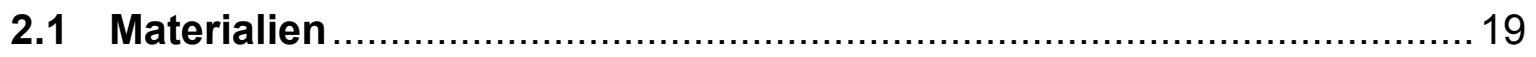

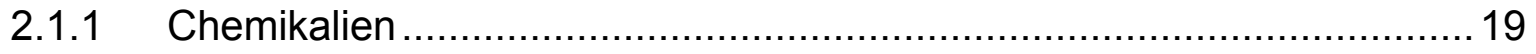

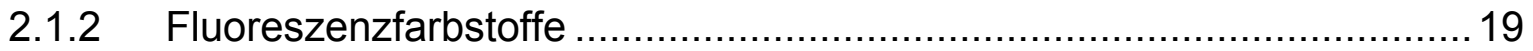

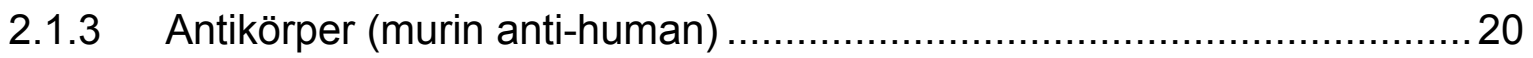

2.1.4 Medien, Puffer und Medienzusätze ............................................... 21

2.1.5 Peptide und inaktiviertes Virus.................................................. 21

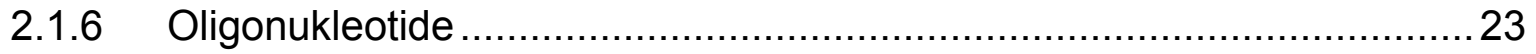

2.1.7 Enzyme und weitere Reagenzien ................................................ 23

2.1.8 Zellkultur- und andere Verbrauchsmaterialien ................................. 23

2.1.9 Geräte.............................................................................. 24

2.1.10 Kommerzielle RNA-Isolations- und PCR-Kits ................................... 24

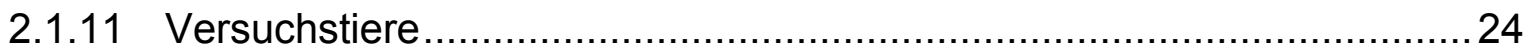

2.1.12 Vakzinekonstrukte und Immunisierungsprotokolle .............................. 25

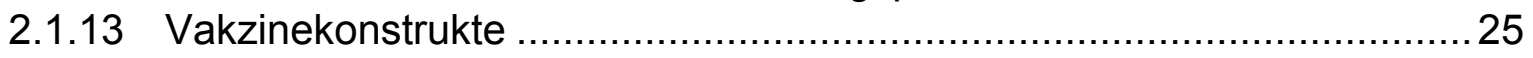

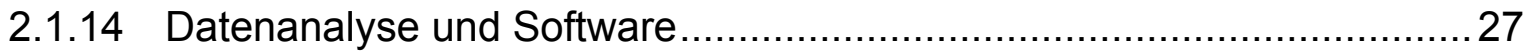

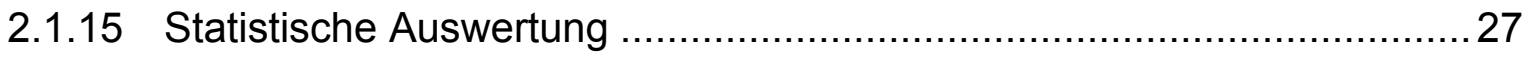




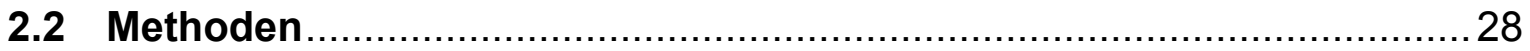

2.2.1 Narkotisierung der Versuchstiere.................................................... 28

2.2.2 Belastungsinfektion der Tiere ........................................................ 28

2.2.3 Erstellung eines Differentialblutbildes ........................................... 28

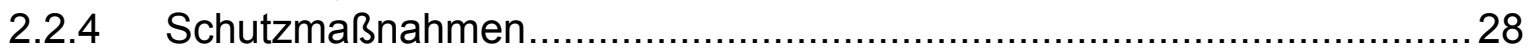

2.2.5 Isolation von Affenleukozyten aus peripherem Blut ...............................29

2.2.6 Vitalitäts- und Zellzahlbestimmung .................................................... 29

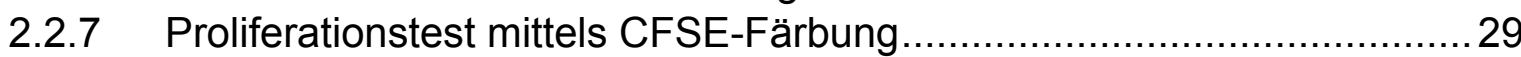

2.2.8 Die polychromatische Durchflusszytometrie ..................................... 30

2.2.8.1 Ermittlungen der optimalen Antikörperkonzentration ..................... 31

2.2.8.2 Vollblutfärbungen ............................................................. 32

2.2.8.3 Antikörper-Kombinationen zur Charakterisierung der Lymphozyten . 32

2.2.8.4 Vollblutfärbung mit Biotin-markierten Antikörpern ............................. 33

2.2.8.5 Intranukleäre Färbung des Proliferationsmarker Ki67 ..................... 33

2.2.8.6 Intrazelluläre Zytokinfärbung (ICS, engl. intracellular cytokine staining) ............................................................................ 34

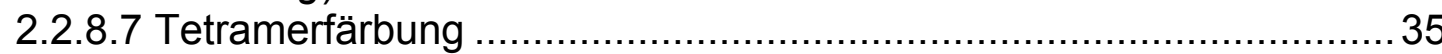

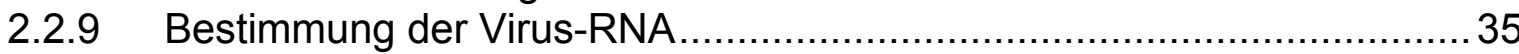

2.2.10 Nachweis von IFNy-sezernierenden Zellen mittels ELISPOT ................. 36

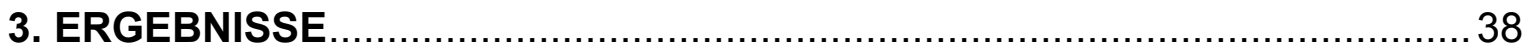

3.1 Ergebnisse der ersten Versuchsreihe (DNA-Ad) ................................ 39

3.1.1 Bestimmung der Anzahl IFNy-sezernierender T-Zellen nach GagStimulation mit der ELISPOT-Technik im Immunisierungszeitraum........39

3.1.2 Bestimmung der Anzahl IFNy-sezernierender T-Zellen nach p26Stimulation mit der ELISPOT-Technik im Immunisierungszeitraum........41 41

3.1.3 Bestimmung der Viruslast nach Belastungsinfektion durch tonsilläre Inokulation von SIVmac239 in der ersten Versuchsreihe mit Hilfe der RT-PCR

3.1.4 Überlebenszeit der Rhesusaffen der ersten Versuchsreihe nach tonsillärer Applikation von SIVmac239

3.1.5 Durchflusszytometrische Untersuchungen der zirkulierenden $\mathrm{CD}^{+}$und $\mathrm{CD}^{+}{ }^{+}$T-Lymphozyten im Blut der Versuchstiere der ersten Versuchsreihe

3.1.5.1 Bestimmung des prozentualen Anteils der CD4 ${ }^{+}$T-Lymphozyten im Blut der Versuchstiere

3.1.5.2 Veränderungen der CD4 ${ }^{+}$Gedächtniszellsubtypen nach Infektion.

3.1.5.3 Veränderungen der $\mathrm{CD}^{+}$Gedächtniszellsubtypen nach Infektion

3.1.6 Bestimmung der Anzahl IFNy-sezernierender T-Zellen nach GagStimulation mit der ELISPOT-Technik nach tonsillärer

Belastungsinfektion.

3.1.7 Bestimmung der Anzahl IFNy-sezernierender T-Zellen nach p26Stimulation mit der ELISPOT-Technik nach tonsillärer Applikation von SIVmac239 
3.2 Ergebnisse der zweiten Versuchsreihe (VLP-Ad)

3.2.1 Bestimmung der Anzahl IFNy-sezernierender T-Zellen nach GagStimulation mit der ELISPOT-Technik im Immunisierungszeitraum.

3.2.2 Bestimmung der Viruslast nach Belastungsinfektion durch tonsilläre Inokulation von SIVmac239 in der zweiten Versuchsreihe mit Hilfe der RT-PCR

3.2.3 Überlebenszeit der Rhesusaffen der zweiten Versuchsreihe nach tonsillärer Inokulation von SIVmac239.

3.2.4 Durchflusszytometrische Untersuchungen zirkulierender CD4 ${ }^{+}$und $\mathrm{CD}^{+}$T-Lymphozyten im Blut der Versuchstiere der zweiten Versuchsreihe

3.2.5 Bestimmung der Anzahl IFNy-sezernierender T-Zellen nach GagStimulation mit der ELISPOT-Technik nach tonsillärer Applikation von SIVmac239

3.2.6 Vergleich des Nachweises von SIV-spezifischen T-Zellen mit Hilfe der ELISPOT-Technik und der Technik der intrazellulären Zytokinfärbung nach Gag-Stimulation nach Belastungsinfektion.

3.2.7 Bestimmung von Gag-spezifischen polyfunktionalen T-Lymphozyten nach tonsillärer Applikation von SIVmac239 mit Hilfe des polyfunktionalen ICS

3.3 Charakterisierung von Tieren mit niedriger Viruslast und SIVspezifischer zellulärer Immunantwort.

3.3.1 Viruslast nach Belastungsinfektion durch tonsilläre Inokulation..............77

3.3.2 Bestimmung der Proliferation nach antigenspezifischer Stimulation.......79

3.3.3 Bestimmung von Gag-spezifischen Zytokin-produzierenden T-Lymphozyten mit Hilfe des polyfunktionalen ICS.

3.3.4 Bestimmung der Anzahl von SIV-spezifischen Lymphozyten in MamuA*01-positiven „Controllern“ nach tonsillärer Applikation von SIVmac239 mit Hilfe der Tetramer-Technik

3.4 Ergebnisse der dritten Versuchsreihe (aVLP-Ad)

3.4.1 Bestimmung der Anzahl IFNy-sezernierender SIV-spezifischer T-Zellen nach Gag-Stimulation mit der ELISPOT-Technik während der Immunisierungsphase

3.4.2 Bestimmung der Viruslast nach Belastungsinfektion durch intravenöse Applikation von SIVmac251 in der dritten Versuchsreihe mit Hilfe der RT-PCR

3.4.3 Durchflusszytometrische Untersuchungen zirkulierender CD4 ${ }^{+}$und $\mathrm{CD}^{+}{ }^{+}$T-Lymphozyten im Blut der Versuchstiere der dritten

Versuchsreihe

3.4.4 Bestimmung der Anzahl IFNy-sezernierender SIV-spezifischer TZellen nach intravenöser Applikation von SIVmac251 mittels ELISPOTTechnik.

3.4.5 Vergleich des Nachweises von SIV-spezifischen T-Zellen mit Hilfe der ELISPOT-Technik und der Technik der intrazellulären Zytokinfärbung nach Gag-Stimulation in der dritten Versuchsreihe.

3.4.6 Kinetik von polyfunktionalen SIV-spezifischen T-Lymphozyten nach intravenöser Applikation von SIVmac251 
3.4.7 Bestimmung der Kinetik von proliferierenden Lymphozyten nach intravenöser Applikation von SIVmac251

3.4.8 Bestimmung der Anzahl und Kinetik von SIV-spezifischen Lymphozyten im Immunisierungszeitraum und nach intravenöser Applikation von SIVmac251 mit Hilfe der Tetramer-Technik. 104

4. DISKUSSION 106

4.1 Vergleich der drei „Prime-Boost“-Immunisierungsprotokolle. 108

4.2 Stärkere zelluläre Immunogenität des „DNA-Prime AdenoBoost“ Protokolls gegenüber der VLP-Applikationen 109

4.3 Reduktion der Spitzenvirämie und der Virusbeladung in der akuten Infektionsphase nach tonsillärer Belastungsinfektion durch die „DNAPrime Adeno-Boost" Immunisierung ...

4.4 Reduktion der Spitzenvirämie nach tonsillärer Belastungsinfektion durch die „VLP-Prime Adeno-Boost“-Immunisierung

4.5 Reduktion der Spitzenvirämie nach systemischer Belastungsinfektion durch die adjuvantierte „VLP-Prime Adeno-Boost"-Immunisierung

4.6 Die drei Immunisierungsstrategien schützen nicht vor dem Verlust von $\mathrm{CD}^{+}$T-Lymphozyten, aber die Hauptzielzellen von SIV bleiben erhalten .. 114

4.7 Die verschiedenen Gedächtniszellpopulationen bleiben in den Impflingen erhalten

4.8 Übereinstimmende Ergebnisse beim Nachweis virusspezifischer TLymphozyten durch die ELISPOT- und die ICS-Technik

4.9 Die Reduktion der Virusbeladung korreliert mit der vermehrten Bildung von IFNy durch polyfunktionale T-Lymphozyten

4.10 In immunisierten Tieren bilden sich SIV-spezifische T-Lymphozyten schneller als in Kontrolltieren

4.11 Nachweis von polyfunktionalen und proliferierenden T-Zellen in Tieren mit reduzierter Virusbeladung.

4.12 Die Rolle der CD4 ${ }^{+}$T-Lymphozyten in der chronischen Infektion

4.13 Abschließende Bewertung und Ausblick

5. ZUSAMMENFASSUNG

7. ANHANG

Abbildungsverzeichnis

Tabellenverzeichnis

Publikationsverzeichnis

Danksagung

Lebenslauf 


\section{Einleitung}

\subsection{Das erworbene Immunschwächesyndrom (AIDS)}

Im Jahr 1981 gab es in den USA erste Berichte über schwere Immunschwächen bei homosexuellen Männern (Siegal et al., 1981; Gottlieb et al., 1981; Masur et al., 1981). Die in diesem Zusammenhang beschriebenen Krankheitszustände wurden durch das US-amerikanische Centers for Disease Control and Prevention (CDC) im Herbst 1982 unter dem Namen „Erworbenes Immunschwächesyndrom“ (AIDS, engl. acquired immunodeficiency syndrome) zusammengefasst. Das Krankheitsbild ist durch eine erhöhte Anfälligkeit für Infektionen mit opportunistischen Pathogenen, neurologische Defekte und die Entwicklung von B-Zell-Lymphomen und anderen Tumoren gekennzeichnet. Im Jahr 1983 wurde als biologische Ursache für die Erkrankung ein bis dahin unbekanntes Retrovirus isoliert, das sich in humanen T-Lymphozyten vermehrt (Barré-Sinoussi et al., 1983).

Dieses Virus sowie zwei weitere Isolate wurden 1986 unter dem Namen HIV-1 (humanes Immundefizienzvirus 1) zusammengefasst (Coffin et al., 1986).

Ein weiteres humanes Immundefizienzvirus wurde ebenfalls im Jahr 1986 isoliert. Da es sich in der Sequenz deutlich von HIV-1 unterscheidet, wurde es als HIV-2 bezeichnet (Clavel et al., 1986).

HIV gehört zu einer Gruppe von komplexen Retroviren, die zur Gattung der Lentiviridae zusammengefasst werden (Murphy et al., 1990).

Die akute HIV-1-Infektion ist in einer Vielzahl der Fälle durch eine vorübergehende symptomatische Erkrankung gekennzeichnet, die mit einer hohen Replikationsrate von HIV und einer expandierenden virus-spezifischen Immunantwort einhergeht. In der Mehrzahl der Fälle entwickelt sich in dieser Phase eine akute, grippeähnliche Erkrankung. Eine sehr hohe, jedoch meist kurzfristige Virämie deutet darauf hin, dass die virale Replikation durch eine Immunantwort kontrolliert wird. Im weiteren Verlauf fällt die Virämie bis auf einen relativ konstanten Wert ab, der viraler „Setpoint“ genannt wird und ein Indikator für eine langfristige Krankheitsprognose ist (Mellors et al., 1997).

Während der akuten HIV-Infektion kommt es zu einem deutlichen Verlust der $\mathrm{CD}^{+}$T-Lymphozyten im Blut, deren Zahl nach der akuten Phase wieder ansteigt, jedoch nur selten die Ausgangswerte erreicht. 
Neben dem Verlust der $\mathrm{CD}^{+}$T-Zellen ist eine Einschränkung der HIV-spezifischen T-Zellfunktionen bereits in der akuten Phase zu beobachten (Rosenberg et al., 1997; Altfeld et al., 2001). Diese Einschränkungen werden mit der bevorzugten Infektion virus-spezifischer CD4 ${ }^{+}$T-Zellen und dem damit einhergehenden Verlust dieser Zellen erklärt (Douek et al., 2002).

\section{Weltweite Verbreitung von AIDS}

Bis zum Ende des Jahres 2006 waren nach Berichten des AIDS-Programms der Vereinten Nationen (UNAIDS) 39,5 Millionen Menschen mit HIV infiziert, von denen 24,7 Millionen im südlichen Afrika leben (Report on the Global AIDS Epidemic-UNAIDS, 2006). Es kam im Jahr 2006 weltweit zu geschätzten 4,3 Millionen HIV-Neuinfektionen und 2,9 Millionen Todesfällen durch AIDS. Damit gehört AIDS weltweit zu einer der häufigsten Todesursachen. Insgesamt sind in den letzten 25 Jahren mehr als 25 Millionen Menschen an den Folgen von AIDS verstorben. Seit einigen Jahren steht eine Kombinationstherapie zur Verfügung, durch die unterschiedliche Schritte im Replikationszyklus von HIV gehemmt werden können. Durch diese Medikamente kam es in den Industrieländern zu einer gesteigerten Lebenserwartung der HIV-Infizierten (Palella et al., 1998). Diese Behandlung ist jedoch sehr kostenintensiv und erzeugt eine Vielzahl von Nebenwirkungen. Da das Virusgenom in das Genom der Zielzelle integriert wird, ist eine vollständige Heilung nur sehr schwer möglich. Aus diesen Gründen ist die Entwicklung eines Impfstoffes zum Schutz vor einer HIV-Infektion dringend notwendig.

\subsection{Das Simiane Immundefizienzvirus (SIV)}

Die simianen Immundefizienzviren gehören wie HIV-1 und HIV-2 zur Familie der Retroviren und werden aufgrund ihrer Genomstruktur und Morphologie zu den Lentiviren gezählt (Daniel et al., 1985; Letvin et al., 1985; Gelderblom et al., 1991).

Die Lentiviren haben eine Reihe von Merkmalen gemeinsam, die sie von anderen Viren unterscheiden (Joag et al., 1996). Das namensgebende Charakteristikum ist eine lange Latenzzeit vor dem Auftreten der ersten Krankheitssymptome (lat. lentus, langsam; Narayan et al., 1989). Weiterhin persistiert das Virus aufgrund seiner Fähigkeit, die eigene Virus-DNA in das Wirtsgenom zu integrieren. Darüber hinaus besitzen Lentiviren eine hohe 
Mutationsrate, die dem Immunsystem des Wirts den Aufbau einer wirksamen Immunität erschwert.

\subsubsection{Vorkommen von SIV}

Bis heute konnte in 40 afrikanischen Primatenspezies eine Infektion mit Lentiviren nachgewiesen werden (VandeWoude et al., 2006), wobei es bei den natürlichen Wirten von SIV trotz hoher Viruslasten im peripheren Blut nicht zu einer Entwicklung von Krankheitssymptomen kommt (Santiago et al., 2002; Hahn et al., 2000). Eine Erkrankung trat nur in den Fällen auf, in denen es zur Übertragung von Lentiviren auf eine andere Primatenspezies gekommen war. Bei den asiatischen Primatenspezies wie den Makaken kommt eine natürliche SIV-Infektion nicht vor. Durch experimentelle Infektion mit SIV-Stämmen entsteht jedoch eine AIDS-ähnliche Erkrankung (Letvin et al., 1985; Daniel et al., 1987). Das zur Infektion verwendete SIV-Isolat wird dementsprechend als SIVmac (engl. simian immunodeficiency virus of macaques) bezeichnet (Coffin et al., 1986). Nachdem weitere Virusvarianten aus verschiedenen Affenspezies isoliert wurden, wurde diese Nomenklatur beibehalten. So wurden neben SIVmac für die Afrikanische Grüne Meerkatze das SIVagm (Cercopithecus aethiops; Kanki et al., 1986), für Mohrenmangaben das SIVsmn (Cercocebus atys; Fultz et al., 1986), für Mandrille das SIVmnd (Papio sphinx; Tsujimoto et al., 1988) und für Schimpansen das SIVcpz (Pan troglodytes; Peeters et al., 1989) beschrieben.

Bei den in dieser Dissertation durchgeführten Arbeiten wurde ausschließlich Material von SIVmac-infizierten Rhesusaffen verwendet. Die Angaben über die Pathogenese beziehen sich auf Krankheitserscheinungen, die durch SIVmac hervorgerufen werden.

\subsubsection{Struktur und Aufbau von SIV}

Die SIV-Partikel sind im Durchmesser 80 bis $100 \mathrm{~nm}$ groß und von einer Lipoproteinhülle umgeben. In dieser Hülle sind 72 etwa $10 \mathrm{~nm}$ große Glykoproteinkomplexe eingebettet. Diese bestehen aus einem externen Anteil (gp120), der spezifisch an CD4-Rezeptoren der Zielzelle bindet und einem Transmembranprotein (gp41) (Dalgleish et al., 1984). 
Während der Knospung des Virus aus der virusproduzierenden Zelle gelangen zusätzlich verschiedene Proteine der Wirtszelle wie z.B. Haupthistokompatibilitätsantigene der Klasse I und II, $\beta$-2-Mikroglobulin, Aktin und Ubiquitin auf die Virushülle (Gelderblom et al., 1987).

An der Innenseite der Virushülle befindet sich das p17-Matrixprotein, das über eine N-terminale Myristylierung an der Hülle verankert ist (Göttlinger et al., 1989). Das zylindrische Kapsid des reifen Virions wird aus phosphorylierten p24-Kapsidproteinen gebildet und enthält das virale Genom in Form zweier einzelsträngiger plus-Strang RNA-Moleküle. Diese RNA-Moleküle liegen als Protein-Nukleinsäurekomplex mit den Nukleokapsidproteinen p7 und p9 vor (Sakaguchi et al., 1993). Im Nukleokapsid befinden sich weiterhin die viralen Enzyme Integrase, Reverse Transkriptase und Protease. Neben den Strukturproteinen werden zusätzlich noch regulatorische und akzessorische Proteine wie Tat, Nef, Vpr und Vif in das Viruspartikel eingebaut (Cohen et al., 1990; Liu et al., 1995).

\subsubsection{Die Organisation des viralen Genoms}

Das virale Genom der Immundefizienzviren ähnelt dem Genom anderer Retroviren. Es besteht aus etwa 9000 bis 11000 Nukleotiden und kodiert für neun Gene (Abbildung 1.1). Diese Gene werden im proviralen Zustand von langen terminalen Wiederholungen (LTR-Regionen, engl. long terminal repeats) flankiert, die für die Integration des Virus in die Wirts-DNA benötigt werden (Leavitt et al., 1992). Wie bei allen anderen Retroviren kodiert das Genom der Immundefizienzviren für die drei Gene gag, pol und env: Das gag-Gen (Gruppenspezifisches Antigen) kodiert die Strukturproteine des Nukleokapsids, das pol-Gen (Polymerase) kodiert die Enzyme der Virusreplikation und Virusintegration, das env-Gen (engl. envelope) kodiert die Proteine der Virushülle. 


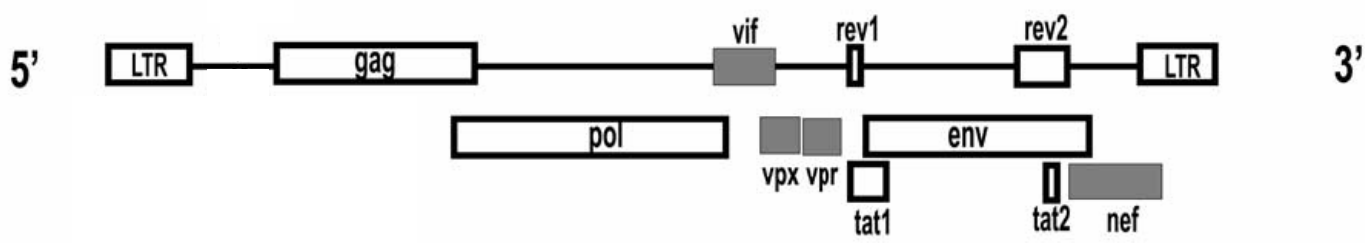

Abb. 1.1: Aufbau des SIV-Genoms

Stellvertretend für die Genomstruktur der Immundefizienzviren ist in der Abbildung der Aufbau des SIV-Genoms skizziert (modifiziert nach Kuate et al., 2003).

\subsubsection{Verlauf des SIV-Replikationszyklus}

Eine Infektion mit SIV erfolgt durch Kontakt mit infiziertem Blut oder Sekret. SIV verfügt wie HIV über einen Tropismus für CD4 ${ }^{+}$T-Zellen (Letvin et al., 1990).

Durch das externe Membranmolekül gp120 kommt es zur Adsorption des Virus an die Zielzelle und die Bindung an das zelluläre CD4-Protein (Abbildung 1.2). Neben dem CD4-Protein sind eine Vielzahl von Korezeptoren beschrieben worden, die am Infektionsprozess beteiligt sind (Björndal et al., 1997). Einer der am besten untersuchten Korezeptoren ist CCR5 (CD195), der durch Interaktion mit gp120 die Fusion der Virushülle mit der Zellmembran vermittelt (Berger et al., 1998). Nach der Membranverschmelzung, die durch gp41 vermittelt wird (Freed et al., 1992), wird die reverse Transkription eingeleitet. Zunächst wird einzelsträngige RNA revers transkribiert und ein DNA-RNA-Hybrid als Zwischenprodukt gebildet. Durch die RNaseH-Funktion der Reversen Transkriptase wird der RNA-Strang abgebaut und gleichzeitig an der DNAMatrize ein komplementärer Strang synthetisiert (Davies et al., 1991). Diese Virus-DNA wird durch die Integrase als Provirus in das Genom der Wirtszelle integriert. In dieser Form kann das Provirus mehrere Jahre lang latent vorliegen (Wang et al., 2000). Durch zelluläre Transkriptionsfaktoren werden die Replikation des Provirus aktiviert und die frühen regulatorischen Proteine Tat, Rev und Nef gebildet. Diese Proteine kontrollieren die weitere Synthese und Prozessierung der Strukturgene. Im Zytosol kommt es zum Zusammenbau von neuen Viruspartikeln, die durch Knospung von der Wirtszelle freigesetzt werden. 


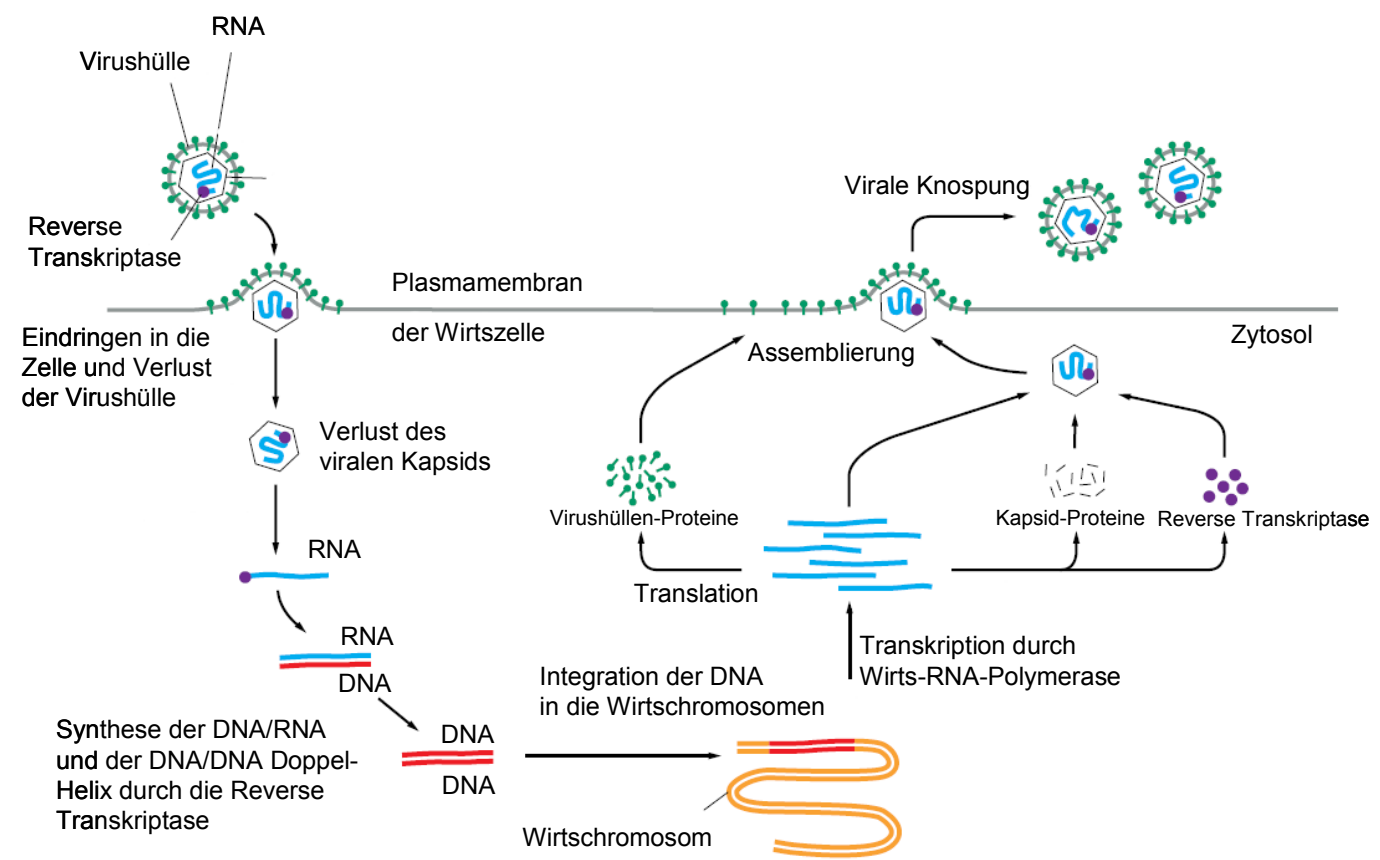

Abb. 1.2: Schematische Darstellung des HIV-Replikationszyklus (modifiziert nach Alberts et al., 1998)

\subsection{Immunpathogenese der SIV-Infektion}

Bei den AIDS-Symptomen handelt es sich um Krankheitserscheinungen, die das Endstadium einer HIV-Infektion bilden. Diese Symptome entstehen aufgrund einer massiven Eliminierung von $\mathrm{CD}^{+}{ }^{+} \mathrm{T}$-Zellen und einem Verlust der Immunkompetenz des Infizierten. Dieser Verlust führt zu einer tödlichen Infektion mit Pathogenen, die für ein gesundes Individuum keine Gefahr darstellen (Ho et al., 1995).

Die Ursache für die CD4-Depletion wird seit langem kontrovers diskutiert. Eine frühe Theorie postuliert die Induktion des Zelltods von infizierten T-Zellen durch die Replikation des Virus. Diese Theorie wurde aufgrund der geringen Anzahl von infizierten T-Zellen im Blut angezweifelt (Meyaard et al., 1994). Die sogenannte „bystander“-Theorie macht eine indirekte Induktion von Apoptose in nicht-infizierten T-Zellen für den Verlust der $\mathrm{CD}^{+}{ }^{+}$T-Lymphozyten verantwortlich (Finkel et al., 1995).

Aktuelle Untersuchungen zum Infektionsverlauf im Rhesusaffenmodell konnten zeigen, dass es durch die Virusinfektion bereits in den ersten Wochen der Infektion zu einem Verlust von Gedächtnis-T-Zellen in den mukosalen Geweben kommt (Abb. 1.3; Mehandru et al., 2007; Li et al., 2005; Mattapillil et al., 2005; Brenchley et al., 2004). 


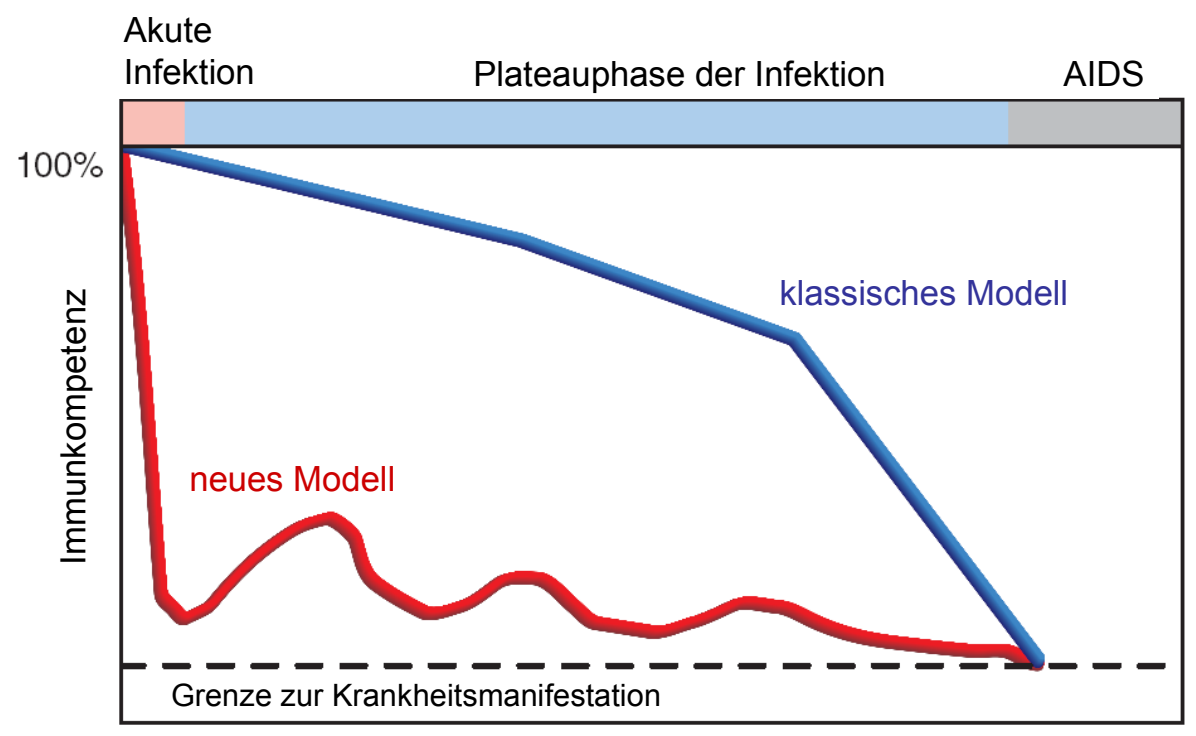

Zeit nach Infektion

Abb. 1.3: Vergleich der konventionellen Sicht des SIV-Infektionsverlaufs mit dem neuen Modell (modifiziert nach Picker et al., 2005)

Drei Tage nach Infektion lassen sich im mukosalen Gewebe erstmals SIV-infizierte Gedächtniszellen nachweisen (Pope et al., 2003). Nach einer Woche ist das Virus in Lymphknoten und dendritischen Zellen und ebenso im Blut nachzuweisen. Durch die systemische Verbreitung werden Zellen in weiteren lymphoiden Geweben wie z.B. dem Darm-assoziierten lymphoiden Gewebe (GALT, engl. gut-associated lymphoid tissue) infiziert, in denen eine Vielzahl von $\mathrm{CD}^{+} 195^{+}$T-Zellen vorhanden sind. Eine Subpopulation von Gedächtnis-T-Zellen, die zentralen Gedächtnis-T-Zellen, exprimieren CD195 besonders stark, so dass es in den lymphoiden Geweben zu einem massiven Verlust dieser Zellpopulation kommt. Durch die Versuche des Organismus, den Verlust dieser Zellen zu ersetzen, kommt es zu einer starken Aktivierung des Immunsystems und dadurch zu einer verstärkten Infektion von weiteren Lymphozyten (Zhang et al., 2004).

Durch die systemische Verbreitung des Virus steigt die Virusmenge im Organismus stark an und erreicht ein Maximum im Zeitraum von zwei bis drei Wochen nach Infektion. Da in der frühen Phase der Infektion ein Großteil der Zielzellen des Virus infiziert und zerstört wird (Phillips et al., 1996), kommt es im weiteren Verlauf der Infektion zu einer Reduktion der Virusmenge im Organismus. Diese Virusreduktion wird durch die einsetzende spezifische Immunantwort verstärkt (Borrow et al., 1994). Im Zeitraum von zwei bis sechs Monaten nach Infektion stellt sich ein Gleichgewicht zwischen der Virusmenge 
und der spezifischen Immunantwort ein, so dass nur eine geringe Anzahl von Viren im Blut vorhanden sind.

Die in der akuten Phase der Infektion zerstörten Gedächtnis-T-Zellen können durch Proliferation und Differenzierung von naiven T-Zellen nur teilweise wieder ersetzt werden, so dass dieser Verlust in der frühen Phase der Infektion einen massiven Einfluss auf den späteren Krankheitsverlauf hat (Picker et al., 2005).

Neben dem Verlust der Gedächtniszellen in der frühen Phase der Infektion ist die chronische Aktivierung des Immunsystems durch die Infektion und Zerstörung von $\mathrm{CD}^{+}$T-Zellen von Bedeutung (Abb. 1.4; Grossmann et al., 2006; Sopper et al., 2003).

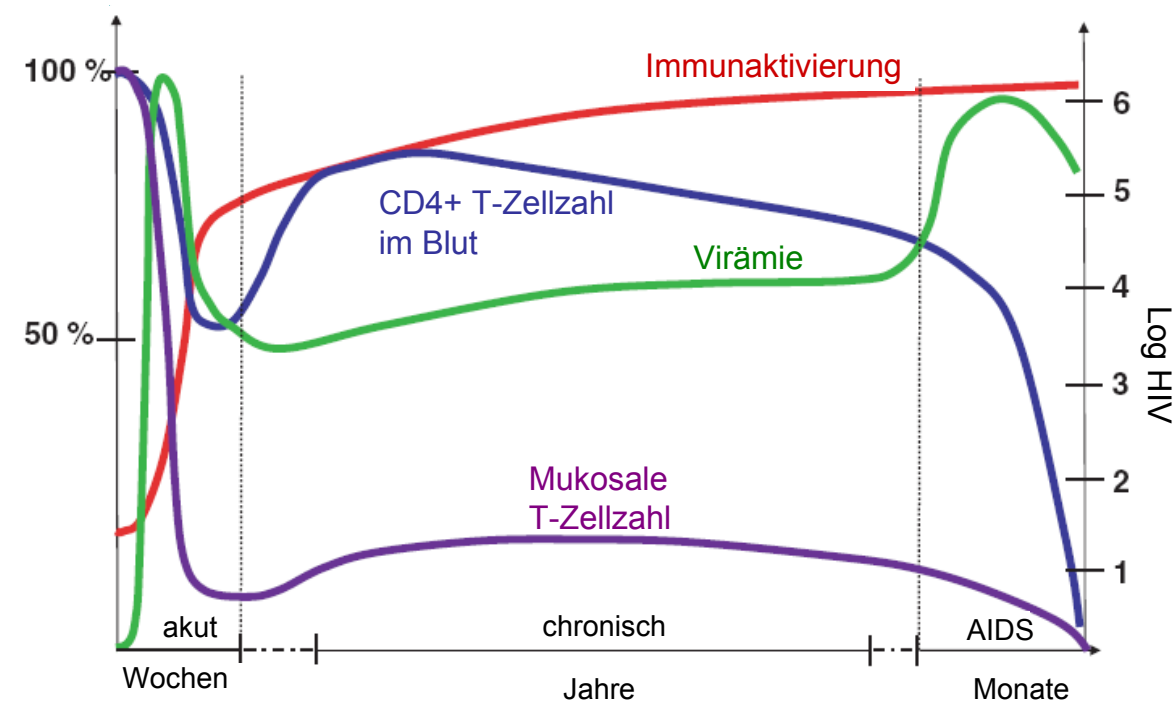

Abb. 1.4: Veränderungen der T-Zellpopulationen, der Virämie und der Immunaktivierung nach SIV-Infektion (modifiziert nach Grossmann et al., 2006)

\subsection{Die Immunantwort gegen SIV}

\subsubsection{Die angeborene Immunantwort}

Die adaptive Immunantwort gegen SIV umfasst sowohl die humoralen als auch die zellulären Komponenten des Immunsystems. Zusätzlich zu diesen Mechanismen bildet in der frühen Phase der Infektion das angeborene Immunsystem einen ersten Schutz vor dem Virus (Ahmed et al., 2005). Bei der angeborenen Immunantwort handelt es sich um eine Reaktion auf das Eindringen eines Erregers, die innerhalb von Stunden einsetzt und die den Erreger nicht über spezifische Epitope, sondern aufgrund von Strukturmerkmalen (PRR, engl. pattern recognition receptors) erkennt. Den zellulären Teil des angeborenen Immunsystems bilden dendritische Zellen, 
Makrophagen, natürliche Killerzellen (NK-Zellen) und $\mathrm{\gamma} \delta$-T-Zellen. NK-Zellen töten infizierte Zellen durch direkten Zell-Zell-Kontakt oder durch die Antikörperabhängige zelluläre Zytotoxizität (ADCC, engl. antibody dependent cellular cytotoxicity; Tyler et al., 1990). Weiterhin bilden die NK-Zellen ebenso wie үठ্-T-Zellen nach Aktivierung eine Vielzahl von antiviral wirkenden Zytokinen wie z.B. Interferone oder $\beta$-Chemokine (Fehniger et al., 1998). Die dendritischen Zellen und die Makrophagen sezernieren ebenfalls eine Reihe von Zytokinen und präsentieren in ihrer Funktion als antigen-präsentierende Zellen Teile des Erregers den Zellen des adaptiven Immunsystems.

\subsubsection{Die adaptive Immunantwort}

Im Gegensatz zur angeborenen Immunität ist das adaptive Immunsystem spezifisch gegen Pathogene gerichtet und durch klonale Selektion von Lymphozyten, die Fähigkeit zur Proliferation und durch die Ausbildung eines immunologischen Gedächtnisses gekennzeichnet.

Die erste adaptive Immunantwort besteht aus der Entwicklung von virusspezifischen zytotoxischen $\mathrm{CD}^{+}$T-Lymphozyten und der Sekretion von Antikörpern durch B-Zellen. Virusspezifische $\mathrm{CD}^{+} \mathrm{T}$-Zellen beginnen nach Infektion zu proliferieren und können dadurch einen Anteil von bis zu 50\% aller $\mathrm{CD}^{+} \mathrm{T}$-Lymphozyten bilden. Diese zytotoxischen T-Zellen erkennen mit ihrem T-Zellrezeptor virusinfizierte Zellen und können diese durch Zell-Zellkontakte direkt töten (Yang et al., 1997). Der direkte Einfluss von CD8 ${ }^{+}$T-Zellen auf die Höhe der SIV-Beladung wurde durch Depletionsexperimente im Rhesusaffenmodell untersucht. Nach Depletion dieser Zellpopulation waren die Tiere nicht in der Lage, die Viruslast zu reduzieren und zeigten einen schnelleren Krankheitsverlauf (Schmitz et al., 1999; Jin et al., 1999).

Obwohl die $\mathrm{CD}^{+}$T-Lymphozyten die bevorzugten Wirtszellen der Immundefizienzviren sind, können nach Infektion virusspezifische T-Helferzellen nachgewiesen werden (Pitcher et al., 1999). Diese CD4 ${ }^{+}$ T-Zellen beginnen nach Infektion zu proliferieren und unterstützen dadurch die Bildung von virusspezifischen CD8 ${ }^{+}$Gedächtniszellen (Sun et al., 2004).

Neben der Immunantwort durch T-Lymphozyten kommt es nach Infektion mit SIV zur Bildung von Antikörpern gegen die Strukturproteine des Virus. 
Die Freisetzung von antigenspezifischen Antikörpern benötigt im Durchschnitt etwa zwei bis vier Wochen, um eine maximale Reaktivität zu erreichen (Lathey et al., 1997). Aufgrund der starken Glykosylierungen und der hohen Variabilität der Virusoberfläche ist die Effektivität dieser Immunantwort erheblich eingeschränkt. Obwohl nach Infektion sowohl systemisch als auch mukosal neutralisierende Antikörper nachgewiesen werden können, reicht dieser Teil der Immunantwort alleine zur Eliminierung des Virus nicht aus (Richman et al., 2003; Moore et al., 1995).

\subsubsection{Die Funktion von Zytokinen bei der adaptiven Immunantwort}

Neben der direkten zytotoxischen Funktion bilden CD8 ${ }^{+}$T-Lymphozyten als Reaktion auf Pathogene verschiedene Chemokine und Zytokine. Als Hauptvertreter der Chemokine sind MIP-1 $\alpha$, MIP-1 $\beta$ und RANTES zu nennen. Diese Chemokine befinden sich in Speicherversikeln und werden nach Aktivierung der Zellen freigesetzt. Die Hauptfunktion dieser Chemokine liegt in der Aktivierung und Anlockung weiterer Zellen zum Ort der Virusinfektion sowie einer Blockierung von Oberflächenrezeptoren, die für die Infektion notwendig sind (Catalfamo et al., 2004; Margolis et al., 1998; Wagner et al., 1998). Neben den Chemokinen bilden T-Zellen nach Aktivierung eine Vielzahl von Zytokinen.

Die Bildung von Interferon (IFN)- $\mathrm{Y}$ wird in vielen Tests als Merkmal für die antigen-spezifische Aktivität von $\mathrm{CD}^{+}$T-Zellen angesehen. Der IFNy-Signalweg reguliert die Expression von Transkriptionsfaktoren, die wiederum die Expression von antiviralen Proteinen wie z.B. der Proteinkinase R regulieren. Weiterhin fördert der IFNy-Signalweg die Expression des TNFa-Rezeptors auf virusinfizierten Zellen, wodurch die Suszeptibilität der Zellen für Apoptosesignale erhöht wird (Schroder et al., 2004). Zusätzlich zu diesen Mechanismen aktiviert IFNy auf antigenpräsentierenden Zellen verschiedene Prozesse, die eine effiziente Prozessierung und Präsentation von viralen Antigenen ermöglichen. Hierzu zählen die Aktivierung des Immunproteasoms, des TAP-Transporterproteins und die Synthese des MHCKlasse-I-Moleküls (Tanaka et al., 1998). Daher ist die Bildung von IFNy ein erster Schritt von T-Zellen zur Bekämpfung einer viralen Infektion.

Neben IFNy ist das Zytokin Interleukin (IL) 2 für die Bekämpfung einer viralen Infektion von großer Bedeutung. IL2 wird von $\mathrm{CD}^{+}{ }^{+}$und $\mathrm{CD}^{+}{ }^{+}$T-Zellen gebildet und fördert die Proliferation und Differenzierung von antigen-spezifischen 
Zellen. Nach Infektion mit HIV konnte gezeigt werden, dass CD4 ${ }^{+}$T-Zellen die Fähigkeit zur IL2-Produktion verlieren (lyasere et al., 2003; Younes et al., 2003). Aus diesem Grund wird die Fähigkeit zur IL2-Sekretion ebenfalls als ein prognostischer Marker für den Verlauf einer HIV-Infektion angesehen.

Der Tumornekrosefaktor a (TNFa) ist in der antiviralen Immunantwort ebenfalls von Bedeutung. In seiner biologisch aktiven Form liegt TNFa als Homotrimer vor und wird von einer Vielzahl von Immunzellen (T-Zellen, B-Zellen, Granulozyten, Monozyten) gebildet. Die Aktivierung des T-Zellrezeptors erhöht in T-Zellen die Freisetzung von TNFa, das dadurch die Bildung von IL12 und IL18 induziert. Diese Zytokine stimulieren wiederum die Bildung von IFNy. Neben der Aktivierung weiterer Mediatoren kann TNFa durch Bindung an den TNF-Rezeptor die zellulären Apoptose-Signalwege aktivieren und dadurch virusinfizierte Zellen töten (Pfeffer et al., 2003).

In neueren Arbeiten wurde nicht nur die Art und Menge der Zytokinproduktion untersucht, sondern die produzierenden Zellen gelangten in den Fokus der Forschung. Es konnte gezeigt werden, dass die Gruppe der Zytokinproduzierenden Zellen in verschiedenen Virusinfektionen sehr heterogen ist (Harari et al., 2005). Insbesondere die Fähigkeit von T-Zellen, mehrere Zytokine gleichzeitig zu produzieren, scheint für den Verlauf einer Infektion von Bedeutung zu sein. So konnte in langzeitüberlebenden HIV-Infizierten (LTNP, engl. long-term non-progressors) ein erhöhter Anteil von polyfunktionalen T-Zellen im Vergleich zu Individuen mit fortschreitender Krankheit nachgewiesen werden (Makedonas et al., 2006). Bisher konnten jedoch keine Korrelationen zwischen der Polyfunktionalität von T-Lymphozyten und einem milderen Krankheitsverlauf gefunden werden.

\subsubsection{Die Funktion von Gedächtniszellen bei der adaptiven Immunantwort}

Die Entwicklung eines immunologischen Gedächtnisses ist die zentrale Funktion des adaptiven Immunsystems (Sallusto et al., 2004). Dieses Gedächtnis resultiert aus der klonalen Expansion und Differenzierung von antigen-spezifischen Lymphozyten. Die Entwicklung von Gedächtniszellen schützt einen Organismus vor wiederholten Infektionen mit den gleichen Pathogenen und ermöglicht die schnelle Entwicklung einer Immunantwort in peripheren Geweben und lymphoiden Organen. Bei den B-Lymphozyten ist die 
Entwicklung von Gedächtnis-B-Zellen lange bekannt. Die Sekretion von Antikörpern erfolgt durch Plasmazellen und der Schutz vor wiederholter Infektion durch das gleiche Pathogen erfolgt durch die Differenzierung von B-Lymphozyten zu Gedächtniszellen, die nach antigener Stimulation proliferieren und sich zu Plasmazellen differenzieren können (Ochsenbein et al., 2000).

Für die T-Lymphozyten ließ sich ein ähnliches System der Differenzierung zu zentralen Gedächtniszellen und Effektorgedächtniszellen nachweisen (Sallusto et al., 1999). Die zentralen Gedächtniszellen bilden in diesem System die langlebigen Zellen, die in lymphoiden Geweben über einen langen Zeitraum vorhanden sind und nach antigenem Stimulus proliferieren. Die Effektorgedächtniszellen gelangen dagegen auch leicht in mukosale Gewebe, um dort durch Ausschüttung von Zytokinen eine Infektion zu bekämpfen (Sallusto et al., 2004). Die genauen Entwicklungswege dieser verschiedenen Lymphozytenpopulationen sind bisher noch nicht verstanden. Zur Erklärung wurden zwei Entwicklungsmodelle vorgeschlagen. Einige Arbeitsgruppen postulieren die lineare Entwicklung von naiven T-Lymphozyten zu zentralen Gedächtniszellen, gefolgt von einer weiteren Differenzierung zu Effektorgedächtniszellen (Wherry et al., 2004; Champagne et al., 2001; Sallusto et al., 1999). Andere Gruppen unterstützen das nicht-lineare Modell der Gedächtniszellentwicklung direkt aus naiven Lymphozyten (Song et al., 2005). Beide Modelle werden in der Literatur kontrovers diskutiert.

Unabhängig von den verschiedenen Entwicklungsmodellen ist die Unterscheidung von Gedächtnis-T-Zellen anhand der Expression einer Vielzahl von spezifischen Oberflächenmolekülen möglich (Gauduin et al., 2006; Picker et al., 2006). Eine weitere Charakterisierungsmöglichkeit besteht in der funktionellen Untersuchung der Proliferationsfähigkeit und der Zytokinsekretion (Sun et al., 2005).

Im Rhesusaffenmodell wurden die verschiedenen Gedächtniszellpopulationen untersucht und es wurden anhand der Expression der Oberflächenmoleküle CD28 und CD95 mehrere Populationen unterschieden (Pitcher et al., 2002). Die zentralen Gedächtniszellen werden dabei durch die Expression von CD28 und CD95 definiert. Die Effektorgedächtniszellen exprimieren dagegen kein CD28 und nur zu einem geringen Anteil CD95. Als dritte Lymphozytenpopulation 
werden die naiven Zellen durch die Expression von CD28 und eine fehlende CD95-Expression definiert.

\subsubsection{Die Tetramer-Technologie zur Messung der zellulären Immunantwort}

Eine wichtige Funktion der zytotoxischen T-Zellen liegt in der Erkennung von virus-infizierten Zellen. Diese Erkennung ist nur möglich, wenn die infizierte Zelle Peptidfragmente des Virus auf dem Haupthistokompatibilitätskomplex (MHC, engl. major histocompatibility complex) der Klasse I präsentiert. Eine $\mathrm{CD}^{+} \mathrm{T}$-Zelle, die mit ihrem T-Zellrezeptor das präsentierte Viruspeptid und den MHC-Komplex binden kann, wird dadurch aktiviert und zerstört die virusinfizierte Zelle.

Die Tetramer-Technologie nutzt diese spezifische Bindung, indem rekombinant hergestellte MHC-Klasse-I-Moleküle mit Peptiden komplexiert werden (Altman et al., 1996). Die künstlichen MHC-Komplexe sind biotinyliert, so dass durch die Bindung an Fluoreszenz-markierte Streptavidin-Moleküle tetramere Komplexe entstehen. An diese Komplexe binden spezifische T-Zellen und können dadurch durchflusszytometrisch bestimmt werden.

Im Rhesusaffenmodell ist es möglich, den MHC-Typ der Versuchstiere zu bestimmen. In Tieren, die das MamuA*01-MHC-Allel exprimieren, konnte eine niedrigere Virusbeladung und eine längere Überlebenszeit nach Infektion nachgewiesen werden (Mühl et al., 2002; Mothe et al., 2003). Diese Tiere entwickeln eine dominante Immunantwort gegen ein Epitop des SIV-GagProteins (Gag181-189, CM9; Miller et al., 1991). Mit diesem CM9-Peptid wurden die rekombinant hergestellten MamuA*01-MHC-Moleküle komplexiert, um so die gegen dieses Peptid gerichteten CD8 ${ }^{+}$T-Lymphozyten zu detektieren (Allen et al., 1998; Kuroda et al., 1998).

Da sich mit Hilfe dieser Tetramere virusspezifische T-Zellen anfärben lassen, sind sie ein wertvolles Hilfsmittel, um nach Infektion die Veränderung dieser spezifischen T-Zellen nachzuweisen (Donahoe et al., 2000; Jordan et al., 1999). Weiterhin kann mit dieser Technik in Impfstoffstudien die Induktion von virusspezifischen T-Zellen untersucht werden (Evans et al., 2005; Allen et al., 2000; Letvin et al., 1999). 


\subsection{Die SIV-Infektion von Rhesusaffen als Tiermodell zur Erforschung der HIV-Infektion des Menschen}

Für die Untersuchung der vielfältigen Funktionen des Immunsystems und die Entwicklung von Impfstoffen gegen HIV ist ein Tiermodell unumgänglich. HIV ließ sich nicht auf Kleinsäugetiere wie Kaninchen oder Mäuse übertragen (Kulaga et al., 1989). Die Übertragung auf nicht-humane Primaten ist nur in Schimpansen (Pan troglodytes; Nara et al., 1987; Arthur et al., 1989) und Gibbons (Hylobates lar; Lusso et al., 1988) möglich. Diese Tiere entwickeln nach Infektion eine bis zu mehrere Monate andauernde Lymphadenopathie, jedoch keine für den Ausbruch der AIDS-Erkrankung typischen Symptome (Johnson et al., 1993). Tierexperimentelle Untersuchungen sind mit diesen Primatenspezies aufgrund ethischer Abwägungen sowie erheblicher finanzieller Kosten für solche Experimente nicht durchführbar.

Sehr bald nach der Entdeckung des HIV wurde aus Rhesusaffengewebe das SIVmac isoliert, welches große Homologien mit HIV aufweist (Daniel et al., 1985). Die große Ähnlichkeit zwischen der durch SIV-induzierten Krankheit in Rhesusaffen und der HIV-Infektion im Menschen machen die SIV-Infektion des Rhesusaffen zu dem wichtigsten Tiermodell für die Untersuchung der AIDSErkrankung und für die Entwicklung von Impfstoffen gegen HIV (Hu et al., 2005; Persidsky et al., 1995).

Als klinische Symptome einer SIV-Infektion treten in Rhesusaffen Lymphadenopathien, Splenomegalien, Diarrhoe, Inappetenz, Gewichtsverlust, opportunistische Infektionen, Fieber, Lymphome und neurologische Ausfallerscheinungen auf. Im Bereich der klinischen Parameter kommt dem Verlust der $\mathrm{CD}^{+}$T-Lymphozyten im Blut und insbesondere im GALT besondere Bedeutung für den Krankheitsverlauf zu (Veazey et al., 1998). Nach einer Infektion mit SIV erkranken die Tiere nach relativ kurzer Zeit und sterben in der Regel innerhalb eines Zeitraumes von zwei Jahren an den Folgen des Immundefizienzsyndroms (Letvin et al., 1990). 


\subsection{Die Entwicklungen von Impfstoffen gegen SIV als Modell für die HIV- Impfstoffentwicklung}

Die Entwicklung einer sicheren und wirkungsvollen Vakzine, die vor einer HIV-Infektion schützt, ist das Hauptziel zur Bekämpfung der AIDS-Epidemie.

Dabei erschweren einige charakteristische Eigenschaften der Immundefizienzviren die Entwicklung eines Impfstoffes.

Bei HIV handelt es sich um ein hochvariables Virus, das durch mutationsbedingte Veränderungen der Strukturgene eine Immunantwort des Wirts erschwert. Neben der Veränderlichkeit der Oberflächenstruktur stellt der hohe Glykosylierungsgrad der Virusoberfläche einen Schutz vor neutralisierenden Antikörpern dar. Die komplexe Struktur des gp120 ermöglicht einen weiteren Schutz vor neutralisierenden Antikörpern. Erst durch Bindung an das CD4-Protein der Zielzelle kommt es zu einer konformellen Umlagerung des gp120 und einer Bindung an die Korezeptoren, die für die Zellfusion nötig ist (Kwong et al., 1998).

Ein weiteres Problem für eine Impfstoffentwicklung ist der Tropismus des HIV. Die Infektion und Zerstörung von Gedächtnis-T-Lymphozyten verhindert eine adäquate Immunantwort wegen fehlender Hilfe für B- und zytotoxische T-Zellen. HIV hat neben der hohen genetischen Variabiliät zusätzlich eine sehr große Replikationsrate, so dass es nach Infektion schnell zu einer systemischen Verbreitung und einer massiven Infektion im gesamten Organismus kommt.

Ein letzter Punkt ist die Integration der Virus-DNA in das Wirtsgenom, wodurch das Virus vor dem Immunsystem des Wirts geschützt ist. Ein Impfstoff müsste daher bereits vor der Primärinfektion schützen und somit die Möglichkeit zur Entwicklung einer latenten Infektion verhindern.

In der aktuellen Forschung zur Impfstoffentwicklung wird versucht, starke CTL-Antworten (CTL, engl. cytotoxic T-lymphocyte) zu induzieren, da in Rhesusaffen durch starke zelluläre Immunantworten ein Schutz vor hohen Virusbeladungen erreicht werden konnte (Kawada et al., 2007; Hel et al., 2006). Hierbei ist die Entwicklung einer CTL-Antwort gegen das Gag-Protein von besonderem Interesse, da es bereits sehr früh nach Infektion auf den infizierten Zellen nachweisbar ist (Sacha et al., 2007).

Durch eine starke CTL-Antwort und den dadurch hervorgerufenen hohen Selektionsdruck kann es jedoch auch zur Entwicklung von resistenten Viren 
durch einen sogenannten „viral escape“ kommen (Barouch et al., 2002). Daher sollte ein effektiver Impfstoff gegen HIV sowohl starke zelluläre Immunantworten als auch neutralisierende Antikörper gegen HIV induzieren.

Durch Immunisierung mit inaktiviertem SIV konnten Rhesusaffen erstmals vor einer Belastungsinfektion geschützt werden (Stahl-Hennig et al., 1992; Desrosiers et al., 1989). Aufgrund der Inaktivierung kann es jedoch zur Zerstörung von immunologisch wichtigen Antigenen kommen, so dass der gebildete Impfschutz zu schwach ist. Ein weiterer Nachteil ist die Gefahr einer Restpathogenität bei einer unvollständigen Inaktivierung des Virus. Eine ähnliche Gefahr besteht bei der Verwendung von attenuierten SIV-LebendvirusImpfstoffen. Bei diesen Impfstoffen werden regulatorische Gene des Virus deletiert und dieses attenuierte SIV als Impfstoff verwendet. Durch Immunisierung mit Nef-deletierten Viren konnte ein Schutz vor der Infektion mit pathogenem SIV erreicht werden (Tenner-Racz et al., 2004; Gundlach et al., 1998; Daniel et al., 1992). Die Anwendung dieser attenuierten retroviralen Impfstoffe beim Menschen ist jedoch aufgrund der hohen Mutationsrate von HIV und der dadurch möglichen Aktivierung des pathogenen Potentials der attenuierten Viren höchst umstritten. Eine zusätzliche onkogene Gefahr liegt in der Integration der Virus-DNA in das Genom des Wirts.

Die Entwicklung von virus-ähnlichen Partikeln (VLP, engl. virus like particles) umgeht die Gefahr einer Aktivierung des Impfvirus, da bei diesen Impfstoffen ausgewählte Virusgene exprimiert und in den VLPs inkorporiert werden (Deml et al., 1997; Wagner et al., 1996). In einigen Studien wurden VLPs schnell neutralisiert und konnten keinen Schutz vor SIV-Infektion induzieren (Notka et al., 1999; Le Grand et al., 1992). Diese Ergebnisse werden damit erklärt, dass die VLPs in verschiedenen Expressionssystemen produziert wurden und es zum Einschluss von zellulären Proteinen in die VLPs kam. Die Immunantwort des Impflings richtete sich gegen diese Proteine und neutralisierte somit die VLPs.

Neuere Entwicklungen in der VLP-Präparation konnten jedoch die Induktion einer CTL-Antwort gegen inkorporierte SIV-Proteine durch VLP-Immunisierung belegen (Kuate et al., 2006; Paliard et al., 2000).

Neben der Injektion von VLP wurde durch die direkte Injektion von DNA-Impfvektoren, die SIV-Strukturgene kodieren, ein neuer Ansatz zur 
Vakzineentwicklung geschaffen. Eine DNA-Immunisierung kann sowohl eine zelluläre als auch eine humorale Immunantwort induzieren, ohne dass ein Pathogenitätsrisiko vorliegt (Rosati et al., 2005). Die DNA-Applikation wird häufig in Form einer „Prime-Boost“-Immunisierung verwendet. In diesen Protokollen dient die ein- oder mehrmalige Applikation der DNA zur Basisimmunisierung. Für die Auffrischungsimmunisierung werden verschiedene Vektoren wie z.B. Adenoviruskonstrukte oder Pockenviruskonstrukte verwendet. Diese Viruskonstrukte können verschiedene SIV-Proteine exprimieren und induzieren eine starke zelluläre Immunantwort (Duerr et al., 2006).

Im Rhesusaffenmodell konnte mit diesen Immunisierungsschemata in vielen Studien die Reduktion der Virusbeladung nach SIV-Infektion nachgewiesen werden (Suh et al., 2006; Casimiro et al., 2005; Amara et al., 2005).

Neben den verschiedenen Impfstoffkonstrukten ist die Applikationsform der Impfstoffe von Bedeutung, da in aktuellen Untersuchungen gezeigt werden konnte, dass die HIV-Infektion in mukosalen Geweben massive Depletionen von $\mathrm{CD}^{+}{ }^{\mathrm{T}}$-Lymphozyten hervorruft (Mattapallil et al., 2005). Um diese Zerstörungen zu verhindern, ist es ein Ziel der Impfstoffentwicklung, starke mukosale Immunantworten zu generieren. Durch ein systemisches „PrimeBoost"-Protokoll konnte im mukosalen Gewebe die Entwicklung von virusspezifischen T-Zellen induziert werden (Baig et al., 2002). Ebenso wurde durch die orale Applikation von attenuierten Viren ein Schutz vor Infektion nachgewiesen (Stahl-Hennig et al., 2002). Die Untersuchung der Immunantworten nach verschiedenen Formen der Impfstoffapplikation wird für die weitere Impfstoffentwicklung von großer Bedeutung sein. 


\subsection{Ziele der Arbeit}

Das Ziel dieser Arbeit war die Untersuchung von drei verschiedenen „PrimeBoost“-Immunisierungsstrategien in Bezug auf ihre Immunogenität und die Wirksamkeit einer zellulären Immunität gegenüber einer Belastungsinfektion. Die erste Studie wurde im Rahmen eines Gemeinschaftsprojektes mit der Pohang University of Science \& Technology, Republik Korea, durchgeführt und beinhaltet ein „DNA-Prime Adenovirus-Boost“-Regime. In der zweiten Versuchsreihe sollte im Rahmen des EU-Forschungsprogramms MUVADEN (Mukosal Vaccines Against Human and Simian Immunodeficiency Viruses Based on Dendritic Cells) die Immunogenität von VLPs und eine Kombination von systemischer und mukosaler Antigenverabreichung untersucht werden. In der dritten Studie wurde im Rahmen des EU-Forschungsprogramms TIPVAC (Explaining and Improving Efficacy of Targeted Immunodeficiency Virus-like Particle Vaccines against AIDS) die Immunogenität der VLPs durch Zugabe von Adjuvantien gesteigert und eine Wiederauffrischungsimpfung durch eine mukosale Adenovirusapplikation untersucht.

Für alle drei Studien wurde die Methode der polychromatischen Durchflusszytometrie zur spezifischen Charakterisierung von Lymphozytenpopulationen auf das Rhesusaffenmodell angewendet. In den letzten beiden Studien wurden zusätzlich mittels dieser Technik virusspezifische zelluläre Immunantworten charakterisiert und mit etablierten Methoden der T-Zell-Analyse verglichen. 


\section{Material und Methoden}

\subsection{Materialien}

\subsubsection{Chemikalien}

5-Brom-4-chlor-3-indoxylphosphat (BCIP)-

Nitroblau-Tetrazoliumchlorid (NBT)-Flüssigsubstratsystem Sigma

5-(6)-Carboxyfluorescein-diazetatsuccinimidylester (CFSE) Molecular Probes

Ethanol Sigma

Formaldehyd $37 \%$ Sigma

Natriumazid Sigma

Saponin Sigma

Triton X-100 Sigma

Tween-20 Sigma

\subsubsection{Fluoreszenzfarbstoffe}

Tab. 2.1: Übersicht über die verwendeten Fluoreszenzfarbstoffe, ihre Absorptions- und Emissionsmaxima und die zur Messung im Durchflusszytometer verwendeten Filter und Laser

\begin{tabular}{|c|c|c|c|c|c|}
\hline Fluoreszenzfarbstoff & $\begin{array}{l}\text { Laser } \\
{[\mathrm{nm}]}\end{array}$ & $\begin{array}{l}\text { Langpass- } \\
\text { filter } \\
{[\mathrm{nm}]}\end{array}$ & $\begin{array}{l}\text { Bandpass- } \\
\text { filter }^{2} \\
{[\mathrm{~nm}]}\end{array}$ & $\begin{array}{l}\text { Absorptions- } \\
\text { maximum } \\
{[\mathrm{nm}]}\end{array}$ & $\begin{array}{l}\text { Emissions- } \\
\text { maximum } \\
{[\mathrm{nm}]}\end{array}$ \\
\hline $\begin{array}{l}\text { FITC } \\
\text { (Fluorescein- } \\
\text { Isothiocyanat) }\end{array}$ & 488 & 505 & $530 / 30$ & 495 & 519 \\
\hline $\begin{array}{l}\text { PE } \\
\text { (Phycoerythrin) }\end{array}$ & 488 & 550 & $575 / 26$ & $408 / 565$ & 578 \\
\hline $\begin{array}{l}\text { ECD } \\
\text { (Texas Red - PE) }\end{array}$ & 488 & 600 & $610 / 20$ & 496 & 615 \\
\hline $\begin{array}{l}\text { PerCP-Cy5.5 } \\
\text { (Peridinin-Chlorophyll- } \\
\text { Proteinkomplex) }\end{array}$ & 488 & 635 & $695 / 20$ & 482 & 695 \\
\hline PE-Cy 7 & 488 & 735 & $780 / 60$ & $480 / 565$ & 785 \\
\hline APC (Allophycocyanin) & 635 & & $660 / 20$ & 650 & 660 \\
\hline AlexaFluor647 & 635 & & $660 / 20$ & 647 & 666 \\
\hline Alexa700 & 635 & 685 & $725 / 50$ & 696 & 720 \\
\hline APC-Cy 7 & 635 & 750 & $780 / 60$ & 651 & 779 \\
\hline Alexa 405 & 405 & & $440 / 40$ & 401 & 421 \\
\hline AmCyan & 405 & 470 & $510 / 40$ & 460 & 489 \\
\hline Pacific Orange & 405 & 470 & $550 / 50$ & 402 & 551 \\
\hline
\end{tabular}

${ }^{1}$ Langpassfilter ermöglichen die Transmission von Licht längerer Wellenlänge als auf dem Filter angegeben.

${ }^{2}$ Bandpassfilter ermöglichen die Transmission von Licht der angegebenen Bandbreite um den Mittelwert. 
2.1.3 Antikörper (murin anti-human)

Tab. 2.2: Übersicht über die verwendeten murinen anti-humanen Antikörper

\begin{tabular}{|c|c|c|c|c|}
\hline mAK-Spezifität & $\begin{array}{l}\text { lg-(Sub) } \\
\text { Klasse }\end{array}$ & Klon & Farbstoff & Quelle \\
\hline CD3 & $\lg G_{3}$ & SP34 & FITC & $\begin{array}{l}\text { BD Biosciences } \\
\text { Pharmingen }\end{array}$ \\
\hline CD3 & $\lg G_{1}$ & SP34-2 & PE-Cy7 & $\begin{array}{l}\text { BD Biosciences } \\
\text { Pharmingen }\end{array}$ \\
\hline CD3 & $\lg G_{1}$ & SP34-2 & Alexa Fluor 700 & $\begin{array}{l}\text { BD Biosciences } \\
\text { Pharmingen }\end{array}$ \\
\hline CD4 & $\lg G_{1}$ & L200 & PerCP-Cy5.5 & $\begin{array}{l}\text { BD Biosciences } \\
\text { Pharmingen }\end{array}$ \\
\hline CD4 & $\lg G_{1}$ & SK3 & PerCP-Cy5.5 & $\begin{array}{l}\text { BD Biosciences } \\
\text { Pharmingen }\end{array}$ \\
\hline CD8 & $\lg _{1}$ & DK25 & $P E$ & DakoCytomation \\
\hline CD8 & $\lg G_{1}$ & SK1 & $\mathrm{PE}$ & $\begin{array}{l}\text { BD Biosciences } \\
\text { Pharmingen }\end{array}$ \\
\hline CD8 & $\lg G_{1}$ & SK1 & APC-Cy7 & $\begin{array}{l}\text { BD Biosciences } \\
\text { Pharmingen }\end{array}$ \\
\hline CD8 & $\lg G_{2 a}$ & 3B5 & Pacific Orange & CALTAG \\
\hline CD28 & $\lg G_{1}$ & CD28.2 & - & $\begin{array}{l}\text { BD Biosciences } \\
\text { Pharmingen }\end{array}$ \\
\hline CD28 & $\lg G_{1}$ & L293 & PerCP-Cy5.5 & $\begin{array}{l}\text { BD Biosciences } \\
\text { Pharmingen }\end{array}$ \\
\hline CD95 & $\lg G_{1}$ & DX2 & APC & $\begin{array}{l}\text { BD Biosciences } \\
\text { Pharmingen }\end{array}$ \\
\hline CD95 & $\lg G_{1}$ & DX2 & Biotin & $\begin{array}{l}\text { BD Biosciences } \\
\text { Pharmingen }\end{array}$ \\
\hline CD195 (CCR5) & $\lg G_{2 a}$ & $3 A 9$ & $\mathrm{PE}$ & $\begin{array}{l}\text { BD Biosciences } \\
\text { Pharmingen }\end{array}$ \\
\hline IFN & $\lg G_{1}$ & B27 & APC & $\begin{array}{l}\text { BD Biosciences } \\
\text { Pharmingen }\end{array}$ \\
\hline IFN & $\lg G_{1}$ & B27 & Alexa Fluor 700 & $\begin{array}{l}\text { BD Biosciences } \\
\text { Pharmingen }\end{array}$ \\
\hline IFN & $\lg G_{1}$ & GZ-4 & - & Mabtech \\
\hline IFN. (Biotin) & $\lg G_{1}$ & 7-B6-1 & - & Mabtech \\
\hline TNF & $\lg G_{1}$ & MAb11 & $\mathrm{PE}$ & $\begin{array}{l}\text { BD Biosciences } \\
\text { Pharmingen }\end{array}$ \\
\hline $\mathrm{IL}-2$ & $\lg G_{2 a}$ & MQ1-17H12 & FITC & $\begin{array}{l}\text { BD Biosciences } \\
\text { Pharmingen }\end{array}$ \\
\hline IL-2 & $\lg G_{2 a}$ & MQ1-17H12 & APC & $\begin{array}{l}\text { BD Biosciences } \\
\text { Pharmingen }\end{array}$ \\
\hline Ki67 & $\lg G_{1}$ & Ki67 & $\mathrm{PE}$ & DakoCytomation \\
\hline
\end{tabular}




\subsubsection{Medien, Puffer und Medienzusätze}

Tab. 2.3: Übersicht über die verwendeten Zellkulturmedien, Puffer und Medienzusätze

\begin{tabular}{|l|l|}
\hline Bezeichnung & Zusammensetzung \\
\hline PBS & Phosphatgepufferte Salzlösung \\
\hline PBS/0,5\% BSA-Puffer & $\begin{array}{l}\text { PBS, supplementiert mit 0,5\% [w/v] bovinem } \\
\text { Serumalbumin (BSA) und 0,03\% [w/v] Natriumazid }\end{array}$ \\
\hline Penicillin (10000 U/ml) & PAN Biotech GmbH \\
\hline $\begin{array}{l}\text { Kulturmedium } \\
\text { (RPMl 1640) }\end{array}$ & $\begin{array}{l}\text { Roswell Park Memorial Institute Medium 1640 (PAN } \\
\text { Biotech GmbH) mit L-Glutamin, supplementiert mit 10\% } \\
\text { [v/v] hitzeinaktiviertem FCS, 100 U/ml Penicillin (Pan } \\
\text { Biotech) und 100 } \mu \mathrm{g} / \mathrm{ml} \text { Streptomycin (PAN Biotech) }\end{array}$ \\
\hline Saponinpuffer & $\begin{array}{l}\text { PBS/0,5\% [v/v] BSA, supplementiert mit 0,5\% [w/v] } \\
\text { Saponin (Sigma) }\end{array}$ \\
\hline $\begin{array}{l}\text { Streptomycin } \\
\text { (10 mg/ml) }\end{array}$ & PAN Biotech GmbH \\
\hline Tritonpuffer & PBS, supplementiert mit 0,3\% [v/v] Triton X-100 (Sigma) \\
\hline Trypanblaulösung & $0,2 \mathrm{~g}[\mathrm{w} / \mathrm{v}]$ in 100 ml destilliertem Wasser \\
\hline Waschpuffer & $0,1 \%[\mathrm{v} / \mathrm{v}]$ Tween-20 in PBS \\
\hline
\end{tabular}

\subsubsection{Peptide und inaktiviertes Virus}

Der Peptidpool für das SIV Gag p26-Protein besteht aus einem Set von 22 Peptiden mit einer Länge von jeweils 20 Aminosäuren, die sich mit jeweils neun Aminosäuren überlappen (Tab. 2.4). Die p26-Peptide wurden vom National Institute for Biological Standards and Control (NIBSC, Großbritannien) mit einer Reinheit von mehr als $80 \%$ bezogen.

Tab. 2.4: Zuordnungsnummer und Peptidsequenzen der 22 Peptide des p26-Peptidpools

\begin{tabular}{|l|l|l|l|}
\hline $\begin{array}{l}\text { Zuordnungs- } \\
\text { Nr. }\end{array}$ & Peptidsequenz & $\begin{array}{l}\text { Zuordnungs- } \\
\text { Nr. }\end{array}$ & Peptidsequenz \\
\hline ARP714.1 & PVQQIGGNYVHLPLSPRTLN & ARP714.12 & QIQWMYRQQNPIPVGNIYRR \\
\hline ARP714.2 & HLPLSPRTLNAWVKLIEEKK & ARP714.13 & PIPVGNIYRRWIQLGLQKCV \\
\hline ARP714.3 & AWVKLIEEKKFGAEVVPGFQ & ARP714.14 & WIQLGLQKCVRMYNPTNILD \\
\hline ARP714.4 & FGAEVVPGFQALSEGCTPYD & ARP714.15 & RMYNPTNILDVKQGPKEPFQ \\
\hline ARP714.5 & ALSEGCTPYDINQMLNCVGD & ARP714.16 & VKQGPKEPFQSYVDRFYKSL \\
\hline ARP714.6 & INQMLNCVGDHQAAMQIIRD & ARP714.17 & SYVDRFYKSLRAEQTDAAVK \\
\hline ARP714.7 & HQAAMQIIRDIINEEAADWD & ARP714.18 & RAEQTDAAVKNWMTQTLLIQ \\
\hline ARP714.8 & IINEEAADWDLQHPQPAPQQ & ARP714.19 & NWMTQTLLIQNANPDCKLVL \\
\hline ARP714.9 & LQHPQPAPQQGQLREPSGSD & ARP714.20 & NANPDCKLVLKGLGVNPTLE \\
\hline ARP714.10 & GQLREPSGSDIAGTTSSVDE & ARP714.21 & KGLGVNPTLEEMLTACQGVG \\
\hline ARP714.11 & IAGTTSSVDEQIQWMYRQQN & ARP714.22 & EMLTACQGVG GPGQKARL \\
\hline
\end{tabular}

Der Peptidpool für das SIV Gag-Protein besteht aus einem Set von 16 Pentadekameren (Tab. 2.5). Die SIV Gag-Peptide wurden vom National Institute for Biological Standards and Control (NIBSC, Großbritannien) mit einer Reinheit von mehr als $80 \%$ bezogen. 
Tab. 2.5: Zuordnungsnummer und Peptidsequenzen der 16 Peptide des Gag-Peptidpools

\begin{tabular}{|l|l|l|l|}
\hline $\begin{array}{l}\text { Zuordnungs- } \\
\text { Nr. }\end{array}$ & Peptidsequenz & $\begin{array}{l}\text { Zuordnungs- } \\
\text { Nr. }\end{array}$ & Peptidsequenz \\
\hline EVA7066.1 & WAANELDRFGLAESL & EVA7066.9 & LQHPQPAPQQGQLRE \\
\hline EVA7066.2 & CQKILSVLAPLVPTG & EVA7066.10 & DEQIQWMYRQQNPIP \\
\hline EVA7066.3 & LAPLVPTGSENLKSL & EVA7066.11 & YRQQNPIPVGNIYRR \\
\hline EVA7066.4 & GSENLKSLYNTVCVI & EVA7066.12 & PVGNIYRRWIQLGLQ \\
\hline EVA7066.5 & NYPVQQIGGNYVHLP & EVA7066.13 & LQKCVRMYNPTNILD \\
\hline EVA7066.6 & PLSPRTLNAWVKLIE & EVA7066.14 & EPFQSYVDRFYKSLR \\
\hline EVA7066.7 & EVVPGFQALSEGCTP & EVA7066.15 & GPGQKARLMAEALKE \\
\hline EVA7066.8 & ALSEGCTPYDINQML & EVA7066.16 & CPDRQAGFLGLGPWG \\
\hline
\end{tabular}

Das Gag CM9-Peptid wurde von der Firma Seqlab (BRD) mit einer Reinheit von $80 \%$ synthetisiert (Tab. 2.6).

Tab. 2.6: Peptidsequenz des Gag CM9-Peptids

\begin{tabular}{|l|l|}
\hline Zuordnungs-Nr. & Peptidsequenz \\
\hline Gag - CM9 & CTPYDINQM \\
\hline
\end{tabular}

Als Kontrolle wurden Peptide des Hepatitis-C-Virus (HCV) verwendet (Tab. 2.7). Der HCV-Peptidpool gHCV besteht aus einem Gemisch von sechs 20mer-Peptiden, die von der Firma GenScript (USA) bezogen wurden.

Tab. 2.7: Beschreibung des HCV-Peptidpools mit den entsprechenden Peptidsequenzen und dem Reinheitsgrad

\begin{tabular}{|l|l|l|}
\hline $\begin{array}{l}\text { Zuordnungs- } \\
\text { Nr. }\end{array}$ & Peptidsequenz & Reinheit \\
\hline gHCV1138 & VIPVRRRGDSRGSLPCPRPC & $83,5 \%$ \\
\hline gHCV1198 & ESMETTMRSPVFTDNSTPPA & $85,0 \%$ \\
\hline gHCV1208 & VFTDNSTPPAVPQTFQVAHL & $98,4 \%$ \\
\hline gHCV1458 & TQTVDFSLDPTFTIDTTTVP & $77,7 \%$ \\
\hline gHCV1528 & ELTPAETSVRLRAYLNTPGL & $75,9 \%$ \\
\hline gHCV1538 & LRAYLNTPGLPVCQDHLEFW & $71,5 \%$ \\
\hline
\end{tabular}

Bei dem Stimulationsantigen AT2-SIV handelt es sich um inaktiviertes und gereinigtes SIVmac239/SUPT-1-CCR5 CL30-Virus.

Zur Herstellung wurden Viruspartikel mit $1 \mathrm{mM}$ Aldrithiol-2 inaktiviert und über Säulenchromatographie gereinigt (Lifson et al., 2004).

Das Stimulationsantigen AT2-SIV wurde von Dr. Jeffrey Lifson vom AIDS Vaccine Program, National Cancer Institute (Frederick, USA) zur Verfügung gestellt. 


\subsubsection{Oligonukleotide}

Die Oligonukleotide und Taqman-Sonden zur Bestimmung der Virus-RNA im Blutplasma wurden von den Firmen biomers.net (BRD) und metabion (BRD) bezogen (Tab. 2.8).

Tab. 2.8: Sequenzen der verwendeten Primer und der Taqman-Sonde

\begin{tabular}{ll}
\hline Primer & Sequenz $\left(5^{\prime} \rightarrow 3^{\prime}\right)$ \\
\hline Gag sense & ACCCAGTACAACAAATAGGTGGTAACT \\
Gag antisense & TCAATTTTACCCAGGCATTTAATGT \\
Taqman-Sonde & Sequenz $\left(5^{\prime} \rightarrow 3^{\prime}\right)$ \\
\hline & FAM-TGTCCACCTGCCATTAAGCCCGAG-TAMRA \\
\hline
\end{tabular}

\subsubsection{Enzyme und weitere Reagenzien}

BD FACS Lysing Solution BD Biosciences

Bovines Serumalbumin (BSA). Sigma

Dako Cytomation Uti-Lyse Erythrocyte Lysing Reagent. Dako Lymphoprep Ficoll PAA

Staphylococcus-Enterotoxin B (SEB) Sigma

Steptavidin-Alkalische Phosphatase-Konjugat Mabtech

\subsubsection{Zellkultur- und andere Verbrauchsmaterialien}

BD Falcon ${ }^{\mathrm{TM}} 5 \mathrm{ml}-$ Polysterol Rundboden-Röhrchen BD Biosciences

BD Vacutainer EDTA. BD Biosciences

Heparin BD Biosciences

Zitrat BD Biosciences

Leucosep-Röhrchen Greiner

96-well-Polyvinyldifluorid (PVDF)-Platte Mabtech

Reaktionsgefäße $0,5 \mathrm{ml}$ und $1,5 \mathrm{ml}$. Greiner 


\subsubsection{Geräte}

Bioreader 3000 Biosys $\mathrm{GmbH}$

$\mathrm{CO}_{2}$-Inkubator Heraeus

Durchflusszytometer BD LSR II, BD Biosciences

Inversmikroskop Axiovert 25, Carl Zeiss AG

Kühlschrank Comfort LIEBHERR

Laminarbank HeraSafe Heraeus

PCR-Geräte 7500 Real-ime PCR System, Applied Biosystems

pH-Meter HI110, HANNAinstruments

Pipetten Eppendorf Reference, Eppendorf AG

Waagen Sartorius AG

Wasserbad GFL (BRD)

Zählkammer (Neubauer) neoLAB Migge Laborbedarf

Zentrifugen 5415C, 5810, Eppendorf AG

Megafuge 1.0R, Heraeus Instruments

\subsubsection{Kommerzielle RNA-Isolations- und PCR-Kits}

MagAttract $\circledast$ Virus Mini M48 Qiagen

QuantiTect $^{\mathrm{TM}}$ Probe RT-PCR Qiagen

\subsubsection{Versuchstiere}

Als Versuchstiere dienten adulte Rhesusaffen (Macaca mulatta) indischer und chinesischer Herkunft. Die Tiere wurden von Züchtern aus China oder England bezogen oder stammten aus der Zucht des Deutschen Primatenzentrums. Die Haltung erfolgte gemäß der Richtlinien des Deutschen Primatenzentrums und gemäß des Deutschen Tierschutzgesetzes vom 25. Mai 1998 in der derzeit geltenden Fassung.

Alle Tiere wurden von Tierärzten und -pflegern der Abteilung Virologie und Immunologie betreut. Der genetische MHC-Hintergrund der verwendeten Versuchstiere wurde von der Arbeitsgruppe Immungenetik unter Leitung von Frau Dr. Sauermann mittels PCR-Verfahren bestimmt. Es wurde versucht, Tiere mit dem MHC-Klasse-I-Allel $A^{*} 01$ gleichmäßig auf die Versuchsgruppen zu verteilen. 


\subsubsection{Vakzinekonstrukte und Immunisierungsprotokolle}

\subsubsection{Vakzinekonstrukte}

Die DNA- und Adenovirusimpfstoffe der ersten Versuchsreihe wurden von der Arbeitsgruppe von Prof. Sung von der Pohang University of Science \& Technology, Republik Korea hergestellt (Stahl-Hennig et al., 2007). Es wurden drei DNA-Vektoren konstruiert, die für die SIV-Gene gag, env, nef-tat-vpx-vif kodierten. Ein zusätzlicher Vektor enthielt das Gen für das humane Interleukin 15, das als immunmodulatorisches Zytokin beschrieben ist (Kutzler et al., 2005; Calarota et al., 2003; Musso et al., 1999; Doherty et al., 1996).

Die Adenoviruskonstrukte enthielten die Gene gag, env, vif-nef und tat-vpx. Es wurde ebenfalls ein Adenoviruskonstrukt mit dem humanen Interleukin 15 hergestellt.

Die VLP- und Adenovirusimpfstoffe der zweiten und dritten Versuchsreihe wurden von der Arbeitsgruppe von Prof. Überla an der Ruhr-Universität Bochum hergestellt (Kuate et al., 2003).

In der dritten Versuchsreihe wurde als Adjuvans eine Mischung aus nicht-methylierten Cytidin-phospatidyl-Guanosin (CpG)-enhaltenden Oligonukleotiden und Polyriboinositol-Polyribocytidinsäure im Komplex mit L-Lysin (polyIC/LC) verwendet, um die Immunantwort zu verstärken (Hartmann et al., 2005; Teleshova et al., 2004; Jakob et al., 1999; Sammons et al., 1977). Es wurden je Tier $500 \mu \mathrm{g} / \mathrm{kg}$ Poly-IC/LC und $2 \mathrm{mg}$ CpG subkutan zusammen mit den VLPs injiziert.

Die Immunisierungsprotokolle bestanden jeweils aus einem „Prime-Boost“Regime, bei dem die Tiere zunächst zwei- oder dreimal mit DNA-Konstrukten bzw. Virus-ähnlichen Partikeln (engl. virus like particles, VLP) immunisiert wurden, und anschließend eine zweimalige Auffrischungsimpfung mittels adenoviraler Vektoren erfolgte. Die Tabellen 2.9 bis 2.11 zeigen die Immunisierungsschemata der drei Versuchsreihen. 
Tab. 2.9: Immunisierungsschema der ersten Versuchsreihe (DNA-Adeno)

\begin{tabular}{|c|c|c|c|c|c|c|}
\hline Gruppe & $\begin{array}{l}\text { Zeitpunkt } \\
\text { (Woche) }\end{array}$ & 0 & 8 & 16 & 24 & 32 \\
\hline & & \multicolumn{3}{|c|}{ Basisimmunisierung } & \multicolumn{2}{|c|}{ Auffrischungsimpfung } \\
\hline \multirow{2}{*}{$\begin{array}{l}1 . \\
(n=6)\end{array}$} & Konstrukt & Puffer & Puffer & Puffer & Puffer & Puffer \\
\hline & Applikationsweg & i.m. & i.m. & i.m. & i.m. & i.m. \\
\hline \multirow[t]{3}{*}{$\begin{array}{l}2 . \\
(n=6)\end{array}$} & Konstrukt & $\begin{array}{l}\text { SIV/IL-15 } \\
\text { DNA }\end{array}$ & $\begin{array}{l}\text { SIV/IL-15 } \\
\text { DNA }\end{array}$ & $\begin{array}{l}\text { SIV/IL-15 } \\
\text { DNA }\end{array}$ & $\begin{array}{l}\text { Ad5-SIVI } \\
\text { IL-15 }\end{array}$ & $\begin{array}{l}\text { Ad5-SIV/ } \\
\text { IL-15 }\end{array}$ \\
\hline & Applikationsweg & i.m. & i.m. & i.m. & tonsillär & i.m. \\
\hline & Menge & $\begin{array}{l}1,5 \mathrm{mg} / \\
\text { Konstrukt }\end{array}$ & $\begin{array}{l}1,5 \mathrm{mg} / \\
\text { Konstrukt }\end{array}$ & $\begin{array}{l}1,5 \mathrm{mg} / \\
\text { Konstrukt }\end{array}$ & $\begin{array}{l}1 \times 10^{9} \mathrm{PFU} / \\
\text { Konstrukt }\end{array}$ & $\begin{array}{l}2 \times 10^{9} \quad \mathrm{PFU} / \\
\text { Konstrukt }\end{array}$ \\
\hline \multirow[t]{3}{*}{$\begin{array}{l}3 . \\
(n=6)\end{array}$} & Konstrukt & $\begin{array}{l}\text { SIV/IL-15 } \\
\text { DNA }\end{array}$ & $\begin{array}{l}\text { SIV/IL-15 } \\
\text { DNA }\end{array}$ & $\begin{array}{l}\text { SIV/IL-15 } \\
\text { DNA }\end{array}$ & $\begin{array}{l}\text { Ad5-SIV/ } \\
\text { IL-15 }\end{array}$ & $\begin{array}{l}\text { Ad5-SIV/ } \\
\text { IL-15 }\end{array}$ \\
\hline & Applikationsweg & i.m. & i.m. & i.m. & i.m. & i.m. \\
\hline & Menge & $\begin{array}{l}1,5 \mathrm{mg} / \\
\text { Konstrukt }\end{array}$ & $\begin{array}{l}1,5 \mathrm{mg} / \\
\text { Konstrukt }\end{array}$ & $\begin{array}{l}1,5 \mathrm{mg} / \\
\text { Konstrukt }\end{array}$ & $\begin{array}{l}1 \times 10^{9} \mathrm{PFU} / \\
\text { Konstrukt }\end{array}$ & $\begin{array}{l}2 \times 10^{9} \quad \mathrm{PFU} / \\
\text { Konstrukt }\end{array}$ \\
\hline
\end{tabular}

Tab. 2.10: Immunisierungsschema der zweiten Versuchsreihe (VLP-Adeno)

\begin{tabular}{|l|l|l|l|l|l|}
\hline Gruppe & $\begin{array}{l}\text { Zeitpunkt } \\
\text { (Woche })\end{array}$ & \multicolumn{2}{|c|}{$\mathbf{0}$} & \multicolumn{1}{c|}{$\mathbf{4}$} & 16 \\
\hline & & \multicolumn{2}{|c|}{ Basisimmunisierung } & \multicolumn{2}{|c|}{ Auffrischungsimpfung } \\
\hline$(n=4)$ & Konstrukt & VLP & VLP & Ad5-SIV & Ad5-SIV \\
\hline & Applikationsweg & tonsillär & tonsillär & tonsillär & tonsillär \\
\hline & Menge & $\begin{array}{l}100 \mu g \\
R^{*}\end{array}$ & $\begin{array}{l}100 \mu g \\
R^{*}\end{array}$ & $\begin{array}{l}4 \times 10^{11} \\
\text { Partikel }\end{array}$ & $\begin{array}{l}4 \times 10^{11} \\
\text { Partikel }\end{array}$ \\
\hline$(n=7)$ & Konstrukt & Puffer & Puffer & Puffer & Puffer \\
\hline & Applikationsweg & tonsillär & tonsillär & tonsillär & tonsillär \\
\hline
\end{tabular}

* normiert auf die RT-Aktivität (Kuate et al., 2003)

Tab. 2.11: Immunisierungsschema der dritten Versuchsreihe (aVLP-Adeno)

\begin{tabular}{|c|c|c|c|c|c|}
\hline Gruppe & $\begin{array}{l}\text { Zeitpunkt } \\
\text { (Woche) }\end{array}$ & 0 & 8 & 24 & 32 \\
\hline & & \multicolumn{2}{|c|}{ Basisimmunisierung } & \multicolumn{2}{|c|}{ Auffrischungsimpfung } \\
\hline \multirow[t]{3}{*}{$(n=4)$} & Konstrukt & $\begin{array}{l}\text { VLP+ } \\
\text { Adjuvans }\end{array}$ & $\begin{array}{l}\text { VLP+ } \\
\text { Adjuvans }\end{array}$ & Ad5-SIV & Ad5-SIV \\
\hline & Applikationsweg & S.C. & S.C. & tonsillär & tonsillär \\
\hline & Menge & $\begin{array}{l}25 \mu g \\
p 27 \mathrm{CA}\end{array}$ & $\begin{array}{l}25 \mu g \\
p 27 \mathrm{CA}\end{array}$ & $\begin{array}{l}3 \times 10^{11} \\
\text { Partikel }\end{array}$ & $\begin{array}{l}3 \times 10^{11} \\
\text { Partikel }\end{array}$ \\
\hline \multirow[t]{2}{*}{$(n=6)$} & Konstrukt & Puffer & Puffer & Puffer & Puffer \\
\hline & Applikationsweg & S.C. & S.C. & S.C. & S.C. \\
\hline
\end{tabular}



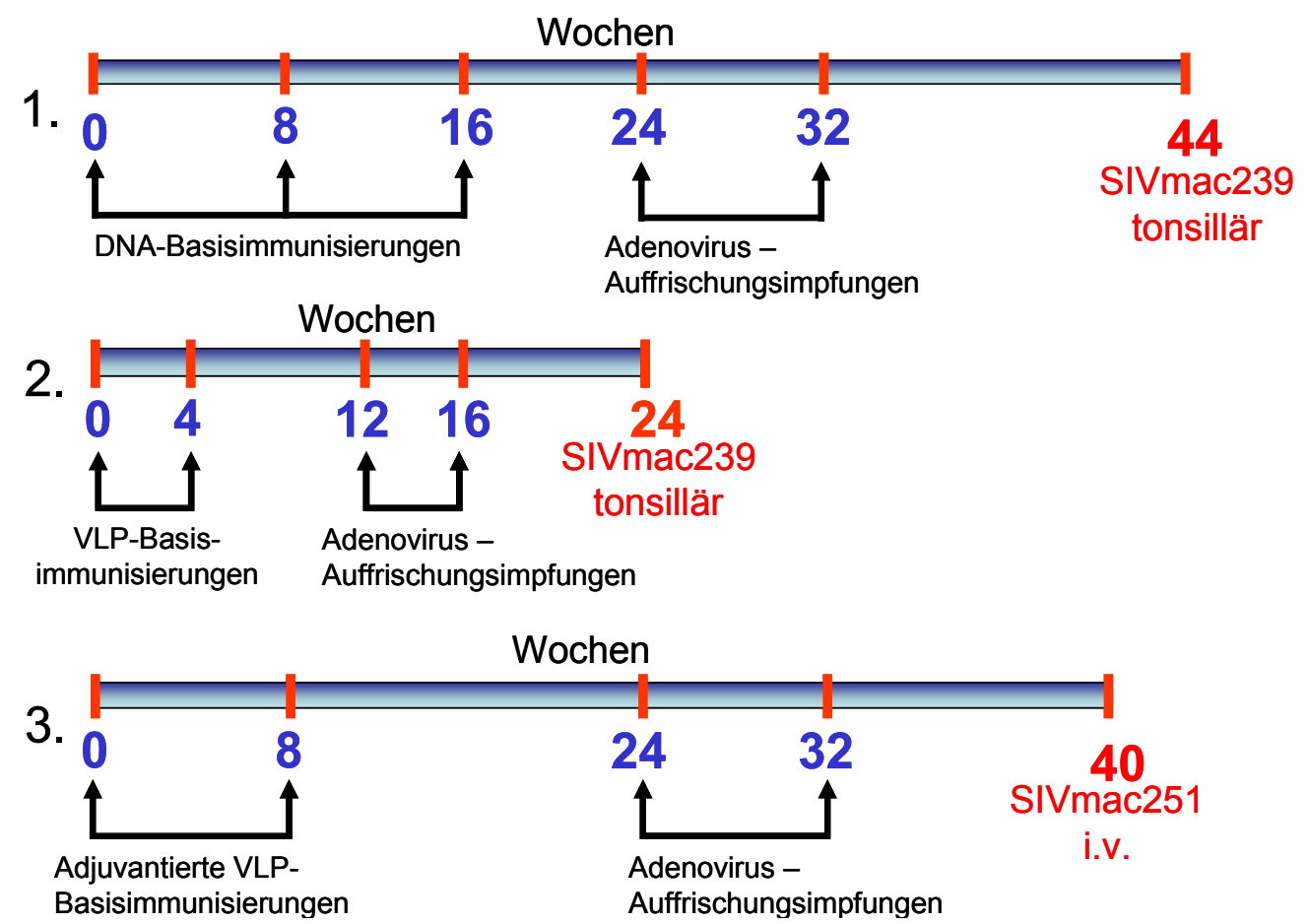

Abb. 2.1: Schematische Darstellung der drei Versuchsreihen

Dargestellt sind die Zeitpunkte der Immunisierung und der Belastungsinfektion der drei unterschiedlichen Versuchsreihen. Die schwarzen Pfeile geben jeweils den Zeitpunkt der Basisimmunisierung und der Auffrischungsimpfung an. In rot ist das Belastungsvirus sowie die Inokulationsroute dargestellt.

\subsubsection{Datenanalyse und Software}

Zur Analyse und Bearbeitung der Daten wurden neben den Microsoft Office Programmen folgende Programme verwendet:

Adobe Photoshop CS Version 8. Adobe Systems Incorporated (USA)

Endnote X Thomson Scientific (USA)

FlowJo Version 6.0 bis 6.4.7 .Tree Star Inc. (USA)

Graph Pad Prism, Version 4 Graph Pad Software Inc. (USA)

\subsubsection{Statistische Auswertung}

Die statistische Auswertung erfolgte mit dem Programm Graph Pad Prism. Für Korrelationsanalysen wurden die nichtparametrische Spearman-Korrelation mit einer zweiseitigen Analyse und einem Konfidenzintervall von 95\% durchgeführt. Für die vergleichenden Auswertungen wurde der nichtparametrische MannWhitney (U) Test verwendet. Auch bei diesem Test wurde eine zweiseitige Analyse mit einem Konfidenzintervall von 95\% gewählt. Als statistisch signifikant wurden in beiden Tests Ergebnisse mit einem p-Wert kleiner als 0,05, als hochsignifikant wurden Ergebnisse mit einem p-Wert kleiner als 0,01 angesehen. 


\subsection{Methoden}

\subsubsection{Narkotisierung der Versuchstiere}

Die Rhesusaffen wurden für Blutentnahmen, Immunisierungen und Operationen narkotisiert. Für Blutentnahmen und Immunisierungen wurde 10 mg Ketamin pro Kilogramm intramuskulär injiziert. Für Operationen und Gewebeentnahmen wurden für eine tiefere Anästhesie $2 \mathrm{mg}$ Xylazin, $10 \mathrm{mg}$ Ketamin und 0,02 mg Atropin pro Kilogramm Körpergewicht injiziert.

Sämtliche Arbeiten wurden von den Tiermedizinern und Tierpflegern der Abteilung Virologie und Immunologie des Deutschen Primatenzentrums durchgeführt.

\subsubsection{Belastungsinfektion der Tiere}

In der ersten und zweiten Versuchsreihe wurde das SIV-Isolat SIVmac239 zur Infektion der Versuchstiere tonsillär appliziert (Stahl-Hennig et al., 1999). Hierzu wurde der ursprüngliche Virusstock $1: 10$ verdünnt, was $1 \times 10^{5} \mathrm{TCID}_{50} / \mathrm{ml}$ entspricht. In der ersten Versuchsreihe erfolgte die tonsilläre Infektion in der 44. Woche nach der ersten Immunisierung, in der zweiten Versuchsreihe in der 24. Woche nach der ersten Immunisierung.

In der dritten Versuchsreihe wurden die Tiere in der Woche 40 mit 20 AID $_{50}$ (Affen-infektiöse Dosis) des SIV-Isolats SIVmac251 intravenös infiziert. Dieses Virus wurde von Dr. A. Aubertin (Institut Pasteur, Straßburg, Frankreich) zur Verfügung gestellt (Le Grand et al., 1992).

\subsubsection{Erstellung eines Differentialblutbildes}

Eine Differentialblutbildanalyse des Vollbluts der Versuchstiere wurde in regelmäßigen Abständen von der Abteilung Hämatologie des Universitätsklinikums Göttingen nach aktuellen Standards vorgenommen. Das Blut wurde nach den von diesem Labor geforderten und dort einzusehenden Vorgaben aufgearbeitet.

\subsubsection{Schutzmaßnahmen}

Die Arbeiten erfolgten unter sterilen Bedingungen und aufgrund der Infektiosität an einer Werkbank der Sicherheitsstufe II und unter Bedingungen der biologischen Sicherheitsstufe III. 


\subsubsection{Isolation von Affenleukozyten aus peripherem Blut}

Die Blutproben wurden durch Punktion der Vena femoralis mit Hilfe von BD Vacutainer-Blutentnahmeröhrchen gewonnen, die zur Verhinderung der Koagulation entweder mit Heparin, EDTA oder mit Zitrat versetzt waren.

Die Trennung der Leukozyten erfolgte mittels Dichtegradientenzentrifugation. In einem Leucosep-Röhrchen (BD Biosciences) wurden $3 \mathrm{ml}$ Ficoll (Dichte 1,077 g/ml; Pansystems $\mathrm{GmbH}$ ) vorgelegt und bei 500 x g zentrifugiert. Anschließend wurde das unverdünnte Blut auf die Leucosepmembran überführt und die Probe 15 Minuten bei 800 x g zentrifugiert. Der Lymphozytensaum wurde an der Interphase zwischen Ficoll und zellfreiem Plasma abgenommen und mit PBS gewaschen. Im Anschluss wurde die Anzahl der lebenden Zellen bestimmt und diese nach einem weiteren Waschschritt in den unterschiedlichen funktionellen Tests eingesetzt.

\subsubsection{Vitalitäts- und Zellzahlbestimmung}

Zur Bestimmung der Vitalität von Zellen wurden diese mit Trypanblaulösung angefärbt. Bei dieser Färbemethode werden nur tote Zellen angefärbt, da der Farbstoff in toten Zellen akkumuliert. Mit Hilfe der Neubauer-Zählkammer erfolgte direkt nach der Färbung die Bestimmung des Anteils der lebenden Zellen.

\subsubsection{Proliferationstest mittels CFSE-Färbung}

$1 \times 10^{7}$ isolierte Affen-PBMCs wurden mit $1 \mu \mathrm{M}$ Carboxyfluorescein in $1 \mathrm{ml}$ PBS für 15 Minuten bei $37^{\circ} \mathrm{C}$ und $5 \% \mathrm{CO}_{2}$ inkubiert und dabei zweimal geschwenkt. Anschließend wurden $100 \mu \mathrm{FCS}$ zugesetzt und die Zellen für 10 Minuten bei 350 x g zentrifugiert. Die Zellen wurden in $1 \mathrm{ml}$ Kulturmedium aufgenommen und für 30 Minuten bei $37^{\circ} \mathrm{C}$ und $5 \% \mathrm{CO}_{2}$ inkubiert. Im Anschluss daran wurden die Zellen zweimal mit PBS/2\% FCS gewaschen und mit einer Dichte von $2 \times 10^{6}$ Zellen pro Vertiefung in 96-well-Rundbodenplatten in $150 \mu \mathrm{l}$ Kulturmedium ausgesät. Die Stimulation der Zellen erfolgte mit Medium, $2 \mu \mathrm{g} / \mathrm{ml}$ AT2-SIV, $2 \mu \mathrm{g} / \mathrm{ml}$ Gag-Peptidpool oder SEB in jeweils $50 \mu \mathrm{l} \mathrm{Kulturmedium.} \mathrm{Die}$ Zellkulturplatten wurden für fünf Tage bei $37^{\circ} \mathrm{C}$ und $5 \% \mathrm{CO}_{2}$ inkubiert. Im Anschluss daran wurden die Zellen in 1,5 ml-Reaktionsgefäße überführt und für die durchflusszytometrischen Färbungen verwendet. 


\subsubsection{Die polychromatische Durchflusszytometrie}

Die Durchflusszytometrie ist eine Technik zur Analyse von einzelnen Zellen oder Zellsubpopulationen aus einer heterogenen Zellpopulation. Dies geschieht, indem die zu messenden Zellen in einem laminaren Flüssigkeitsstrom einzeln durch die Messzelle des Durchflusszytometers geleitet werden und dabei mit Laserlicht einer definierten Wellenlänge bestrahlt werden.

Passiert eine Zelle die Laser des Durchflusszytometers, so streut sie das auf sie treffende Licht in unterschiedliche Richtungen. Die Lichtstreuung wird von verschiedenen Zelleigenschaften beeinflusst (Querschnittsfläche, Refraktionsindex, Faltung der Zellmembran, intrazelluläre Granularität, u.a.). Die Streuung erfolgt nicht in alle Richtungen gleichmäßig, da das nach vorne gestreute Licht den Großteil des Streulichts ausmacht. Dieses wird im so genannten Forward-Scatter (FSC) detektiert und gibt Auskunft über die Größe der untersuchten Zelle. Der sehr viel kleinere seitlich gestreute Lichtanteil gelangt zum Side-Scatter (SSC)-Detektor und ist abhängig von der Granularität der Zelle.

Durch den Einsatz von spezifischen, Fluorochrom-markierten Antikörpern gegen verschiedene Proteine der Zelle kann die Expression dieser Moleküle auf oder innerhalb der Zelle analysiert werden. Die durch das Laserlicht angeregte Emission der Fluorochrome wird zu den entsprechenden Detektoren geleitet und dort in elektrische Impulse umgewandelt. Für die Erfassung des Fluoreszenzlichts und des seitwärts gestreuten Lichts, die beide sehr intensitätsarm sind, sind Photodetektoren (PMT, engl. photomultiplier tube) erforderlich, welche die Impulse verstärken und in messbare elektrische Signale transformieren. Hierbei wird die Signalhöhe auf 16384 Ebenen und die Signalweite mit einer $10 \mathrm{MHz}$-Rasterung gemessen. Aus der Signalhöhe und der Signalweite ergeben sich die Signalfläche und der Zeitverlauf des gemessenen Signals.

In der nachfolgenden Rechner-gestützten Multiparameteranalyse werden die zeitgleich aufgenommenen Parameter kombiniert und die entsprechenden Zellpopulationen analysiert.

Das in dieser Arbeit verwendete Durchflusszytometer (LSR II, BD) ermöglicht in der vorhandenen Konfiguration die gleichzeitige Analyse von zehn Fluorochromen. Zur Fluoreszenzanregung werden drei Laser verwendet: Zur 
Erzeugung von monochromatischem Licht der Wellenlänge $405 \mathrm{~nm}$ wird ein Coherent Vioflame Diodenlaser, für die Wellenlänge $488 \mathrm{~nm}$ ein Argonionenlaser und für $635 \mathrm{~nm}$ ein JDS Uniphase Helium-Neon-Laser verwendet.

Da sich die Fluoreszenzspektren der verschiedenen Fluorochrome in bestimmten Bereichen überlappen, muss beim Einsatz von mehreren Fluorochromen darauf geachtet werden, dass die Emissionsspektren möglichst verschieden sind (Baumgarth et al., 2000), da sich eine Überlagerung der Emissionsspektren nicht komplett vermeiden lassen. Aus diesem Grund muss vor jeder Messung eine Kompensationsmessung durchgeführt werden. Hierzu werden Zellen oder Kügelchen mit einem einzelnen Fluorochrom gefärbt und gemessen. Mit Hilfe der Kompensationselektronik der Software FACS Diva (BD) wird das auftretende Signal in allen Detektoren ermittelt und der Anteil der Überlappung elektronisch subtrahiert.

Sämtliche Daten werden nach der Digitalisierung an die Analysesoftware weitergeleitet und dort dargestellt. Übliche Darstellungen der Messdaten sind das Histogramm, in dem die Anzahl der gemessenen Ereignisse gegen die Signalintensität aufgetragen ist, oder das Zytogramm (engl. dot plot), in dem jedes Ereignis durch zwei Werte beschrieben ist.

\subsubsection{Ermittlungen der optimalen Antikörperkonzentration}

Die optimale Antikörper-Konzentration, welche zum Färben der Zellen verwendet wurde, wurde durch Verdünnungsreihen ermittelt. Hierzu wurden Vollblutzellen nach Standardprotokoll gefärbt. Ausgehend von der vom Hersteller angegebenen Konzentration wurde eine Verdünnungsreihe angesetzt. Dazu wurde die Ausgangskonzentration viermal jeweils 1:2 verdünnt. Die Konzentration an Konjugat, bei der bei geringem Hintergrund ein deutliches Signal messbar war, wurde für die weiteren Versuche verwendet. 


\subsubsection{Vollblutfärbungen}

Für die Färbung wurden jeweils $50 \mu \mathrm{l}$ Vollblut in BD-Rundbodenröhrchen gegeben, $20 \mu \mathrm{l}$ Antikörpermix zugesetzt und das Blut für 20 Minuten bei Raumtemperatur im Dunkeln inkubiert. Im Anschluss daran wurde $1 \mathrm{ml} \mathrm{BD-}$ Lysepuffer zugesetzt, das Blut für weitere 10 Minuten bei RT inkubiert und für 10 Minuten bei 350 x g und RT zentrifugiert. Der Überstand wurde dekantiert und die Zellen mit $1 \mathrm{ml}$ PBS/0,5\% BSA-Puffer gewaschen. Nach einer 10-minütigen Zentrifugation bei $350 \times \mathrm{g}$ wurden die Zellen in $50 \mu \mathrm{l}$ 0,3\%iger Formaldehydlösung aufgenommen und im Durchflusszytometer gemessen.

\subsubsection{Antikörper-Kombinationen zur Charakterisierung der Lymphozyten}

In den Tabellen 2.12 und 2.13 sind die Kombinationen von Antikörpern zusammengestellt, die für die Charakterisierung der Lymphozyten verwendet wurden.

Tab. 2.12: Übersicht über die verwendeten Kombinationen der jeweiligen AntikörperFluorochrom-Konjugate (Tab. 2.2) zur Charakterisierung der T-Zellen

\begin{tabular}{|l|c|c|c|}
\hline Fluorochrom & \multicolumn{3}{|c|}{ Antigen } \\
\hline FITC & CD29 & CD 29 & CD 29 \\
\hline PE & CD 195 & KI67 & CM9-Tetramer \\
\hline PerCP-Cy5.5 & CD 28 & CD 28 & CD 28 \\
\hline PE-Cy7 & CD 95* & CD 95* & CD 95* \\
\hline Alexa700 & CD 3 & CD 3 & CD 3 \\
\hline Alexa405 & CD 4 & CD 4 & CD 4 \\
\hline AmCyan & CD 8 & CD 8 & CD 8 \\
\hline
\end{tabular}

\# Fluorochrom ist mit Streptavidin konjugiert

* anti-CD95 Antikörper ist biotinyliert 
Tab. 2.13: Übersicht über die Kombination der verwendeten Antikörper-FluorochromKonjugate (Tab. 2.2) für die intrazelluläre Zytokinfärbung

\begin{tabular}{|l|c|c|}
\hline Fluorochrom & zweite Versuchsreihe & dritte Versuchsreihe \\
\hline FITC & IL2 & IL2 \\
\hline PE & CD 8 & TNFa \\
\hline PerCP-Cy5.5 & CD 4 & - \\
\hline APC & IFNy & IFNy \\
\hline Alexa700 & CD 3 & CD 3 \\
\hline Alexa405 & - & CD 4 \\
\hline AmCyan & - & CD 8 \\
\hline
\end{tabular}

\subsubsection{Vollblutfärbung mit Biotin-markierten Antikörpern}

Die Färbung mit Biotin-markierten Antikörpern wurde wie oben beschrieben durchgeführt. Nach dem Dekantieren des Überstandes wurden $20 \mu \mathrm{l}$ Streptavidin-PE-Cy7-markierter Antikörper zugesetzt und die Zellen für 20 Minuten bei Raumtemperatur im Dunkeln inkubiert. Nach der Inkubationszeit wurde wie unter 2.2.8.2 verfahren.

\subsubsection{Intranukleäre Färbung des Proliferationsmarker Ki67}

Zur intranukleären Färbung des Proliferationsmarker Ki67 wurde zunächst wie unter 2.2.8.2 beschrieben eine Oberflächenfärbung der Zellen durchgeführt. Im Anschluss an die Färbung wurden die Zellen zur Membranpermeabilisierung mit $100 \mu \mathrm{l}$ Tritonpuffer für 3 Minuten bei Raumtemperatur inkubiert. Anschließend wurden $500 \mu \mathrm{l}$ PBS/0,5\% BSA-Puffer zugesetzt, die Zellen bei $350 \times \mathrm{g}$ für 10 Minuten zentrifugiert und der Pufferüberstand entfernt. Daraufhin erfolgt die Inkubation mit $20 \mu \mathrm{l}$ anti-Ki67-Antikörper (gelöst in PBS/0,5\% BSA-Puffer) für 45 Minuten bei $4^{\circ} \mathrm{C}$. Anschließend wurden $1 \mathrm{ml} \mathrm{PBS} / 0,5 \%$ BSA-Puffer zugesetzt und die Zellen bei $350 \times$ g für 10 Minuten zentrifugiert. Der Überstand wurde entfernt und die Zellen in $50 \mu \mathrm{l}$ PBS/0,5\% BSA-Puffer aufgenommen. Im Anschluss an die Färbung erfolgte die Messung im Durchflusszytometer. 


\subsubsection{Intrazelluläre Zytokinfärbung (ICS, engl. intracellular cytokine staining)}

$5 \times 10^{5}$ bis $1,5 \times 10^{6}$ isolierte Affen-PBMCs wurden in 1,5 ml-Reaktionsgefäßen in $250 \mu \mathrm{l}$ Kulturmedium unter Zugabe von $50 \mu \mathrm{l}$ Peptidmix stimuliert. Es wurden zur Stimulation folgende Peptidpools verwendet: SIV-Peptide: Gag, p26 und AT2-SIV (Konzentrationen: jew. $2 \mu \mathrm{g} / \mathrm{ml}$ ). Als Negativkontrolle dienten Kulturmedium und Peptide des Hepatitis-C-Virus (HCV), als Positivkontrolle wurde $1 \mu \mathrm{g} / \mathrm{ml}$ Staphylococcus-Enterotoxin B (SEB) verwendet. In sämtlichen Ansätzen wurde als Kostimulator ein anti-CD28-Antikörper in einer Konzentration von $1 \mu \mathrm{g} / \mathrm{ml}$ zugesetzt.

Die Stimulationsansätze wurden für eine Stunde bei $37^{\circ} \mathrm{C}$ und $5 \% \quad \mathrm{CO}_{2}$ inkubiert. Nach dieser Stunde wurden $50 \mu \mathrm{l}$ Kulturmedium, versetzt mit Brefeldin A (Endkonzentration im Stimulationsansatz: $10 \mu \mathrm{g} / \mathrm{ml}$ ), zugesetzt und die Zellen für weitere $5 \mathrm{~h}$ bei $37^{\circ} \mathrm{C}$ und $5 \% \mathrm{CO}_{2}$ inkubiert.

Im Anschluss an die Inkubationszeit wurden die Zellen bei $350 \times \mathrm{g}$ für 10 Minuten zentrifugiert, das Kulturmedium entfernt, das Zellpellet durch Vortexen gelöst und $20 \mu \mathrm{l}$ des Antikörpermixes für die Oberflächenfärbung zugesetzt. Der Färbeansatz wurde für 20 Minuten bei Raumtemperatur im Dunkeln inkubiert und die Zellen im Anschluss daran mit $1 \mathrm{ml} \mathrm{PBS/0,5 \%} \mathrm{BSA-}$ Puffer gewaschen und bei 350 x g für 10 Minuten zentrifugiert. Der Waschpuffer wurde abgesaugt und die Zellen zur Fixierung in 3,5\% Formaldehydlösung für 10 Minuten bei $37^{\circ} \mathrm{C}$ und $5 \% \mathrm{CO}_{2}$ inkubiert. Nach Zentrifugation bei $700 \mathrm{x} \mathrm{g}$ für 5 Minuten wurden die Zellen in $400 \mu \mathrm{l}$ PBS/0,5\% BSA-Puffer aufgenommen und über Nacht bei $4^{\circ} \mathrm{C}$ im Dunkeln gelagert. Am nächsten Tag wurden sie erneut bei $700 \times \mathrm{g}$ für 5 Minuten zentrifugiert, der Waschpuffer abgesaugt und das Zellpellet durch mechanisches Reiben gelöst. Für die intrazelluläre Färbung wurden $20 \mu \mathrm{l}$ Antikörpermix (verdünnt in Saponinpuffer) zugesetzt und für 45 Minuten bei $4^{\circ} \mathrm{C}$ im Dunkeln inkubiert. Im Anschluss wurden $1 \mathrm{ml}$ Saponinpuffer zugesetzt und die Zellen bei $700 \times \mathrm{g}$ für 5 Minuten zentrifugiert. Der Pufferüberstand wurde entfernt und die Zellen wurden in $75 \mu \mathrm{PBS} / 0,5 \%$ BSAPuffer aufgenommen. Die Messung im Durchflusszytometer erfolgte sofort im Anschluss an diese Färbung. 


\subsubsection{Tetramerfärbung}

Tetramere sind rekombinant hergestellte MHC-Klasse-I-Moleküle, die mit Peptiden komplexiert, biotinyliert und anschließend an Fluoreszenz-markierte Streptavidin-Moleküle gebunden wurden. Da am Streptavidin vier Bindungsstellen für Biotin existieren, entstehen tetramere Komplexe. Diese können sich mit ausreichender Avidität direkt an die T-Zellen mit der entsprechenden Spezifität binden und diese dadurch mit einem Fluorochrom markieren, welches durchflusszytometrisch bestimmt werden kann.

Die in dieser Arbeit verwendeten Tetramere wurden mit der CM9-Peptidsequenz (Gag181-189, CTPYDINQM) komplexiert, so dass an diese Tetramere nur die $\mathrm{CD}^{+} \mathrm{T}$-Zellen binden, die dieses Peptid mit ihrem T-Zellrezeptor spezifisch detektieren. Die CM9-Tetramere wurden von der Firma Beckman Coulter bezogen.

Für die Färbung dieser T-Zellpopulation wurden 0,7 $\mu$ ler Tetramerlösung in der Vollblutfärbung (2.2.8.2) verwendet.

\subsubsection{Bestimmung der Virus-RNA}

Zum Nachweis einer erfolgten Infektion der Versuchstiere ist die quantitative Bestimmung der SIV-spezifischen RNA im Blutplasma mittels reverser Transkriptions-Polymerasekettenreaktion (RT-PCR) möglich. Diese Untersuchungen wurden von Frau Dr. Sauermann, Arbeitsgruppe Immungenetik der Abteilung Virologie und Immunologie durchgeführt.

Hierzu wurde die virale RNA aus $200 \mu$ Serum mit Hilfe des MagAttract $₫$ Virus Mini M48-Kit und des BioRobot M48 der Firma Qiagen isoliert. Mit Hilfe des QuantiTect $^{\text {TM }}$ Probe RT-PCR-Kits der Firma Qiagen und des 7500 Real-Time PCR System von Applied Biosystems wurde mit den in Tabelle 2.8 angegebenen Primern und Sonden eine RT-PCR durchgeführt (Negri et al., 2004). Dazu wurden folgende Probenmengen eingesetzt: 
Tab. 2.14: Reaktionsansatz für die RT-PCR

\begin{tabular}{lc}
\hline Reagenz & Endkonzentration \\
\hline Mastermix-Qiagen & $12,5 \mu \mathrm{l} /$ Ansatz \\
Gag sense & $2,4 \mu \mathrm{M}$ \\
Gag antisense & $2,4 \mu \mathrm{M}$ \\
Taqman-Sonde & $1,2 \mu \mathrm{M}$ \\
RT-Mix & $0,5 \mathrm{U} /$ Ansatz \\
RNA & $5 \mu \mathrm{l} /$ Ansatz \\
$\mathrm{H}_{2} \mathrm{O}$ & ad $2 \mu \mathrm{l}$ \\
\hline
\end{tabular}

Tab. 2.15: PCR-Bedingungen für die RT-PCR

\begin{tabular}{llll}
\hline Zyklusschritt & Temperatur $\left({ }^{\circ} \mathrm{C}\right)$ & Dauer $(\mathrm{min})$ & Zyklenzahl \\
\hline Reverse Transkription & 50 & 30 & 1 \\
\hline PCR & & & \\
Initiale Aktivierung & 95 & 10 & 1 \\
\hline Denaturierung & 95 & 0,15 & 45 \\
Annealing und Elongation & 60 & 1 & 45 \\
\hline
\end{tabular}

Die Ergebnisse der RT-PCR wurden von Frau Dr. Sauermann mit der 7500 System SDS-Software von Applied Biosystems ausgewertet.

\subsubsection{Nachweis von IFNy-sezernierenden Zellen mittels ELISPOT}

Aktivierte $\mathrm{CD}^{+}$T-Zellen produzieren nach spezifischer Antigenstimulation u.a. das Zytokin IFNy. Der Nachweis von sezerniertem IFNy erfolgte mit der Technik des ELISPOT (engl. enzyme-linked immuno spot technique). Diese Technik wurde zunächst von Czerkinsky (Czerkinsky et al., 1983) und Sedgwick (Sedgwick et al., 1983) für die Bestimmung der Antikörperfreisetzung aus B-Zellen beschrieben und dann zum Nachweis einer Zytokinsekretion durch Effektor-T-Zellen weiterentwickelt (Czerkinsky et al., 1988). Durch van der Meide (van der Meide et al., 1995) und Kumar (Kumar et al., 2001) wurde der Test für Rhesusaffen optimiert.

Bei der ELISPOT-Methode werden IFNy-Moleküle durch Festphase-assoziierte Antikörper gebunden und mit einem zweiten Enzym-gekoppelten Antikörper durch Farbreaktion detektiert. Durch die Enzymreaktion kommt es zur Bildung eines punktförmigen, violetten Niederschlags, der quantifiziert werden kann und jeweils einer IFNy- produzierenden, antigenspezifischen T-Zelle entspricht. 
Die in dieser Arbeit präsentierten ELISPOT-Daten wurden von den Mitarbeitern der Arbeitsgruppe Tiermodelle erhoben.

Hierzu wurde eine 96-well-PVDF-Platte (Mabtech) mit Ethanol gewaschen und über Nacht bei $4^{\circ} \mathrm{C}$ mit $100 \mu \mathrm{l}$ des anti-IFNy-Antikörpers (Klon GZ-4, Konzentration $1 \mu \mathrm{g} / \mathrm{ml}$ ) mit Spezifität gegen ein Epitop des IFNy-Moleküls beschichtet. Nach Entfernung der Antikörperlösung wurde die Platte sechsmal mit PBS gewaschen und unspezifische freie Bindungsstellen durch Zugabe von jeweils $100 \mu$ l einer Lösung von RPMI-Medium für $2 \mathrm{~h}$ abgesättigt. Im Anschluss daran wurde die Platte sechsmal mit PBS gewaschen und je Vertiefung $1 \times 10^{5}$ PBMC in $50 \mu$ l Kulturmedium und $50 \mu$ l Peptidpool (Gag, p26 oder CM9; Peptidkonzentration $2 \mu \mathrm{g} / \mathrm{ml}$ ) oder AT2-SIV (Konzentration $2 \mu \mathrm{g} / \mathrm{ml}$ ) zugesetzt. Als Negativkontrolle dienten Kulturmedium und Peptide des HCV, als Positivkontrolle wurde $1 \mu \mathrm{g} / \mathrm{ml}$ Staphylococcus-Enterotoxin B (SEB) verwendet. Diese Ansätze wurden für $17 \mathrm{~h}$ bei $37^{\circ} \mathrm{C}$ und $5 \% \mathrm{CO}_{2}$ inkubiert. Im Anschluss an diese Inkubationszeit wurde die Zellkulturplatte sechsmal mit Waschpuffer gewaschen.

Je Vertiefung wurden nun $100 \mu$ des zweiten anti-IFNy-Antikörper (Klon 7-B6-1; Konzentration $10 \mu \mathrm{g} / \mathrm{ml}$ ), der gegen ein anderes IFNY-Epitop gerichtet und Biotin-markiert ist, zugesetzt. Nach einer Inkubationszeit von zwei Stunden bei $37^{\circ} \mathrm{C}$ wurde die Platte sechsmal mit Waschpuffer gewaschen und $100 \mu$ l eines Streptavidin-Alkalische-Phosphatase-Konjugat (Konzentration $10 \mu \mathrm{g} / \mathrm{ml}$ ) zugesetzt. Darauf folgte eine erneute zweistündige Inkubation bei Raumtemperatur, anschließend sechsmaliges Waschen und die Zugabe von BCIP/NBT. Innerhalb von fünf bis zehn Minuten kam es durch Umsatz des Farbstoffs zur Bildung von blau-violetten Punkten (engl. spots), die nach Trocknung der Platte mittels ELISPOT-Reader (Bioreader 3000, Biosys GmbH) ausgezählt wurden.

Das Ergebnis wurde als positiv bewertet, wenn nach SIV-Peptidstimulation mehr als 100 Spots und im Vergleich zum HCV-Peptidpool die doppelte Spot-Zahl pro $1 \times 10^{6}$ Zellen vorhanden waren. 


\section{Ergebnisse}

In der vorliegenden Arbeit wurde die Wirksamkeit von drei verschiedenen Immunisierungsprotokollen im Rhesusaffenmodell zum Schutz vor SIV-Infektion untersucht.

In der ersten Versuchsreihe wurde ein „Prime-Boost"-Immunisierungsprotokoll untersucht, bei dem zunächst eine Basisimmunisierung durch dreimalige intramuskuläre Applikation von DNA-Konstrukten erfolgte. Nach einer Wartezeit von acht Wochen erfolgten zwei Auffrischungsimpfungen mit oraler oder intramuskulärer Applikation von Adenoviruskonstrukten. Diese Versuchsreihe wird in der weiteren Beschreibung auch als „DNA-Ad“ bezeichnet.

In der zweiten Versuchsreihe wurde ein „Prime-Boost“-Immunisierungsschema angewandt, bei dem die Impflinge zweimal im Abstand von vier Wochen oral mit VLPs als Basisimmunisierung behandelt wurden. Nach einer Wartezeit von acht Wochen erfolgten zwei Auffrischungsimpfungen durch orale Applikation der Adenoviruskonstrukte. Diese Versuchsreihe wird in der weiteren Beschreibung auch als „VLP-Ad“ bezeichnet.

In der dritten Versuchsreihe wurde ein „Prime-Boost“-Immunisierungsschema getestet, bei dem im Abstand von acht Wochen zunächst zweimal adjuvantierte VLPs subkutan appliziert wurden. Nach einer Wartezeit von 16 Wochen erfolgte die Auffrischungsimpfung durch zweimalige orale Applikation von Adenoviruskonstrukten. Diese Versuchsreihe wird in der weiteren Beschreibung auch als „aVLP-Ad“ bezeichnet.

In den ersten beiden Versuchsreihen erfolgte die Belastungsinfektion mit SIVmac239 jeweils acht Wochen nach der letzten Applikation der Adenoviruskonstrukte über die tonsilläre Route (Stahl-Hennig et al., 1999). In der dritten Versuchsreihe erfolgte die Belastungsinfektion durch intravenöse Applikation von SIVmac251 zu demselben Zeitpunkt. 


\subsection{Ergebnisse der ersten Versuchsreihe (DNA-Ad)}

\subsubsection{Bestimmung der Anzahl IFNy-sezernierender T-Zellen nach Gag- Stimulation mit der ELISPOT-Technik im Immunisierungszeitraum}

Zur Untersuchung der zellulären Immunantwort wurde die Anzahl von IFNYsezernierenden T-Zellen nach Stimulation mit dem SIV-Gag-Peptidpool bestimmt.

In der Kontrollgruppe ließen sich im Immunisierungszeitraum keine spezifischen T-Lymphozyten nach Gag-Peptidstimulation nachweisen (Abb. 3.1 A).

Dagegen stieg die Anzahl von IFNy-sezernierenden T-Lymphozyten in den Impflingen der Gruppe 2 nach der ersten Basisimmunisierung in drei von sechs Tieren auf 310 bis 570 Gag-spezifische T-Lymphozyten pro $1 \times 10^{6}$ PBMC (Abb. $3.1 \mathrm{~B}$ ) an. Nach der ersten Auffrischungsimmunisierung mit adenoviralen Vektoren (Woche 24), die im Gegensatz zur Gruppe 3 durch oropharyngeale Applikation des rekombinanten Adenoviruskonstruktes durchgeführt wurde, zeigte sich nur in zwei Tieren ein leichter Anstieg in der Anzahl der IFNy-sezernierenden Zellen auf 296 bzw. 320 Gag-spezifische T-Lymphozyten pro $1 \times 10^{6}$ PBMC. Nach der zweiten Auffrischungsimmunisierung (Woche 32) war dagegen in allen Tieren ein starker Anstieg der IFNY-sezernierenden Zellen auf 247 bis 1547 Gag-spezifische T-Lymphozyten zu verzeichnen. In den acht Wochen bis zur Belastungsinfektion sank dieser Anteil in allen Tieren, erreichte jedoch immer noch einen mittleren Wert von 652 Gag-spezifischen TLymphozyten pro $1 \times 10^{6} \mathrm{PBMC}$.

In der Gruppe 3 war nach der Basisimmunisierung bis zur Woche 20 in fünf von sechs Tieren ein Anstieg von IFNy-sezernierenden Zellen zu detektieren (Abb. 3.1 C). Dieser lag zwischen 100 bis 560 Gag-spezifischen T-Lymphozyten pro $1 \times 10^{6}$ PBMC. Nach der ersten Auffrischungsimmunisierung (Woche 24) mit intramuskulär appliziertem Adenoviruskonstrukt stieg die Anzahl von IFNy-sezernierenden Zellen in allen Tieren deutlich an. Bei zwei der sechs Tiere war ein Anstieg auf über 1300 Gag-spezifische TLymphozyten pro $1 \times 10^{6}$ PBMC zu messen. Bis zum Zeitpunkt der zweiten Applikation (Woche 28) sank die Zahl der Gag-spezifischen T-Lymphozyten in allen Tieren und stieg nach der zweiten intramuskulären Applikation in fünf der sechs Tiere erneut an. Die Höhe dieser Immunantwort erreichte jedoch nicht die Werte nach der ersten Adenovirusapplikation. 
Der Vergleich der mittleren Anzahl von Gag-spezifischen T-Lymphozyten der drei Tiergruppen (Abb. 3.1 D) ergab, dass die Anzahl von Gag-spezifischen T-Lymphozyten in der Gruppe 3 vier Wochen nach der ersten Auffrischungsimmunisierung mit rekombinatem Adenoviruskonstrukt signifikant höher war als in der Gruppe 2. Nach der zweiten Gabe des Adenoviruskonstrukts ließen sich keine Unterschiede zwischen den beiden Gruppen detektieren. Zum Zeitpunkt der Belastungsinfektion (Woche 44) waren in der Gruppe 2 signifikant mehr IFNy-sezernierende Zellen zu beobachten als in Gruppe 3 (652 gebenüber 192 IFNy-sezernierende Zellen pro $1 \times 10^{6}$ PBMC).

A)

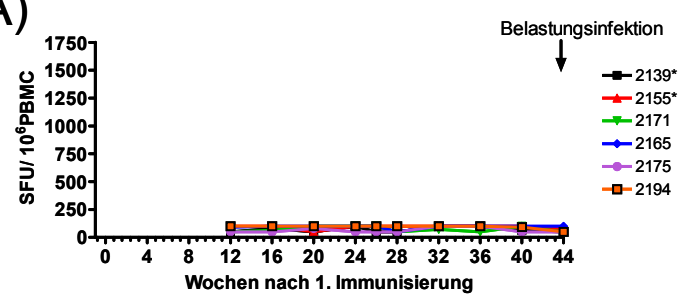

C)

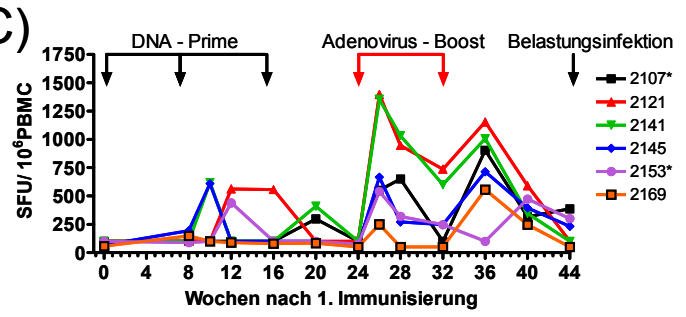

B)

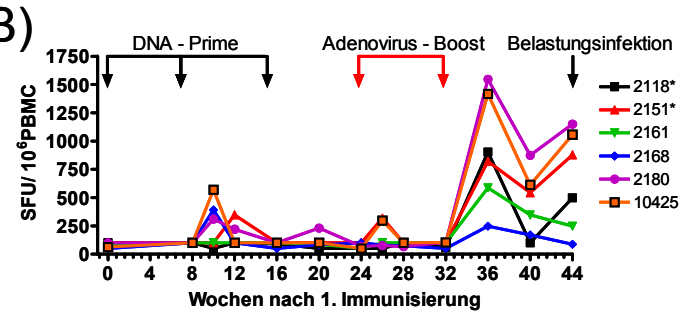

D)

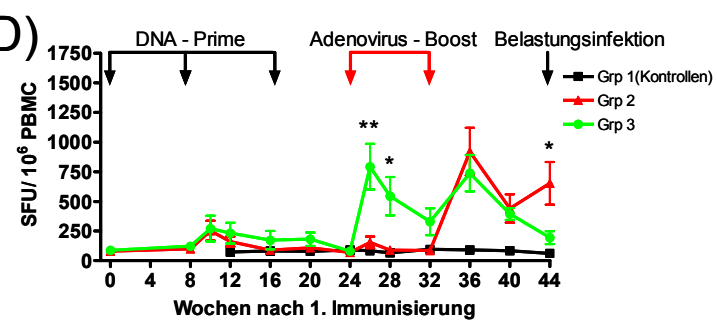

Abb. 3.1: Anzahl IFNy-sezernierender Zellen im Zeitraum der „Prime- und Boost“Immunisierungen nach Gag-Stimulation

PBMC wurden mittels Ficoll isoliert und mit $2 \mu \mathrm{g} / \mathrm{ml}$ Gag-Peptiden für $18 \mathrm{~h}$ stimuliert. Das durch die Stimulation freigesetzte IFNy wurde durch spezifische Antikörper gebunden und mittels chromogenem Substratumsatzes sichtbar gemacht. Die gebildeten spots repräsentieren hierbei jeweils eine IFNY-produzierende Zelle (SFU).

Die Abszisse zeigt die Zeit in Wochen bezogen auf die erste Immunisierung der Tiere. Die Ordinate gibt die Anzahl der SFU pro $1 \times 10^{6}$ PBMC wieder.

A) Kontrolltiere

B) Gruppe 2 („DNA-Prime“, orale und intramuskuläre Auffrischungsimpfung)

C) Gruppe 3 („DNA-Prime“, zweifache intramuskuläre Auffrischungsimpfung)

D) Mittlere Anzahl IFNy sezernierender Zellen der drei Gruppen

Die Linien geben den Mittelwert und die Fehlerbalken die Standardabweichung der jeweiligen Gruppe wieder. Mit Sternen sind signifikante Unterschiede nach dem Mann-Whitney-Test zwischen der Gruppe 2 und 3 gekennzeichnet $\left({ }^{*} p<0,05\right.$; $\left.{ }^{* *} p<0,01\right)$. 


\subsubsection{Bestimmung der Anzahl IFNy-sezernierender T-Zellen nach p26- Stimulation mit der ELISPOT-Technik im Immunisierungszeitraum}

Neben dem Gag-Peptidpool wurden die PBMC in dieser Versuchsreihe auch mit dem SIV-Gag p26-Peptidpool stimuliert. Dieser Peptidpool enthält 22 Peptide mit einer Länge von jeweils 20 Aminosäuren.

In der Kontrollgruppe ließen sich im Immunisierungszeitraum keine spezifischen T-Lymphozyten nach p26-Peptidstimulation nachweisen (Abb. 3.2 A).

In der Gruppe 2 zeigte sich nach den Basisimmunisierungen nur in einem von sechs Tieren einen Anstieg der IFNy-sezernierenden T-Lymphozyten (Abb. 3.2 B). Nach der Applikation der Auffrischungsimmunisierungen kam es in der Woche 36 in allen Tieren zu einem Anstieg der p26-spezifischen IFNy-Sekretion. Dieser Anstieg war jedoch unterschiedlich stark ausgeprägt und lag zwischen 157 und 813 p26-spezifischen T-Lymphozyten pro $1 \times 10^{6}$ PBMC.

In der Gruppe 3 erhöhte sich in zwei von sechs Tieren in der Woche 10 (zwei Wochen nach der zweiten Basisimmunisierung) der Anteil der IFNy-sezernierenden Lymphozyten (Abb. 3.2 C). In der Woche 18 (zwei Wochen nach der ersten Adenovirus-Applikation) zeigten dieselben Tiere erneut einen leichten Anstieg der IFNy-sezernierenden Zellen. In der Woche 26 (zwei Wochen nach der zweiten Applikation des Adenoviruskonstrukts) war in einem der beiden Tiere eine Erhöhung der IFNy-sezernierenden Lymphozyten zu messen. Das andere Tier zeigte dagegen keine Reaktion. Zum Zeitpunkt der Belastungsinfektion in der Woche 44 reagierten die Zellen von keinem Tier der Gruppe 3 auf die p26-Stimulation.

Der Vergleich der mittleren Anzahl von p26-spezifischen T-Lymphozyten der drei Tiergruppen (Abb. $3.2 \mathrm{D}$ ) ergab, dass die Anzahl von p26-spezifischen T-Lymphozyten in der Gruppe 3 in den vier Wochen nach der ersten Auffrischungsimmunisierung mit rekombinanten Adenoviruskonstrukten signifikant höher war als in der Gruppe 2. Zwei und vier Wochen nach der zweiten Auffrischungsimmunisierung war die mittlere Reaktivität der p26-spezifischen T-Lymphozyten in der Gruppe 3 ebenfalls signifikant höher im Vergleich zur Gruppe 2. Zum Zeitpunkt der Belastungsinfektion ließen sich keine signifikanten Unterschiede zwischen den Gruppen nachweisen. 
A)

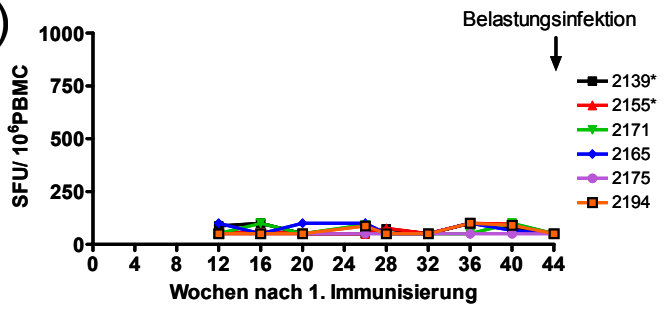

C)

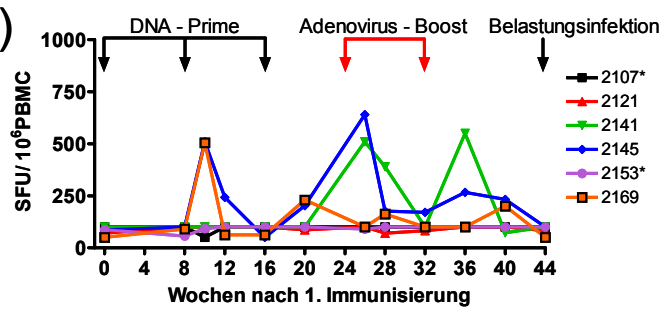

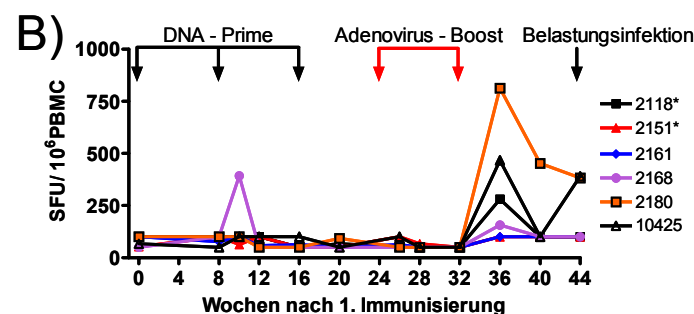

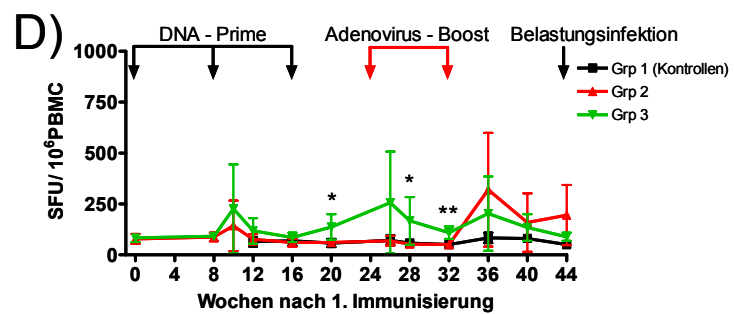

Abb. 3.2: Anzahl IFNy-sezernierender Zellen im Zeitraum der „Prime- und Boost“Immunisierungen nach p26-Stimulation

PBMC wurden mittels Ficoll isoliert und mit $2 \mu \mathrm{g} / \mathrm{ml}$ p26-Peptiden für $18 \mathrm{~h}$ stimuliert. Das durch die Stimulation freigesetzte IFNy wurde durch spezifische Antikörper gebunden und mittels chromogenem Substratumsatzes sichtbar gemacht. Die gebildeten spots repräsentieren hierbei jeweils eine IFNy-produzierende Zelle (SFU).

Die Abszisse zeigt die Zeit in Wochen bezogen auf die erste Immunisierung der Tiere. Die Ordinate gibt die Anzahl der SFU pro 1 × $10^{6}$ PBMC wieder.

A) Kontrolltiere

B) Gruppe 2 („DNA-Prime“, orale und intramuskuläre Auffrischungsimpfung)

C) Gruppe 3 („DNA-Prime“, zweifache intramuskuläre Auffrischungsimpfung)

D) Mittlere Anzahl IFNy sezernierender Zellen der drei Gruppen

Die Linien geben den Mittelwert und die Fehlerbalken die Standardabweichung der jeweiligen Gruppe wieder. Mit Sternen sind signifikante Unterschiede nach dem Mann-Whitney-Test zwischen der Gruppe 2 und 3 gekennzeichnet $\left({ }^{*} p<0,05 ;{ }^{* *} p<0,01\right)$.

\subsubsection{Bestimmung der Viruslast nach Belastungsinfektion durch tonsilläre Inokulation von SIVmac239 in der ersten Versuchsreihe mit Hilfe der RT-PCR}

Der wichtigste Parameter zur Untersuchung eines Impfschutzes ist die Bestimmung der Viruslast im Blut (Watson et al., 1997; Mellors et al., 1997).

Die Viruslast der Rhesusaffen der ersten Versuchsreihe wurde nach der SIV-Belastungsinfektion quantitativ als Anzahl viraler Kopien im Blutplasma der Versuchstiere analysiert (Abb. 3.3).

Sowohl die immunisierten Tiere als auch die Kontrolltiere waren nach tonsillärer Applikation von SIVmac239 produktiv infiziert.

Die Kontrolltiere wiesen zwei Wochen nach Belastungsinfektion eine Spitzenvirämie mit einer mittleren Viruslast von $1,6 \times 10^{7}$ viralen Kopien pro Milliliter Blutplasma $(\mathrm{c} / \mathrm{ml})$ auf. Diese Viruslast reduzierte sich zur Woche 4 kurzfristig auf $3,9 \times 10^{5} \mathrm{c} / \mathrm{ml}$, um danach wieder auf $1 \times 10^{6} \mathrm{c} / \mathrm{ml}$ bis zur Woche 24 anzusteigen. 
Hingegen war bei beiden Impfgruppen zur Spitzenvirämie in der Woche 2 eine hochsignifikante Reduktion der Virusbeladung im Vergleich zur Kontrollgruppe messbar. Die mittlere Virusbeladung lag in beiden Gruppen bei $4 \times 10^{5} \mathrm{c} / \mathrm{ml}$.

Vier Wochen nach Infektion sank die mittlere Virusbeladung in beiden Impfgruppen auf $2 \times 10^{4} \mathrm{c} / \mathrm{ml}$ und war in beiden Fällen hochsignifikant niedriger als in den Kontrolltieren. Bis zur Woche 16 blieb die mittlere Virusbeladung in beiden Gruppen im Bereich von 1,4 bis $3,4 \times 10^{4} \mathrm{c} / \mathrm{ml}$ und stieg bis zur Woche 24 auf $1 \times 10^{5}$ an. Ein signifikanter Unterschied zur Kontrollgruppe war ab Woche 8 nicht mehr festzustellen.

Der Vergleich der Virusbeladung im Blutplasma der einzelnen Tiere (Abb. $3.3 \mathrm{~B}$ bis $\mathrm{D}$ ) ergab, dass es in den Tieren, die Träger des MamuA*01MHC-Allels sind, zu einer deutlich schnelleren und stärkeren Reduktion der Virusbeladung im Blutplasma kam. Ebenso war die Spitzenvirämie in diesen Tieren im Vergleich zu den übrigen Tieren in der entsprechenden Gruppe deutlich reduziert. Die Virusreduktion war unabhängig von der Immunisierungsroute der Tiere.

Eine Ausnahme in der Gruppe der MamuA*01-Tiere bildete das Tier mit der Nummer 2107 in der Gruppe 3, da es eine ebenso ausgeprägte Spitzenvirämie wie die MamuA*01-negativen Tiere dieser Gruppe und auch im weiteren Verlauf der Infektion eine Viruslast von ca. $10^{4} \mathrm{c} / \mathrm{ml}$ aufwies. 


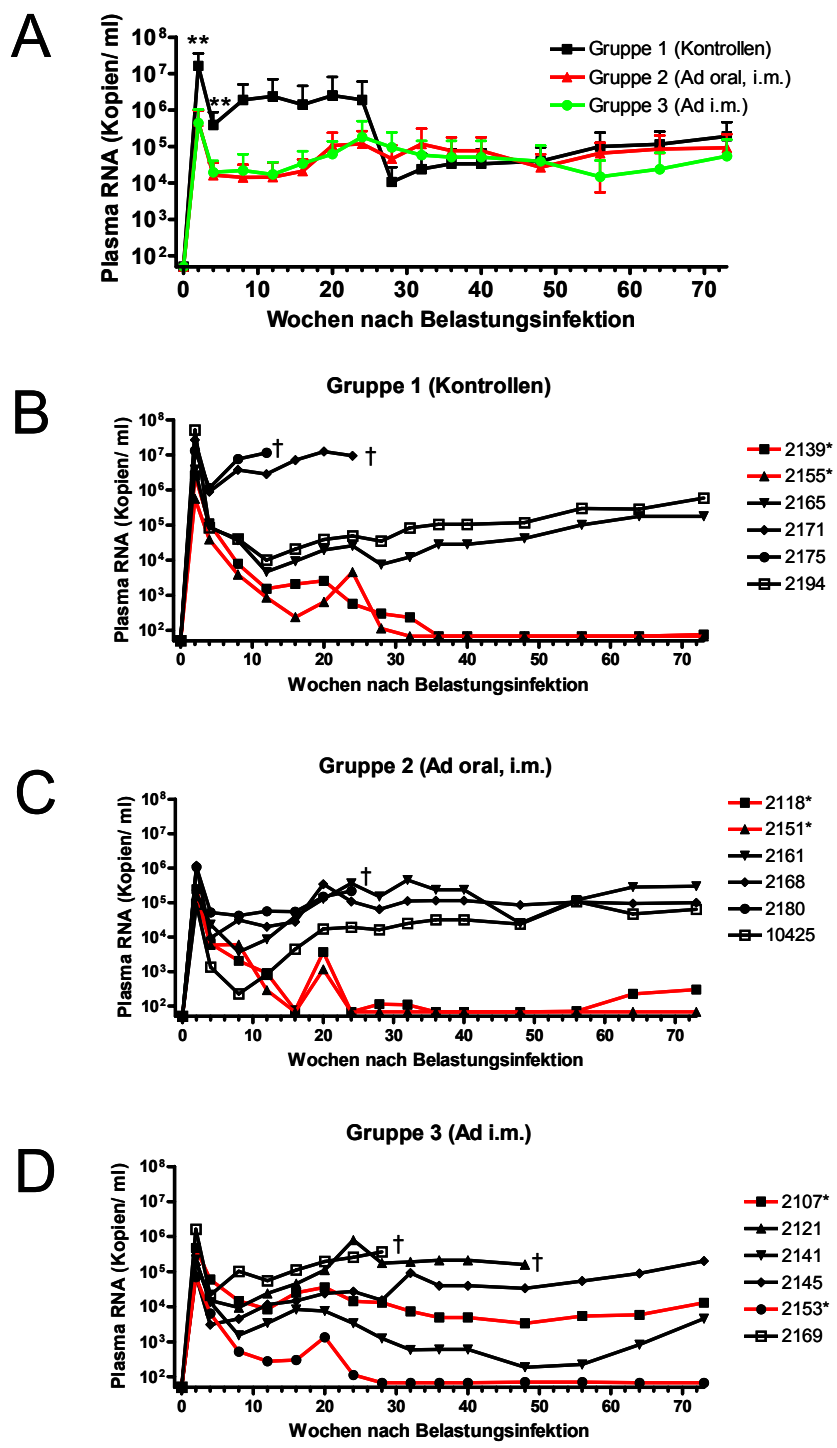

Abb 3.3: Anzahl der viralen RNA-Kopien pro Milliliter Blutplasma im Zeitverlauf nach Belastungsinfektion

Die virale RNA wurde aus $200 \mu$ l Blutplasma isoliert und mit Hilfe des QuantiTect ${ }^{\mathrm{TM}}$ Probe RT-PCR-Kits der Firma Qiagen amplifiziert und detektiert. Auf diese Weise wurde der virologische Status der Rhesusaffen nach SIV-Inokulation bestimmt.

Teil A zeigt die mittlere Anzahl der viralen Kopien in den drei Gruppen.

Die Linien geben den Mittelwert und die Fehlerbalken die Standardabweichung der jeweiligen Gruppe an. Mit den Sternen sind signifikante Unterschiede nach dem Mann-Whitney-Test zwischen den Impfgruppen und den Kontrollen gekennzeichnet $\left({ }^{* *} p<0,01\right)$.

Die Teile B bis D zeigen die Einzelwerte der jeweiligen Gruppe.

Mit Sternen und roten Linien sind die Tiere gekennzeichnet, die Träger des MamuA*01-MHCAllels sind. Tiere, die im Versuchsverlauf wegen AIDS-ähnlicher Erkrankungen euthanasiert werden mussten, sind mit einem † gekennzeichnet.

B) Kontrolltiere

C) Gruppe 2 („DNA-Prime“, orale und intramuskuläre Auffrischungsimpfung)

D) Gruppe 3 („DNA-Prime“, zweifache intramuskuläre Auffrischungsimpfung) 


\subsection{4 Überlebenszeit der Rhesusaffen der ersten Versuchsreihe nach tonsillärer Applikation von SIVmac239}

Die Kaplan-Meier-Analyse der Überlebenszeit der Tiere in der ersten Versuchsreihe läßt eine längere Überlebenszeit der Tiere der zweiten Gruppe im Vergleich zu den Kontrolltieren und den Tieren der Gruppe 3 erkennen (Abb. 3.4).

Im Vergleich zu den Impfgruppen musste das erste Tier der Kontrollen bereits nach 10 Wochen aufgrund von AIDS-ähnlichen Erkrankungen euthanasiert werden. Ein Jahr nach Belastungsinfektion lag der Anteil der überlebenden Tiere in der Gruppe 2 bei 83\%. In der Kontrollgruppe und in der Gruppe 3 lag der Anteil der überlebenden Tiere dagegen bei $66 \%$.

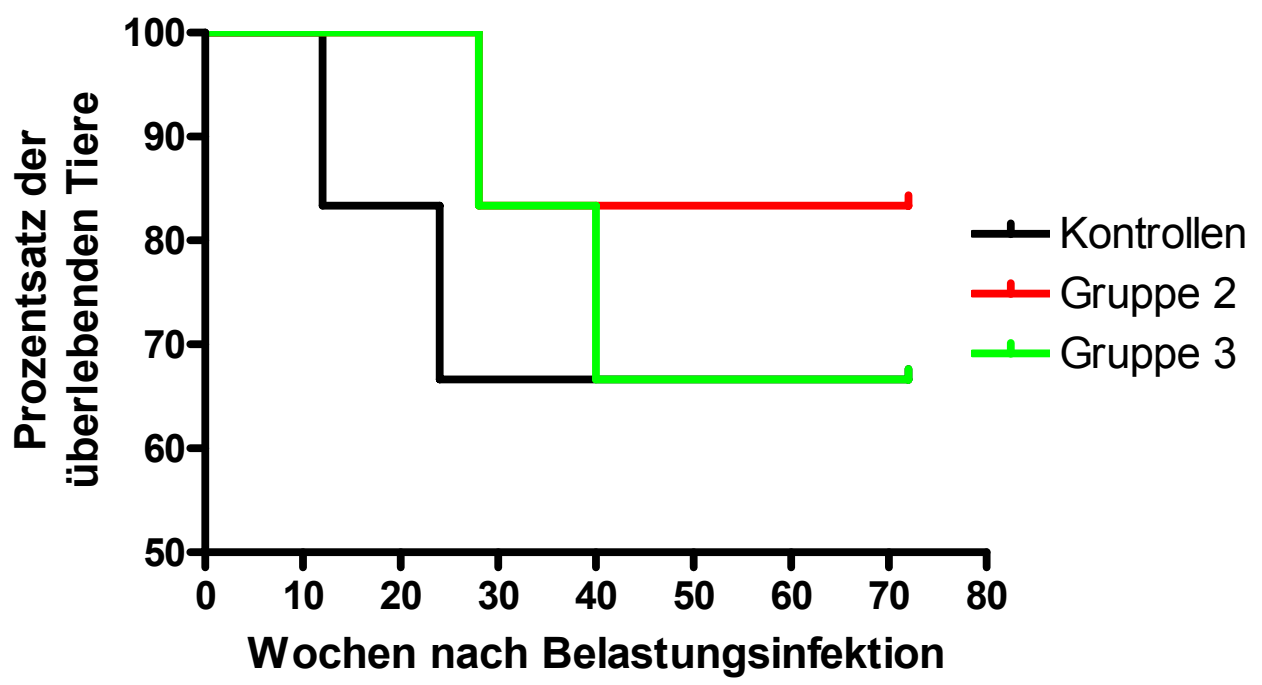

Abb. 3.4: Kaplan-Meier-Darstellung des Anteils der überlebenden Tiere der ersten Versuchsreihe nach Belastungsinfektion

Dargestellt ist der Prozentsatz der überlebenden Tiere der drei Versuchsgruppen im zeitlichen Verlauf der Versuchsreihe.

\subsubsection{Durchflusszytometrische Untersuchungen der zirkulierenden CD4 ${ }^{+}$} und $\mathrm{CDB}^{+}{ }^{\mathrm{T}}$-Lymphozyten im Blut der Versuchstiere der ersten Versuchsreihe

Mittels polychromatischer Durchflusszytometrie wurde eine phänotypische Charakterisierung und quantitative Analyse der T-Zellpopulationen durchgeführt. Bei dieser Analyse wurden vor der Belastungsinfektion von jedem Tier mindestens zwei autologe Präinfektionswerte erhoben, deren Ergebnisse gemittelt wurden. Diese gemittelten Werte wurden als 100\% festgelegt und die 
gemessenen Werte nach Belastungsinfektion auf diesen mittleren Präinfektionswert bezogen.

Zunächst erfolgte die Bestimmung des prozentualen Anteils der CD4 ${ }^{+}$T-Zellen, der ein wichtiges prognostisches Merkmal für den Beginn einer Immundefizienz darstellt. Zusätzlich wurde die Veränderung der CD4 ${ }^{+} 195^{+}$ T-Zellen untersucht. Diese Zellen stellen die Hauptzielzellen von SIV dar, da sie den Korezeptor CCR5 (CD195) exprimieren. Weiterhin wurde der Anteil der $\mathrm{CD}^{+}$und $\mathrm{CD}^{+}$Gedächtniszellen untersucht, da der Erhalt dieser Zellpopulationen ebenfalls als ein prognostisches Kennzeichen für den Krankheitsverlauf angesehen werden kann (Acierno et al., 2006; Mattapallil et al., 2006).

\subsubsection{Bestimmung des prozentualen Anteils der CD4 ${ }^{+}$T-Lymphozyten im} Blut der Versuchstiere

Der Vergleich des prozentualen Anteils der $\mathrm{CD}^{+}{ }^{+} \mathrm{T}$-Zellen an den $\mathrm{CD}^{+}$ T-Lymphozyten (Abb. 3.5 A) ergab in der akuten Phase der Belastungsinfektion eine Reduktion in allen drei Versuchsgruppen. Die Abnahme in den Kontrolltieren war bis zur Woche 8 deutlich stärker ausgeprägt. Zu diesem Zeitpunkt bestand ein signifikanter Unterschied zu den beiden Impfgruppen (Abb. 3.5 B).

Im weiteren Verlauf der Infektion ließen sich keine signifikanten Unterschiede zwischen den drei Versuchsgruppen nachweisen. 
A)

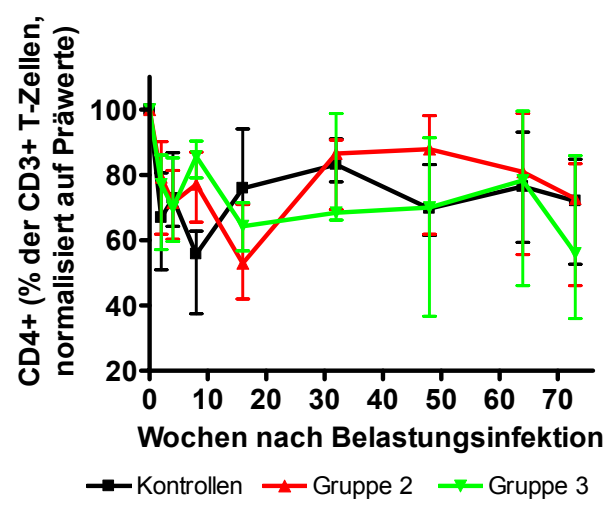

B)

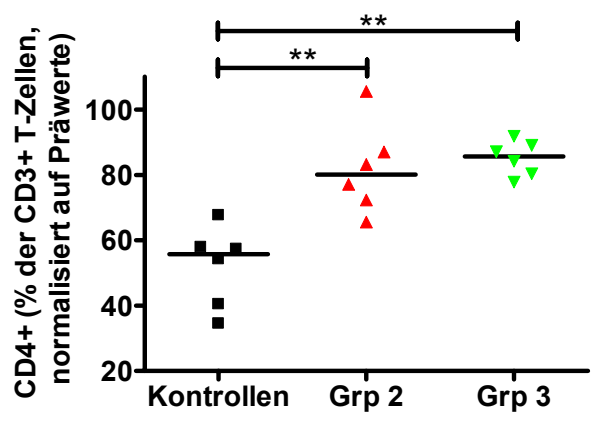

Abb. 3.5: Anteil der $\mathrm{CD}^{+}{ }^{+}$T-Lymphozyten an den Gesamtlymphozyten nach Belastungsinfektion

Teil A zeigt die Veränderungen des prozentualen Anteils der $\mathrm{CD}^{+} \mathrm{T}$-Lymphozyten an den CD3+ T-Lymphozyten im Zeitverlauf des Experiments in den drei Versuchsgruppen. Die Linien geben den Median der jeweiligen Gruppe wieder, die Fehlerbalken zeigen den Interquartilabstand $\mathrm{I}_{50}$.

Teil B zeigt die Einzelwerte der prozentualen Anteile der CD4 ${ }^{+}$T-Lymphozyten an den $\mathrm{CD}^{+}$ T-Lymphozyten im Blut der Kontrolltiere $(\boldsymbol{\square})$ und den Tieren der Gruppen $2(\boldsymbol{\Delta})$ und $3(\boldsymbol{\nabla})$ in der Woche 8 nach Belastungsinfektion.

Die Querstriche geben den Median der jeweiligen Gruppe an. Mit den Querbalken und Sternen sind signifikante Unterschiede nach dem Mann-Whitney-Test zwischen den Gruppen gekennzeichnet $\left({ }^{* *} p<0,01\right)$.

Primäre Zielzellen von HIV und SIV sind die CD4 ${ }^{+}$T-Lymphozyten. Zur Bindung an die Zelloberfläche benötigt das Virus den Korezeptor CD195 (Bleul et al., 1997). Daher werden während der HIV- bzw. SIV-Infektion zunächst die $\mathrm{CD}^{+} 195^{+}$T-Lymphozyten infiziert (Mattapallil et al., 2005; Nishimura et al., 2004; Picker et al., 2004).

Um zu überprüfen, ob die Vakzinierung einen Einfluss auf den Verlust dieser Population hat, wurde zusätzlich die Expression des CD195-Oberflächenantigens gemessen.

Die Kontrollen wiesen bereits zwei Wochen nach der Belastungsinfektion mit SIVmac239 eine signifikante Reduktion der $\mathrm{CD}^{+} 195^{+}$Zellpopulation auf (Abb. 3.6 A). Im Gegensatz dazu nahm der Anteil der CD4 ${ }^{+} 195^{+}$ T-Lymphozyten in den beiden Impfgruppen nach Infektion deutlich zu (Abb. 3.6 B). Vier Wochen nach Belastungsinfektion war der Anteil der $\mathrm{CD}^{+} 195^{+}$T-Lymphozyten in den Kontrolltieren weiterhin deutlich reduziert und im Vergleich zu den Impfgruppen lag jeweils ein hochsignifikanter Unterschied vor (Abb. $3.6 \mathrm{C}$ ). Im weiteren Verlauf des Experiments gab es keine weiteren signifikanten Unterschiede. 
A)

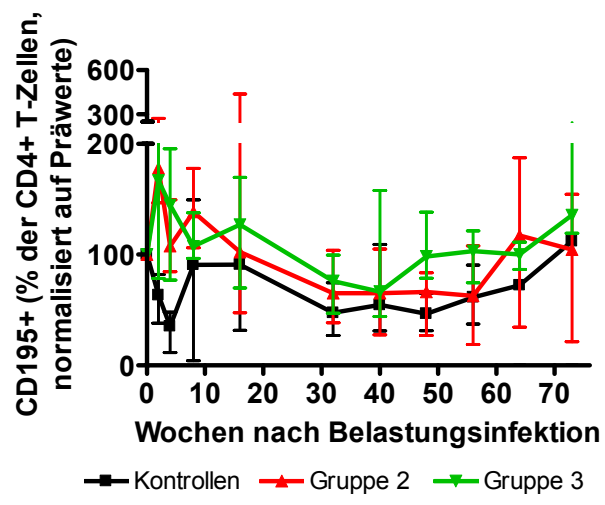

B)

C)
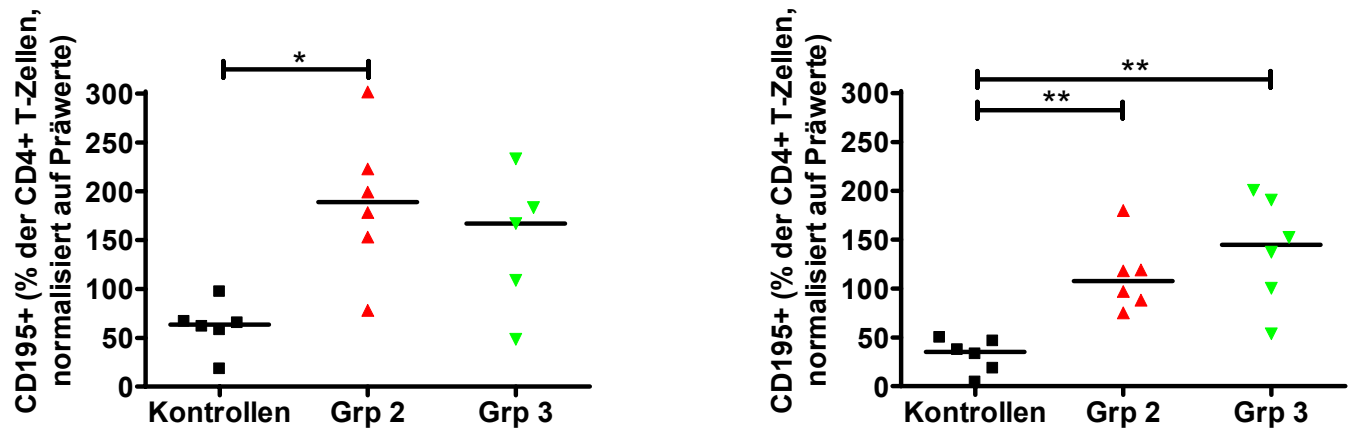

Abb. 3.6: Anteil der $\mathrm{CD} 195^{+}$T-Lymphozyten an den $\mathrm{CD}^{+} \mathrm{T}$-Lymphozyten nach Belastungsinfektion

Teil A zeigt die Veränderungen des prozentualen Anteils der CD4 $195^{+}$T-Lymphozyten im Zeitverlauf des Experiments in den drei Versuchsgruppen. Die Linien geben den Median der jeweiligen Gruppe wieder, die Fehlerbalken zeigen den Interquartilabstand $I_{50}$.

Die Teile B und C zeigen die Einzelwerte der prozentualen Anteile der CD4 $195^{+} \mathrm{T}$ -

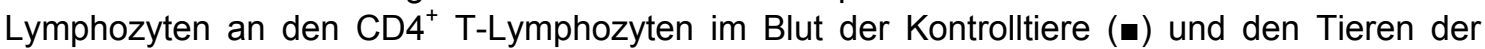
Gruppen $2(\Delta)$ und $3(\nabla)$ in den Wochen $2(B)$ und $4(C)$ nach Belastungsinfektion.

Die Querstriche geben den Median der jeweiligen Gruppe an. Mit den Querbalken und Sternen sind signifikante Unterschiede nach dem Mann-Whitney-Test zwischen den Gruppen gekennzeichnet $\left({ }^{*} p<0,05 ;{ }^{* *} p<0,01\right)$.

Korrelation der Expression von CD195 auf den CD4 ${ }^{ \pm}$T-Zellen mit der Virusbeladung

Die Virusbeladung in der Woche 2 wies eine signifikant negative Korrelation zur Expression von CD195 in der Woche 4 auf (Abb. 3.7 A; $p=0,0063$; $r=-0,618)$. Zusätzlich korrelierte die Virusbeladung der Woche 4 invers mit der Expression von CD195 in den Wochen 2 und 4 (Abb. 3.7 B und C; $p=0,013$; $r=-0,558$ und $p=0,0001 ; r=-0,787)$. 
A)

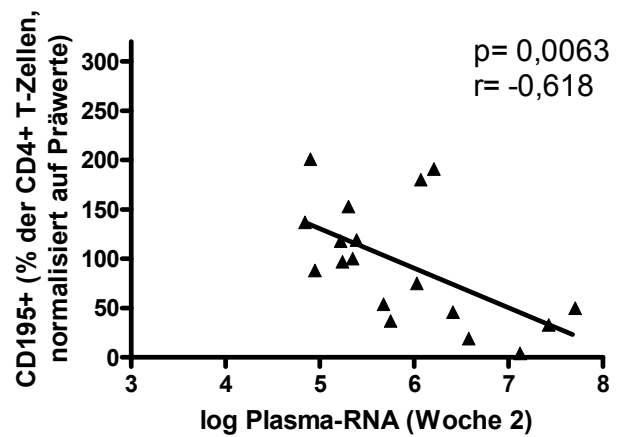

B)

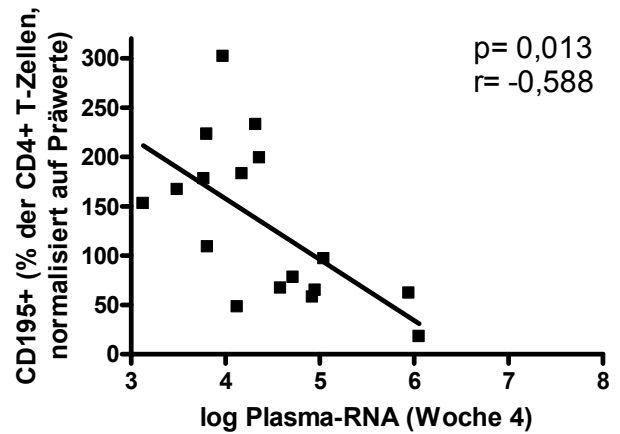

C)

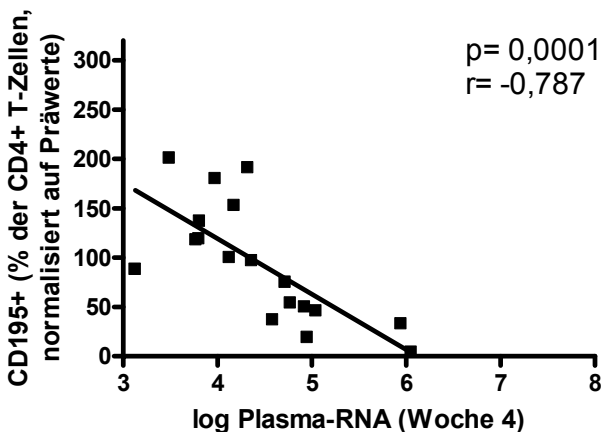

Abb. 3.7: Korrelation der Plasma-RNA mit der Expression von CD195 auf den CD4 ${ }^{+}$ T-Lymphozyten

Teil A zeigt die Korrelation der Plasma-RNA der Woche 2 mit der CD195-Expression der Woche 2. Die Teile $B$ und $C$ zeigen die Korrelation der Plasma-RNA der Woche 4 mit der CD195-Expression der Woche 2 und 4.

Mit $r$ ist der Spearman-Korrelationskoeffizient und mit $p$ das Signifikanzniveau angegeben.

Die Expression des zur TNF-Rezeptor-Familie gehörenden Oberflächenantigens CD95 wird in vielen Studien mit einem Gedächtnisphänotyp von T-Lymphozyten assoziiert (Pitcher et al, 2002). Ein Erhalt dieser Gedächtniszellen korreliert mit längerem Überleben der Versuchstiere (Kawada et al., 2007). Daher wurde in der polychromatischen Färbung von Blutlymphozyten auch die Veränderung der CD95-Expression auf den T-Lymphozyten untersucht. Es zeigte sich, dass die Kontrolltiere bereits zwei Wochen nach Belastungsinfektion eine signifikante Reduktion der $\mathrm{CD}^{+} 95^{+}$Zellpopulation im Vergleich $\mathrm{zu}$ den Impflingen aufwiesen (Abb. 3.8 A und B). Im weiteren Verlauf der Infektion ließen sich jedoch keine weiteren signifikanten Unterschiede zwischen den Kontrollen und den Impflingen nachweisen. 
A)

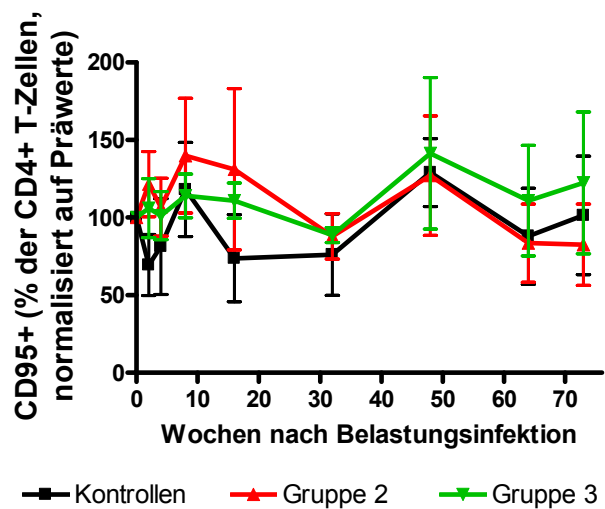

B)

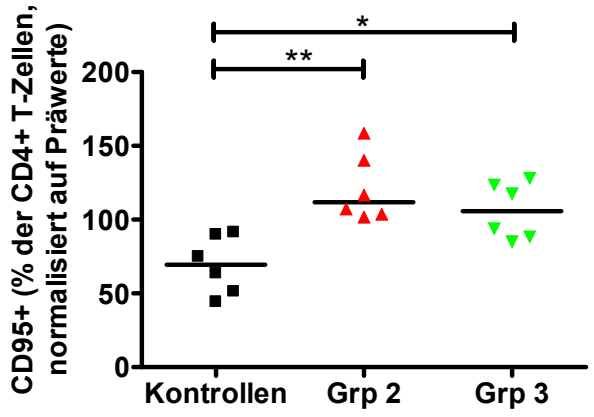

Abb. 3.8: Anteil der $\mathrm{CD}^{+} 5^{+} \mathrm{T}$-Lymphozyten an den $\mathrm{CD}^{+} \mathrm{T}$-Lymphozyten nach Belastungsinfektion

Teil A zeigt die Veränderungen des prozentualen Anteils der $\mathrm{CD}^{+} 95^{+} \mathrm{T}$-Lymphozyten im Zeitverlauf des Experiments in den drei Versuchsgruppen. Die Linien geben den Median der jeweiligen Gruppe wieder, die Fehlerbalken zeigen den Interquartilabstand $I_{50}$.

Teil B zeigt die Einzelwerte der prozentualen Anteile der CD4 $4^{+} 195^{+}$T-Lymphozyten an den $\mathrm{CD} 4^{+} \mathrm{T}$-Lymphozyten im Blut der Kontrolltiere ( $\left.\mathbf{}\right)$ und den Tieren der Gruppen $2(\boldsymbol{\Delta})$ und $3(\boldsymbol{\nabla})$ in der Woche 2 nach Belastungsinfektion.

Die Querstriche geben den Median der jeweiligen Gruppe an. Mit den Querbalken und Sternen sind signifikante Unterschiede nach dem Mann-Whitney-Test zwischen den Gruppen gekennzeichnet $\left({ }^{*} p<0,05 ;{ }^{* *} p<0,01\right)$.

Korrelation der Expression von CD95 auf den CD4 ${ }^{ \pm}$T-Zellen mit der Virusbeladung

Die Virusbeladung der Woche 2 korrelierte invers mit der Expression von CD95 auf den $\mathrm{CD}^{+}$T-Zellen in den Wochen 2 und 4 nach Belastungsinfektion (Abb. 3.9 A und $B ; p=0,006 ; r=-0,620$ und $p=0,0249 ; r=-0,526$ ). Weitere Korrelationen konnten für die $\mathrm{CD}^{+} 95^{+}$Zellpopulation nicht nachgewiesen werden.

A)

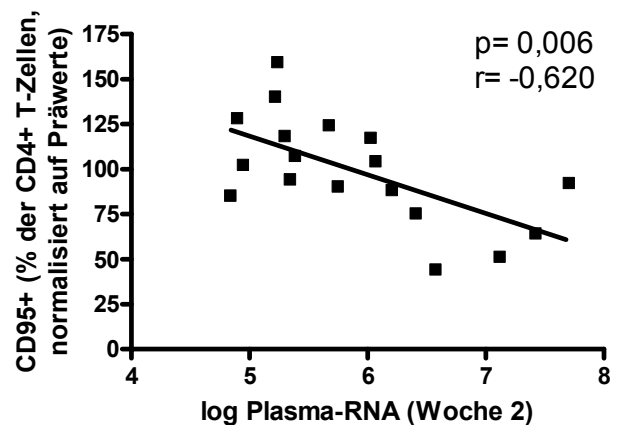

B)

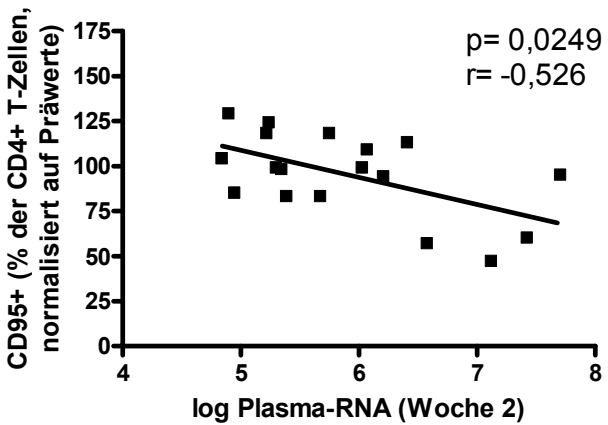

Abb. 3.9: Korrelation der Plasma-RNA mit der Expression von CD95 auf den CD4 ${ }^{+}$ T-Lymphozyten

Die Abbildung zeigt die Korrelation der Plasma-RNA der Woche 2 mit der CD95-Expression der Woche 2 (A) und der Woche 4 (B).

Mit $r$ ist der Spearman-Korrelationskoeffizient und mit $p$ das Signifikanzniveau angegeben. 


\subsubsection{Veränderungen der $\mathrm{CD} 4^{+}$Gedächtniszellsubtypen nach Infektion}

Die verschiedenen Subtypen der Gedächtniszellen sind in der aktuellen HIV- und SIV-Forschung von großer Bedeutung, da der Erhalt dieser Population mit längerem Überleben der infizierten Tiere korreliert (Mattapallil et al., 2005; Picker et al., 2004). Daher wurde in der polychromatischen Färbung die Analyse der $\mathrm{CD}^{+} 5^{+} 8^{+}$T-Lymphozytenpopulation, die als zentrale Gedächtniszellen (TCM, engl. central memory T-cell) bezeichnet werden, eingeschlossen.

Im Vergleich zu der Impfgruppe 2, die oral und intramuskulär mit Adenoviruskonstrukten immunisiert wurde, führte die Belastungsinfektion in den Kontrolltieren nach zwei Wochen zu einer signifikanten Reduktion der zentralen Gedächtniszellen (Abb. 3.10 A und B). Ein Unterschied zwischen den beiden Impfgruppen war jedoch nicht nachweisbar.

Im weiteren Verlauf des Experiments konnten keine weiteren Unterschiede zwischen den Kontrolltieren und den Impfgruppen nachgewiesen werden.

Eine weitere Gedächtniszellsubpopulation sind die Effektorgedächtniszellen (TEM, engl. effector memory $T$-cell), die durch eine niedrige bis mittlere Expression von CD95 und dem Fehlen der CD28-Expression definiert sind (Pitcher et al., 2002).

Die Untersuchung dieser Gedächtniszellpopulation ergab in den Kontrolltieren im Vergleich zu den Impflingen einen signifikanten Anstieg in der Woche 2 nach Belastungsinfektion (Abb. 3.10 C und D). Im weiteren Verlauf des Experiments konnten keine signifikanten Unterschiede detektiert werden.

Die naiven $\mathrm{CD}^{+} \mathrm{T}$-Zellen, die durch die Expression von CD28 und dem Fehlen der CD95-Expression definiert werden, wiesen nach Belastungsinfektion keine Veränderungen auf (Daten nicht gezeigt). 
A)

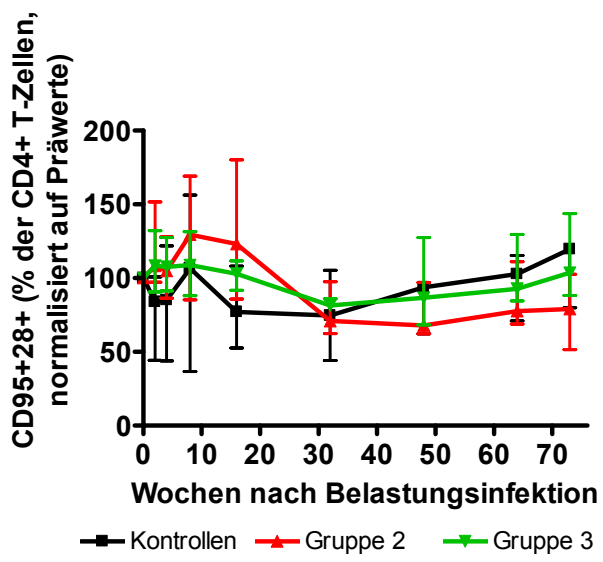

C)

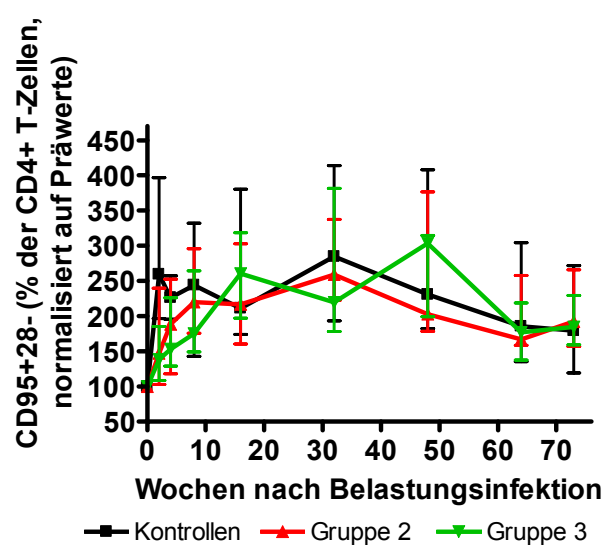

B)

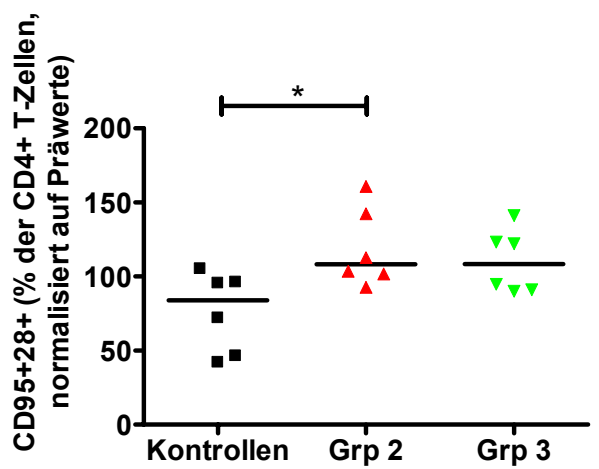

D)

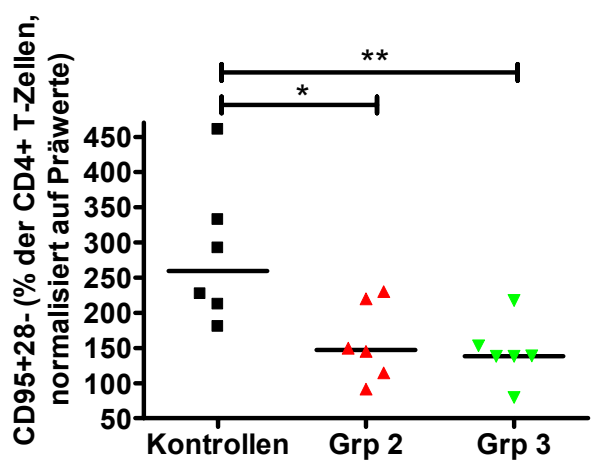

Abb. 3.10: Anteil der CD95 ${ }^{+} 28^{+} \mathrm{T}^{-L y m p h o z y t e n ~(T C M) ~ u n d ~ d e r ~ C D 95 ~}{ }^{+} 28^{-}$T-Lymphozyten (TEM) an den $\mathrm{CD}^{+}{ }^{+} \mathrm{T}$-Lymphozyten nach Belastungsinfektion

Die Teile $A$ und $C$ zeigen die Veränderungen des prozentualen Anteils der $C D 4^{+} 95^{+} 28^{+}(A)$ und der $\mathrm{CD}^{+} 95^{+} 28^{-}$(C) T-Lymphozyten im Zeitverlauf des Experiments in den drei Versuchsgruppen. Die Linien geben den Median der jeweiligen Gruppe wieder, die Fehlerbalken zeigen den Interquartilabstand $\mathrm{I}_{50}$.

Die Teile $B$ und $D$ zeigen die Einzelwerte der prozentualen Anteile der $C D 4^{+} 95^{+} 28^{+}$(B) und $\mathrm{CD}^{+} 95^{+} 28^{-}$(D) T-Lymphozyten an den CD4 ${ }^{+}$T-Lymphozyten im Blut der Kontrolltiere ( $\bullet$ ) und den Tieren der Gruppen $2(\Delta)$ und $3(\nabla)$ in der Woche 2 nach Belastungsinfektion.

Die Querstriche geben den Median der jeweiligen Gruppe an. Mit den Querbalken und Sternen sind signifikante Unterschiede nach dem Mann-Whitney-Test zwischen den Gruppen gekennzeichnet $\left({ }^{*} p<0,05\right.$; $\left.^{* *} p<0,01\right)$.

\section{Korrelation der CD4 ${ }^{ \pm}$Gedächtniszellsubtypen mit der Virusbeladung}

Die Virusbeladung in der Woche 2 korrelierte invers mit dem Anteil der zentralen $\mathrm{CD}^{+}$Gedächtniszellen in den Wochen 2 und 4 nach Belastungsinfektion (Abb. 3.11 A und B; $p=0,0266 ; r=-0,521$ und $p=0,0314$; $r=-0,508)$. Weiterhin ließ sich eine positive Korrelation der Virusbeladung der Woche 2 mit dem Anteil der CD4 ${ }^{+}$Effektorgedächtniszellen in den Wochen 2 und 4 nachweisen (Abb. $3.11 C$ und $D ; p=0,0018 ; r=0,682$ und $p=0,0147$; $r=0,565)$. 
A)

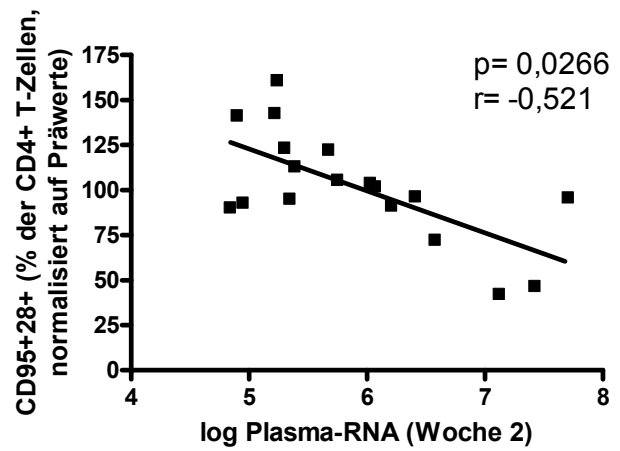

C)

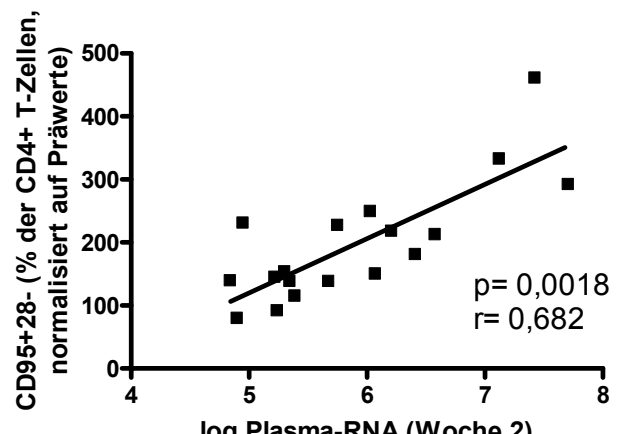

B)

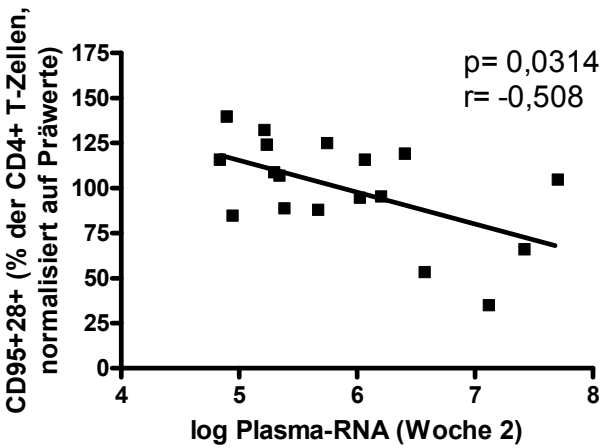

D)

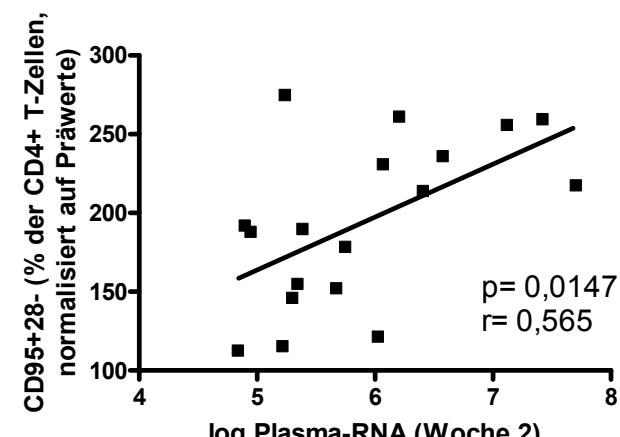

Abb. 3.11: Korrelation der Plasma-RNA mit dem Anteil der CD4 ${ }^{+}$TCM und CD4 ${ }^{+}$TEM Die Abbildung zeigt die Korrelation der Plasma-RNA der Woche 2 mit dem Anteil der $\mathrm{CD}^{+} 95^{+} 28^{+}$T-Lymphozyten (TCM) der Woche $2(\mathrm{~A})$ und der Woche 4 (B) sowie mit dem Anteil der CD4 ${ }^{+} 95^{+} 28^{-}$T-Lymphozyten (TEM) der Woche 2 (C) und der Woche 4 (D).

Mit $r$ ist der Spearman-Korrelationskoeffizient und mit $p$ das Signifikanzniveau angegeben. 


\subsubsection{Veränderungen der $\mathrm{CD}^{+}$Gedächtniszellsubtypen nach Infektion}

Die Unterscheidung von zentralen Gedächtniszellen und von Effektorgedächtniszellen wurde auch bei $\mathrm{CD} 8^{+}$Lymphozyten durchgeführt. Die Veränderungen innerhalb dieser Populationen sind in der Abbildung 3.12 dargestellt.

Im Vergleich zu den Kontrolltieren kam es in den Tieren der Gruppe 2 zu einem signifikanten Anstieg der zentralen $\mathrm{CD}^{+}$Gedächtniszellen in der Woche 2 nach Belastungsinfektion (Abb. 3.12 A und B). Der Anstieg dieser Population in der Gruppe 3 war im Vergleich zu den Kontrolltieren nicht signifikant. Ein signifikanter Unterschied zwischen den Impfgruppen war nicht nachweisbar.

Im weiteren Verlauf der Infektion ließen sich keine signifikanten Unterschiede zwischen den drei Versuchsgruppen nachweisen.

Die Population der $\mathrm{CD}^{+}$Effektorgedächtniszellen war in den Kontrollen im Vergleich zu den Impfgruppen zwei Wochen nach Belastungsinfektion signifikant erhöht (Abb. 3.12 C und D). Ein Unterschied zwischen den Impfgruppen lag nicht vor.

Im weiteren Verlauf des Experiments waren keine Unterschiede in Bezug auf die Veränderung der $\mathrm{CD}^{+}{ }^{+}$Effektorgedächtniszellen messbar.

Der Anteil der naiven $\mathrm{CD}^{+}{ }^{+}$T-Lymphozyten war in den Kontrolltieren zwei Wochen nach Belastungsinfektion im Vergleich zu den Impflingen signifikant reduziert (Abb $3.12 \mathrm{E}$ und $\mathrm{F}$ ). Ein Unterschied zwischen den beiden Impfgruppen bestand nicht.

Die Veränderungen der $\mathrm{CD} 8^{+} \mathrm{T}$-Lymphozytenpopulationen korrelierten jedoch nicht mit der Virusbeladung. 
A)

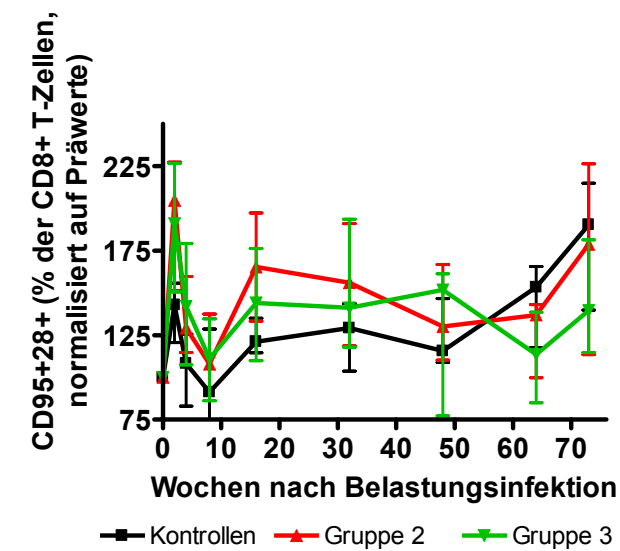

C)

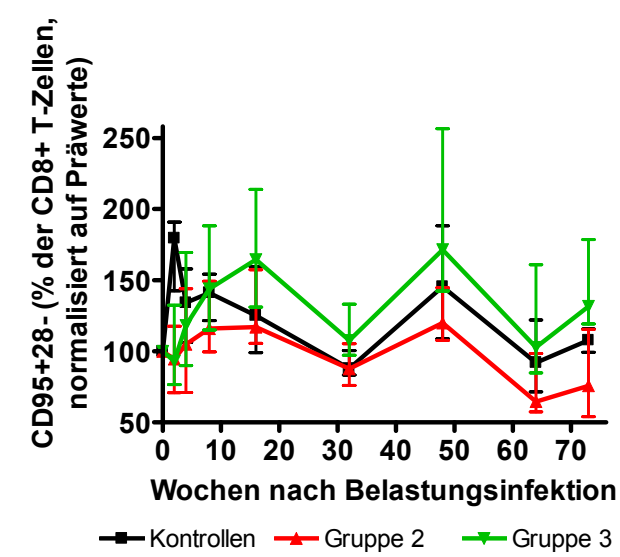

E)

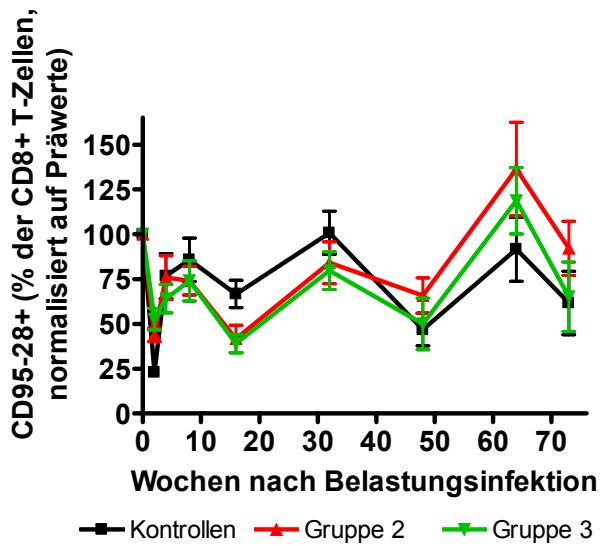

B)

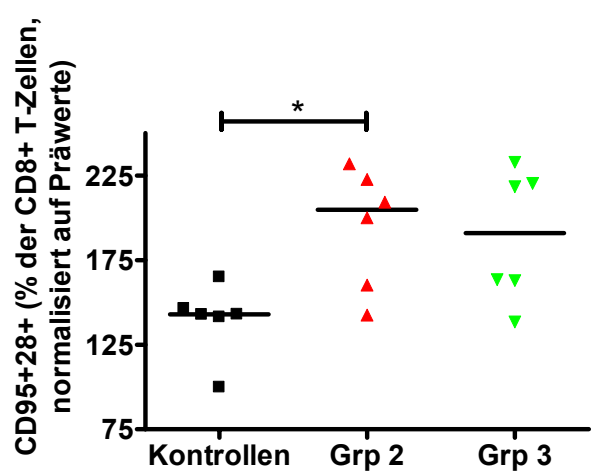

D)

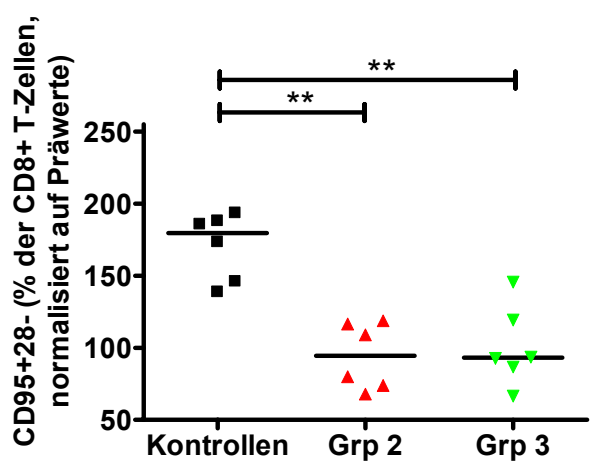

F)

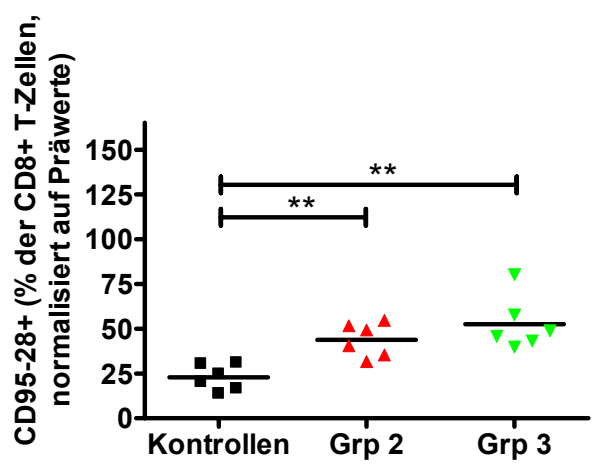

Abb. 3.12: Anteil der $\mathrm{CD}^{+} 5^{+} 28^{+}$(TCM), der CD95 $28^{-}$(TEM) und der naiven T-Lymphozyten an den $\mathrm{CDB}^{+}$T-Zellen im Zeitverlauf und in der Woche 2 im Blut der Versuchstiere

Die Teile $A, C$ und $E$ zeigen die Veränderungen des prozentualen Anteils der $C D 8^{+} 95^{+} 28^{+}(A)$, der $\mathrm{CD}^{+} 95^{+} 28^{-}(\mathrm{C})$ und der naiven (E) T-Lymphozyten im Zeitverlauf des Experiments in den drei Versuchsgruppen. Die Linien geben den Median der jeweiligen Gruppe wieder, die Fehlerbalken zeigen den Interquartilabstand $I_{50}$.

Die Teile B, D und F zeigen die Einzelwerte der prozentualen Anteile der $\mathrm{CD}^{+} 95^{+} 28^{+}$(B), $\mathrm{CD}^{+} 95^{+} 28^{-}$(D) und naiven (F) T-Lymphozyten an den $\mathrm{CD}^{+}$T-Lymphozyten im Blut der Kontrolltiere ( $\bullet$ ) und den Tieren der Gruppen $2(\Delta)$ und $3(\nabla)$ in der Woche 2 nach Belastungsinfektion.

Die Querstriche geben den Median der jeweiligen Gruppe an. Mit den Querbalken und Sternen sind signifikante Unterschiede nach dem Mann-Whitney-Test zwischen den Gruppen gekennzeichnet $\left({ }^{*} p<0,05 ;{ }^{* *} p<0,01\right)$. 
Zusammenfassend lässt sich in der akuten Phase der Infektion ein Erhalt der $\mathrm{CD}^{+}$Gedächtniszellen in den Impflingen nachweisen. Bei den $\mathrm{CD}^{+}$ Gedächtniszellen kam es zu einem leichten Anstieg der zentralen Gedächtniszellen und zu keinen Veränderungen der $\mathrm{CD}^{+}$Effektorgedächtniszellen in den Impflingen, was auf eine geringere Aktivierung des Immunsystems schließen lässt.

\subsubsection{Bestimmung der Anzahl IFNy-sezernierender T-Zellen nach Gag- Stimulation mit der ELISPOT-Technik nach tonsillärer Belastungsinfektion}

Aufgrund der vergleichbaren Virusbeladung im Blut der Impflinge wurden die Gruppen 2 und 3 in der Auswertung als Impflinge zusammengefasst und mit den Kontrollen verglichen (Abb. 3.13, linke Spalte). Zusätzlich wurden die beiden Gruppen jeweils einzeln mit den Kontrollen verglichen (Abb. 3.13, rechte Spalte).

Zum Zeitpunkt der Belastungsinfektion lag in der Gesamtheit der Impflinge eine signifikant höhere Anzahl von IFNy-sezernierenden Zellen nach Gag-Stimulation als in den Kontrolltieren vor (Abb. 3.13 A).

Der Einzelvergleich der beiden Impfgruppen mit den Kontrollen ergab eine stärkere Immunantwort in den Tieren der Gruppe 2, welche die adenovirale Auffrischungsimpfung sowohl oral als auch intramuskulär erhalten hatten (Abb. 3.13 B). Die Tiere, die den Impfstoff zweimal intramuskulär erhalten hatten (Gruppe 3), wiesen ebenfalls eine stärkere Immunantwort als die Kontrollen auf. Der Unterschied der Immunantwort zwischen den beiden Impfgruppen erreichte allerdings kein statistisch signifikantes Niveau.

Zwei Wochen nach Belastungsinfektion (Abb. $3.13 \mathrm{C}$ und $\mathrm{D}$ ) ließ sich eine signifikant höhere Anzahl von IFNy-sezernierenden Lymphozyten nach Gag-Stimulation in der Gesamtheit der Impflinge im Vergleich zu den Kontrollen nachweisen. Ein Unterschied zwischen den beiden Impfgruppen bestand nicht.

Vier und acht Wochen nach Belastungsinfektion (Abb. 3.13 E, F und $G, H$ ) war jeweils eine signifikant höhere Anzahl von IFNy-sezernierenden Lymphozyten nach Gag-Stimulation in der Gesamtheit der Impflinge im Vergleich zu den Kontrollen messbar. Vier Wochen nach Infektion war in beiden Impfgruppen eine signifikant stärkere Immunantwort als in der Kontrollgruppe nachzuweisen. 
Acht Wochen nach Infektion war dies nur in der Gruppe 2 messbar. Beim Vergleich der beiden Impfgruppen waren keine Unterschiede nachweisbar.

Zwölf und 16 Wochen nach Belastungsinfektion (Abb. $3.13 \mathrm{I}, \mathrm{J}$ und K, L) ließ sich jeweils eine signifikant höhere Anzahl von IFNY-sezernierenden Lymphozyten nach Gag-Stimulation in der Gesamtheit der Impflinge im Vergleich zu den Kontrollen zeigen. Die Tiere beider Impfgruppen wiesen in der zwölften Woche eine signifikant stärkere Immunantwort als die Kontrollgruppe auf. In der 16. Woche war ein signifikanter Unterschied zu den Kontrollen nur in der Gruppe 2 nachweisbar. Zu keinem Zeitpunkt lag ein signifikanter Unterschied zwischen den beiden Impfgruppen vor.

$A b$ der zwanzigsten Woche nach der Belastungsinfektion ließen sich keine signifikanten Unterschiede zwischen den Gruppen in Bezug auf die Anzahl von IFNy-sezernierenden Lymphozyten nach Gag-Stimulation nachweisen.

Zusammenfassend lässt sich feststellen, dass in den Impflingen im Zeitraum von 16 Wochen nach Belastungsinfektion eine signifikant höhere Anzahl von IFNY-sezernierenden Lymphozyten nach Gag-Stimulation vorlag. Der Vergleich der beiden Impfgruppen ergab keine signifikanten Unterschiede zwischen den beiden Impfgruppen, jedoch war die Anzahl der IFNy-sezernierenden Lymphozyten in der Gruppe 2 größer als in der Gruppe 3. Zusätzlich war in der Gruppe 2 häufiger ein signifikanter Unterschied im Vergleich zu den Kontrollen nachweisbar.

Diese Ergebnisse bestätigen die Wirksamkeit der Kombination von mukosaler und systemischer Auffrischungsimmunisierung. 
A)

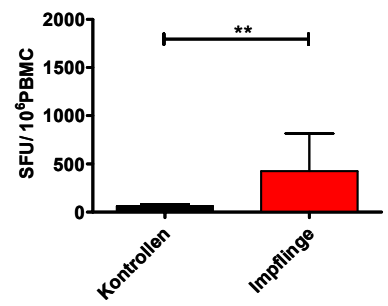

C)

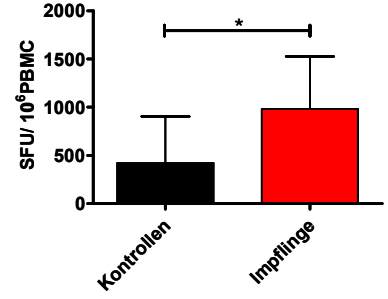

E)

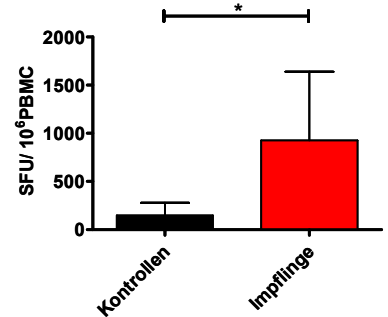

G)

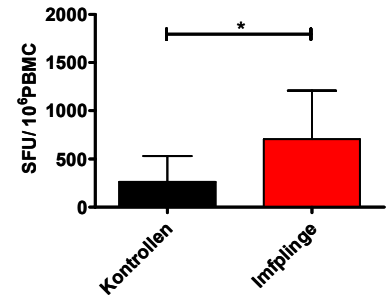

I)

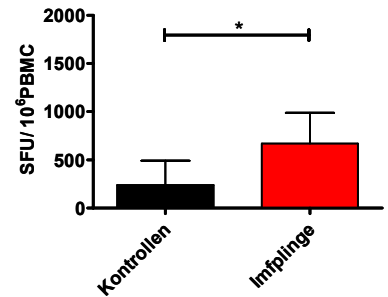

K)

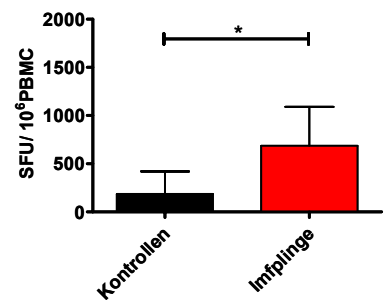

B)

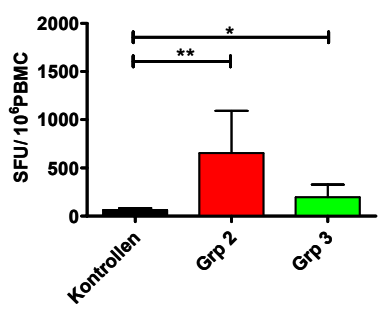

D)

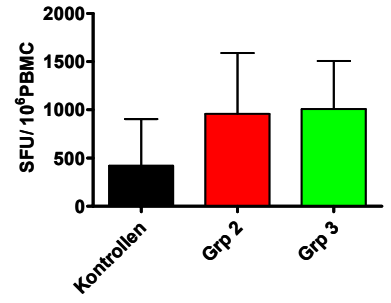

F)

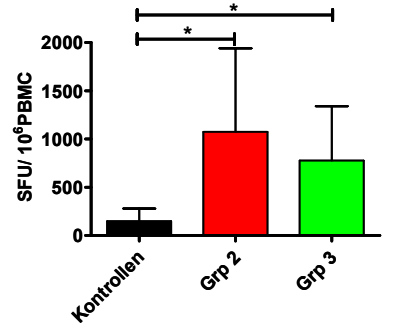

H)

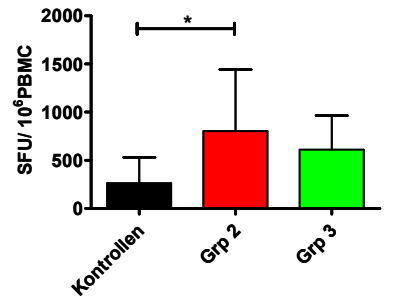

J)

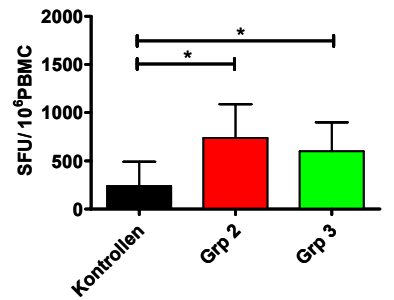

L)

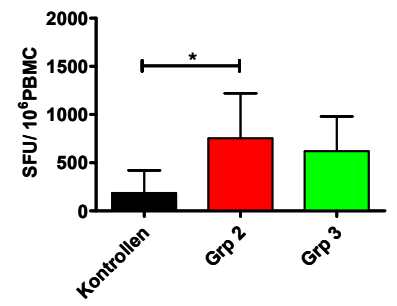

Abb. 3.13: Anzahl IFNy-sezernierender PBMC in den drei Versuchsgruppen nach GagStimulation im Zeitraum nach Belastungsinfektion

In der linken Spalte der Abbildung wurden die immunisierten Tiere zu einer Gruppe zusammengefasst und mit den Kontrolltieren verglichen. Die rechte Spalte zeigt den Vergleich beider Impfgruppen mit den Kontrolltieren.

Die Diagramme zeigen die Mittelwerte und die Fehlerbalken die Standardabweichung der Gruppen. Mit den Querbalken und Sternen sind signifikante Unterschiede nach dem MannWhitney-Test zwischen den Gruppen gekennzeichnet $\left({ }^{*} p<0,05 ;{ }^{* *} p<0,01\right)$.

Teile A und B: Zeitpunkt der Infektion

Teile E und F: Vier Wochen nach Infektion

Teile I und J: Zwölf Wochen nach Infektion
Teile C und D: Zwei Wochen nach Infektion

Teile G und H: Acht Wochen nach Infektion

Teile K und L: 16 Wochen nach Infektion 


\subsubsection{Bestimmung der Anzahl IFNy-sezernierender T-Zellen nach p26- Stimulation mit der ELISPOT-Technik nach tonsillärer Applikation von SIVmac239}

Zum Zeitpunkt der Belastungsinfektion lag in der Gesamtheit der Impflinge eine signifikant höhere Anzahl von IFNy-sezernierenden Zellen nach p26-Stimulation als in den Kontrolltieren vor (Abb. 3.14 A und B).

Der Vergleich der beiden Impfgruppen mit den Kontrollen belegt eine stärkere Immunantwort in den Tieren, welche die adenovirale Auffrischungsimpfung sowohl oral als auch intramuskulär erhalten hatten.

Die Tiere, die den Impfstoff zweimal intramuskulär erhalten hatten, zeigten ebenfalls eine stärkere Immunantwort als die Kontrollen. Der Unterschied der Immunantwort zwischen den beiden Impfgruppen war nicht signifikant.

Zwei Wochen nach Belastungsinfektion (Abb. 3.14 C und D) ließ sich keine höhere Anzahl von IFNy-sezernierenden Lymphozyten nach p26-Stimulation in der Gesamtheit der Impflinge im Vergleich zu den Kontrollen nachweisen. Ein signifikanter Unterschied zwischen den beiden Impfgruppen war nicht vorhanden.

Vier Wochen nach Belastungsinfektion (Abb. 3.14 E und F) war die Anzahl von IFNy-sezernierenden Lymphozyten nach p26-Stimulation in der Gesamtheit der Impflinge im Vergleich zu den Kontrollen signifikant erhöht. Die Tiere der Gruppe 2 wiesen eine signifikant stärkere Immunantwort als die Tiere der Kontrollgruppe auf. Ein signifikanter Unterschied zwischen den beiden Impfgruppen war nicht nachweisbar.

Ein ähnliches Bild war zur Woche $8 \mathrm{zu}$ beobachten (Abb. $3.14 \mathrm{G}$ und H), allerdings waren die Immunantworten der Impfgruppe 2 zudem signifikant höher als die der Gruppe 3.

Ab der zwölften Woche nach der Belastungsinfektion ließen sich keine signifikanten Unterschiede zwischen den Gruppen in Bezug auf die Anzahl von IFNy-sezernierenden Lymphozyten nach p26-Stimulation nachweisen.

Die Ergebnisse der p26-Stimulation stimmen mit den Ergebnissen der Gag-Stimulation überein und bestätigen eine höhere Immunogenität der Kombination von mukosaler und systemischer Auffrischungsimmunisierung. 
A)

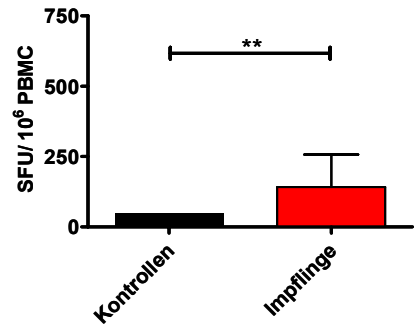

C)

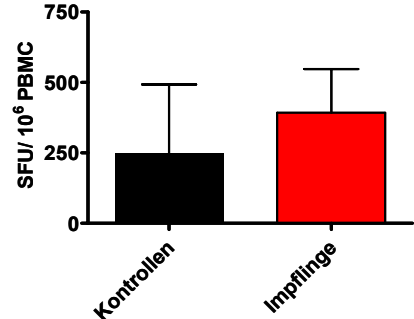

E)

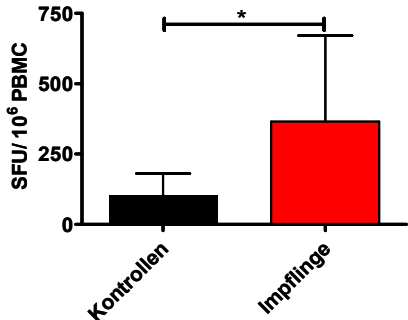

G)

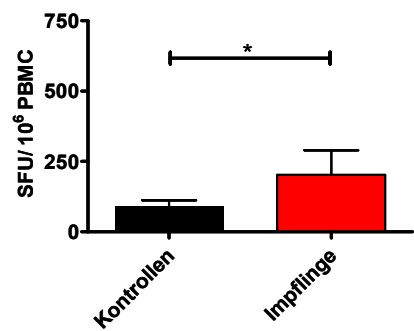

B)

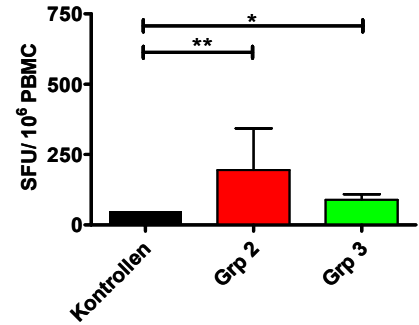

D)

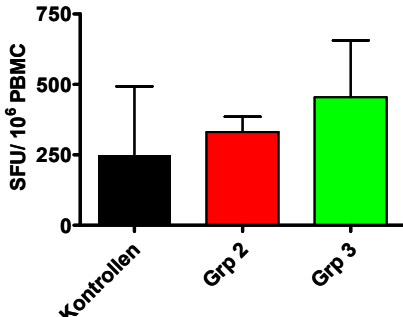

F)

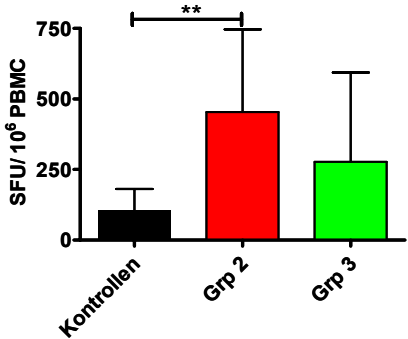

H)

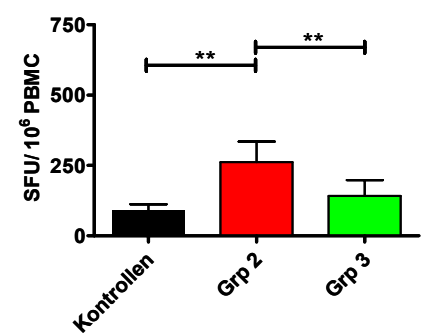

Abb. 3.14: Anzahl IFNy-sezernierender PBMC in den drei Versuchsgruppen nach p26Stimulation im Zeitraum nach Belastungsinfektion

In der linken Spalte der Abbildung wurden die immunisierten Tiere zu einer Gruppe zusammengefasst und mit den Kontrolltieren verglichen. Die rechte Spalte zeigt den Vergleich beider Impfgruppen mit den Kontrolltieren.

Die Diagramme zeigen die Mittelwerte und die Fehlerbalken die Standardabweichung der Gruppen. Mit den Querbalken und Sternen sind signifikante Unterschiede nach dem MannWhitney-Test zwischen den Gruppen gekennzeichnet $\left({ }^{*} p<0,05 ;{ }^{* *} p<0,01\right)$.

Teile A und B: Zeitpunkt der Infektion

Teile E und F: Vier Wochen nach Infektion
Teile C und D: Zwei Wochen nach Infektion

Teile G und H: Acht Wochen nach Infektion 


\subsection{Ergebnisse der zweiten Versuchsreihe (VLP-Ad)}

\subsubsection{Bestimmung der Anzahl IFNy-sezernierender T-Zellen nach Gag-} Stimulation mit der ELISPOT-Technik im Immunisierungszeitraum

In der zweiten Versuchsreihe wurde ein „Prime-Boost"-Immunisierungsschema untersucht, bei dem die Basisimmunisierung statt mit DNA wie in der ersten Versuchsreihe mit VLPs durchgeführt wurde. Die Tiere wurden zweimal mit VLPs immunisiert, und nach einer Wartezeit von acht Wochen wurde eine zweimalige orale Auffrischungsimpfung mit Adenoviruskonstrukten durchgeführt.

In der Impfgruppe zeigte sich nach oraler Applikation von VLPs kein deutlicher Anstieg der IFNy-sezernierenden PBMC nach Stimulation mit dem Gag-Peptidpool (Abb. 3.15 A). Nur das Tier 12531 wies zu den Zeitpunkten Woche 2 und 8 einen geringen Anstieg auf 307 IFNy-produzierende T-Zellen pro $1 \times 10^{6}$ PBMC auf.

Zwei Wochen nach oraler Applikation der Adenoviruskonstrukte stieg in drei der vier Tiere die Zahl der IFNy-produzierenden T-Zellen an. Dieser Anstieg war hierbei in den beiden MamuA*01-positiven Tieren der Gruppe mit 507 bzw. 813 IFNy-produzierenden T-Zellen am höchsten. Das Tier 12531 wies nur einen Anstieg auf 203 IFNy-produzierende T-Zellen auf.

In dem Tier 12534 war kein Anstieg der IFNy-produzierenden T-Zellen messbar.

Zwei Wochen nach wiederholter Applikation des Adenoviruskonstruktes war in allen vier Tieren ein starker Anstieg der Anzahl IFNy-produzierender T-Zellen zu messen. Die beiden MamuA*01-positiven Tiere wiesen hierbei mit 1080 und 873 IFNy-produzierenden T-Zellen die größte Anzahl auf.

Im weiteren Zeitverlauf sank die Zahl der IFNy-produzierenden T-Zellen nach Gag-Stimulation in allen vier Tieren deutlich ab (negative Werte bis 493 SFU). In der Kontrollgruppe ließen sich im Immunisierungszeitraum keine spezifischen T-Lymphozyten nach Gag-Peptidstimulation nachweisen (Abb. 3.15 B).

Zum Zeitpunkt der Belastungsinfektion (Woche 24) war in vier Tieren eine unspezifische Reaktion auf die Stimulation mit den Gag-Peptiden nachweisbar. 
A)

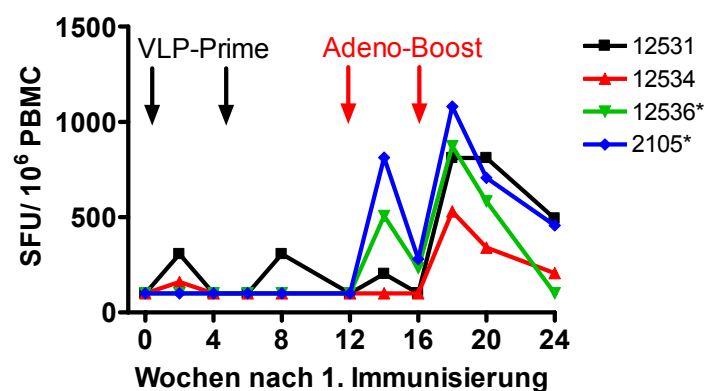

B)

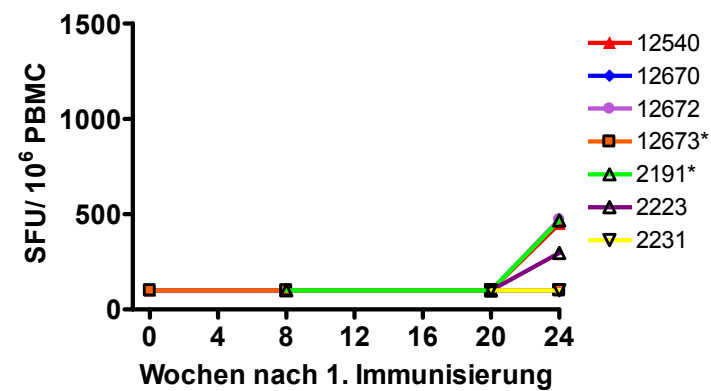

Abb. 3.15: Anzahl IFNy-sezernierender Zellen in der Impfgruppe (A) und den Kontrolltieren (B) im Zeitraum der „Prime- und Boost“-Immunisierungen nach GagStimulation

PBMC wurden mittels Ficoll isoliert und mit $2 \mu \mathrm{g} / \mathrm{ml}$ Gag-Peptiden für $18 \mathrm{~h}$ stimuliert. Das durch die Stimulation freigesetzte IFNy wurde durch spezifische Antikörper gebunden und mittels chromogenem Substratumsatzes sichtbar gemacht. Die gebildeten spots repräsentieren hierbei jeweils eine IFNy-produzierende Zelle (SFU).

Die Abszisse zeigt die Zeit in Wochen bezogen auf die erste Immunisierung der Tiere. Die Ordinate gibt die Anzahl der SFU pro $1 \times 10^{6}$ PBMC wieder. Mit den Sternen sind die Tiere gekennzeichnet, die Träger des MamuA*01-MHC-Allels sind.

Teil A zeigt die Werte der Impfgruppe, Teil B die Werte der Kontrolltiere.

\subsubsection{Bestimmung der Viruslast nach Belastungsinfektion durch} tonsilläre Inokulation von SIVmac239 in der zweiten Versuchsreihe mit Hilfe der RT-PCR

Sowohl die immunisierten Tiere als auch die Kontrolltiere waren nach tonsillärer Applikation von SIVmac239 produktiv infiziert.

Die Kontrolltiere wiesen zwei Wochen nach Belastungsinfektion eine Spitzenvirämie mit einer mittleren Viruslast von $4,3 \times 10^{6} \mathrm{c} / \mathrm{ml}$ auf (Abb. 3.16 A). Diese Viruslast reduzierte sich bis zur Woche 4 auf $4 \times 10^{5} \mathrm{c} / \mathrm{ml}$. Bis zur Woche 24 nach Infektion lag die mittlere Virusbeladung im Blutplasma der Kontrolltiere bei $3,1 \times 10^{5} \mathrm{c} / \mathrm{ml}$.

In den geimpften Tieren war zum Zeitpunkt Woche 2 nach Belastungsinfektion eine signifikante Reduktion der Virusbeladung im Vergleich zur Kontrollgruppe messbar. Die mittlere Virusbeladung lag bei $7,4 \times 10^{5} \mathrm{c} / \mathrm{ml}$.

Zum Zeitpunkt Woche 4 reduzierte sich die mittlere Viruslast auf 3,1 $\times 10^{4}$ virale Kopien und lag damit signifikant niedriger als die Viruslast der Kontrolltiere. Bis zur Woche 12 lag die mittlere Virusbeladung im Bereich von 3,4 bis $4,5 \times 10^{4}$ $\mathrm{c} / \mathrm{ml}$ und stieg bis zur Woche 24 auf eine Größenordnung von $1,1 \times 10^{5}$ an. Ein signifikanter Unterschied zur Kontrollgruppe war ab Woche 6 nicht mehr festzustellen. 
Ein Vergleich der Virusbeladung im Blutplasma der einzelnen Tiere (Abb. 3.16 $\mathrm{B}$ und $\mathrm{C}$ ) zeigte, dass es in drei von vier Tieren, die Träger des MamuA*01-MHC-Allels sind, zu einer deutlich schnelleren und stärkeren Reduktion der Virusbeladung im Blutplasma kam. Die Spitzenvirämie dieser Tiere war jedoch nicht reduziert.

Eine Ausnahme dazu bildete das Tier 12673, welches die Virusbeladung im Plasma nicht reduzierte und eine vergleichbare Virusbeladung wie die übrigen Tiere aufwies. Dieses Tier musste 44 Wochen nach der Belastungsinfektion aufgrund von AIDS-ähnlichen Symptomen euthanasiert werden.

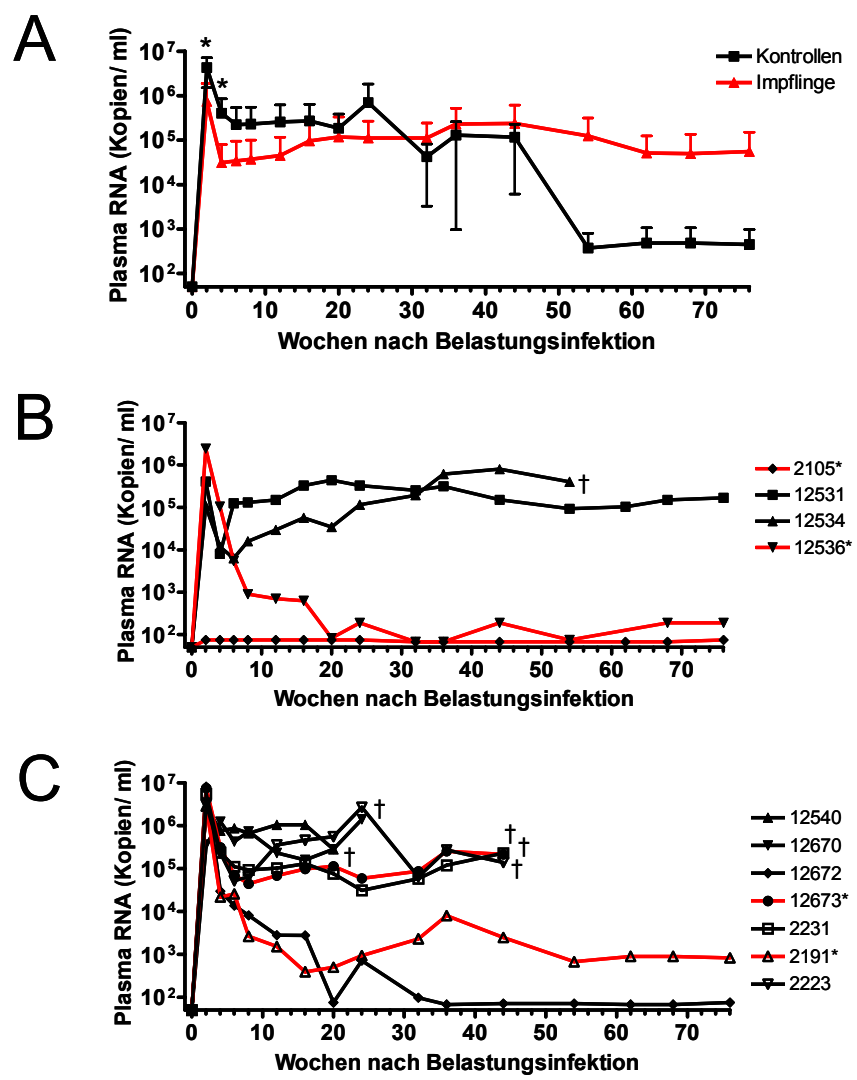

Abb 3.16: Anzahl der viralen RNA-Kopien pro Milliliter Blutplasma im Zeitverlauf nach Belastungsinfektion

Die virale RNA wurde aus $200 \mu$ B Blutplasma isoliert und mit Hilfe des QuantiTect ${ }^{\mathrm{TM}}$ Probe RT-PCR-Kits der Firma Qiagen amplifiziert und detektiert. Auf diese Weise wurde der virologische Status der Rhesusaffen nach SIV-Inokulation bestimmt.

Teil A zeigt die mittlere Anzahl der viralen Kopien in den zwei Gruppen.

Die Linien geben den Mittelwert und die Fehlerbalken die Standardabweichung der jeweiligen Gruppe an. Mit den Sternen sind signifikante Unterschiede nach dem Mann-Whitney-Test zwischen den Impfgruppen und den Kontrollen gekennzeichnet $\left({ }^{*} p<0,05\right)$.

Die Teile B und C zeigen die Einzelwerte der jeweiligen Gruppe.

Mit Sternen und roten Linien sind die Tiere gekennzeichnet, die Träger des MamuA*01-MHCAllels sind. Tiere, die im Versuchsverlauf wegen AIDS-ähnlicher Erkrankungen euthanasiert werden mussten, sind mit einem † gekennzeichnet.

B) Impflinge

C) Kontrolltiere 


\subsection{3 Überlebenszeit der Rhesusaffen der zweiten Versuchsreihe nach tonsillärer Inokulation von SIVmac239}

Die Kaplan-Meier-Analyse zur Überlebenszeit der Tiere in der zweiten Versuchsreihe belegt eine längere Überlebenszeit der Impflinge im Vergleich zu den Kontrolltieren (Abb. 3.17).

Ein Jahr nach Belastungsinfektion lag der Anteil der überlebenden Tiere in der Gruppe der Impflinge bei $75 \%$, in der Gruppe der Kontrollen bei $29 \%$.

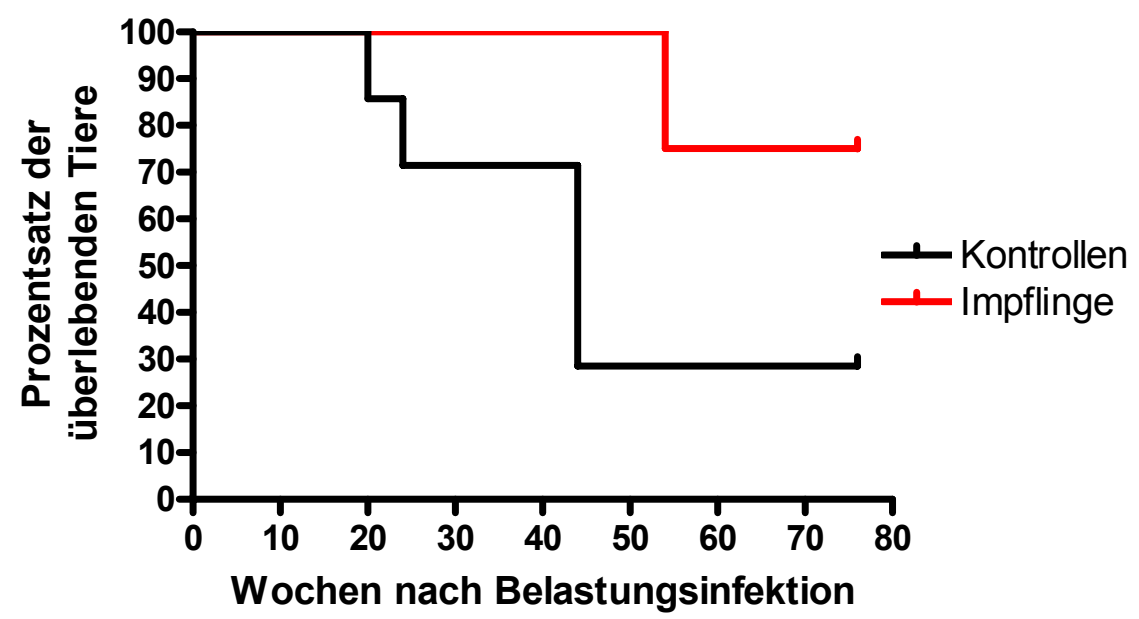

Abb. 3.17: Kaplan-Meier-Darstellung des Anteils der überlebenden Tiere der zweiten Versuchsreihe nach Belastungsinfektion

Dargestellt ist der Prozentsatz der überlebenden Tiere der zwei Versuchsgruppen im zeitlichen Verlauf der Versuchsreihe.

\subsubsection{Durchflusszytometrische Untersuchungen zirkulierender $\mathrm{CD4}^{+}$und} $\mathrm{CD8}^{+}$T-Lymphozyten im Blut der Versuchstiere der zweiten Versuchsreihe

In der zweiten Versuchsreihe war nach Belastungsinfektion kein Unterschied hinsichtlich der $\mathrm{CD}^{+}{ }^{+} \mathrm{T}$-Lymphozytenpopulationen zwischen den Impflingen und den Kontrolltieren nachweisbar (Abb. 3.18).

In beiden Gruppen kam es zu einem 20 bis $40 \%$ igen Verlust des mittleren Anteils der $\mathrm{CD}^{+}{ }^{+} \mathrm{T}$-Lymphozyten im Vergleich zu den Präinfektionswerten. Dieser Verlust dauerte bis zur Woche 40 an. Ein folgender Anstieg erreichte jedoch nicht mehr das Niveau der Präinfektionswerte. 


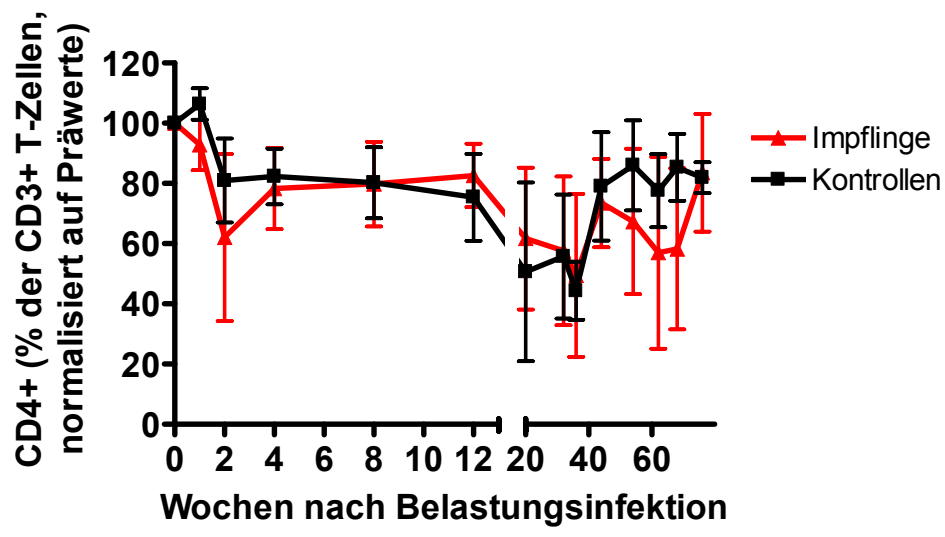

Abb. 3.18: Anteil der $\mathrm{CD}^{+} \mathrm{T}$-Lymphozyten an den Gesamtlymphozyten im Blut der Versuchstiere nach Belastungsinfektion

Die Abbildung zeigt die Veränderungen des prozentualen Anteils der CD4 ${ }^{+} \mathrm{T}$-Lymphozyten im Zeitverlauf des Experiments in den zwei Versuchsgruppen. Die Linien geben den Median der jeweiligen Gruppe wieder, die Fehlerbalken zeigen den Interquartilabstand $I_{50}$.

Zur besseren Darstellung der akuten Infektionsphase (Wochen 0 - 12) wurde die Achse geteilt.

Das Hauptangriffsziel für SIV bzw. HIV stellt die Population der CD4 ${ }^{+} 195^{+}$ T-Lymphozyten dar, die als erste Zellpopulation zerstört wird. Der Vergleich des mittleren Anteils der CD4 ${ }^{+} 195^{+}$T-Lymphozyten zwischen den Impflingen und Kontrollen ergab einen starken Abfall dieser Zellpopulation in den Kontrolltieren in der zweiten und vierten Woche nach Belastungsinfektion(Abb. 3.19). Der Unterschied zu den Impflingen erreichte jedoch keine statistische Signifikanz.

Ein signifikanter Unterschied im Bezug auf den mittleren Anteil der CD4 ${ }^{+} 195^{+}$ T-Lymphozytenpopulation war nur in der Woche 12 nach Belastungsinfektion messbar. $\mathrm{Zu}$ diesem Zeitpunkt war der Anteil dieser Zellpopulation in den Kontrolltieren im Vergleich zu den Impflingen signifikant reduziert.

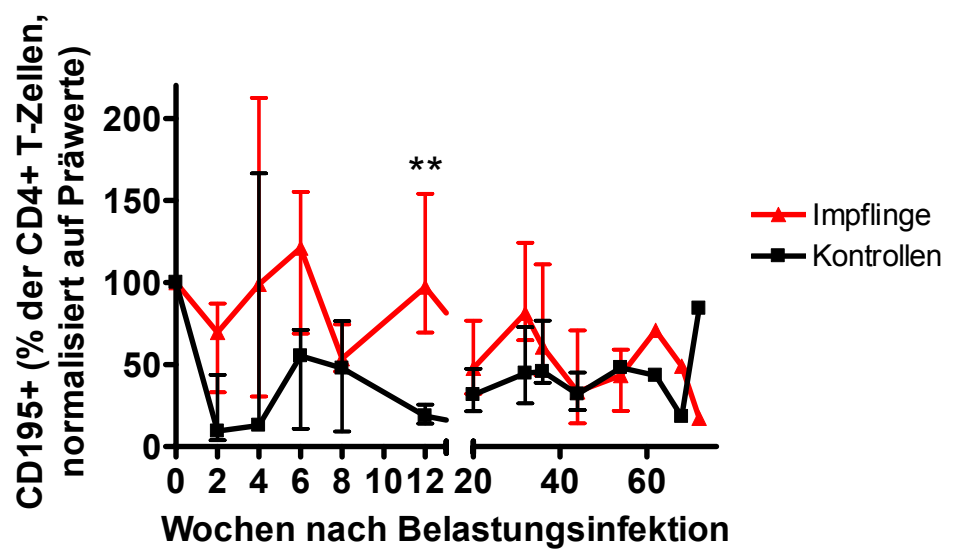

Abb. 3.19: Anteil der $\mathrm{CD}^{+} 195^{+} \mathrm{T}$-Lymphozyten an den Gesamtlymphozyten im Blut der Versuchstiere nach Belastungsinfektion

Die Abbildung zeigt die Veränderungen des prozentualen Anteils der CD4 ${ }^{+} 195^{+}$T-Lymphozyten im Zeitverlauf des Experiments in den zwei Versuchsgruppen. Die Linien geben den Median der jeweiligen Gruppe wieder, die Fehlerbalken zeigen den Interquartilabstand $I_{50}$.

Mit den Sternen sind signifikante Unterschiede nach dem Mann-Whitney-Test zwischen den Gruppen gekennzeichnet $\left({ }^{* *} p<0,01\right)$. 
Der Vergleich der Expression des zur TNF-Rezeptor-Familie gehörenden Oberflächenmarkers CD95, der gleichzeitig auch als Gedächtniszellmarker definiert wird (Hamann et al., 1997), auf den CD4 ${ }^{+}$T-Lymphozyten ergab bis zur Woche 12 nach Belastungsinfektion signifikante Unterschiede zwischen den Impflingen und den Kontrolltieren. Die Expression von CD95 war in den Kontrolltieren zu den Zeitpunkten Woche 1, 4, 6 und 12 nach Belastungsinfektion signifikant reduziert. Im weiteren Verlauf des Experiments waren keine Unterschiede feststellbar (Abb. 3.20). Diese Ergebnisse belegen eine unveränderte $\mathrm{CD}^{+}$Gedächtniszellpopulation in den Impflingen während der akuten Phase der Infektion.

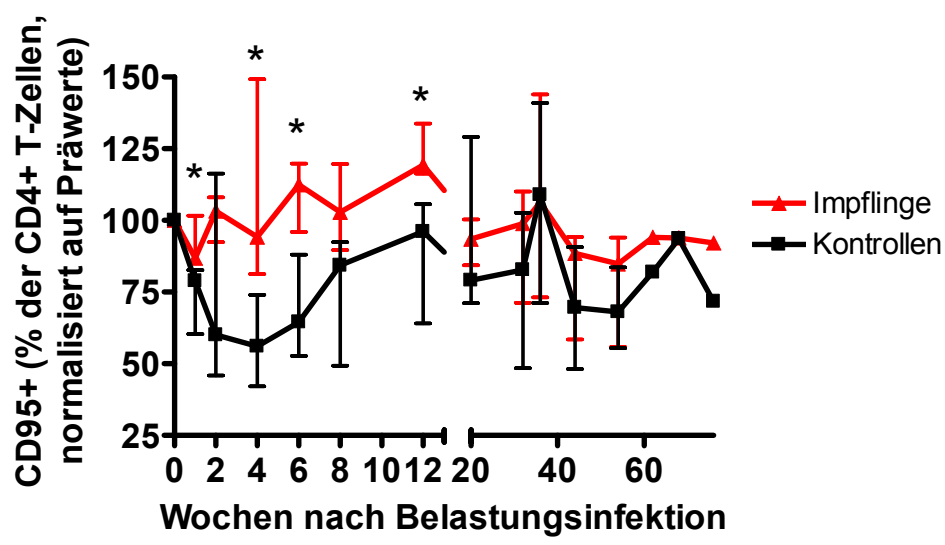

Abb. 3.20: Anteil der $\mathrm{CD}^{+} 95^{+}$T-Lymphozyten an den Gesamtlymphozyten im Blut der Versuchstiere nach Belastungsinfektion

Die Abbildung zeigt die Veränderungen des prozentualen Anteils der CD4 ${ }^{+} 95^{+}$T-Lymphozyten im Zeitverlauf des Experiments in den zwei Versuchsgruppen. Die Linien geben den Median der jeweiligen Gruppe wieder, die Fehlerbalken zeigen den Interquartilabstand $I_{50}$.

Mit den Sternen sind signifikante Unterschiede nach dem Mann-Whitney-Test zwischen den Gruppen gekennzeichnet $\left({ }^{*} p<0,05\right)$.

Für die Populationen der $\mathrm{CD}^{+}$(Abb. $\left.3.21 \mathrm{~A}\right)$ und der $\mathrm{CD}^{+}$(Abb. $3.21 \mathrm{~B}$ ) zentralen Gedächtniszellen waren über den gesamten Beobachtungszeitraum keine signifikanten Unterschiede zwischen den Impflingen und den Kontrollen nachweisbar.

Für die Populationen der $\mathrm{CD}^{+}$Effektorgedächtniszellen war nur in der Woche 54 nach Infektion ein signifikanter Unterschied zwischen Impflingen und Kontrollen messbar (Abb. $3.21 \mathrm{C}$ ). Für die $\mathrm{CD}^{+}$Effektorgedächtniszellen ließ sich kein Unterschied nachweisen (Abb. 3.21 D)

Die Veränderungen der T-Lymphozyten nach Belastungsinfektion korrelierten im Gegensatz zum DNA-Ad-Experiment nicht mit der Virusbeladung. 
A)

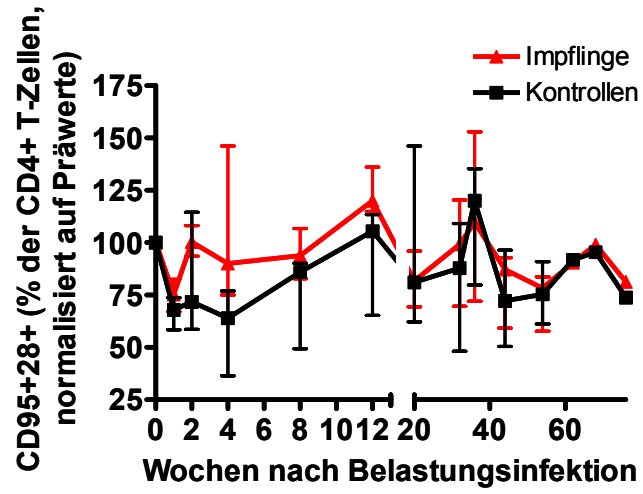

C)

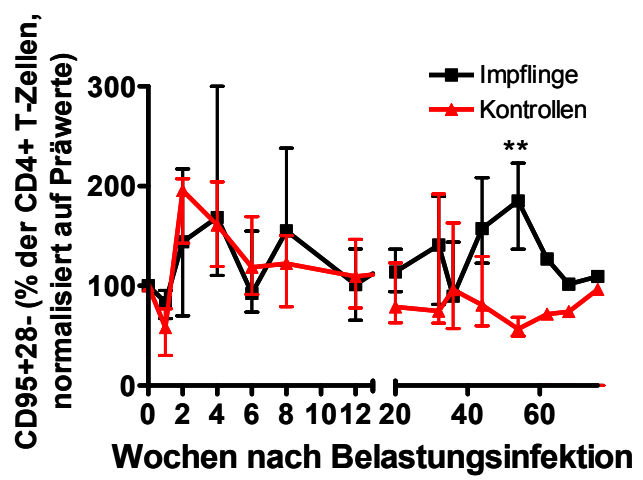

B)

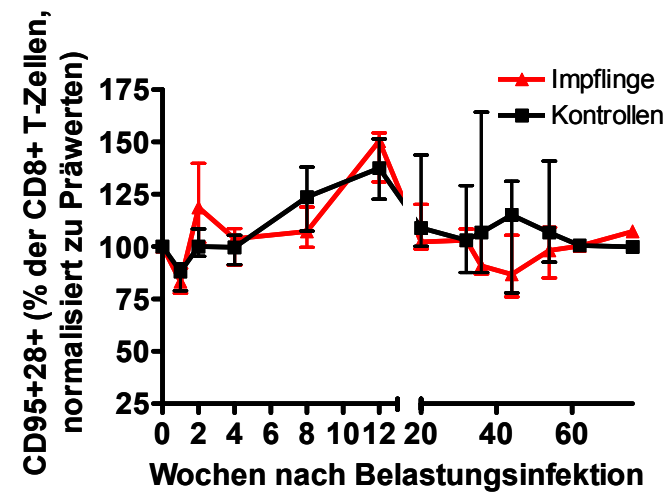

D)

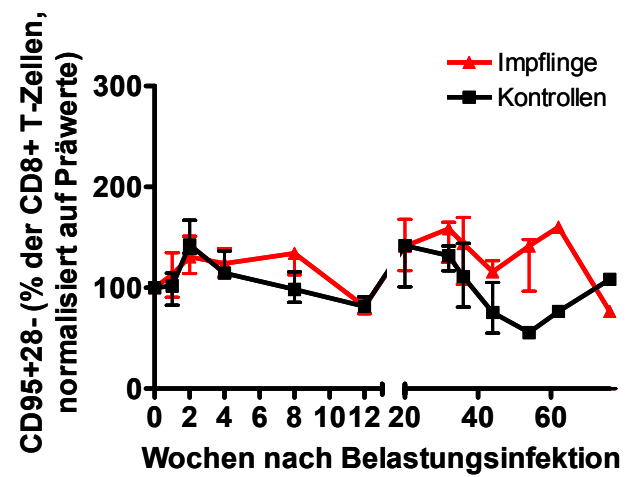

Abb. 3.21: Anteil der zentralen Gedächtniszellen (TCM) und der Effektorgedächtniszellen (TEM) im Blut der Versuchstiere nach Belastungsinfektion

Die Abbildung zeigt die Veränderungen des prozentualen Anteils der zentralen Gedächtniszellen und der Effektorgedächtniszellen im Zeitverlauf des Experiments in den zwei Versuchsgruppen. Die Linien geben den Median der jeweiligen Gruppe wieder, die Fehlerbalken zeigen den Interquartilabstand $\mathrm{I}_{50}$. Mit den Sternen sind signifikante Unterschiede nach dem Mann-Whitney-Test zwischen den Gruppen gekennzeichnet (** $p<0,01$ ).

Teil A zeigt die $\mathrm{CD}^{+} 95^{+} 28^{+}\left(\mathrm{CD} 4^{+} \mathrm{TCM}\right)$, Teil B die CD8 $8^{+} 95^{+} 28^{+}\left(\mathrm{CD} 8^{+} \mathrm{TCM}\right)$ T-Lymphozyten.

Teil C zeigt die $\mathrm{CD}^{+} 95^{+} 28^{-}\left(\mathrm{CD} 4^{+} \mathrm{TEM}\right)$, Teil D die CD8 ${ }^{+} 95^{+} 28^{-}\left(\mathrm{CD} 8^{+}\right.$TEM) T-Lymphozyten. 


\subsubsection{Bestimmung der Anzahl IFNy-sezernierender T-Zellen nach Gag-Stimulation mit der ELISPOT-Technik nach tonsillärer Applikation von SIVmac239}

Der Vergleich der geimpften Tiere mit den Kontrolltieren ergab zum Zeitpunkt der Belastungsinfektion keine signifikanten Unterschiede im Bezug auf die Anzahl der IFNy-sezernierenden Zellen pro $10^{6}$ PBMC nach Gag-Stimulation (Abb. 3.22).

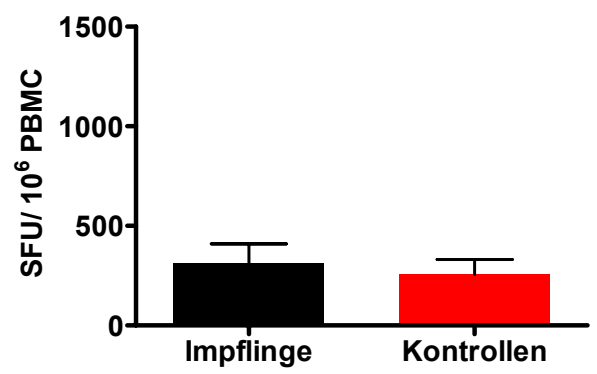

Abb. 3.22: Vergleich der mittleren Anzahl der IFNy-sezernierenden Zellen in der Impfgruppe und den Kontrollen nach Gag-Stimulation zum Zeitpunkt der Belastungsinfektion

Das Diagramm gibt die mittlere Anzahl der IFNy-sezernierenden Zellen und die Fehlerbalken die Standardabweichung der Impflinge und Kontrollen wieder. Die Ordinate zeigt die Anzahl der SFU pro $1 \times 10^{6}$ PBMC.

Auch für den weiteren Zeitraum nach Belastungsinfektion ließen sich zu keinem Zeitpunkt signifikante Unterschiede zwischen den Tieren der Impfgruppe und den Kontrollen nachweisen.

In der Impfgruppe (Abb. 3.23 A) wies das MamuA*01-positive Tier 12536 über den gesamten Zeitraum der Untersuchung eine hohe Anzahl IFNy-sezernierender Zellen nach Gag-Stimulation auf. In dem ebenfalls MamuA*01-positiven Tier 2105, in dem nur transient Virus nachzuweisen war, war dagegen nahezu keine Reaktion auf die Gag-Stimulation zu detektieren. Nur in der Woche 20 war ein geringer Anstieg der IFNy-sezernierenden T-Zellen messbar.

Die beiden weiteren Tiere zeigten im Zeitraum nach Belastungsinfektion nur zeitweilige Anstiege der IFNy-sezernierenden T-Zellen.

Bei den Kontrolltieren (Abb. 3.23 B) war zwei Wochen nach Belastungsinfektion in vier von sieben Tieren ein starker Anstieg der IFNy-sezernierenden T-Zellen festzustellen. Die Tiere 12540 und 12670 wiesen keinen Anstieg der IFNy-sezernierenden T-Zellen nach Belastungsinfektion auf. Diese beiden Tiere 
mussten in der Woche 20 bzw. 24 aufgrund von AIDS-ähnlichen Symptomen euthanasiert werden.

In dem MamuA*01-positiven Tier 2191 stieg ab der Woche 8 der Anteil der IFNy-sezernierenden T-Zellen auf einen Wert von 2000 IFNy-positiven T-Zellen pro $10^{6}$ PBMC an. Diesen Wert erreichte nach einem Abfall in der Woche 12 auch das MamuA*01-negative Tier 12672.

In dem zweiten MamuA*01-positiven Tier gab es dagegen nur einen geringen Anstieg der IFNy-positiven T-Zellen mit einem Maximum von 1307 in der Woche 20 nach Infektion. Danach kam es bis zur Woche $68 \mathrm{zu}$ einem deutlichen Abfall der Reaktivität.

A)

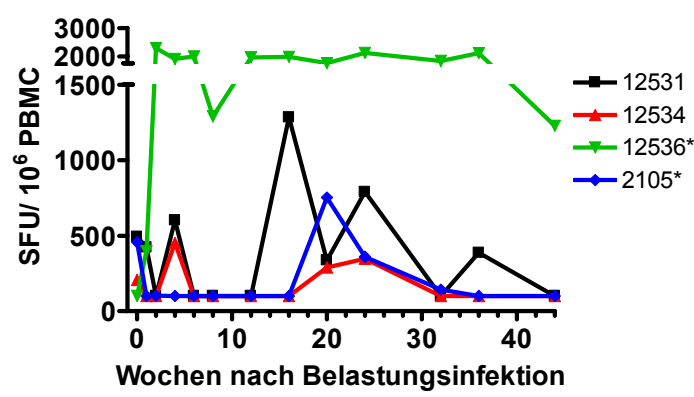

B)

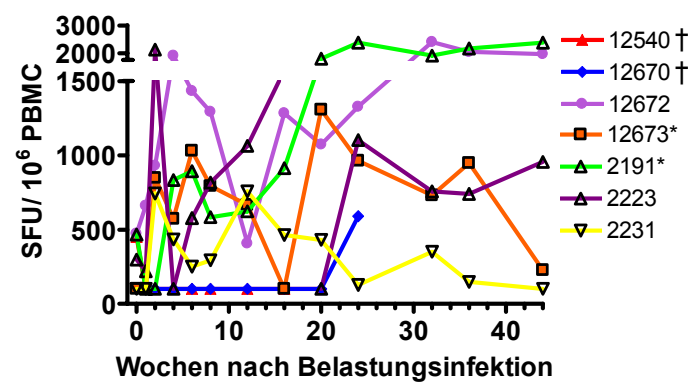

Abb. 3.23: Anzahl IFNy-sezernierender Zellen in der Impfgruppe (A) und den Kontrolltieren (B) nach Gag-Stimulation im Zeitraum nach Belastungsinfektion

PBMC wurden mittels Ficoll isoliert und mit $2 \mu \mathrm{g} / \mathrm{ml}$ Gag-Peptiden für $18 \mathrm{~h}$ stimuliert. Das durch die Stimulation freigesetzte IFNy wurde durch spezifische Antikörper gebunden und mittels chromogenem Substratumsatzes sichtbar gemacht. Die gebildeten spots repräsentieren hierbei jeweils eine IFNy-produzierende Zelle (SFU).

Die Abszisse zeigt die Wochen nach Belastungsinfektion. Die Ordinate gibt die Anzahl der SFU pro $1 \times 10^{6} \mathrm{PBMC}$ wieder. Mit den Sternen sind die Tiere gekennzeichnet, die Träger des MamuA*01-MHC-Allels sind.

Teil A zeigt die Werte der Impfgruppe, Teil B die Werte der Kontrolltiere.

Tiere, die im Versuchsverlauf wegen AIDS-ähnlicher Erkrankungen euthanasiert werden mussten, sind mit einem $†$ gekennzeichnet.

\subsubsection{Vergleich des Nachweises von SIV-spezifischen T-Zellen mit Hilfe der ELISPOT-Technik und der Technik der intrazellulären Zytokinfärbung nach Gag-Stimulation nach Belastungsinfektion}

In dieser Versuchreihe wurden zwei Methoden zur Bestimmung von Zytokinsezernierenden T-Lymphozyten parallel angewendet.

Mit der ELISPOT-Technik kann freigesetztes IFNy mit spezifischen Antikörpern gebunden und in einer Farbreaktion detektiert werden. Über die gemessenen spots wird auf die Anzahl von IFNY-sezernierenden Zellen in der 
Ausgangspopulation geschlossen. Eine weitere Charakterisierung der IFNy-sezernierenden T-Zellpopulationen ist mit dieser Technik nicht möglich.

Der Nachweis von Zytokinen mit der intrazellulären Zytokinfärbung (ICS) beruht auf dem Nachweis von intrazellulär akkumulierten Zytokinen. Nach der Peptidstimulation werden die Zellen mit dem Sekretionsinhibitor Brefeldin A behandelt, so dass der Vesikeltransport vom Golgi-Apparat zur Zelloberfläche in den stimulierten Zellen blockiert wird. Dadurch akkumulieren die aufgrund der Aktivierung gebildeten Zytokine in zytosolischen Vesikeln und können nicht freigesetzt werden. Diese Zytokine werden dann mit Fluorochrom-markierten Antikörpern intrazellulär gefärbt und zusammen mit angefärbten Oberflächenmolekülen im Durchflusszytometer detektiert. Durch die gemeinsame Oberflächen- und intrazelluläre Färbung ist eine phänotypische Bestimmung der immunreaktiven Zellen wie z.B. die Unterscheidung von CD4 ${ }^{+}$ und $\mathrm{CD}^{+} \mathrm{T}$-Lymphozyten möglich.

Die parallele Anwendung beider Techniken ermöglichte die Nutzung der sensitiven ELISPOT-Technik und die Charakterisierung der Lymphozytenpopulationen.

Die Abbildung 3.24 zeigt den Vergleich der Ergebnisse des ELISPOT und des ICS nach Gag-Stimulation in den vier Impflingen der zweiten Versuchsreihe im Zeitraum nach Belastungsinfektion. In den Tieren 2105 und 12531 ließen sich mit beiden Techniken nur sehr geringe Anteile von IFNy-produzierenden Zellen nachweisen. Das Tier 2105 wies im Zeitraum von zwei Wochen nach Belastungsinfektion 457 IFNy-sezernierende T-Zellen pro $10^{6}$ PBMC auf. Die Ergebnisse des ICS zeigten, dass es sich bei diesen Zellen um CD8 ${ }^{+}$ T-Lymphozyten handelte, da mit der ICS-Technik 0,2 \% CD8 ${ }^{+}$T-Lymphozyten, jedoch keine CD4 ${ }^{+}$T-Zellen nachgewiesen wurden.

Das Tier 12531 wies 100 bis maximal 307 IFNy-sezernierende T-Zellen pro $10^{6}$ PBMC nach Gag-Stimulation in einem Zeitraum von acht Wochen nach Belastungsinfektion auf. In diesem Fall konnten mit der ICS-Technik keine Zytokin-positiven T-Lymphozyten detektiert werden.

Im Tier 12534 ließen sich mit der ELISPOT-Technik bis zur achten Woche nach Belastungsinfektion 100 bis maximal 160 IFNy-sezernierende T-Zellen pro $10^{6}$ PBMC nachweisen. Zum Zeitpunkt der stärksten Reaktivität in der Woche 4 
nach Belastungsinfektion konnte mit Hilfe der ICS-Technik gezeigt werden, dass es sich bei dieser Antwort sowohl um eine Zytokinsekretion von $\mathrm{CD}^{+}$als auch von $\mathrm{CD} 8^{+} \mathrm{T}$-Lymphozyten handelte.

Im Tier 12536 ergab sich in der Woche 4 ein identisches Muster, wobei der Anteil der IFNy-sezernierenden T-Zellen deutlich größer war als in den übrigen Tieren dieser Versuchsgruppe. Das Maximum der IFNy-Sekretion war in der Woche 26 zu messen. Hierbei handelte es sich um eine Reaktion sowohl von $\mathrm{CD}^{+}$als auch $\mathrm{CD} 8^{+} \mathrm{T}$-Zellen. Im weiteren Verlauf der Infektion nahm der Anteil der $\mathrm{CD}^{+}{ }^{+}$T-Lymphozyten deutlich ab, so dass die Antwort der $\mathrm{CD}^{+}$ T-Lymphozyten überwog. Erst im sehr späten Verlauf der Infektion konnte in der Woche 56 erneut ein Anteil von IFNy-positiven CD4 ${ }^{+}$T-Lymphozyten gemessen werden.
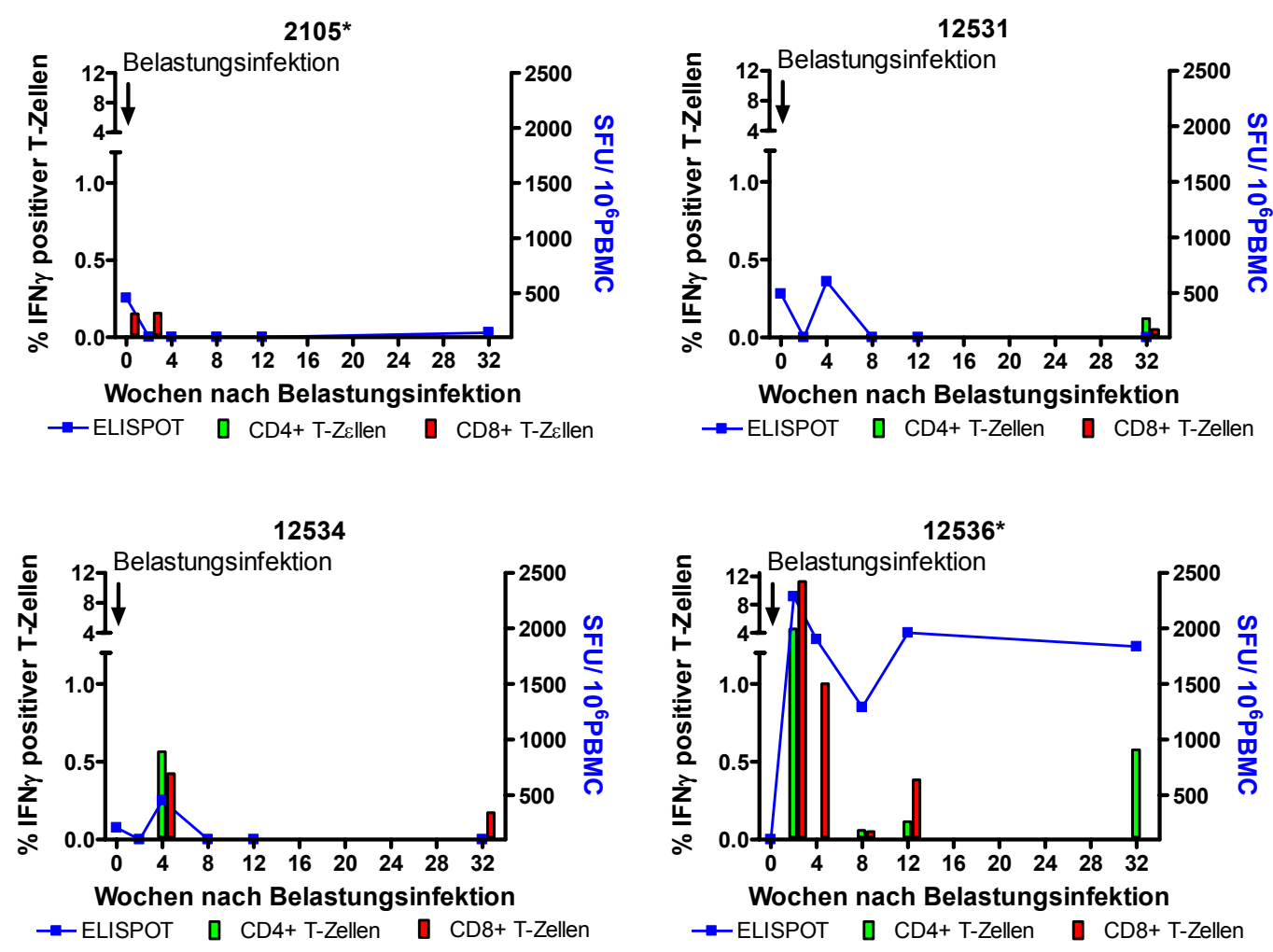

Abb. 3.24: Vergleich der ELISPOT- und ICS-Ergebnisse nach Gag-Stimulation in den Impflingen nach Belastungsinfektion in der zweiten Versuchsreihe

Die Graphen zeigen die Ergebnisse des ICS und des ELISPOT der vier Impflinge nach GagStimulation in der zweiten Versuchsreihe. Auf der Abszisse sind jeweils die Wochen nach der Belastungsinfektion dargestellt. Auf der linken Ordinate ist der prozentuale Anteil der IFNYpositiven T-Zellen des ICS, auf der rechten Ordinate die Anzahl der IFNY-produzierenden Zellen pro $10^{6}$ PBMC der ELISPOT-Technik angegeben. 
Die Abbildung 3.25 zeigt den Vergleich der Ergebnisse des ELISPOT und des ICS nach Gag-Stimulation in den sieben Kontrolltieren der zweiten Versuchsreihe im Zeitraum nach Belastungsinfektion.

In den Tieren 12540 und 12670 ließen sich im Zeitraum nach Belastungsinfektion weder mit der ELISPOT-Technik noch mit dem ICS IFNYsezernierende T-Zellen nachweisen. Bei diesen Tieren handelte es sich um die ersten Tiere, die 20 bzw. 24 Wochen nach Infektion wegen des Auftretens von AIDS-ähnlichen Symptomen euthanasiert werden mussten.

In den anderen fünf Tieren ließen sich mit beiden Methoden IFNY-sezernierende T-Zellen nachweisen.

Das Tier 12672 wies in der Woche 4 nach Belastungsinfektion einen hohen Anteil von 1913 IFNy-sezernierenden T-Zellen pro $10^{6}$ PBMC auf. Das ICS belegte, dass es sich hierbei sowohl um $\mathrm{CD}^{+}$als auch um $\mathrm{CD}^{+}$ T-Lymphozyten handelte. Bis zur Woche 36 kam es zu einem Abfall der Gagspezifischen T-Zellen. In der Woche 56 nach Belastungsinfektion ließen sich 2400 IFNy-sezernierende T-Zellen nachweisen. Mit dem ICS ließen sich zu diesem Zeitpunkt jedoch nur $\mathrm{CD}^{+}$T-Lymphozyten messen.

Das Tier 2191 zeigte einen ähnlichen Verlauf wie Tier 12672, wobei sich in der akuten Phase nur 833 IFNy-sezernierende T-Zellen nachweisen ließen. Zu diesem Zeitpunkt waren mittels ICS in diesem Tier ausschließlich CD8 ${ }^{+}$ T-Lymphozyten nachweisbar. In der Woche 56 wies dieses Tier ebenfalls eine hohe Anzahl von Gag-spezifischen T-Zellen auf.

In dem Tier 12673 ließen sich über den gesamten Zeitraum der Infektion je Messzeitpunkt etwa 700 IFNy-sezernierenden T-Zellen pro $10^{6}$ PBMC nachweisen. Die Ergebnisse des ICS zeigten, dass es sich hierbei ausschließlich um CD8 ${ }^{+}$T-Lymphozyten handelte.

In dem Tier 2223 war bereits zwei Wochen nach Infektion ein Maximum mit mehr als 2100 IFNy-sezernierenden T-Zellen pro $10^{6}$ PBMC nachweisbar. Diese Gag-spezifische Antwort wurde zum größten Teil von $\mathrm{CD}^{+}$ T-Lymphozyten hervorgerufen. Im weiteren Verlauf kam es zunächst zu einem massiven Abfall der Gag-spezifischen Antwort, gefolgt von einem erneuten leichten Anstieg. Das ICS belegte, dass das IFNy in dieser Phase der Infektion nur von $\mathrm{CD}^{+}$T-Lymphozyten gebildet wurde. Zum Ende des 
Untersuchungszeitraums ließen sich in der Woche 56 in diesem Tier wieder reaktive $\mathrm{CD}^{+}{ }^{+} \mathrm{T}$-Lymphozyten nachweisen.

Das Tier 2231 wies in der Woche 26 zunächst einen leichten Anstieg auf 743 IFNy-sezernierende T-Zellen auf. Bis zur Woche 32 kam es zu einem leichten Abfall mit einem erneuten Anstieg in der Woche 36 auf 757 IFNy-sezernierende T-Zellen pro $10^{6}$ PBMC. In diesem Tier ließen sich in den Wochen 28, 36 und 56 sowohl CD4 ${ }^{+}$als auch $\mathrm{CD}^{+}{ }^{+}$T-Lymphozyten nachweisen.

Der Vergleich beider Methoden lässt auf eine höhere Sensitivität der ELISPOTTechnik gegenüber der ICS-Technik schließen, da eine ICS-Positivität erst ab etwa 500 SFU nachweisbar war. 
12540

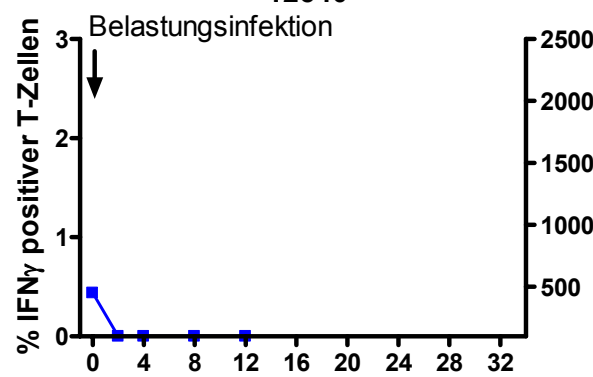

Wochen nach Belastungsinfektion

$\rightarrow$ ELISPOT $\mathrm{C}$ CD4+ T-Zellen

0 CD8+ T-Zellen

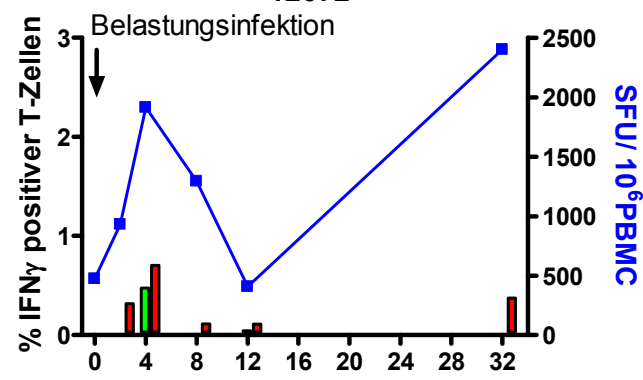

Wochen nach Belastungsinfektion

$\rightarrow$ ELISPOT 0 CD4+ T-Zellen

0 CD8+ T-Zellen

12673*

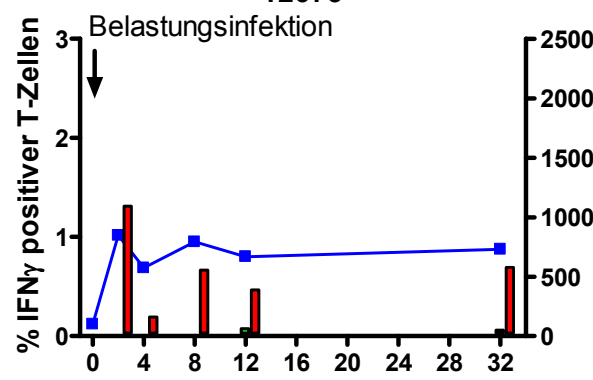

Wochen nach Belastungsinfektion

$\rightarrow$ ELISPOT $\mathrm{C}$ CD4+ T-Zellen

C CD8+ T-Zellen

12670

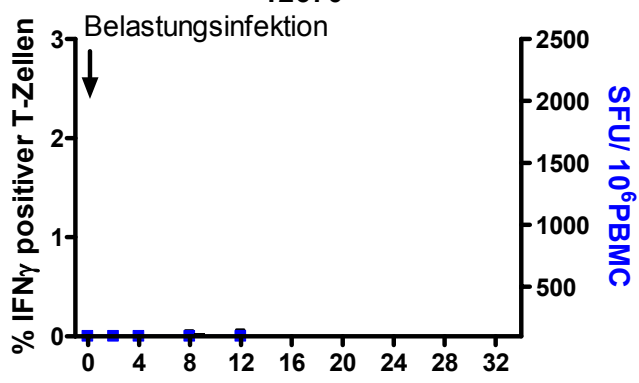

Wochen nach Belastungsinfektion

$\rightarrow$ ELISPOT $\mathrm{CD}$ 4+ T-Zellen C CD8+ T-Zellen

2191*

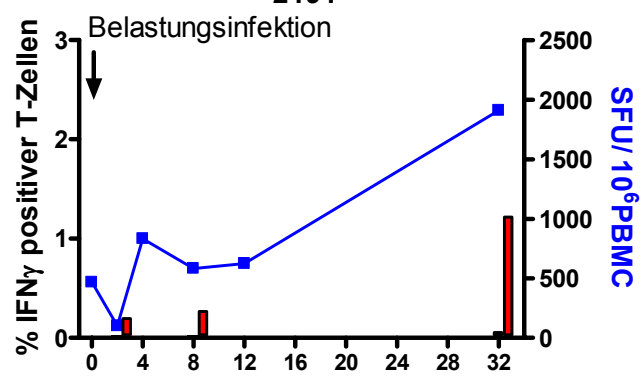

Wochen nach Belastungsinfektion

$\rightarrow$ ELISPOT $\mathrm{C}$ CD4+ T-Zellen 0 CD8+ T-Zellen

2223

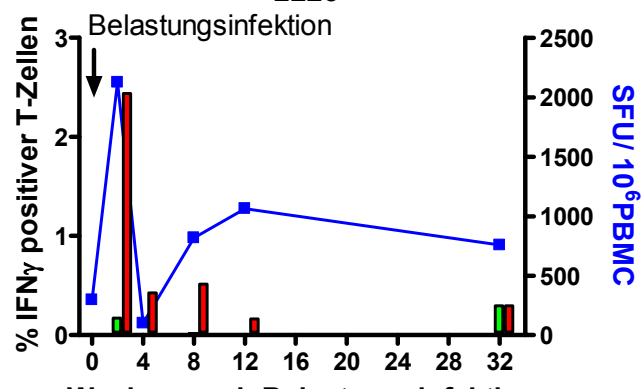

Wochen nach Belastungsinfektion

$\rightarrow$ ELISPOT $\mathrm{CD}$ 4+ T-Zellen a CD8+ T-Zellen

2231

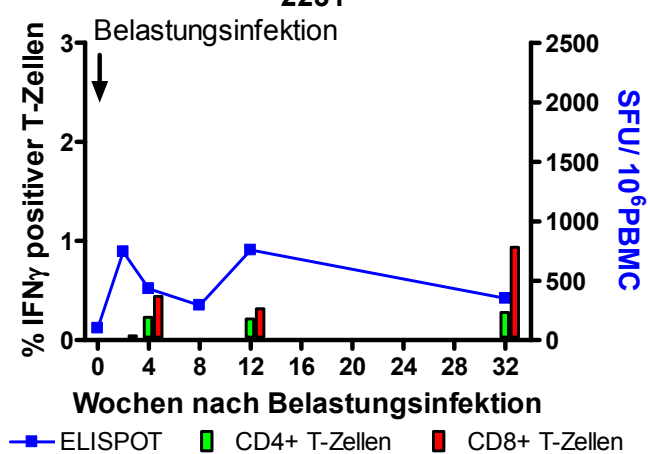

Abb. 3.25: Vergleich der ELISPOT- und ICS-Ergebnisse nach Gag-Stimulation in den Kontrollen nach Belastungsinfektion in der zweiten Versuchsreihe

Die Graphen zeigen die Ergebnisse des ICS und des ELISPOT der sieben Kontrolltiere nach Gag-Stimulation in der zweiten Versuchsreihe. Auf der Abszisse sind jeweils die Wochen nach Belastungsinfektion dargestellt. Auf der linken Ordinate ist der prozentuale Anteil der IFNYpositiven T-Zellen des ICS, auf der rechten Ordinate die Anzahl der IFNY-produzierenden Zellen pro $10^{6}$ PBMC der ELISPOT-Technik angegeben. 
Die Abbildung 3.26 zeigt die Mediane und den Interquartilabstand $I_{50}$ der ELISPOT- und ICS-Ergebnisse nach Gag-Stimulation in den Impflingen und den Kontrolltieren.

In der Woche 2 nach Belastungsinfektion lag in den Impflingen eine starke Streuung der Ergebnisse vor, da zwei der vier Tiere eine hohe $\mathrm{CD} 4^{+}$und $\mathrm{CD} 8^{+}$ T-Zellantwort aufwiesen. Im weiteren Verlauf der Infektion ließen sich jedoch keine weiteren Unterschiede finden.

Zum direkten Vergleich der beiden Techniken zur Detektion von Zytokinproduzierenden T-Zellen wurde eine Korrelationsanalyse der ELISPOT- und ICS-Ergebnisse durchgeführt. Das Ergebnis wies für die ersten 16 Wochen signifikant positive Korrelationen mit Korrelationskoeffizienten zwischen 0,67 und 0,78 auf.
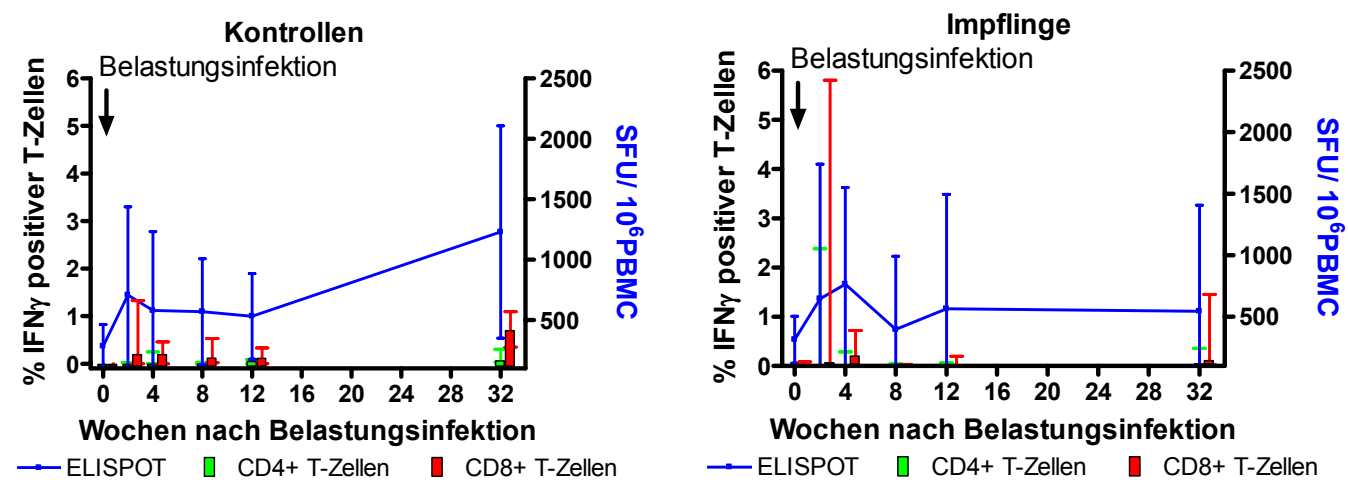

Abb. 3.26: Vergleich der ELISPOT- und ICS-Ergebnisse nach Gag-Stimulation im Zeitverlauf nach Belastungsinfektion in der zweiten Versuchsreihe

Die Graphen zeigen die medianen Ergebnisse des ICS und des ELISPOT der Impflinge und der Kontrolltiere nach Gag-Stimulation in der zweiten Versuchsreihe. Die Fehlerbalken zeigen den Median und den Interquartilabstand $I_{50}$. Auf der Abszisse sind jeweils die Wochen nach Belastungsinfektion dargestellt. Auf der linken Ordinate ist der prozentuale Anteil der IFNYpositiven T-Zellen des ICS, auf der rechten Ordinate die Anzahl der IFNy-produzierenden Zellen pro $10^{6}$ PBMC der ELISPOT-Technik angegeben.

\subsubsection{Bestimmung von Gag-spezifischen polyfunktionalen}

\section{T-Lymphozyten nach tonsillärer Applikation von SIVmac239 mit} Hilfe des polyfunktionalen ICS

Mit dem Begriff "polyfunktional“ werden Zellen bezeichnet, die nach Antigenstimulation mehr als ein Zytokin gleichzeitig sezernieren. Diese verschiedenen Zytokine können mit der ICS-Technik simultan intrazellulär gefärbt und im Durchflusszytometer gemessen werden. 
In der zweiten Versuchsreihe wurde neben der Expression des Zytokins IFNy auch das Zytokin IL2 nach Gag-Stimulation gemessen. Aus der Analyse resultieren daher drei verschiedene Möglichkeiten der Zytokinexpression. Sowohl $\mathrm{CD}^{+}$als auch $\mathrm{CD}^{+}$T-Lymphozyten können nur IFNy oder IL2 exprimieren. Diese Populationen bezeichnet man als einfach positiv. Eine weitere Möglichkeit ist die gleichzeitige Expression der beiden Zytokine.

In der zweiten Versuchsreihe sollte untersucht werden, ob die Immunisierung in den Impflingen Veränderungen in der Art und Anzahl der polyfunktionalen T-Lymphozyten im Vergleich zu den Kontrollen hervorruft. Die Abbildung 3.27 zeigt den gemittelten Anteil an $\mathrm{CD} 4^{+}$und $\mathrm{CD} 8^{+} \mathrm{T}$-Lymphozyten, die nach GagStimulation nur IFNy oder IL2 oder beide Zytokine gleichzeitig zum Zeitpunkt Woche 2 nach Belastungsinfektion exprimieren. In den Impflingen war der Anteil der IFNy-positiven T-Lymphozyten zu diesem Zeitpunkt erhöht. Im weiteren Verlauf wurden jedoch keine Unterschiede detektiert (Daten nicht gezeigt).

Zu keinem Zeitpunkt war ein signifikanter Unterschied zwischen den einfach positiven oder polyfunktionalen T-Lymphozyten im Vergleich der Impflinge und der Kontrollen zu beobachten.

A)

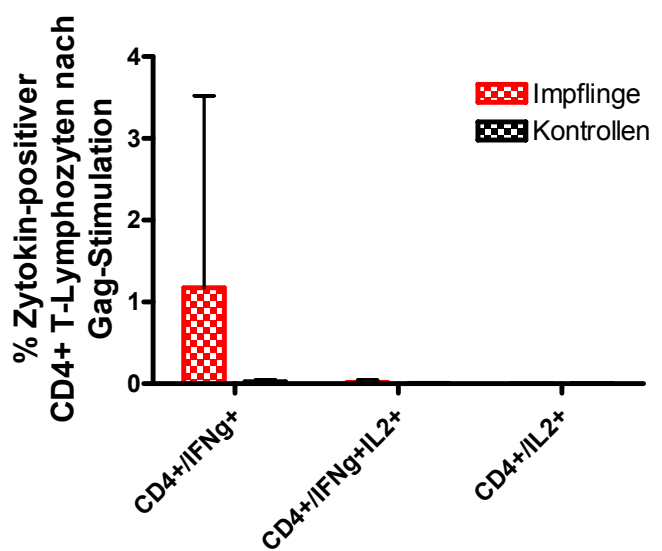

B)

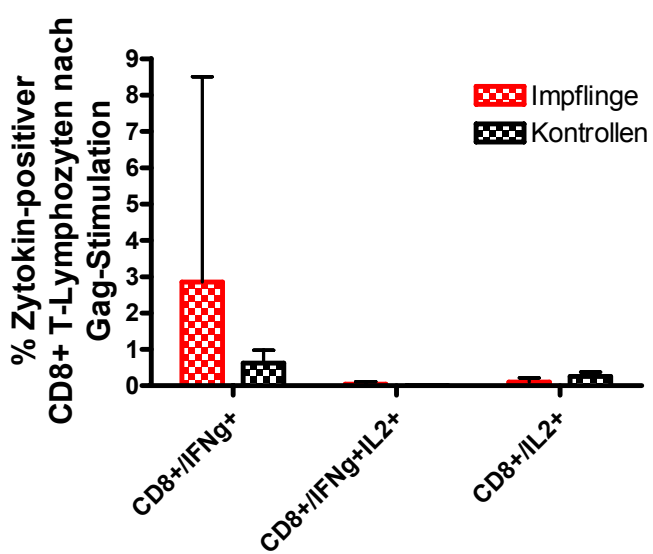

Abb. 3.27: Gemittelter Anteil an Zytokin-einfach positiven und polyfunktionalen $\mathrm{CD}^{+}$und $\mathrm{CD8}^{+}$T-Lymphozyten nach Gag-Stimulation zwei Wochen nach Belastungsinfektion in der zweiten Versuchsreihe

Die Graphen zeigen die drei möglichen Populationen des polyfunktionalen ICS nach GagStimulation in den Impflingen und den Kontrolltieren zwei Wochen nach der Belastungsinfektion in der zweiten Versuchsreihe. Auf der Ordinate ist der prozentuale Anteil der Zytokin-positiven T-Zellen angegeben. Die Säulen zeigen die Mittelwerte der Gruppen, die Balken zeigen die Standardabweichung.

Teil A zeigt die Ergebnisse der CD4 ${ }^{+}$T-Lymphzyten, Teil B die CD8 ${ }^{+}$T-Lymphozyten. 


\subsection{Charakterisierung von Tieren mit niedriger Viruslast und SIV-spezifischer zellulärer Immunantwort}

\subsubsection{Viruslast nach Belastungsinfektion durch tonsilläre Inokulation}

Innerhalb der ersten beiden Versuchsreihen konnten unabhängig davon, ob es sich um Impflinge oder nicht-geimpfte Kontrollen handelte, von 29 Tieren zehn Tiere identifiziert werden, welche die Virusbeladung im Plasma innerhalb von zwölf Wochen auf unter $10^{4}$ RNA-Kopien reduzierten (Abb. 3.28). Diese Tiere werden im Weiteren als viruskontrollierende Tiere (engl. Controller) bezeichnet. In diesen Tieren wurde in dem Zeitraum 64 bis 72 Wochen nach Belastungsinfektion die zelluläre Immunantwort mittels polyfunktionalem ICS, einem Proliferationstest und in den MamuA*01-positiven Tieren zusätzlich mittels Tetramerfärbung untersucht.

In den Abbildungen 3.28 und 3.29 sind die Anzahl der viralen RNA-Kopien in der Gruppe der viruskontrollierenden Tiere und der nicht-viruskontrollierenden Tiere (engl. Non-Controller) der ersten und zweiten Versuchsreihe dargestellt.

Aus der Gruppe der nicht-viruskontrollierenden Tiere rekrutierten sich auch die vier Kontrolltiere für das polyfunktionale ICS, die in dem oben beschriebenen Zeitraum eine mittlere Virusbeladung von 2,1 x $10^{5}$ RNA-Kopien aufwiesen (Abb. 3.29). Aus experimentellen Gründen konnten im Proliferationstest nur uninfizierte Tiere als Kontrollen verwendet werden.

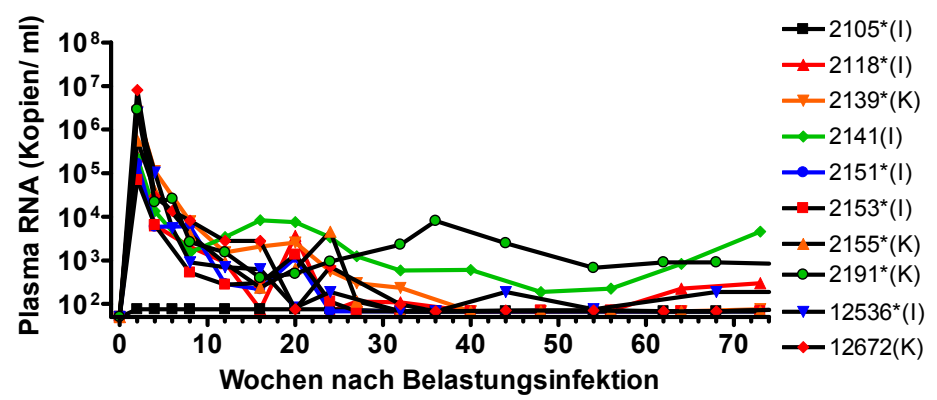

Abb 3.28: Anzahl der viralen RNA-Kopien pro Milliliter Blutplasma im Zeitverlauf nach Belastungsinfektion in den viruskontrollierenden Tieren

Die virale RNA wurde aus $200 \mu \mathrm{l}$ Blutplasma isoliert und mit Hilfe des QuantiTect ${ }^{\mathrm{TM}}$ Probe RT-PCR-Kits der Firma Qiagen amplifiziert und detektiert. Auf diese Weise wurde der virologische Status der Rhesusaffen nach SIV-Inokulation bestimmt.

Mit den Sternen sind die Tiere gekennzeichnet, die Träger des MamuA*01-MHC-Allels sind.

Mit (I) sind Impflinge, mit (K) Tiere aus den Kontrollgruppen gekennzeichnet 


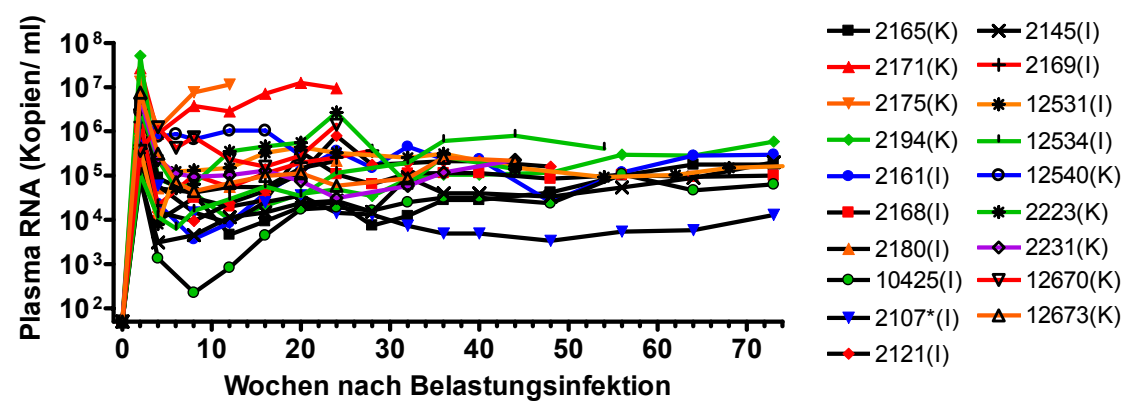

Abb 3.29: Anzahl der viralen RNA-Kopien pro Milliliter Blutplasma im Zeitverlauf nach Belastungsinfektion in den nicht-viruskontrollierenden Tieren

Die virale RNA wurde aus $200 \mu$ l Blutplasma isoliert und mit Hilfe des QuantiTect ${ }^{\mathrm{TM}}$ Probe RT-PCR-Kits der Firma Qiagen amplifiziert und detektiert. Auf diese Weise wurde der virologische Status der Rhesusaffen nach SIV-Inokulation bestimmt.

Mit den Sternen sind die Tiere gekennzeichnet, die Träger des MamuA*01-MHC-Allels sind.

Mit (I) sind Impflinge, mit (K) Tiere aus den Kontrollgruppen gekennzeichnet

Die Abbildung 3.30 zeigt die mittlere Anzahl von viralen RNA-Kopien pro Milliliter Blutplasma in den zehn „Controllern“ und den 15 „Non-Controllern“. Ab der achten Woche nach Belastungsinfektion war eine hochsignifikante Reduktion der RNA-Kopien in den „Controllern“ im Vergleich zu den „NonControllern“ zu beobachten.

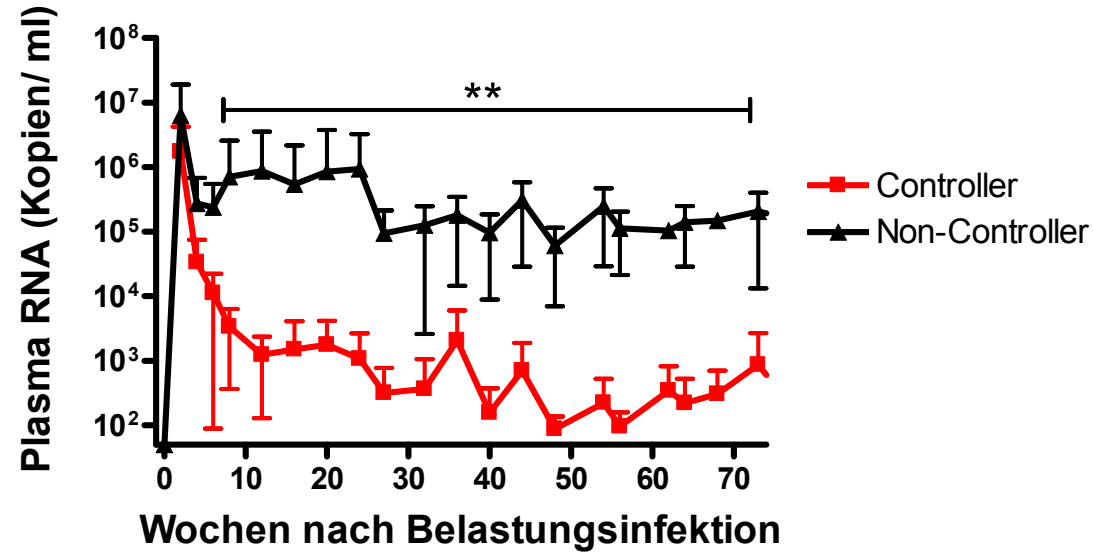

Abb. 3.30: Mittlere Anzahl von viralen RNA-Kopien pro Milliliter Blutplasma im Zeitverlauf nach Belastungsinfektion in den viruskontrollierenden Tieren und den Tieren mit hoher Viruslast

Die virale RNA wurde aus $200 \mu$ l Blutplasma isoliert und mit Hilfe des QuantiTect ${ }^{\mathrm{TM}}$ Probe RT-PCR-Kits der Firma Qiagen amplifiziert und detektiert. Auf diese Weise wurde der virologische Status der Rhesusaffen nach SIV-Inokulation bestimmt.

Die Linien geben den Mittelwert der jeweiligen Gruppe, die Balken die Standardabweichung wieder. Mit dem Querbalken und den Sternen ist der Zeitraum mit signifikanten Unterschieden nach dem Mann-Whitney-Test zwischen den beiden Gruppen gekennzeichnet $\left({ }^{* *} p<0,01\right)$. 


\subsubsection{Bestimmung der Proliferation nach antigenspezifischer Stimulation}

Die Fähigkeit zur Proliferation von T-Helferzellen nach Antigenstimulation geht relativ früh nach einer HIV-Infektion des Menschen oder einer SIV-Infektion von Rhesusaffen verloren (Kneitz et al., 1993; Dittmer et al., 1994).

Zur Bestimmung der Proliferationsfähigkeit der T-Lymphozyten wurden die Zellen mit Peptiden des Gag-Proteins, mit chemisch inaktiviertem AT2-SIV oder als Positivkontrolle mit Staphylococcus-Enterotoxin B (SEB) für fünf Tage stimuliert. Zur Messung der Proliferation wurden die PBMC zu Stimulationsbeginn mit CFSE gefärbt und nach der Inkubationszeit im Durchflusszytometer gemessen. Das CFSE bindet während des Färbeprozesses kovalent an Aminogruppen zellulärer Proteine, so dass es bei Zellteilung zu einer Halbierung der Signalintensität in den Tochterzellen kommt. Daher werden in der Analyse die Zellen, die ein niedriges CFSE-Signal zeigen, als proliferierende Zellen betrachtet. Als proliferierende Population wurde ein Anteil von mindestens 1\% CFSE-negativen T-Zellen angesehen.

Die Ergebnisse aus dem Ansatz mit Zellen der "Controller“ zeigten, dass in acht der zehn Tiere die $\mathrm{CD}^{+}$und in neun der zehn Tiere die CD8 ${ }^{+}$T-Lymphozyten nach AT2-SIV-Stimulation proliferierten (Abb. 3.31 A und B). Der Anteil von proliferierenden Zellen lag dabei jedoch zwischen 1,4\% und 29\%.

Nach Stimulation mit Gag-Peptiden proliferierten in zwei Tieren die CD4 ${ }^{+}$ T-Lymphozyten (Abb. $3.31 \mathrm{~A}$ ) und in vier von zehn Tieren die CD8 ${ }^{+}$ T-Lymphozyten (Abb. 3.31 B). Die Positivkontrolle der Stimulation mit SEB wies in allen Tieren starke Proliferationswerte zwischen $7 \%$ und $65 \%$ CFSEnegativen T-Zellen auf.

Ein Großteil der proliferierenden T-Lymphozyten nach Antigenstimulation sind Gedächtniszellen (Abate et al., 2005). Daher wurden die T-Lymphozyten mit dem Gedächtniszellmarker CD95 gefärbt und auf ihre Proliferationsfähigkeit untersucht (Abb. 3.31 C und D).

Im Vergleich zur Analyse der Proliferationsfähigkeit aller $\mathrm{CD}^{+}$und $\mathrm{CD}^{+}$ T-Zellen gab es bei Eingrenzung der Population auf den Gedächtniszelltyp nur geringe Unterschiede nach Stimulation mit AT2-SIV.

In sieben der zehn Tiere proliferierten nach AT2-SIV-Stimulation die CD4 ${ }^{+} 95^{+}$ und in neun der zehn Tiere die $\mathrm{CD}^{+} 95^{+}$T-Lymphozyten. Nach Stimulation mit 
Gag-Peptiden proliferierten in einem Tier die CD4 ${ }^{+} 95^{+}$T-Lymphozyten und in vier von zehn Tieren die CD8 ${ }^{+} 95^{+}$T-Lymphozyten.

Die SEB-Positivkontrolle ergab in allen Tieren erwartungsgemäß positive Proliferationswerte.

A)

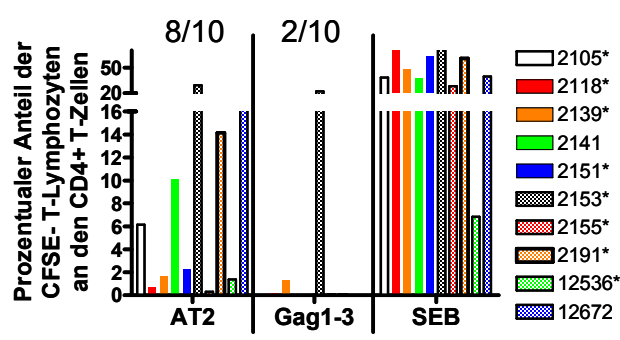

C)

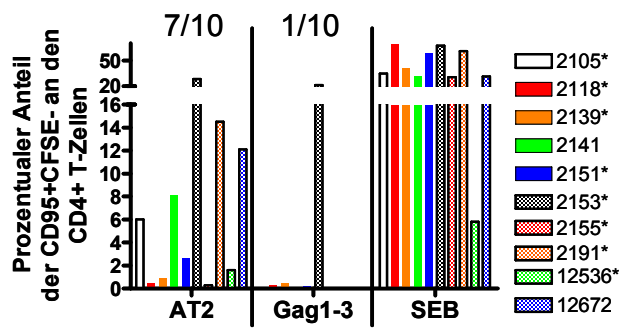

B)

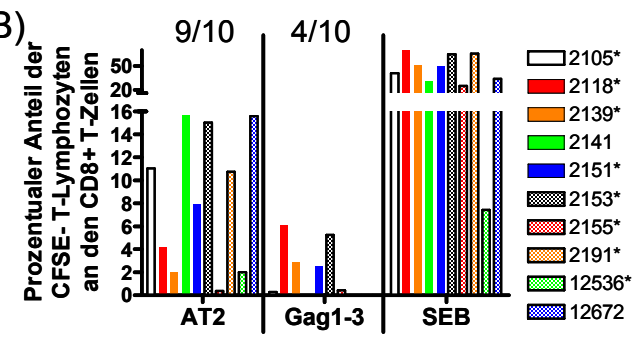

D)

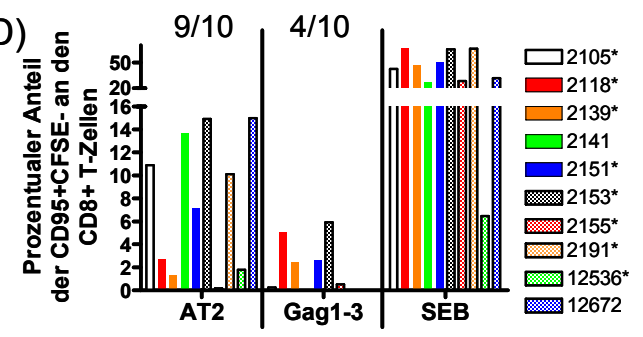

Abb. 3.31: Prozentualer Anteil von proliferierenden Gedächtnis-T-Lymphozyten nach antigenspezifischer Stimulation in den Viruscontrollern in der chronischen Phase der Belastungsinfektion

Teil A zeigt den Anteil von CFSE $\mathrm{CD}^{+}{ }^{+}$T-Lymphozyten, Teil B den Anteil von CFSE- CD8 ${ }^{+}$ T-Lymphozyten. Die Teile C und D zeigten den Anteil der CFSE $\mathrm{CD}^{+} 95^{+}$und CFSE- $\mathrm{CD}^{+} 95^{+}$ T-Lymphozyten 62 bis 74 Wochen nach Belastungsinfektion. Die Abzisse gibt die Art der Stimulation, die Ordinate den prozentualen Anteil der CFSE T-Lymphozytenpopulation wieder. Mit den Sternen sind die Tiere gekennzeichnet, die Träger des MamuA*01-MHC-Allels sind.

Um nachzuweisen, dass es sich bei der Proliferation nach Antigenstimulation nicht um eine allgemeine Fähigkeit von T-Lymphozyten handelt, wurden T-Zellen von vier uninfizierten Tieren im Proliferationstest untersucht. Bei den Untersuchungen wiesen zwei der vier Tiere eine unspezifische Proliferationsaktivität auf (Abb. 3.32 A bis D). Aus diesem Grund wurden für die Auswertungen der „Viruscontroller“ nur Ergebnisse als positiv gewertet, die oberhalb dieses unspezifischen Hintergrundes von $1 \%$ lagen.

Die SEB-Positivkontrolle ergab in allen Tieren erwartungsgemäß positive Proliferationswerte. 
A)

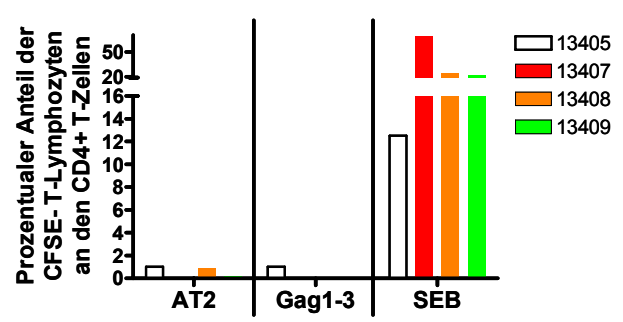

C)

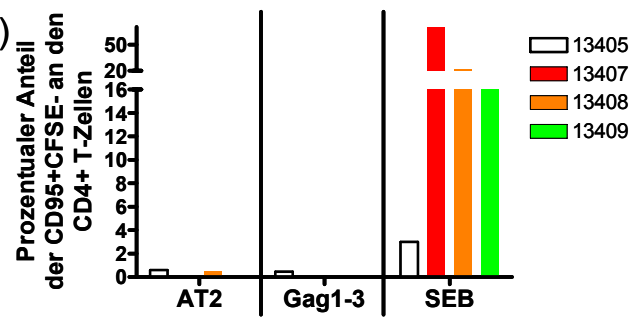

B)

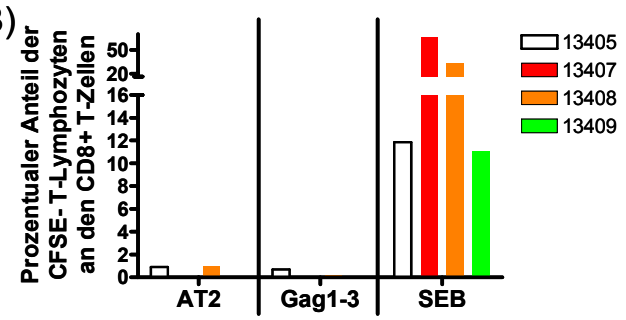

D)

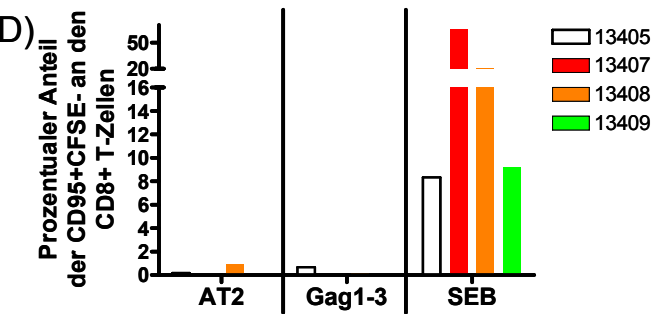

Abb. 3.32: Prozentualer Anteil von proliferierenden T-Lymphozyten nach antigenspezifischer Stimulation in nicht-infizierten Kontrolltieren

Teil A zeigt den Anteil von CFSE $\mathrm{CD}^{+}$T-Lymphozyten, Teil B den Anteil von CFSE $\mathrm{CD}^{+}$ T-Lymphozyten. Die Teile C und D zeigten den Anteil der CFSE ${ }^{-} \mathrm{CD}^{+} 95^{+}$und CFSE $\mathrm{CD}^{+} 95^{+}$ T-Lymphozyten. Die Abzisse gibt die Art der Stimulation, die Ordinate den prozentualen Anteil der CFSE- T-Lymphozytenpopulation wieder.

\subsubsection{Bestimmung von Gag-spezifischen Zytokin-produzierenden} T-Lymphozyten mit Hilfe des polyfunktionalen ICS

In Immunisierungsstudien gegen das Hepatitis-B-Virus, Tetanustoxoid und HIV wurden zur Bestimmung von polyfunktionalen T-Lymphozyten bis zu fünf verschiedene Zytokine gleichzeitig untersucht (De Rosa et al., 2004). Durch eine Infektion mit HIV verändert sich die Zytokinexpression der $\mathrm{CD} 4^{+}$und $\mathrm{CD} 8^{+}$ T-Zellen hin zur verstärkten Bildung von IFNy (Betts et al., 2005).

Daher wurden die zehn "Controller" im Zeitraum von 62 bis zu 74 Wochen nach Belastungsinfektion auf die Expression der drei Zytokine IFNy, TNFa und IL2 untersucht.

Die Abbildung 3.31 zeigt das Expressionsprofil der aus diesen Untersuchungen resultierenden sieben T-Zellsubpopulationen mit unterschiedlicher Funktionalität.

In fünf von neun Tieren war eine Zytokinexpression in $\mathrm{CD}^{+}$ T-Lymphozyten nach Gag-Stimulation nachweisbar. Zwei Tiere wiesen polyfunktionale T-Zellpopulationen auf (Abb. 3.33 A).

In den $\mathrm{CD}^{+}{ }^{+} \mathrm{T}$-Lymphozyten konnten in acht von neun Tieren polyfunktionale T-Zellen nach Gag-Stimulation nachgewiesen werden (Abb. 3.33 B).

Einen Sonderfall stellt das Tier 2105 dar, da es die Viruslast nach Belastungsinfektion sehr schnell kontrollierte und ein Virusnachweis nur 
transient durch Virusisolierung möglich war. Zu den untersuchten Zeitpunkten konnten in diesem Tier keine Zytokin-produzierenden T-Lymphozyten nach Gag-Stimulation nachgewiesen werden.

A)

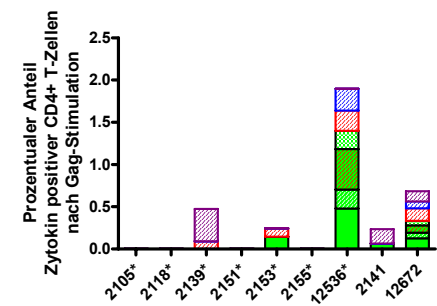

B)

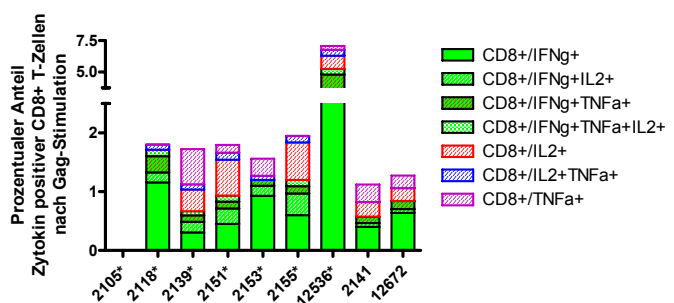

Abb. 3.33: Polyfunktionale T-Lymphozyten nach Gag-Stimulation in den Viruscontrollern 62 bis 74 Wochen nach Belastungsinfektion

Teil A zeigt den Anteil der $\mathrm{CD4}^{+}$, Teil B den Anteil der CD8 ${ }^{+}$T-Lymphozyten.

Auf der Abszisse sind die Tiernummern, auf der Ordinate der prozentuale Anteil der Zytokinpositiven T-Lymphzyten angegeben.

Die Legende zeigt die sieben möglichen polyfunktionalen T-Zellsubpopulationen, wobei mit einer grünen Hintergrundfarbe die T-Zellen dargestellt sind, die das Zytokin IFNy einfach oder in Kombination mit TNFa und/ oder IL2 exprimieren.

Mit den Sternen sind die Tiere gekennzeichnet, die Träger des MamuA*01-MHC-Allels sind.

Die Abbildung 3.34 zeigt die Polyfunktionalität der Lymphozyten nach Stimulation mit SEB, welches als Positivkontrolle verwendet wurde.

Dabei konnten in allen Tieren polyfunktionale $\mathrm{CD}^{+}$und $\mathrm{CD}^{+}{ }^{+} \mathrm{T}$-Lymphozyten nachgewiesen werden.

A)

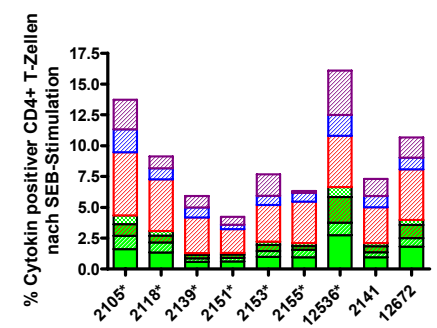

B)

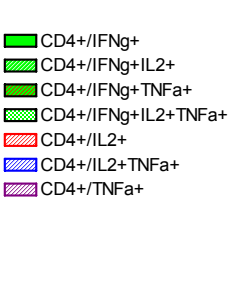

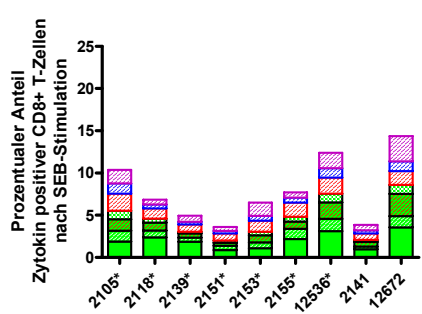

$\mathrm{CD} 8+/ / \mathrm{FNg}+$ CD8+//FNg+IL2+ CD8+/FNg+TNFa+ CD8+//FNg+TNFa+IL2+ DD $8+/ / \mathrm{L} 2+$ $\mathrm{CD} 8+/ / \mathrm{L} 2+\mathrm{TNFa}+$ CD8+/TNFa+

Abb. 3.34: Polyfunktionale T-Lymphozyten nach SEB-Stimulation in den Viruscontrollern 62 bis 74 Wochen nach Belastungsinfektion

Der Teil A zeigt den Anteil der CD4 ${ }^{+}$, der Teil B den Anteil der CD8 ${ }^{+}$T-Lymphozyten.

Auf der Abszisse sind die Tiernummern, auf der Ordinate der prozentuale Anteil der Zytokinpositiven T-Lymphzyten angegeben.

Die Legende zeigt die sieben möglichen polyfunktionalen T-Zellsubpopulationen, wobei mit einer grünen Hintergrundfarbe die T-Zellen dargestellt sind, die das Zytokin IFNy einfach oder in Kombination mit TNFa und/ oder IL2 exprimieren.

Mit den Sternen sind die Tiere gekennzeichnet, die Träger des MamuA*01-MHC-Allels sind. 
Im Gegensatz zu den viruskontrollierenden Tieren lag in den vier untersuchten „Non-Controllern“ im Zeitraum von Woche 62 bis 74 keine Expression von Zytokinen nach Gag-Stimulation vor (Daten nicht gezeigt).

Nach Stimulation mit SEB konnte in zwei der vier Tiere eine polyfunktionale $\mathrm{CD}^{+}$T-Lymphozytenpopulation nachgewiesen werden. In den beiden anderen Tieren war die Antwort nur gering ausgeprägt. Polyfunktionale CD8 ${ }^{+}$ T-Lymphozyten konnten nach SEB-Stimulation in allen vier Tieren nachgewiesen werden (Abb. 3.35).

A)

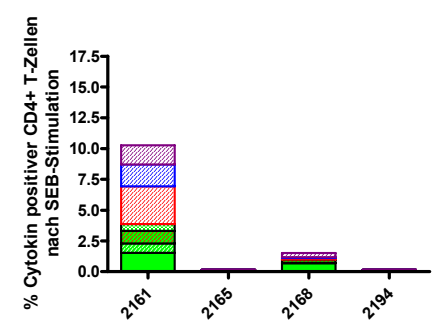

B)

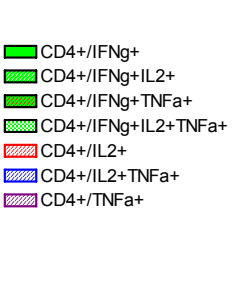

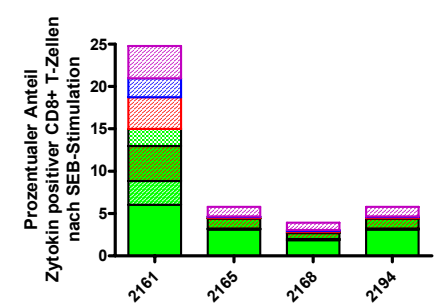

Abb. 3.35: Polyfunktionale T-Lymphozyten nach SEB-Stimulation in den Non-Controllern 62 bis 74 Wochen nach Belastungsinfektion

Der Teil A zeigt den Anteil der CD4 ${ }^{+}$, der Teil B den Anteil der CD8 ${ }^{+}$T-Lymphozyten.

Auf der Abszisse sind die Tiernummern, auf der Ordinate der prozentuale Anteil der Zytokinpositiven T-Lymphzyten angegeben.

Die Legende zeigt die sieben möglichen polyfunktionalen T-Zellsubpopulationen, wobei mit einer grünen Hintergrundfarbe die T-Zellen dargestellt sind, die das Zytokin IFNy einfach oder in Kombination mit TNFa und/ oder IL2 exprimieren.

Mit den Sternen sind die Tiere gekennzeichnet, die Träger des MamuA*01-MHC-Allels sind.

\subsubsection{Bestimmung der Anzahl von SIV-spezifischen Lymphozyten in} MamuA*01-positiven „Controllern“" nach tonsillärer Applikation von SIVmac239 mit Hilfe der Tetramer-Technik

Es konnten in allen MamuA*01-positiven Tieren CM9-Tetramer-positive CD8 ${ }^{+}$ T-Zellen nachgewiesen werden. Der Anteil an den $\mathrm{CD} 8^{+} \mathrm{T}$-Zellen lag zwischen $0,11 \%$ und $12 \%$ (Abb. 3.36). Als Negativkontrollen dienten die Tiere 2141 und 12672, die das MamuA*01-Allel nicht besitzen und daher keine positiven GagTetramerpopulationen zeigen durften.

In dem Tier 2105 konnte mittels RT-PCR nach Belastungsinfektion kein Virus nachgewiesen werden. Mit der Bestimmung der zellgebundenen Viruslast durch die Endpunkt-Verdünnungsmethode konnte in diesem Tier das Virus transient nachgewiesen werden (Daten nicht gezeigt). Dieses Ergebnis und das Vorhandensein einer geringen Gag-Tetramer-positiven $\mathrm{CD}^{+}{ }^{+}$T-Zellpopulation 
belegen, dass dieses Tier erfolgreich mit SIV infiziert worden war, jedoch die Viruslast im Blut sehr deutlich reduzieren konnte.

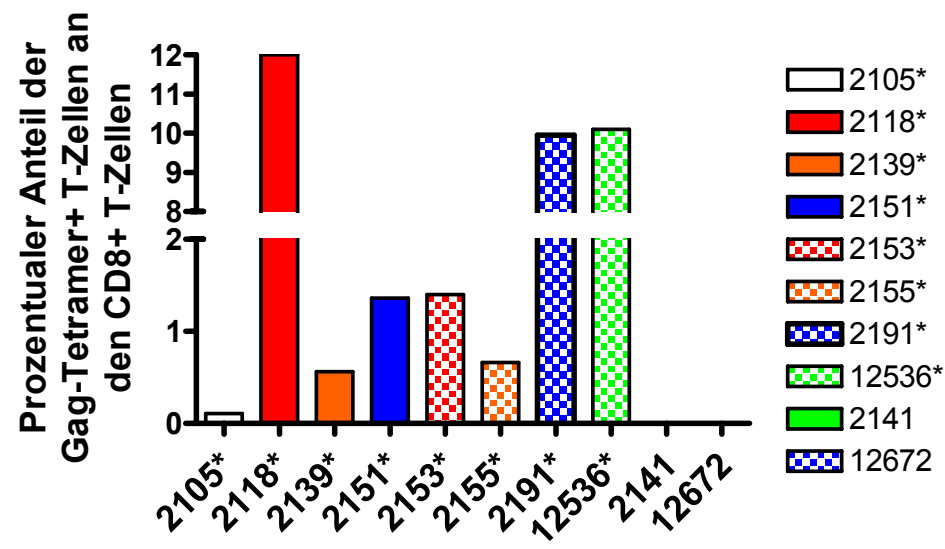

Abb. 3.36: Prozentualer Anteil der CM9-Tetramer ${ }^{+} \mathrm{CD} 8^{+} \mathrm{T}-$ Lymphozyten

Die Abbildung zeigt die prozentualen Anteile der CM9-Tetramer ${ }^{+} \mathrm{CD}^{+}{ }^{+}$T-Lymphozyten in den MamuA*01-positiven "Viruscontrollern“. Die Abzisse zeigt die Tiernummern, die Ordinate den relativen Anteil der CM9-Tetramer-positiven T-Zellen an den CD8 ${ }^{+}$T-Lymphozyten. Mit den Sternen sind die Tiere gekennzeichnet, die Träger des MamuA*01-MHC-Allels sind. Die zwei Tiere ohne Sternkennzeichung sind MamuA*01-negativ und dienten als Negativkontrollen zur Validierung der Tetramerspezifität.

Die Tabellen 3.1 und 3.2 zeigen eine Zusammenstellung der Ergebnisse der viruskontrollierenden Tiere. Es lässt sich feststellen, dass in diesen Tieren eine ausgeprägte zelluläre Immunantwort vorlag. So ließen sich in nahezu allen Tieren proliferierende T-Lymphozyten nach Stimulation mit inaktiviertem AT2-SIV nachweisen. Dagegen proliferierten die T-Lymphozyten nach Stimulation mit dem Gag-Peptidpool nur in wenigen Tieren. Das inaktivierte AT2-SIV regt eine größere Bandbreite von T-Zellen zur Proliferation an als der Gag-Peptidpool. Durch die Stimulation mit dem Gag-Peptidpool ließen sich dagegen in fast allen Tieren polyfunktionale $\mathrm{CD} 8^{+} \mathrm{T}$-Lymphozyten nachweisen. Die Ergebnisse bestätigen die bedeutende Funktion der zellulären Immunantwort für die Reduktion der Virusbeladung in der chronischen Phase der Infektion. 
Tab. 3.1: Ergebnisse des ELISPOT und des Proliferationstests in den zehn viruskontrollierenden Tieren

\begin{tabular}{|c|c|c|c|c|c|c|c|c|c|}
\hline \multirow[b]{3}{*}{$\begin{array}{l}\text { Tier- } \\
\text { nummer }\end{array}$} & \multirow[t]{3}{*}{ ELISPOT $^{\#}$} & \multicolumn{8}{|c|}{ Proliferationstest } \\
\hline & & \multicolumn{4}{|c|}{$\begin{array}{l}\text { Prozentualer Anteil der CFSE- } \\
\text { negativen Zellen nach Gag- } \\
\text { Stimulation }\end{array}$} & \multicolumn{4}{|c|}{$\begin{array}{l}\text { Prozentualer Anteil der CFSE- } \\
\text { negativen Zellen nach AT2-SIV- } \\
\text { Stimulation }\end{array}$} \\
\hline & & $\mathrm{CD}^{+}$ & $\mathrm{CD}^{+}$ & $\begin{array}{l}\mathrm{CD}^{+} \\
95^{+}\end{array}$ & $\begin{array}{l}\mathrm{CD}^{+} \\
95^{+}\end{array}$ & $\mathrm{CD}^{+}$ & $\mathrm{CD}^{+}$ & $\begin{array}{l}\mathrm{CD}^{+} \\
95^{+}\end{array}$ & $\begin{array}{l}\mathrm{CD}^{+} \\
95^{+}\end{array}$ \\
\hline $2105^{*}$ & $0^{+}$ & - & - & - & - & 6,1 & 11,0 & 6 & $\overline{10,9}$ \\
\hline $2118^{*}$ & 2403 & - & 6,1 & - & 5,1 & - & 4,2 & - & 2,7 \\
\hline $2139^{*}$ & 826 & 1,3 & 3,0 & - & 2,5 & 1,7 & 2,0 & - & 1,3 \\
\hline 2141 & 1112 & - & - & - & - & 10,1 & 15,6 & 8,1 & 13,7 \\
\hline $2151^{*}$ & 1649 & - & 2,5 & - & 2,6 & 2,3 & 7,9 & 2,7 & 7,2 \\
\hline $2153^{*}$ & 636 & 22,0 & 5,3 & 21,4 & 6,0 & 29,1 & 15,0 & 28,1 & 14,9 \\
\hline $2155^{*}$ & 1615 & - & - & - & - & - & - & - & - \\
\hline 2191 & 2446 & - & - & - & - & 14,1 & 10,8 & 14,5 & 10,1 \\
\hline $12536^{*}$ & 2470 & - & - & - & - & 1,4 & 2,0 & 1,6 & 1,8 \\
\hline $12672^{*}$ & 1569 & - & - & - & - & 17,9 & 15,6 & 12,1 & 15,0 \\
\hline
\end{tabular}

\# Mittlere Anzahl IFNy-positiver Zellen pro $10^{6}$ PBMC nach Gag-Stimulation im Zeitraum zwischen 57 und 92 Wochen nach Belastungsinfektion

* MamuA*01-positive Tiere

${ }^{+}$Nach Stimulation mit dem CM9-Peptid lag die mittlere Anzahl IFNy-positiver Zellen pro $10^{6}$ PBMC bei 215 SFU

Tab. 3.2: Ergebnisse der CM9-Tetramerfärbung und des ICS in den zehn viruskontrollierenden Tieren

\begin{tabular}{|c|c|c|c|c|c|}
\hline $\begin{array}{l}\text { Tier- } \\
\text { nummer }\end{array}$ & $\begin{array}{l}\text { \% CM9- } \\
\text { Tetramere }\end{array}$ & $\begin{array}{l}{ }_{0 \mathrm{CD}^{+}{ }^{+} \mathrm{IFNy}{ }^{+}} \\
\text {nach Gag- } \\
\text { Stimulation }\end{array}$ & $\begin{array}{l}\text { Polyfunktionalitäts- } \\
\text { grad der CD4 }{ }^{+} \mathrm{T} \text { - } \\
\text { Zellen }\end{array}$ & $\begin{array}{l}\text { \% } \mathrm{CD}^{+} \mathrm{IFNy}^{+} \\
\text {nach Gag- } \\
\text { Stimulation }\end{array}$ & $\begin{array}{l}\text { Polyfunktionalitäts- } \\
\text { grad der CD8 }{ }^{+} \text {T- } \\
\text { Zellen }{ }^{\#}\end{array}$ \\
\hline $2105^{*}$ & 0,1 & - & - & - & 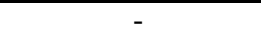 \\
\hline $2118^{*}$ & 12 & - & - & 1,7 & 3 \\
\hline $2139^{*}$ & 0,6 & - & 1 & 0,7 & 3 \\
\hline 2141 & 0 & 0,1 & 1 & 0,6 & 2 \\
\hline $2151^{*}$ & 1,4 & 0 & - & 0,9 & 3 \\
\hline $2153^{*}$ & 1,4 & 0,1 & 1 & 1,2 & 2 \\
\hline $2155^{*}$ & 0,7 & 0 & - & 1,2 & 3 \\
\hline 2191 & 10,0 & nd & nd & nd & nd \\
\hline $12536^{*}$ & 10,1 & 1,4 & 3 & 5,3 & 3 \\
\hline $12672^{*}$ & 0 & 0,3 & 3 & 0,8 & 2 \\
\hline
\end{tabular}

* MamuA*01-positive Tiere nd: nicht gemessen

\# Polyfunktionalitätsgrad: Bewertungsmaßstab zur Bewertung der Polyfunktionalität der T-Zellen

$1=$ Zellen sezernieren nur ein Zytokin

2= Zellen sezernieren zwei Zytokine

$3=$ Zellen sezernieren drei Zytokine

- keine Zytokinpopulation nachweisbar 


\subsection{Ergebnisse der dritten Versuchsreihe (aVLP-Ad)}

\subsubsection{Bestimmung der Anzahl IFNy-sezernierender SIV-spezifischer} T-Zellen nach Gag-Stimulation mit der ELISPOT-Technik während der Immunisierungsphase

Die Bestimmung der Anzahl IFNy-sezernierender T-Lymphozyten nach GagPeptidstimulation ergab, dass es erst nach der zweiten VLP-Immunisierung in einem der vier Impflinge einen geringen Anstieg der Werte gab (Abb. 3.37 A).

Nach der ersten Adenovirusapplikation war bei drei der vier Tiere ein Anstieg der IFNy-sezernierenden T-Lymphozyten zu beobachten. Das Tier 12056, das bereits nach dem „VLP-Prime“ eine Reaktion aufwies, zeigte nach dem ersten Adenovirusboost die größte Anzahl IFNy-sezernierender T-Lymphozyten.

Nach der zweiten Adenovirusapplikation war nur in diesem Tier ein erneuter Anstieg IFNy-sezernierender Lymphozyten messbar.

In der Kontrollgruppe ließ sich in den ersten zehn Wochen eine unspezifische Reaktivität nach Gag-Stimulation messen (Abb. 3.37 B). Im Zeitraum zwischen der Woche 10 und 32 war keine Reaktivität vorhanden. Im Zeitraum von Woche 32 bis 40 war in zwei Tieren eine unspezifische Reaktivität nach Gag-Stimulation nachweisbar.

A)

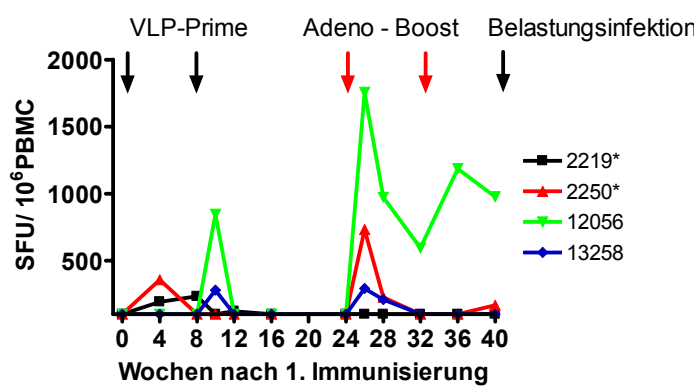

B)

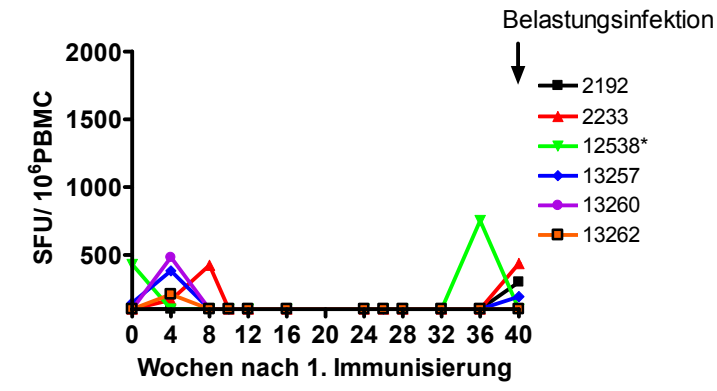

Abb. 3.37: Anzahl IFNy-sezernierender Zellen in der Impfgruppe (A) und den Kontrolltieren (B) im Zeitraum der „Prime- und Boost"-Immunisierungen nach GagStimulation

PBMC wurden mittels Ficoll isoliert und mit $2 \mu \mathrm{g} / \mathrm{ml}$ Gag-Peptiden für $18 \mathrm{~h}$ stimuliert. Das durch die Stimulation freigesetzte IFNy wurde durch spezifische Antikörper gebunden und mittels chromogenem Substratumsatzes sichtbar gemacht. Die gebildeten spots repräsentieren hierbei jeweils eine IFNy-produzierende Zelle (SFU).

Die Abszisse zeigt die Zeit in Wochen bezogen auf die erste Immunisierung der Tiere. Die Ordinate gibt die Anzahl der SFU pro $1 \times 10^{6}$ PBMC wieder. Mit den Sternen sind die Tiere gekennzeichnet, die Träger des MamuA*01-MHC-Allels sind.

Teil A zeigt die Werte der Impfgruppe, Teil B die Werte der Kontrolltiere. 


\subsubsection{Bestimmung der Viruslast nach Belastungsinfektion durch intravenöse Applikation von SIVmac251 in der dritten Versuchsreihe mit Hilfe der RT-PCR}

In der dritten Versuchsreihe wurden die VLPs mit Adjuvantien appliziert, um neben der zellulären Immunantwort auch eine verstärkte humorale Immunantwort zu induzieren. Da das SIVmac239-Virus in Neutralisationstests schlecht zu neutralisieren ist, wurde das besser zu neutralisierende SIVmac251 zur Belastungsinfektion verwendet.

Die Belastungsinfektion wurde im Gegensatz zu den beiden vorherigen Versuchsreihen intravenös durchgeführt. Sowohl die immunisierten Tiere als auch die Kontrolltiere waren nach intravenöser Applikation von SIVmac251 produktiv infiziert.

In der dritten Versuchsreihe wurde ebenfalls ein „Prime-Boost“Immunisierungsschema untersucht. Hierbei wurden vier Tiere zweimal im Abstand von acht Wochen subkutan mit VLP und Adjuvantien als "Prime“ immunisiert. Als Adjuvantien wurde eine Mischung aus CpG-enhaltenden Oligonukleotiden und Polyriboinositol-Polyribocytidinsäure im Komplex mit L-Lysin (polylC/LC) verwendet, um die Immunantwort zu verstärken (Teleshova et al., 2004; Hartmann et al., 2005; Sammons et al., 1977). Nach einer Wartezeit von 16 Wochen wurde zweimal eine tonsilläre Auffrischungsimpfung mit Adenoviruskonstrukten durchgeführt. Als Kontrolle dienten sechs Tiere, die nicht immunisiert wurden.

Um eine Aussage über die frühe Kinetik der SIVmac251-Infektion zu machen, wurde die Bestimmung der Anzahl von viralen RNA-Kopien im Blutplasma der Tiere engmaschig an den Tagen 3, 7, 10 und 14 nach Belastungsinfektion durchgeführt. Im weiteren Verlauf erfolgte die Messung im Abstand von zwei bis vier Wochen.

In den Kontrolltieren stieg die Anzahl der RNA-Kopien im Blutplasma bis zum Tag 14 nach Belastungsinfektion auf einen Wert von 5,8 x 10 $\mathrm{c} / \mathrm{ml}$ an. Bis vier Wochen nach Belastungsinfektion sank der Wert auf 1,3 × $10^{6}$ und lag bis zur Woche $17 \mathrm{im}$ Mittel bei $1,4 \times 10^{6} \mathrm{c} / \mathrm{ml}$.

Die mittlere Anzahl der viralen RNA-Kopien im Blutplasma der Impflinge (Abb. 3.38) stieg bis zum Tag 10 auf ein Maximum von $8,7 \times 10^{5} \mathrm{c} / \mathrm{ml}$. Bis zum 
Tag 14 reduzierte sich dieser Wert auf $1,8 \times 10^{5} \mathrm{c} / \mathrm{ml}$ und lag zu diesem Zeitpunkt hochsignifikant niedriger als in den Kontrolltieren. Vier Wochen nach Belastungsinfektion lag die mittlere Anzahl bei $2,7 \times 10^{5} \mathrm{c} / \mathrm{ml}$ und damit signifikant niedriger als in den Kontrollen. Im weiteren Zeitverlauf bis Woche 17 lag die mittlere Anzahl bei $3,8 \times 10^{5} \mathrm{c} / \mathrm{ml}$. Ein statistisch signifikanter Unterschied zu den Kontrollen war nicht nachweisbar.

Bis zum Tag 10 der Infektion ergab sich kein Unterschied in der Virusbeladung der Impflinge und der Kontrollen. Erst in den folgenden vier Tagen entwickelte sich der hochsignifikante Unterschied zwischen den beiden Gruppen.

Beim Vergleich der Virusbeladung im Blutplasma der einzelnen Tiere (Abb. $3.38 \mathrm{~B}$ und $\mathrm{C}$ ) zeigte sich, dass es in den Tieren, die Träger des MamuA*01-MHC-Allels sind, zu einer deutlich schnelleren und stärkeren Reduktion der Virusbeladung im Blutplasma kam.

In den beiden Tieren der Impfgruppe kam es ab der Woche 2 zu einer deutlichen Reduktion der RNA-Kopien im Blutplasma. Hingegen sank die RNA-Kopienzahl in dem MamuA*01-positiven Kontrolltier nicht unter $10^{5} \mathrm{c} / \mathrm{ml}$. 

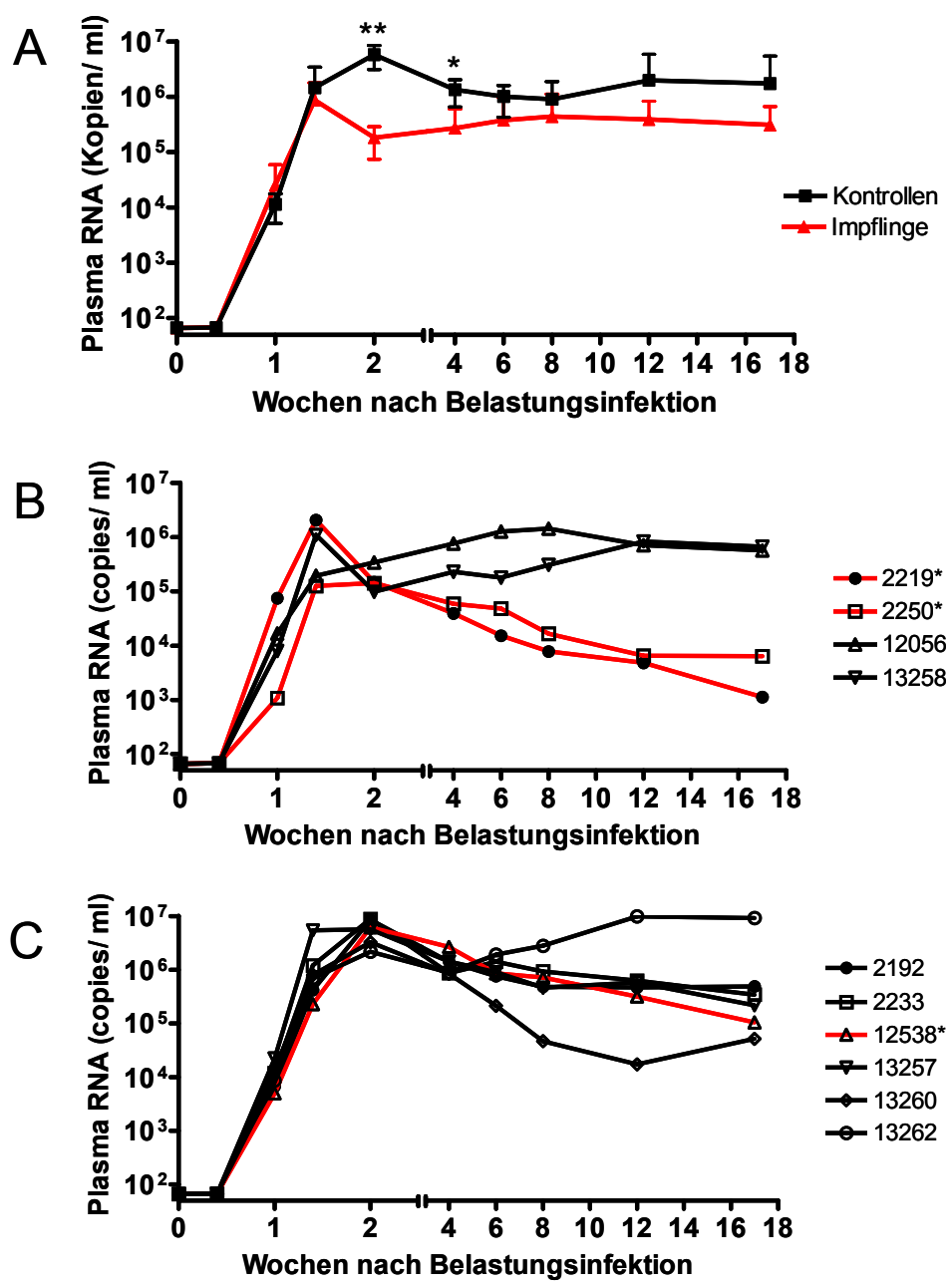

Abb 3.38: Anzahl der viralen RNA-Kopien pro Milliliter Blutplasma im Zeitverlauf nach Belastungsinfektion

Die virale RNA wurde aus $200 \mu \mathrm{l}$ Blutplasma isoliert und mit Hilfe des QuantiTect ${ }^{\mathrm{TM}}$ Probe RT-PCR-Kits der Firma Qiagen amplifiziert und detektiert. Auf diese Weise wurde der virologische Status der Rhesusaffen nach SIV-Inokulation bestimmt.

Teil A zeigt die mittlere Anzahl der viralen Kopien in den zwei Gruppen.

Die Linien geben den Mittelwert und die Fehlerbalken die Standardabweichung der jeweiligen Gruppe an. Mit den Sternen sind signifikante Unterschiede nach dem Mann-Whitney-Test zwischen den Impfgruppen und den Kontrollen gekennzeichnet $\left({ }^{*} p<0,05,{ }^{* *} p<0,01\right)$.

Die Teile B und C zeigen die Einzelwerte der jeweiligen Gruppe.

Mit Sternen und roten Linien sind die Tiere gekennzeichnet, die Träger des MamuA*01-MHCAllels sind.

B) Impflinge

C) Kontrolltiere 


\subsubsection{Durchflusszytometrische Untersuchungen zirkulierender $\mathrm{CD4}^{+}$und} CD8 $^{+}$T-Lymphozyten im Blut der Versuchstiere der dritten Versuchsreihe

In der dritten Versuchsreihe war zwischen den Impflingen und den Kontrolltieren kein Unterschied in Bezug auf Veränderungen der CD4 ${ }^{+}$ T-Lymphozytenpopulationen nach Belastungsinfektion nachweisbar (Abb. 3.39). In beiden Gruppen kam es zu einem Verlust des mittleren Anteils der CD4 ${ }^{+}$ T-Lymphozyten auf ein Niveau von etwa $70 \%$ der Präinfektionswerte. Dieser Verlust bestand bis zur Woche 17, die das Ende des Untersuchungszeitraumes darstellte.

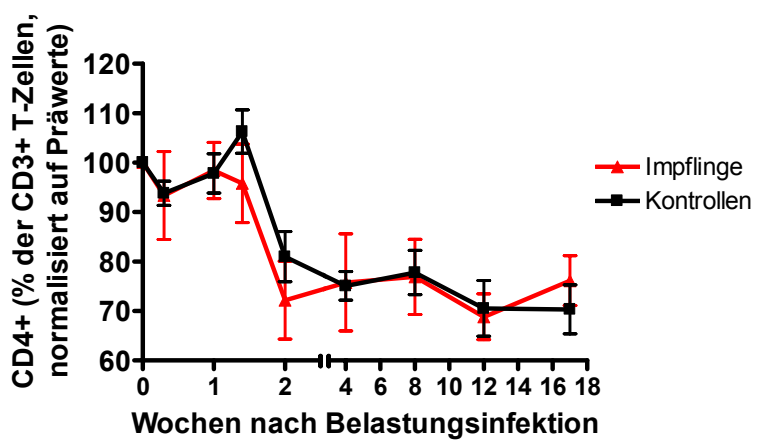

Abb. 3.39: Anteil der $\mathrm{CD}^{+}$T-Lymphozyten an den Gesamtlymphozyten im Blut der Versuchstiere nach Belastungsinfektion

Die Abbildung zeigt die Veränderungen des prozentualen Anteils der $\mathrm{CD} 4^{+} \mathrm{T}$-Lymphozyten im Zeitverlauf des Experiments in den zwei Versuchsgruppen. Die Linien geben den Median der jeweiligen Gruppe wieder, die Fehlerbalken zeigen den Interquartilabstand $I_{50}$.

Signifikante Unterschiede zwischen den Kontrolltieren und den Impflingen waren dagegen bereits drei Tage nach Infektion in der CD4 ${ }^{+} 195^{+}$ T-Lymphozytenpopulation, die als primäre Zielzellen für die SIV-Infektion angesehen wird, nachweisbar (Abb. 3.40).

In den Impflingen war der Anteil dieser Population bereits ab dem dritten Tag signifikant erhöht. In den Kontrolltieren blieb die CD4 ${ }^{+} 195^{+}$T-Zellpopulation bis zum zehnten Tag nach Infektion unverändert und sank dann in der Woche 2 stark ab. Für den restlichen Untersuchungszeitraum blieb der Anteil dieser Population unterhalb des Niveaus der Präinfektionswerte.

In den Impflingen stieg der Anteil dieser vorgenannten Zellen dagegen im Vergleich zu den Präinfektionswerten an und erreichte in der Woche 4 nach Belastungsinfektion ein Maximum. Bis zur Woche 17 sank der mittlere Anteil dieser Population wieder ab, lag jedoch zu diesem Zeitpunkt noch deutlich 
oberhalb des Präinfektionswertes. Für den gesamten Untersuchungszeitraum ergaben sich signifikante Unterschiede zwischen den Impflingen und Kontrollen.

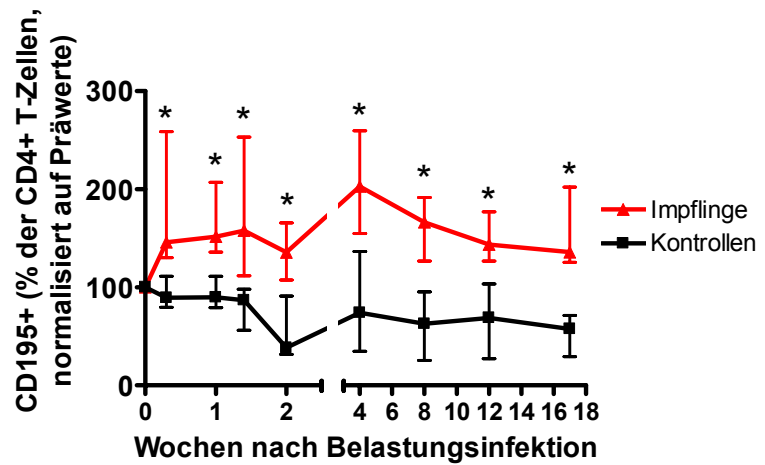

Abb. 3.40: Anteil der $\mathrm{CD4}^{+} 195^{+} \mathrm{T}$-Lymphozyten an den Gesamtlymphozyten im Zeitverlauf im Blut der Versuchstiere nach Belastungsinfektion

Die Abbildung zeigt die Veränderungen des prozentualen Anteils der CD4 ${ }^{+} 195^{+}$T-Lymphozyten im Zeitverlauf des Experiments in den zwei Versuchsgruppen. Die Linien geben den Median der jeweiligen Gruppe wieder, die Fehlerbalken zeigen den Interquartilabstand $I_{50}$.

Mit den Sternen sind signifikante Unterschiede nach dem Mann-Whitney-Test zwischen den Gruppen gekennzeichnet $\left({ }^{*} p<0,05\right)$.

Der mittlere Anteil der $\mathrm{CD}^{+}$Gedächtniszellen, die über die Expression des Oberflächenmoleküls CD95 definiert werden können, veränderte sich nach der Belastungsinfektion sowohl in den Impflingen als auch in den Kontrolltieren deutlich (Abb. 3.41).

In den ersten zehn Tagen nach Belastungsinfektion konnte kein signifikanter Unterschied zwischen den beiden Gruppen detektiert werden.

In der Woche $2 \mathrm{kam}$ es in den Kontrollen zu einem starken Abfall dieser Population auf $60 \%$ des Präinfektionswertes, wohingegen der Anteil in den Impflingen nur auf $90 \%$ des Präinfektionswertes sank. Bis zur vierten Woche nach Infektion stieg der Anteil der Gedächtniszellen in den Kontrollen auf 78\%. In den Impflingen lag der Anteil der $\mathrm{CD}^{+} 95^{+}$Gedächtniszellen dagegen zu diesem Zeitpunkt oberhalb des Präinfektionswertes bei $118 \%$.

In den Wochen 2 und 4 nach Belastungsinfektion war der Anteil der Gedächtniszellpopulation in den Kontrolltieren signifikant niedriger als in den Impflingen. Im weiteren Verlauf der Infektion wurden keine weiteren signifikanten Unterschiede zwischen den beiden Gruppen detektiert. 


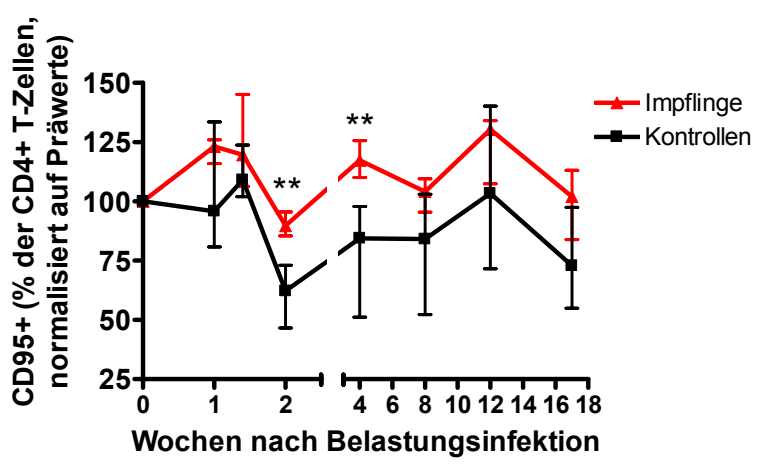

Abb. 3.41: Anteil der CD4 ${ }^{+} 95^{+} \mathrm{T}$-Lymphozyten an den Gesamtlymphozyten im Zeitverlauf im Blut der Versuchstiere nach Belastungsinfektion

Die Abbildung zeigt die Veränderungen des prozentualen Anteils der $\mathrm{CD} 4^{+} 95^{+}$T-Lymphozyten im Zeitverlauf des Experiments in den zwei Versuchsgruppen. Die Linien geben den Median der jeweiligen Gruppe wieder, die Fehlerbalken zeigen den Interquartilabstand $I_{50}$.

Mit den Sternen sind signifikante Unterschiede nach dem Mann-Whitney-Test zwischen den Gruppen gekennzeichnet $\left({ }^{* *} p<0,01\right)$.

Der Vergleich des mittleren Anteils der zentralen $\mathrm{CD}^{+}$Gedächtniszellen $\left(\mathrm{CD} 4^{+} \mathrm{TCM}\right)$ zwischen den beiden Gruppen ergab signifikante Unterschiede in den Wochen 2 und 4 nach Infektion (Abb. 3.42 A).

In beiden Gruppen kam es in der Woche 2 nach Infektion zu einem Verlust dieser Population, wobei der Verlust in den Kontrollen signifikant stärker war als in den Impflingen. Der weitere Infektionsverlauf war in beiden Gruppen ähnlich, wobei der Anteil der Gedächtniszellen in den Impflingen in der 4. Woche nach Infektion signifikant höher lag als in den Kontrollen. Ab der 8. Woche nach Infektion gab es keine weiteren signifikanten Unterschiede zwischen den beiden Gruppen.

Die mittleren Anteile der $\mathrm{CD}^{+}$Effektorgedächtniszellen wiesen nach Belastungsinfektion keine Unterschiede zwischen den Impflingen und den Kontrollen auf (Daten nicht gezeigt).

Der Vergleich des mittleren Anteils der $\mathrm{CD}^{+}$zentralen Gedächtniszellen $\left(\mathrm{CD} 8^{+} \mathrm{TCM}\right)$ ergab eine signifikante Erhöhung dieser Population in der Woche 2 nach Belastungsinfektion in den Impflingen im Vergleich zu den Kontrollen (Abb. 3.42 B). Im weiteren Verlauf der Infektion ließen sich jedoch keine signifikanten Unterschiede nachweisen. 
A)

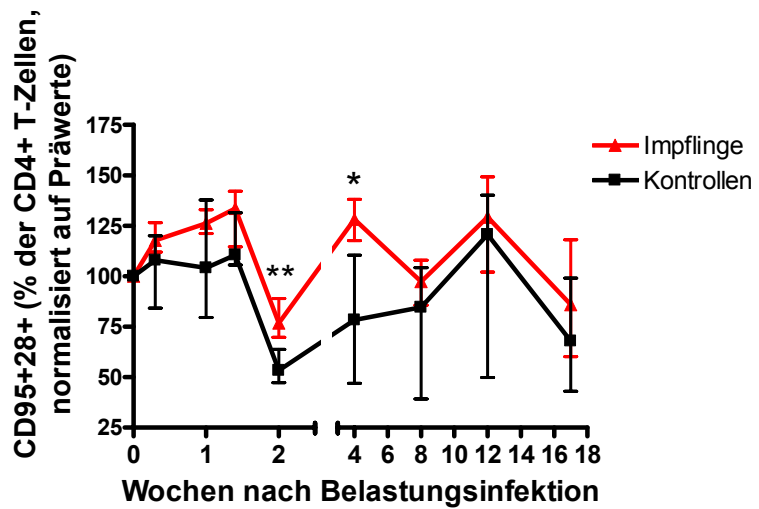

B)

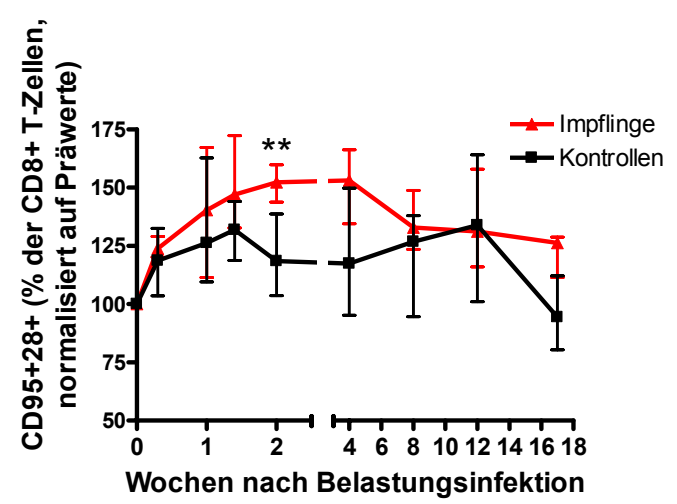

Abb. 3.42: Anteil der $\mathrm{CD}^{+} 95^{+} 28^{+}$und der $\mathrm{CD}^{+} 95^{+} 28^{+}$T-Lymphozyten an den Gesamtlymphozyten im Zeitverlauf im Blut der Versuchstiere nach Belastungsinfektion Die Abbildung zeigt die Veränderungen des prozentualen Anteils der $\mathrm{CD}^{+} 95^{+} 28^{+}(\mathrm{A})$ T-Lymphozyten und $\mathrm{CD}^{+} 95^{+} 28^{+}$(B) T-Lymphozyten im Zeitverlauf des Experiments in den zwei Versuchsgruppen. Die Linien geben den Median der jeweiligen Gruppe wieder, die Fehlerbalken zeigen den Interquartilabstand $I_{50}$.

Mit den Sternen sind signifikante Unterschiede nach dem Mann-Whitney-Test zwischen den Gruppen gekennzeichnet $\left({ }^{*} p<0,05 ;{ }^{* *} p<0,01\right)$.

\subsubsection{Bestimmung der Anzahl IFNy-sezernierender SIV-spezifischer} T-Zellen nach intravenöser Applikation von SIVmac251 mittels ELISPOT-Technik

Zum Zeitpunkt der Belastungsinfektion war in der Kontrollgruppe eine unspezifische Reaktivität nach Gag-Stimulation messbar (Abb. 3.43 A und B). Im Vergleich mit den Impflingen war kein signifikanter Unterschied nachweisbar.

Zehn Tage nach Belastungsinfektion (Abb. $3.43 \mathrm{C}$ ) war die Anzahl von IFNy-sezernierenden Lymphozyten nach SIV-Gag-Stimulation in den Impflingen im Vergleich zu den Kontrollen hochsignifikant erhöht, was eindeutig als anamnestische Immunantwort einzustufen ist. In den Kontrolltieren war eine Primärantwort erst nach vier Wochen messbar war. Im weiteren Verlauf bestanden keine signifikanten Unterschiede. 
A)

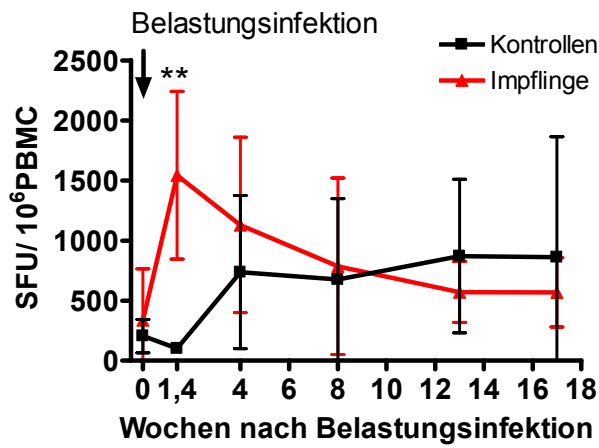

B)

C)
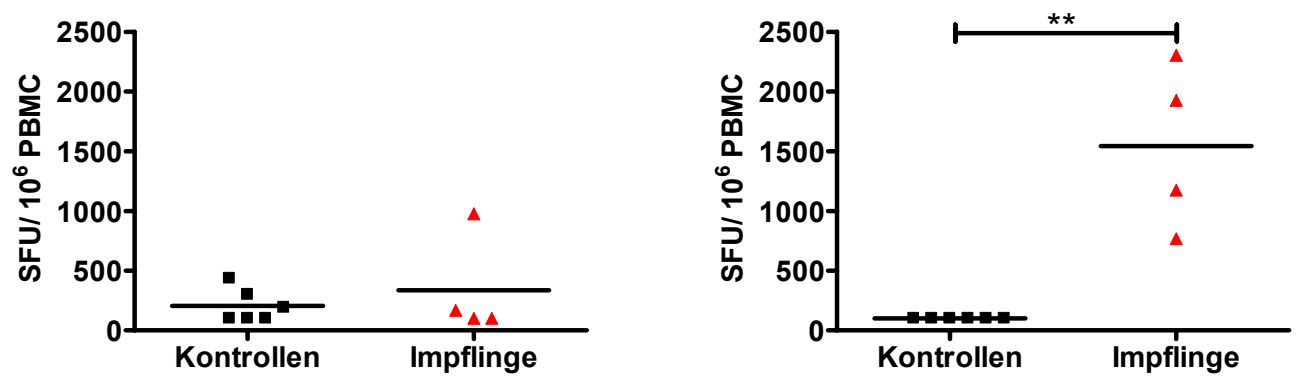

Abb. 3.43: Anteil IFNy-sezernierender PBMC in den zwei Versuchsgruppen nach GagStimulation in der dritten Versuchsreihe

Auf der Ordinate ist die Anzahl der SFU pro $10^{6}$ PBMC dargestellt. Die Abzisse zeigt in A die Wochen nach Belastungsinfektion und in $B$ und $C$ die Gruppen dieser Versuchsreihe.

Teil A zeigt die Anzahl der SFU pro $10^{6}$ PBMC im Zeitverlauf des Experiments. Teil B zeigt den Zeitpunkt der Belastungsinfektion mit SIVmac251 und Teil C zeigt die Anzahl SFU am Tag 10 nach Belastungsinfektion.

Mit den Querbalken und Sternen sind signifikante Unterschiede nach dem Mann-Whitney-Test zwischen den Gruppen gekennzeichnet $\left({ }^{* *} p<0,01\right)$.

\subsubsection{Vergleich des Nachweises von SIV-spezifischen T-Zellen mit Hilfe der ELISPOT-Technik und der Technik der intrazellulären Zytokinfärbung nach Gag-Stimulation in der dritten Versuchsreihe}

Auch in der dritten Versuchsreihe wurden IFNY-sezernierende T-Lymphozyten mit der Methode des ELISPOT und des ICS parallel bestimmt.

Die Abbildung 3.44 zeigt den Vergleich der beiden Methoden nach Gag-Stimulation in den Impflingen.

Alle vier Impflinge wiesen bereits 10 Tage nach Belastungsinfektion einen Anstieg der IFNy-sezernierenden T-Zellen auf. Bei drei der vier Tiere stellte dieser Zeitpunkt das Maximum der IFNy-Freisetzung dar. Die Ergebnisse des ICS zeigten, dass ein Großteil der aktivierten Zellen aus CD8 ${ }^{+}$Zellen bestand, während nur bei zwei Tieren schwache $\mathrm{CD}^{+}$Reaktivitäten messbar waren. Eine Besonderheit bildete das Tier 12056 mit einem Anteil von mehr als 15\% $\mathrm{CD}^{+}$T-Lymphozyten, die nach Gag-Stimulation IFNy bildeten. Neben dieser 
$\mathrm{CD}^{+}$Antwort ließen sich zusätzlich $\mathrm{CD} 4^{+}$T-Lymphozyten, die IFNy bildeten, nachweisen.

Im weiteren Verlauf der Infektion kam es in allen Tieren zu einem Abfall der Reaktivität, die jedoch auch im späteren Verlauf hauptsächlich durch die Aktivierung von $\mathrm{CD} 8^{+} \mathrm{T}$-Lymphozyten gekennzeichnet war.

Die hohen anamnestischen $\mathrm{CD}^{+}$-Antworten schützten die Impflinge jedoch nicht vor den hohen Viruslasten in der akuten Phase der Infektion.

2219

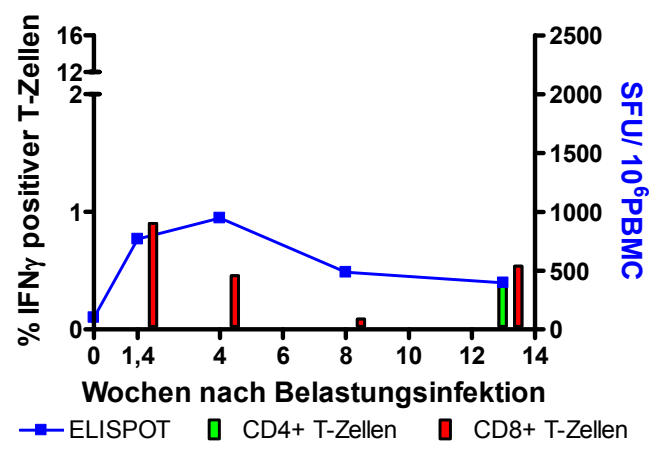

12056

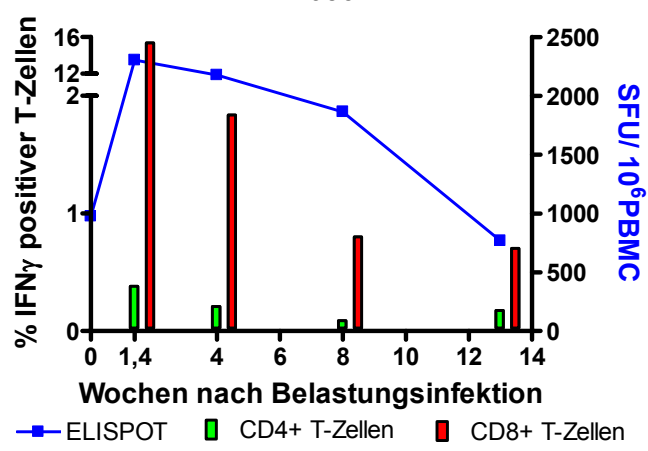

2250

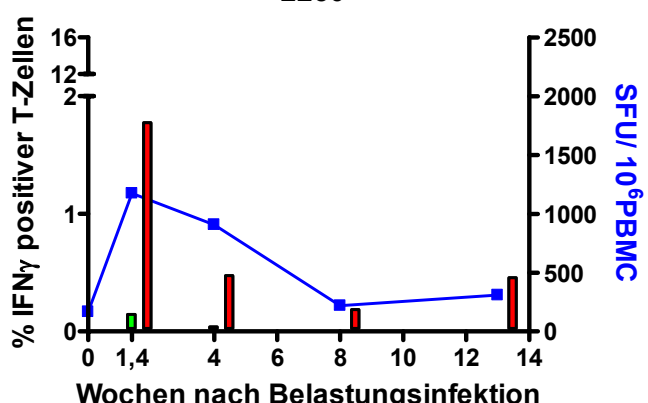

$\rightarrow$ ELISPOT a CD4+ T-Zellen a CD8+ T-Zellen

13258

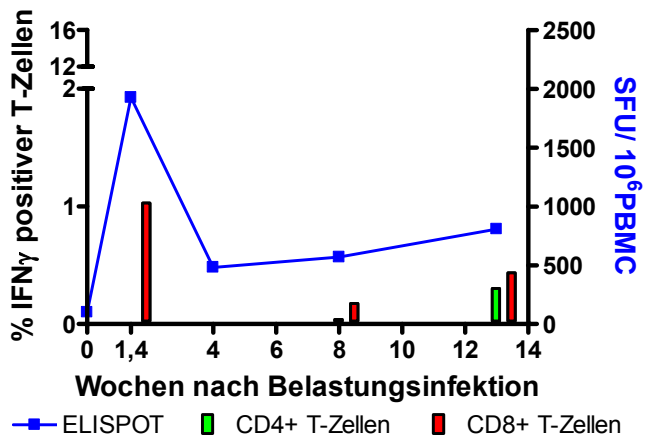

Abb. 3.44: Vergleich der ELISPOT- und ICS-Ergebnisse der Impflinge nach GagStimulation im Zeitverlauf nach Belastungsinfektion in der dritten Versuchsreihe

Die Graphen zeigen die Ergebnisse des ICS und des ELISPOT der vier Impflinge nach GagStimulation in der dritten Versuchsreihe. Auf der Abszisse sind jeweils die Wochen nach der Belastungsinfektion dargestellt. Auf der linken Ordinate ist der prozentuale Anteil IFNy-positiver T-Zellen des ICS, auf der rechten Ordinate die Anzahl IFNy-produzierender Zellen pro $10^{6}$ PBMC angegeben.

In der Abbildung 3.45 ist der Vergleich der ELISPOT-Technik und des ICS in den Kontrolltieren der dritten Versuchsreihe dargestellt. Hieraus wird deutlich, dass die Aktivierung von IFNY-sezernierenden T-Zellen in den Kontrollen im Vergleich zu den Impflingen deutlich schwächer ausgeprägt war.

In zwei Tieren (2192 und 13262) waren nahezu keine IFNY-sezernierenden T-Zellen vorhanden. Nur die Tiere 12538 und 13260 wiesen einen mit den 
Impflingen vergleichbaren Anteil an IFNy-sezernierenden T-Lymphozyten auf, dies jedoch erst in Woche 4.

Die Auswertung der ICS-Ergebnisse ergab, dass der Anteil der IFNy ${ }^{+} \mathrm{T}$-Zellen in den Kontrolltieren geringer war als in den Impflingen. In drei der sechs Tiere (2192, 13257 und 13260) war am Tag 10 nach Belastungsinfektion eine geringe Aktivierung von $\mathrm{CD}^{+}$und $\mathrm{CD} 8^{+}$T-Lymphozyten nachweisbar. Mit Hilfe des ELISPOT konnte zu diesem Zeitpunkt jedoch kein freigesetztes IFNy nachgewiesen werden. Im weiteren Verlauf zeigte sich, dass die starke Antwort auf Gag-Stimulation in den Tieren 12538 und 13260 durch CD8 ${ }^{+}$ T-Lymphozyten hervorgerufen wurde. Als einziges Tier wies das Tier 13257 vier Wochen nach Belastungsinfektion sowohl eine Antwort von $\mathrm{CD}^{+}$als auch von $\mathrm{CD}^{+}$T-Lymphozyten auf.

Im weiteren Verlauf des Experiments bis zur Woche 13 nach Belastungsinfektion blieb der Anteil der IFNY-sezernierenden T-Zellen auf dem Niveau der Woche 4 nach Belastungsinfektion. 
2192

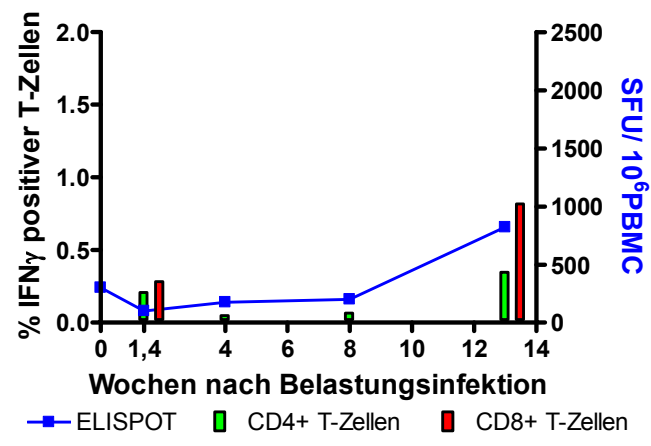

12538

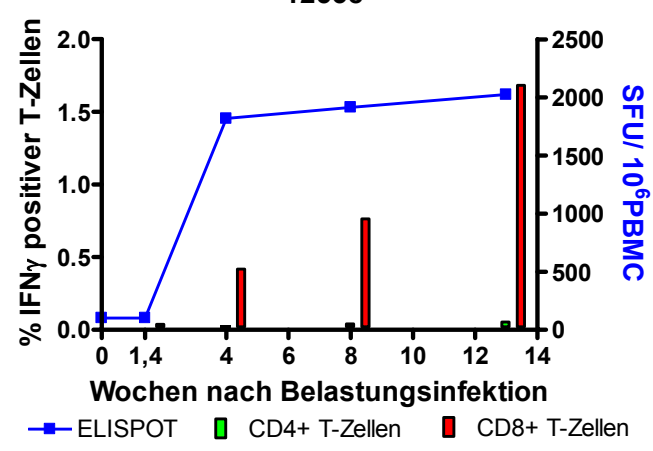

13260

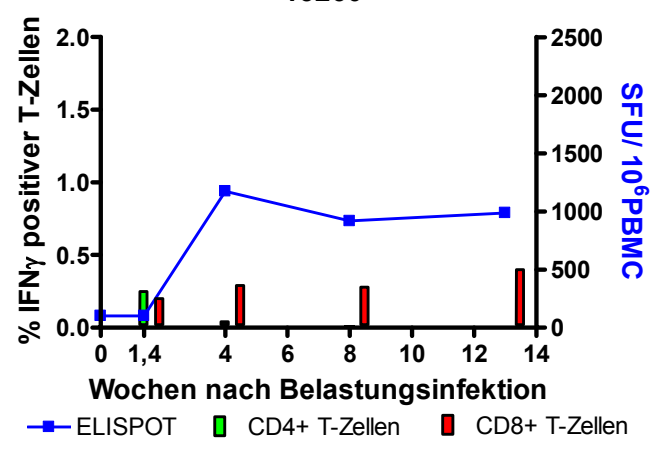

2233

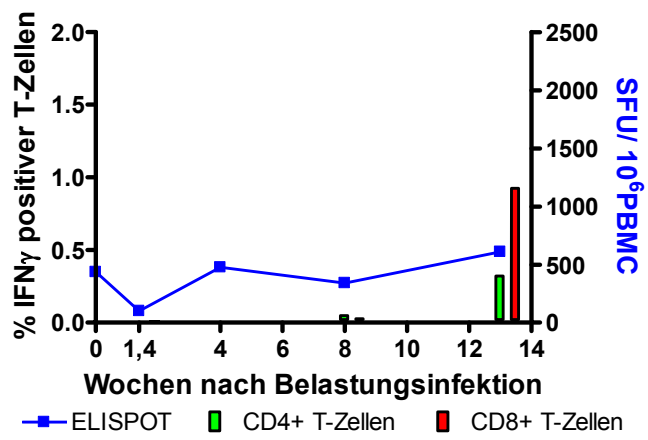

13257

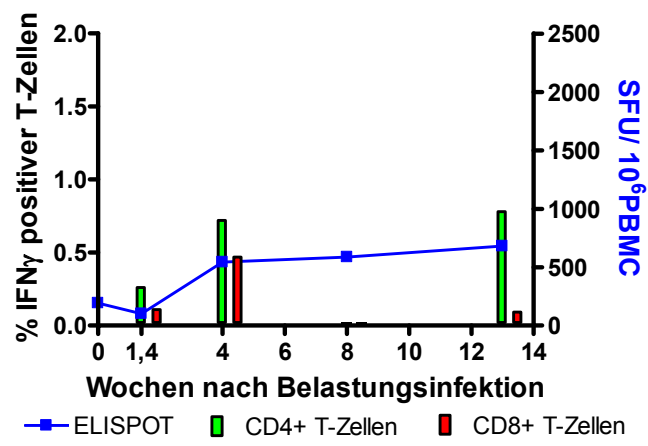

13262

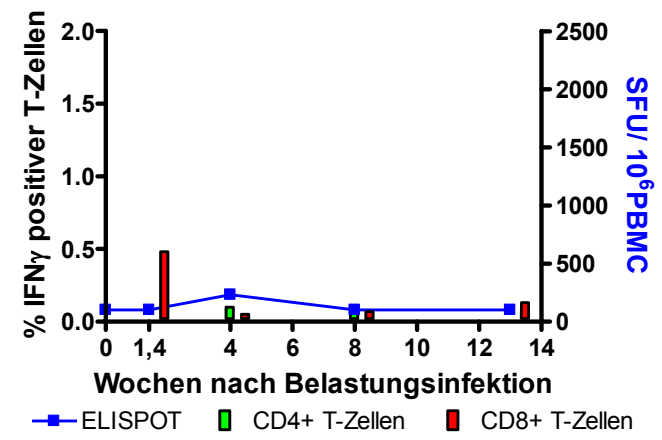

Abb. 3.45: Vergleich der ELISPOT- und ICS-Ergebnisse der Kontrollen nach GagStimulation im Zeitverlauf nach Belastungsinfektion in der dritten Versuchsreihe

Die Graphen zeigen die Ergebnisse des ICS und des ELISPOT der sechs Kontrolltiere nach Gag-Stimulation in der dritten Versuchsreihe. Auf der Abszisse sind jeweils die Wochen nach der Belastungsinfektion dargestellt. Auf der linken Ordinate ist der prozentuale Anteil IFNYpositiver T-Zellen des ICS, auf der rechten Ordinate die Anzahl IFNY-produzierender Zellen pro $10^{6}$ PBMC angegeben. 
Der Vergleich der mittleren ELISPOT- und ICS-Ergebnisse (Abb. 3.46) ergab, dass in den Impflingen im frühen Zeitraum nach Belastungsinfektion deutlich mehr IFNy nach Gag-Stimulation freigesetzt wurde als in den Kontrolltieren. Diese Freisetzung erfolgte primär von $\mathrm{CD} 8^{+} \mathrm{T}$-Lymphozyten.

Es zeigte sich weiterhin, dass die Freisetzung von IFNy in den Impflingen bereits zehn Tage nach Belastungsinfektion ein Maximum aufwies, während bei den Kontrollen zu diesem frühen Zeitpunkt nahezu keine IFNy-Freisetzung nach Gag-Stimulation erfolgte.

Die Korrelationsanalyse zum direkten Vergleich der beiden Techniken ergab auch in dieser Versuchsreihe eine signifikant positive Korrelation der ELISPOTund ICS-Ergebnisse. Die Korrelationskoeffizienten lagen für den gesamten Untersuchungszeitraum dieser Versuchsreihe zwischen 0,67 und 0,95.
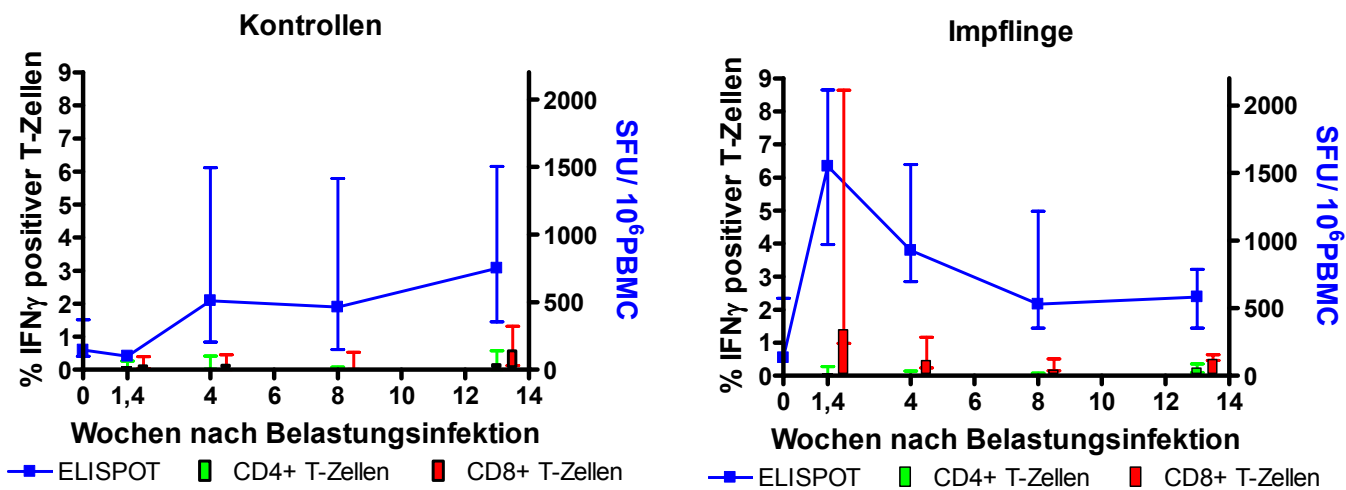

Abb. 3.46: Vergleich der medianen ELISPOT- und ICS-Ergebnisse nach Gag-Stimulation im Zeitverlauf nach Belastungsinfektion in der dritten Versuchsreihe

Die Graphen zeigen die medianen Ergebnisse des ICS und des ELISPOT der Impflinge und der Kontrolltiere nach Gag-Stimulation in der dritten Versuchsreihe. Die Fehlerbalken zeigen den Median und den Interquartilabstand $I_{50}$. Auf der Abszisse sind jeweils die Wochen nach der Belastungsinfektion dargestellt. Auf der linken Ordinate ist der prozentuale Anteil der IFNYpositiven T-Zellen des ICS, auf der rechten Ordinate die Anzahl der IFNY-produzierenden Zellen pro $10^{6} \mathrm{PBMC}$ angegeben. 


\subsubsection{Kinetik von polyfunktionalen SIV-spezifischen T-Lymphozyten nach intravenöser Applikation von SIVmac251}

Nach HIV- oder SIV-Infektion verändert sich innerhalb von drei Wochen die Zytokinsekretion von Gedächtnis-T-Zellen. Sowohl $\mathrm{CD}^{+}$als auch CD8 ${ }^{+}$ polyfunktionale T-Lymphozyten bilden nach antigener Stimulation vermehrt IFNy (Betts et al., 2005; Mattapallil et al., 2006).

Daher wurden die Tiere der dritten Versuchsreihe nach Belastungsinfektion auf die Anwesenheit von polyfunktionalen T-Zellen untersucht. Zu diesem Zweck wurden die drei Zytokine IFNy, TNFa und IL2 gleichzeitig gefärbt. Die daraus resultierenden sieben funktionalen T-Zellsubpopulationen wurden in den CD4 ${ }^{+}$ und $\mathrm{CD}^{+}{ }^{\mathrm{T}}$-Lymphozyten $\mathrm{zu}$ verschiedenen Zeitpunkten untersucht. Die Abbildungen 3.47 und 3.48 geben die Ergebnisse dieser Untersuchungen der $\mathrm{CD}^{+}$und $\mathrm{CD}^{+}$T-Lymphozyten in den einzelnen Tieren wieder.

Eine CD4 ${ }^{+}$-Antwort war in der frühen Phase der Infektion (Tag 10) nur in zwei der vier Impflinge nachweisbar (Abb. 3.47 A), von denen im Tier 12056 auch polyfunktionale Zellen nachweisbar waren. In den Kontrollen waren in drei Tieren Zytokin-positive CD4 ${ }^{+}$T-Zellen nachweisbar (Abb. 3.47 B), wobei in zwei Tieren polyfunktionale Zellen messbar waren.

Vier Wochen nach Belastungsinfektion war in zwei der vier Impflinge eine sehr geringe $\mathrm{CD}^{+}$-Antwort nachweisbar (Abb. $3.47 \mathrm{C}$ ). In der Kontrollgruppe ließ sich im Tier 13257 eine einfach positive Zytokinpopulationen detektieren (Abb. $3.47 \mathrm{D})$.

Acht Wochen nach Belastungsinfektion ließen sich weder in den Impflingen noch in den Kontrollen deutliche CD4 ${ }^{+}$T-Lymphozytenpopulationen mit einfachoder mehrfach-positiver Zytokinsekretion nachweisen (Abb. 3.47 E und F).

In der Woche 13 nach Belastungsinfektion waren in drei der vier Impflinge erneut Zytokin-positive $\mathrm{CD}^{+}$T-Zellpopulationen nach Gag-Stimulation vorhanden (Abb. 3.47 G). In den Kontrolltieren zeigten vier der sechs Tiere eine CD4 ${ }^{+}$-Antwort (Abb. $\left.3.47 \mathrm{H}\right)$. 
A)

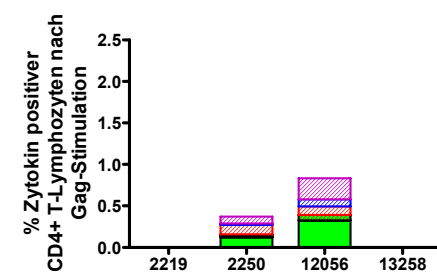

C)

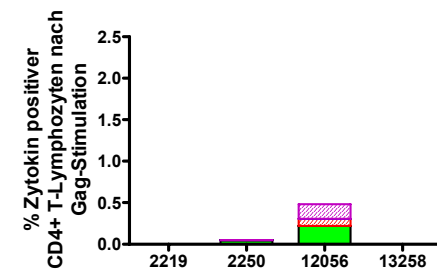

E)

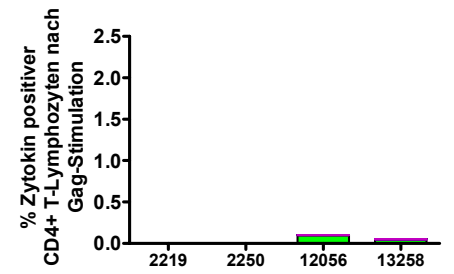

G)

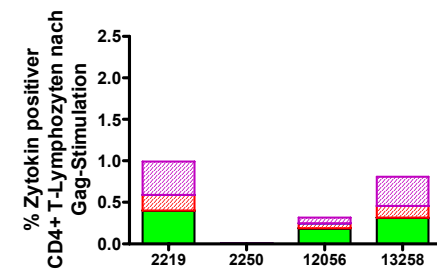

B)

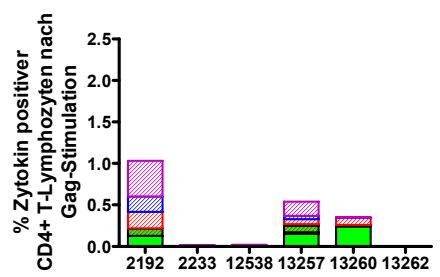

$\square \mathrm{CD} 4+/ / \mathrm{FNg}+$

$\square \mathrm{CD} 4+/ / \mathrm{FNg}+\mathrm{IL2+}$

$\square \mathrm{CD} 4+/ \mathrm{IFNg}+\mathrm{TNFa}^{+}$

$\square \mathrm{CD} 4+/ / \mathrm{NFg}+\mathrm{IL2}+\mathrm{TNFa}+$

$\mathrm{CD} 4+/ / \mathrm{L} 2+$

酐 $+/ \mathrm{LL} 2+\mathrm{TNFa}$

CD4+/IL2+TNFa+

CD4+/TNFa+

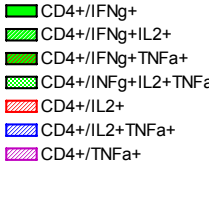

D)
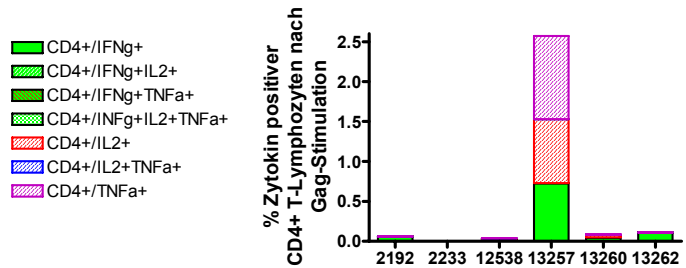

$\square \mathrm{CD} 4+/ / \mathrm{FNg}+$

$\square \mathrm{CD} 4+/ / \mathrm{FNg}+\mathrm{IL2}+$

$\mathrm{CD} 4+/ \mathrm{IFNg}+\mathrm{TNFa}+$

$\square \mathrm{CD} 4+/ / \mathrm{NFg}+\mathrm{IL2} 2+\mathrm{TNFa}+$

CD4+//L2+

CD4+//L2+TNFa+

F)
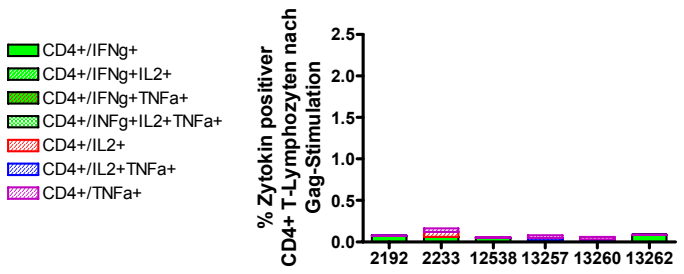

$\square \mathrm{CD} 4+/ \mathrm{FNg}+$

$\square \mathrm{CD} 4+/ \mathrm{IFN}+\mathrm{IL2}+$ $\square \mathrm{CD} 4+/ / \mathrm{FNg}+\mathrm{TNFa}+$

$\square \mathrm{CD} 4+/ / \mathrm{NFg}+$

CD4+//L2+

CD4+/TNFa+

2192223312538132571326013262

H)

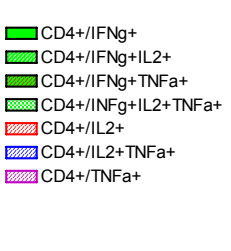

$\square \mathrm{CD} 4+/ \mathrm{FNg}+$

CD4+/IFNg+IL2+

CD4+//FNg+TNFa+

$\square \mathrm{CD} 4+/ \mathrm{INFg}+\mathrm{LL} 2+\mathrm{TNFa}$

$\square \mathrm{CD} 4+/ \mathrm{IL} 2+$

CD4+//L2+TNFa+

CD4+/TNFa+

Abb. 3.47: Polyfunktionale CD4 ${ }^{+}$T-Lymphozyten nach Gag-Stimulation in den Impflingen und Kontrollen der dritten Versuchsreihe nach Belastungsinfektion

Die linke Spalte zeigt den Anteil der $\mathrm{CD}^{+}{ }^{+}$T-Lymphozyten in den Impflingen, die rechte Spalte den Anteil der CD4 ${ }^{+}$T-Lymphozyten in den Kontrollen.

Auf der Abszisse sind die Tiernummern, auf der Ordinate der prozentuale Anteil der Zytokinpositiven T-Lymphzyten angegeben.

Die Legende zeigt die sieben möglichen polyfunktionalen T-Zellsubpopulationen, wobei mit einer grünen Hintergrundfarbe die T-Zellen dargestellt sind, die das Zytokin IFNy einfach oder in Kombination mit TNFa und/ oder IL2 exprimieren.
A und B: 10 Tage nach Infektion
C und D: Vier Wochen nach Infektion
E und F: Acht Wochen nach Infektion
G und H: 13 Wochen nach Infektion 
In den Impflingen war 10 Tage nach Infektion eine starke CD8 ${ }^{+}$T-Zellantwort im Vergleich zu den Kontrollen zu beobachten (Abb. 3.48 A). Dabei wies das Tier 12056 eine massiv erhöhte Antwort mit mehr als 12\% IFNy-positiven CD8 ${ }^{+}$ T-Lymphozyten auf. In drei der vier Tiere konnte zudem eine polyfunktionale Population mit IFNy und TNFa doppelt-positiven T-Lymphozyten gemessen werden. Hingegen waren in den Kontrollen zu diesem Zeitpunkt nur sehr wenige Zytokin-positive Zellen nachweisbar (Abb. 3.48 B).

Vier Wochen nach Belastungsinfektion war eine starke $\mathrm{CD} 8^{+} \mathrm{T}$-Zellantwort in drei von vier Impflingen nachweisbar (Abb. $3.48 \mathrm{C}$ ). Polyfunktionale Zellen ließen sich zu diesem Zeitpunkt jedoch nicht messen.

In den Kontrolltieren war in drei der sechs Tiere eine geringe $\mathrm{CD}^{+}$ T-Zellantwort auf die Gag-Stimulation messbar (Abb. 3.48 D).

In den Impflingen waren acht Wochen nach Belastungsinfektion in allen vier Tieren $\mathrm{CD}^{+} \mathrm{IFNY}^{+}$T-Zellpopulationen vorhanden (Abb. $3.48 \mathrm{E}$ ). In den Kontrollen ließen sich in fünf der sechs Tiere Zytokine nachweisen, wobei nur in drei Tieren IFNY ${ }^{+}$T-Zellen gemessen werden konnten (Abb. 3.48 F).

In den Impflingen war in der Woche 13 in allen Tieren eine $\mathrm{CD}^{+}{ }^{+} \mathrm{T}$-Zellantwort nachweisbar (Abb. $3.48 \mathrm{G}$ ). Es zeigte sich jedoch, dass nur in einem der vier Tiere (13258) eine polyfunktionale Population messbar war. In den drei anderen Tieren waren jeweils zwei einfach-positive Zytokinpopulationen nachweisbar.

In den Kontrolltieren war zu diesem Zeitpunkt in jedem Tier eine einfach-positive IFNy $\mathrm{CD}^{+}$T-Zellpopulation nachweisbar. In drei der sechs Tiere konnten zusätzlich auch weitere einfach-positive TNFa und IL2 Populationen gemessen werden (Abb. $3.48 \mathrm{H}$ ). 
A)

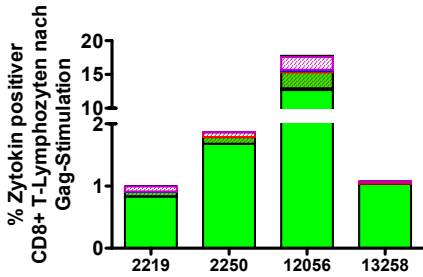

C)

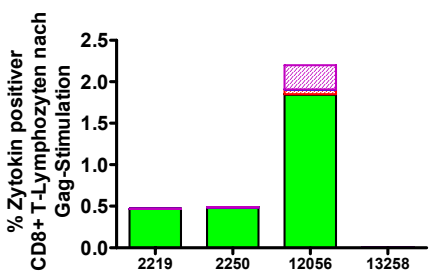

E)

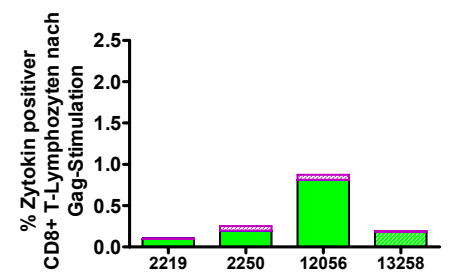

G)

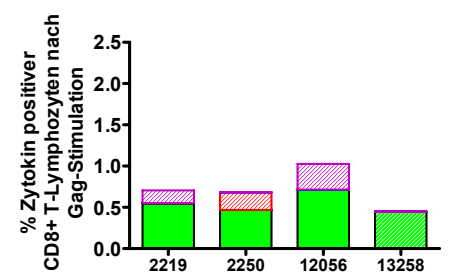

B)
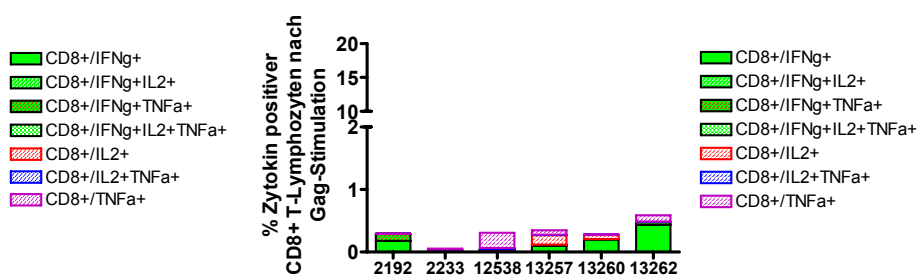

D)
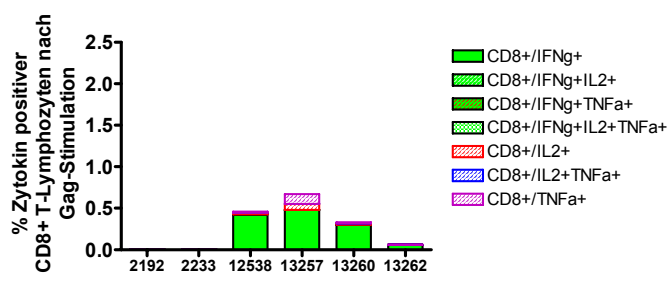

F)
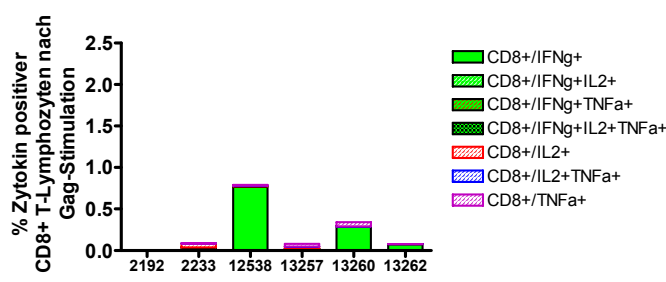

H)

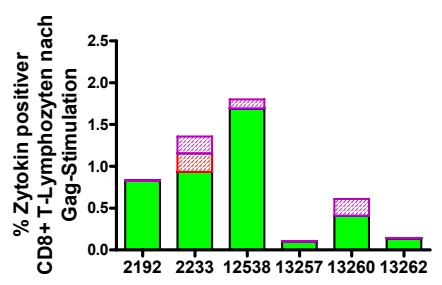

$\square \mathrm{CD} 8+/ / \mathrm{FNg}+$ $\square \mathrm{CD8}+/ / \mathrm{FNg}+\mathrm{LL} 2+$ $\square \mathrm{CD} 8+/ / \mathrm{FNg}+\mathrm{TNFa}^{+}$ $\square \mathrm{CD} 8+/ / \mathrm{FNg}+\mathrm{IL2}+\mathrm{TNFa}+$ CD8+//L2+ CD8+//L2+TNFa+ CD8+/TNFa+

Abb. 3.48: Polyfunktionale CD8 ${ }^{+}$T-Lymphozyten nach Gag-Stimulation in den Impflingen und Kontrollen der dritten Versuchsreihe nach Belastungsinfektion

Die linke Spalte zeigt den Anteil der CD8 ${ }^{+}$T-Lymphozyten in den Impflingen, die rechte Spalte den Anteil der CD8 ${ }^{+}$T-Lymphozyten in den Kontrollen.

Auf der Abszisse sind die Tiernummern, auf der Ordinate der prozentuale Anteil der Zytokinpositiven T-Lymphzyten angegeben.

Die Legende zeigt die sieben möglichen polyfunktionalen T-Zellsubpopulationen, wobei mit einer grünen Hintergrundfarbe die T-Zellen dargestellt sind, die das Zytokin IFNy einfach oder in Kombination mit TNFa und/ oder IL2 exprimieren.

A und B: 10 Tage nach Infektion

C und D: Vier Wochen nach Infektion

E und F: Acht Wochen nach Infektion

G und H: 13 Wochen nach Infektion 


\subsubsection{Bestimmung der Kinetik von proliferierenden Lymphozyten nach intravenöser Applikation von SIVmac251}

Bei dem Molekül Ki67 handelt es sich um ein Protein, das zu Beginn des Zellzyklus intranukleär gebildet wird (Gerdes et al., 1984). Das Protein lässt sich nach der Permeabilisierung der Zell- und der Kernmembran intranukleär mit Antikörpern färben (Bahbouhi et al., 2004).

Durch diese Färbung können proliferierende Zellen nachgewiesen werden. Auf eine direkte Zellteilung lässt sich bei dieser Methode allerdings nicht schließen. In der dritten Versuchsreihe sollte nachgewiesen werden, ob die Impfung einen Einfluss auf die Expression des Proliferationsmarkers Ki67 und damit auf die Proliferation von T-Lymphozyten hat.

Die Ergebnisse dieser Untersuchung sind in der Abbildung 3.49 dargestellt. Die Expression von Ki67 in den $\mathrm{CD}^{+}{ }^{+}$T-Lymphozyten war in den Impflingen im Vergleich zu den Kontrollen zwei Wochen nach Belastungsinfektion signifikant erhöht.

In den $\mathrm{CD}^{+}$T-Zellen war eine signifikant erhöhte Ki67 Expression bereits am Tag 10 nach Infektion nachweisbar. Zwei Wochen nach Infektion war der Unterschied zwischen Impflingen und Kontrollen nicht signifikant. In der Woche 4 nach Infektion war in den $\mathrm{CD}^{+} \mathrm{T}$-Zellen der Impflinge wiederum eine signifikant höhere Ki67-Expression nachzuweisen.

Im weiteren Verlauf der Infektion bestand kein Unterschied zwischen den Impflingen und den Kontrolltieren.

A)

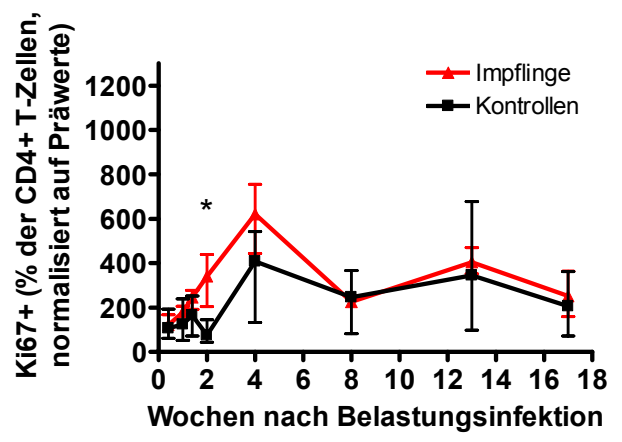

B)

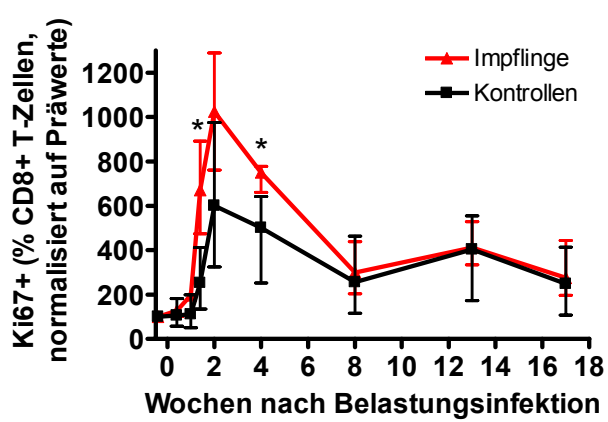

Abb. 3.49: Expression von Ki67 in den T-Lymphozyten im Zeitverlauf in den Impflingen und Kontrollen

Die Abbildung zeigt die Veränderungen der Expression von Ki67 in $\mathrm{CD}^{+}(\mathrm{A})$ und $\mathrm{CD} 8^{+}(\mathrm{B})$ T-Lymphozyten im Zeitverlauf des Experiments. Die Linien geben den Median der jeweiligen Gruppe wieder, die Fehlerbalken zeigen den Interquartilabstand $\mathrm{I}_{50}$.

Mit den Sternen sind signifikante Unterschiede nach dem Mann-Whitney-Test zwischen den Gruppen gekennzeichnet ( $\left.{ }^{*} p<0,05\right)$. 


\subsubsection{Bestimmung der Anzahl und Kinetik von SIV-spezifischen} Lymphozyten im Immunisierungszeitraum und nach intravenöser Applikation von SIVmac251 mit Hilfe der Tetramer-Technik

Die Abbildung 3.50 zeigt den prozentualen Anteil der CM9-Tetramer-positiven $\mathrm{CD}^{+}$T-Zellen im Zeitverlauf des Experiments. Der Anteil der CM9-Tetramerpositiven Zellen wurde erstmals zwei Wochen nach Applikation der ersten Adenovirusimmunisierung bestimmt.

In beiden MamuA*01-positiven Tieren der Impfgruppe war eine CM9-Tetramer-positive T-Zellpopulation vorhanden. In dem Tier 2219 lag der Anteil dieser Population nur bei 0,4\%. In dem Tier 2250 erreichte diese Population mit 7,5\% den Wert von publizierten Daten (Allen et al., 2000). Trotz der zweiten Adenovirusimmunisierung sank der Anteil der CM9-Tetramerpositiven T-Lymphozyten in beiden Tieren bis zum Zeitpunkt der Belastungsinfektion kontinuierlich ab.

Das MamuA*01-positive Kontrolltier 12538 wies im Immunisierungszeitraum keine CM9-spezifischen T-Lymphozyten auf.

Nach der Belastungsinfektion stieg der Anteil der CM9-Tetramer-positiven T-Lymphozyten in den Impflingen ab dem Tag 10 nach Infektion deutlich an. Ein Maximum war in beiden Tieren zwei Wochen nach Infektion erreicht. Im weiteren Verlauf des Experiments sank der Anteil der CM9-Tetramer-positiven $\mathrm{CD}^{+}{ }^{+}$T-Lymphozyten auf etwa $2 \%$.

In dem Kontrolltier 12538 kam es erst ab der zweiten Woche nach Belastungsinfektion zu einem Anstieg der CM9-Tetramer-positiven CD8 ${ }^{+}$ T-Lymphozyten. Ein erstes Maximum wurde in der Woche 4 mit 5\% CM9-positiven T-Lymphozyten erreicht. Im weiteren Verlauf kam es zu einem geringen Abfall gefolgt von einem weiteren Anstieg auf 6,9\% CM9-Tetramerpositive T-Zellen. 


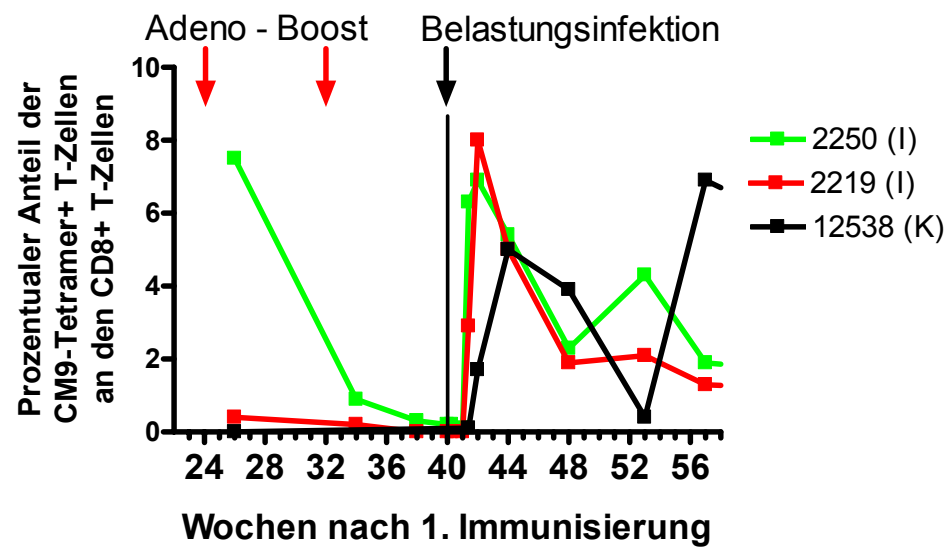

Abb. 3.50: Prozentualer Anteil der CM9-Tetramer ${ }^{+} \mathrm{CD}^{+}{ }^{+}$T-Lymphozyten

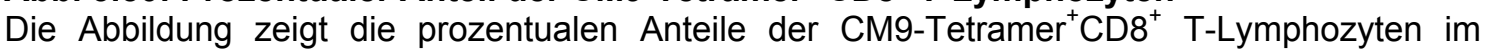
Zeitverlauf in den drei MamuA*01-positiven Tieren dieser Versuchsreihe. Die Abzisse zeigt die Wochen nach der 1. Immunisierung der Tiere, die Ordinate den relativen Anteil der CM9Tetramer-positiven T-Zellen an den CD8 ${ }^{+}$T-Lymphozyten. Mit den roten Pfeilen sind die beiden Zeitpunkte der Adenovirusimmunisierungen, mit dem schwarzen Pfeil und der Linie ist der Zeitpunkt der Belastungsinfektion gekennzeichnet.

Mit (I) sind die beiden Impflinge, mit (K) das Kontrolltier gekennzeichnet.

Die Veränderungen der relativen Anteile der CM9-Tetramer positiven CD8 ${ }^{+}$ T-Lymphozyten spiegelten sich auch in den absoluten Zellzahlen wider (Abbildung 3.51). Diese Daten wurden aus den relativen Anteilen der CM9-Tetramer-positiven $\mathrm{CD}^{+} \quad \mathrm{T}^{+}$-Lymphozyten und den Daten des Differentialblutbildes der Tiere berechnet. Hieraus ergaben sich die absoluten Zellzahlen pro Mikroliter Blut.

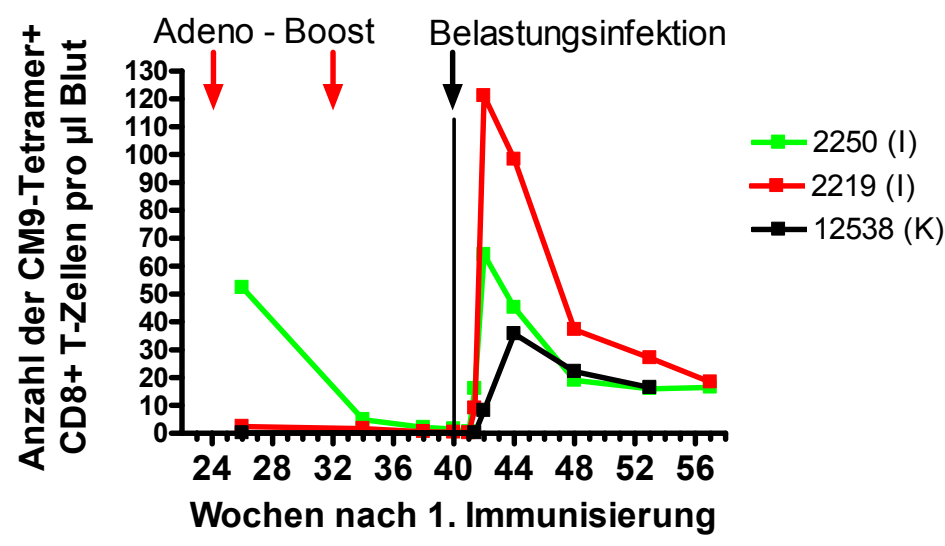

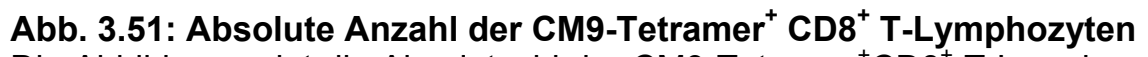

Die Abbildung zeigt die Absolutzahl der CM9-Tetramer ${ }^{+} \mathrm{CD}^{+}{ }^{+} \mathrm{T}$-Lymphozyten pro Mikroliter Blut der MamuA*01-positiven Tiere im Zeitverlauf der dritten Versuchsreihe. Die Abzisse zeigt die Wochen nach der 1 . Immunisierung der Tiere, die Ordinate die absolute Anzahl der CM9Tetramer-positiven T-Zellen. Mit den roten Pfeilen sind die beiden Zeitpunkte der Adenovirusimmunisierungen, mit dem schwarzen Pfeil und der Linie ist der Zeitpunkt der Belastungsinfektion gekennzeichnet.

Mit (I) sind die beiden Impflinge, mit (K) das Kontrolltier gekennzeichnet. 


\section{Diskussion}

Eine Wirksamkeitsprüfung von neuen HIV-Impfstoffen am Menschen ist nur in klinischen Studien der Phase III möglich, die mehrere Tausend Probanden aus Höchstrisikogruppen umfassen und mindestens drei Jahre dauern (Chow et al., 2002). Daher ist notwendig, die Immunogenität, Wirksamkeit und Sicherheit neuartiger präklinischer Impfstoffe und Darreichungsformen in relevanten Tiermodellen zu testen. Aufgrund der großen Ähnlichkeit zwischen HIV und SIV bezüglich ihrer genetischen Struktur, ihres Replikationszyklus und der hervorgerufenen Krankheitssymptome spielt das Rhesusaffenmodel hierfür eine herausragende Rolle (Desrosiers et al., 1995). In diesem Modell wurde in den letzten Jahren bereits eine Vielzahl von Impfstoffpräparationen getestet.

Ein Vakzineansatz besteht in der Induktion von neutralisierenden Antikörpern mit einer breiten Spezifität gegenüber HIV. Die Infusion von neutralisierenden Antikörpern gegen HIV kann Rhesusaffen vor einer mukosalen Infektion mit einem chimären HI-/SI-Virus (SHIV) schützen (Mascola et al., 2000). Selbst die Applikation von neutralisierenden Antikörpern sieben Tage nach SIVmac239Infektion vermittelt noch eine Reduktion der Peakvirämie (Yamamoto et al., 2007). Bei der Applikation von neutralisierenden Antikörpern nach Infektion kommt es jedoch durch virale Mutationen sehr schnell zu strukturellen Veränderungen des Virus, so dass neutralisierende Antikörper nicht weiter binden können (Richman et al., 2003; Gauduin et al., 1997). Dieser als „viraler Escape“ bezeichnete Prozess trägt dazu bei, dass ein Schutz vor Infektion nur durch das Vorhandensein von neutralisierenden Antikörpern zum Zeitpunkt der Infektion möglich sein kann.

Aufgrund der großen Variabilität des HIV-Hüllproteins und der komplexen Struktur der Oberflächenmoleküle gp120 und gp41 ist es äußerst schwierig, neutralisierende Antikörper zu generieren, die verschiedene HIV-Subtypen neutralisieren können (Moore et al., 1995). So konnten bislang mit keinem Impfstoffansatz breit neutralisierende Antikörper induziert werden, die einen dauerhaften Schutz vor HIV-Infektion bieten (Pantophlet et al., 2006; Desrosiers et al., 2004).

Aus diesen Gründen konzentrierte man sich auf die Entwicklung von Impfstoffpräparationen, die auf der Induktion von T-Zellimmunität basieren 
(Wilson et al., 2006; Schmitz et al., 1999; Jin et al., 1999; Pitcher et al., 1999). Mothe und Kollegen konnten zeigen, dass es in der akuten Phase der Infektion zur Entwicklung von virus-spezifischen $\mathrm{CD} 8^{+}$T-Lymphozyten kommt (Mothe et al., 2002).

Diese Art der Impfstoffentwicklung zur Induktion von virus-spezifischen T-Zellen wurde in der vorliegenden Arbeit im Detail untersucht.

Weitere Bereiche der Vakzineentwicklung gegen HIV- und SIV liegen in der Art der Impfstoffapplikation. Es wird postuliert, dass eine erfolgreiche HIV-Vakzine auch eine starke mukosale Immunantwort induzieren sollte, um das Virus an der mukosalen Eintrittspforte abzuwehren (Neutra et al., 2006). Für die Applikation von mukosalen Impfstoffen bieten neben den Tonsillen noch die Lunge, das Rektum und bei weiblichen Individuen das Vaginalgewebe einen möglichen Ort für Immunisierungen.

Eine orale Immunisierung mit multigenen Adenoviruskonstrukten und einer intramuskulären Auffrischungsimmunisierung mit SIV-gp120-Polypeptiden reduzierte die Viruslast in Rhesusaffen nach einer rektalen SIVmac251Infektion für mehr als sechs Monate (Patterson et al., 2004). Durch die Kombination von systemischer DNA-Immunisierung mit oraler und rektaler MVA-Immunisierung konnte nach intravenöser SHIV-Infektion die Viruslast über einen Zeitraum von sechs Monaten reduziert werden (Makitalo et al., 2004). Eine weitere Impfstrategie bestand aus mehrfachen DNABasisimmunisierungen und intradermaler sowie intrarektaler MVAAuffrischungsimpfung. Diese Impfstrategie reduzierte nach einer rektalen SIVmac239-Infektion die Virusbeladung im Blut nur in der akuten, jedoch nicht in der chronischen Phase der Infektion (Horton et al., 2002).

Diese genannten Untersuchungen zeigen, dass eine orale Applikation von HIV-Impfstoffen eine effektive und attraktive Impfroute darstellt, da sie einfach durchzuführen ist und auf den Einsatz von Injektionsnadeln verzichtet werden kann.

In der vorliegenden Arbeit sollten drei verschiedene Impfstoffpräparationen, die über unterschiedliche Routen appliziert wurden, auf ihre Immunogenität und Schutzwirkung untersucht werden. Ein weiterer Aspekt der Arbeit bestand in der Untersuchung der Immunpathogenese nach Belastungsinfektion mit SIV. 
Die erste Versuchsreihe wurde im Rahmen eines Gemeinschaftsprojektes mit der Pohang University of Science \& Technology, Republik Korea, durchgeführt.

In der zweiten Versuchsreihe wurden im Rahmen des EU-Forschungsprogramms MUVADEN (Mukosal Vaccines Against Human and Simian Immunodeficiency Viruses Based on Dendritic Cells) tonsillär applizierte virusähnliche Partikel (VLPs) und Adenoviruskonstrukte zur Immunisierung eingesetzt.

In der dritten Versuchsreihe sollte im Rahmen des EU-Forschungsprogramms TIPVAC (Explaining and Improving Efficacy of Targeted Immunodeficiency Virus-like Particle Vaccines against AIDS) die Immunogenität der VLPS durch Zugabe von Adjuvantien gesteigert und eine Kombination von systemischer und mukosaler Antigenverabreichung untersucht werden.

Bei den ersten beiden Versuchsreihen war es im Rahmen dieser Arbeit möglich, eine Untersuchung bis zu einem Zeitpunkt von mehr als 70 Wochen nach Belastungsinfektion durchzuführen. Die dritte Versuchsreihe konnte bis in die postakute Phase der Infektion (Woche 17 nach Infektion) verfolgt werden.

\subsection{Vergleich der drei „Prime-Boost“-Immunisierungsprotokolle}

Bei allen drei Versuchsreihen handelt es sich jeweils um ein heterologes „Prime-Boost“-Immunisierungsschema. Bei dieser Immunisierungsform erfolgt eine wiederholte Applikation des gleichen Antigens, das in verschiedenen Vektoren exprimiert wird. Durch den Kontakt mit dem ersten Vektor entwickelt sich eine primäre Immunantwort („Prime“) und durch Applikation des gleichen Antigens in anderer Form kommt es zu einer Verstärkung („Boost“) dieser Immunantwort. Ein anderer Begriff für diese Art der Immunisierung ist "heterologer Boost", um es von der traditionellen Methode des „homologen Boost" durch wiederholte Gabe von Tot-, Untereinheiten- oder Lebendimpfstoffen zu unterscheiden. Der Vorteil des "heterologen Boost“ liegt darin, dass bei dieser Applikationsform das Auftreten von vektorspezifischen Immunantworten reduziert wird. Zunächst erfolgt mit einem Vektorkonstrukt der "Prime“ zur Induktion einer primären Immunantwort. Sollte sich zusätzlich gegen den Vektor eine Immunantwort bilden, so hat diese Immunität auf die 
spätere Auffrischungsimpfung keinen negativen Einfluss, da der "Boost“ mit einem anderen Vektorkonstrukt erfolgt (Thorner et al., 2006).

Da es sich bei HIV und SIV um Retroviren handelt, die in das Genom des Wirts integrieren können, stellt die Gabe von lebend-attenuiertem Virus ein hohes Risiko für gesunde Menschen dar und wird daher kontrovers diskutiert. Die Entwicklung von präventiven Impfstoffen greift deshalb auf die Expression von strukturellen und regulatorischen Komponenten des HIV bzw. SIV durch sichere Vektoren zurück (Neeson et al., 2006; Someya et al., 2006; Suh et al., 2006; Makitalo et al., 2004). Derartige Vektoren ermöglichen es, HIV- bzw. SIVKomponenten in das Zytoplasma der Zielzellen zu transportieren, wo sie über den MHC-Klasse-I-Weg prozessiert und auf der Zelloberfläche präsentiert werden können.

Shiver und Kollegen konnten in Studien mit insgesamt 35 Rhesusaffen zeigen, dass eine Immunisierung mit SIV-Gag-DNA-Vektoren und einer Auffrischungsimpfung mit replikationsdefizientem SIV-Gag-Adenovirus oder eine alleinige Applikation von SIV-Gag-Adenovirus einen stärkeren Schutz vor einer SHIV-Infektion vermittelte als es Immunisierungen mit DNA alleine oder in Kombination mit MVA vermochten (Shiver et al., 2002).

In den eigenen Versuchsreihen wurden für die Auffrischungsimmunisierungen nicht-vermehrungsfähige Konstrukte des Adenovirus mit dem Serotyp 5 (Ad5) verwendet.

\subsection{Stärkere zelluläre Immunogenität des „DNA-Prime AdenoBoost“ Protokolls gegenüber der VLP-Applikationen}

In dem DNA-Ad-Experiment (erste Versuchsreihe) wurden die Versuchstiere zunächst dreimal mit DNA-Vektoren immunisiert, die die Gene für gag, env, nef, tat, vpx und vif kodierten. Zusätzlich kodiert ein Vektor das Gen für das humane Interleukin 15, das als immunmodulatorisches Zytokin beschrieben ist (Calarota et al., 2003; Musso et al., 1999; Doherty et al., 1996). Nach einer Wartezeit von acht Wochen wurden die Tiere zweimal mit ansteigenden Dosierungen der Adenoviruskonstrukte immunisiert. In der Gruppe 2 dieser Versuchsreihe erfolgte die erste Ad5-Applikation tonsillär, um auf diese Weise eine mukosale Immunität zu erlangen. Die zweite Applikation zur Verstärkung der 
Immunantwort erfolgte intramuskulär. In der Gruppe 3 wurden beide Applikationen intramuskulär vorgenommen.

In den Impflingen war nach den Immunisierungen mit den DNA-Vektoren nur eine geringe zelluläre Immunantwort gegen das Gag-Protein messbar. Erst nach der systemischen Gabe der Adenoviruskonstrukte konnte in beiden Impfgruppen ein Anstieg der zellulären Immunantwort gezeigt werden. Ein ähnlicher Immunisierungsverlauf wurde von Suh und Kollegen beschrieben (Suh et al., 2006).

Beim Vergleich der beiden Impfgruppen stelle sich heraus, dass die Impfgruppe, welche die erste Adenovirusdosis tonsillär verabreicht bekam, nach dieser Immunisierung keinen Anstieg der zellulären Immunantwort zeigte. Erst nach der systemischen Applikation der zweiten Dosis war in allen Tieren eine ausgeprägte Immunantwort detektierbar, welche die Antwort der anderen Impfgruppe in der Stärke noch übertraf.

Möglicherweise reichte die Menge an tonsillär appliziertem Adenoviruskonstrukt nicht aus, um einen starken Anstieg der Immunantwort zu induzieren. Dennoch scheint ein Effekt vorzuliegen, da die Immunantwort nach der zweiten Immunisierung mit Adenoviruskonstrukten deutlich ausgeprägt war.

In dem VLP-Ad-Experiment (zweite Versuchsreihe) wurden die Versuchstiere tonsillär mit virus-ähnlichen Partikeln (VLPs, engl. virus-like particles) immunisiert, die nicht-replikationsfähig waren. Diese Immunisierungen mit VLPs wurden gewählt, da frühere Experimente mit attenuierten Immundefizienzviren zwar den besten Schutz vor einer Belastungsinfektion vermittelt hatten, aber derartige attenuierte Viren auch pathogenes Potential beherbergen (Johnson et al., 1999; Daniel et al., 1992; Gundlach et al., 1998). Eine weitere Entwicklung führte zur Immunisierung mit nicht-vermehrungsfähigen Viren, die durch gleichzeitige Applikation von einer spezifischen tRNA in der Lage waren, noch einen Replikationszyklus zu durchlaufen. Diese attenuierten Viren werden als SCIV (engl. single-cycle immunodeficiency viruses) bezeichnet (Kuate et al., 2003). In Experimenten konnten Kuate und Kollegen zeigen, dass es durch Immunisierung mit derartigen Vektoren bei den Versuchstieren zu einer Reduktion der Peakvirämie kam. 
Beide Formen der Impfstoffpräparation beinhalten das Risiko, dass es zur Integration des Vakzinevirus in das Genom des Rezipienten und dadurch zu einer späteren Reaktivierung des Virus oder zu onkogenen Veränderungen kommt. Daher wurden die SCIVs so modifiziert, dass sie nach Applikation nicht in das Genom des Empfängers integrieren können. Die so entstandenen Viruspartikel werden als VLPs bezeichnet und sollten eine zelluläre Immunantwort induzieren (Kuate et al., 2006; Kang et al., 2003).

Die tonsilläre Applikation von VLPs induzierte in der zweiten Versuchsreihe nur in einem einzigen Tier eine geringe zelluläre Immunantwort. Erst nach tonsillärer Auffrischungsimpfung mit rekombinanten Adenoviruskonstrukten stieg der Anteil der IFNy-produzierenden T-Zellen an. Ein ähnlicher Verlauf ist von Kuate und Kollegen beschrieben worden (Kuate et al., 2006). In früheren Studien konnten Lehner und Kollegen durch wiederholte oro-rektale Applikation von VLPs die Induktion einer humoralen und zellulären Immunantwort nachweisen (Lehner et al., 1993).

In dem aVLP-Ad-Experiment (dritte Versuchsreihe) wurden die Tiere mit VLPs in Kombination mit Adjuvantien immunisiert. Die Applikation erfolgte in diesem Experiment subkutan. Nach den ersten beiden Immunisierungen ließen sich jedoch auch in diesem Experiment keine Virus-spezifischen T-Zellantworten nachweisen. Ähnlich des VLP-Ad-Experiments waren deutliche T-Zellantworten erst nach der heterologen Auffrischungsimpfung, die in Form von Adenoviruskonstrukten verabreicht wurde, messbar. Die Ergebnisse stimmen mit Daten von Montefiori und Kollegen überein, die bestätigen, dass die alleinige systemische Applikation von VLPs nur eine geringe zelluläre Immunantwort induziert (Montefiori et al., 2001).

\subsection{Reduktion der Spitzenvirämie und der Virusbeladung in der akuten Infektionsphase nach tonsillärer Belastungsinfektion durch die „DNA-Prime Adeno-Boost“ Immunisierung}

Nach tonsillärer Belastungsinfektion mit SIVmac239 wiesen die Impflinge der ersten Versuchsreihe eine zehnfach niedrigere Peakvirämie als die Kontrolltiere und eine signifikant reduzierte Viruslast in den ersten vier Wochen nach Infektion auf. Ähnliche Werte sind in verschiedenen Immunisierungsstudien 
beschrieben worden (Suh et al., 2006; Amara et al., 2005; Casimiro et al., 2005; Horton et al., 2002).

Die Reduktion der Viruslast in der akuten Phase der SIV-Infektion ist für den Erhalt der $\mathrm{CD}^{+}$Gedächtniszellen von zentraler Bedeutung und korreliert auch mit dem Erhalt dieser Zellpopulation in mukosalen Geweben (Picker et al., 2005; Mattapallil et al., 2006).

In der ersten Impfstudie war die mittlere Viruslast in den Impflingen um den Faktor $35 \mathrm{im}$ Vergleich zu den Kontrollen auf einen Wert von 4,6 x 10 $0^{5}$ viralen Kopien pro Milliliter Plasma gesunken. Bei dieser Anzahl von viralen Kopien scheint ein Erhalt der $\mathrm{CD} 4^{+} \mathrm{T}$-Lymphozyten im mukosalen Gewebe und damit ein längeres Überleben der Tiere möglich (Picker et al., 2005).

Die Tatsache, dass sich aus den Gruppen dieser Versuchsreihe viele Viruscontroller rekrutieren, bestätigt diese Aussage.

In dem DNA-Ad-Experiment wurde eine Kombination von tonsillärer und systemischer Applikation der advenoviralen Konstrukte mit der ausschließlich systemischen Applikation verglichen. Im Zeitraum nach der Belastungsinfektion zeigte die Impfgruppe 2, die sowohl tonsillär als auch systemisch immunisiert worden war, eine stärkere und länger anhaltende Immunantwort als die Gruppe 3, welche ausschließlich systemisch immunisiert worden war.

Möglicherweise lassen sich die Unterschiede zwischen den beiden Impfgruppen im Zeitraum nach der Belastungsinfektion mit der tonsillären Applikation der Adenoviruskonstrukte erklären.

Belyakov und Kollegen konnten durch einen Vergleich von mukosaler und systemischer Immunisierung nachweisen, dass nach rektaler Immunisierung mit SIV-Peptiden mehr funktionell aktive CD8 ${ }^{+}$T-Zellen im GALT nachweisbar sind als nach subkutaner Immunisierung (Belyakov et al., 2007).

Dies könnte die Ergebnisse dieser Arbeit erklären, da die Applikation des VLP-Impfstoffs am gleichen Ort erfolgte wie die spätere orale Belastungsinfektion. Dadurch induzierte die Immunisierung vermutlich eine mukosale Immunität (Tenner-Racz et al., 2004), die nach tonsillärer Belastungsinfektion eine stärkere Immunreaktion hervorrief und die Tiere der Gruppe 2 besser schützte. 
Zusammenfassend lässt sich feststellen, dass eine Kombination aus tonsillärer und systemischer Applikation von adenoviralen Vektoren nach Basisimmunisierung mit DNA-Vektoren eine gute Schutzwirkung erzeugte und im Hinblick auf die Entwicklung eines HIV-Impfstoffes von Vorteil ist.

\subsection{Reduktion der Spitzenvirämie nach tonsillärer Belastungsinfektion durch die „VLP-Prime Adeno-Boost“-Immunisierung}

Die Basisimmunisierung mit VLPs und die Auffrischungsimmunisierung mit Adenoviruskonstrukten vermittelte nach tonsillärer Belastungsinfektion nur eine Reduktion der mittleren Peakvirämie um den Faktor 5. Eine signifikant niedrigere Virusbeladung konnte nur in den ersten vier Wochen nach Belastungsinfektion gemessen werden. Ab der Woche 16 nach Belastungsinfektion war kein Unterschied zwischen den Impflingen und den Kontrollen zu verzeichnen.

Kuate und Kollegen konnten in zwei Tieren nach siebenmaliger VLP-Immunisierung in einem Zeitraum von 65 Wochen eine Reduktion der Spitzenvirämie sowie eine Reduktion der Virusbeladung bis zur Woche 117 nach Belastungsinfektion nachweisen. Eine Wiederholung dieser Impfstrategie über einen kürzeren Immunisierungszeitraum in einer Gruppe von vier Tieren ergab eine fünffache Reduktion der Peakvirämie, allerdings keine Veränderungen während des späteren Infektionsverlaufs (Kuate et al., 2006).

Als einen Grund für die unterschiedlichen Ergebnisse diskutieren Kuate und Kollegen Unterschiede in der Produktion der VLPs und dem längeren Immunisierungszeitraum in der erfolgreichen Studie. Beide Aspekte könnten auch eine Erklärung für die geringen Schutzeffekte in der zweiten Versuchreihe der vorliegenden Arbeit darstellen.

\subsection{Reduktion der Spitzenvirämie nach systemischer Belastungsinfektion durch die adjuvantierte „VLP-Prime Adeno- Boost"-Immunisierung}

In der dritten Versuchsreihe wurde eine signifikante Reduktion der Peakvirämie durch einen „VLP-Prime-“" mit einem „Adeno-Boost"-Immunisierungsschema erreicht. Die VLPs wurden zusammen mit Adjuvantien appliziert, um stärkere Immunantworten zu erzielen. 
Im Gegensatz zu den ersten beiden Versuchsreihen wurden die Tiere intravenös mit SIVmac251 infiziert und eine Messung der Virusbeladung bereits drei Tage nach Infektion durchgeführt.

Bis zum Tag 7 nach Infektion war ein identischer Anstieg der Virusbeladung in den Impflingen und den Kontrollen nachweisbar. Im Gegensatz zu den Impflingen stieg die Virusbeladung im Blut der Kontrolltiere bis zum Tag 10 stark an. In den Impflingen hingegen sank die Anzahl der Viruskopien zu diesem Zeitpunkt bereits wieder.

Die maximale mittlere Virusbeladung lag in den Impflingen am Tag 10 bei 8,7 x $10^{5}$ RNA-Kopien pro Milliliter Blut. In den Kontrollen lag die maximale Virusbeladung am Tag 14 bei 5,8 x 106 RNA-Kopien.

Ein Vergleich der Maximalwerte ergab bei den Impflingen nur eine fünffache Reduktion der Viruslast im Vergleich zu den Kontrolltieren.

Legt man auch bei den Impflingen den Wert der zweiten Woche zugrunde, so kam es zu einer Reduktion der Virusbeladung um den Faktor 30.

In der ersten und zweiten Versuchsreihe wurde die Virusbeladung in Impflingen und Kontrollen erst am Tag 14 nach Infektion verglichen.

Möglicherweise wird durch den Vergleich zu diesem späten Zeitpunkt die Reduktion der Virusbeladung überschätzt, da die maximale Viruslast in den Impflingen möglicherweise schon am Tag 10 nach Infektion auftrat. Aus diesem Grund sollte die Virusbeladung nach Infektion in weiteren Versuchen sehr engmaschig analysiert werden.

\subsection{Die drei Immunisierungsstrategien schützen nicht vor dem Verlust von CD4 ${ }^{+}$T-Lymphozyten, aber die Hauptzielzellen von SIV bleiben erhalten}

Das zentrale Phänomen nach der Infektion mit SIV ist der Verlust der CD4 ${ }^{+}$ T-Zellen, die den SIV-Korezeptor CD195 exprimieren (Nishimura et al., 2004; Picker et al., 2004; Bleul et al., 1997).

In dieser Arbeit kam es in allen drei Versuchsreihen zu einem Verlust von $20 \%-30 \%$ der CD4 ${ }^{+}$T-Lymphozyten im Blut der Versuchstiere. Signifikante Unterschiede zwischen den Impflingen und Kontrollen ließen sich nicht nachweisen. 
Der Verlust der $\mathrm{CD}^{+}{ }^{+}$T-Lymphozyten im Blut kann in der frühen Phase der Infektion jedoch nicht als direktes Merkmal für die Krankheitsprogression angesehen werden (Picker et al., 2004). Es ist vielmehr nötig, die Lymphozytenpopulationen weiter zu differenzieren, um Aussagen über die Funktion der einzelnen Zellpopulationen zu machen.

Die Entwicklung der Multiparameter-Durchflusszytometrie ermöglicht die Untersuchung einer Vielzahl von T-Zellpopulationen (De Rosa et al., 2001). Pitcher und Kollegen untersuchten die T-Lymphozyten in Rhesusaffen auf die Expression verschiedener Oberflächenmarker und konnten dadurch verschiedene Gedächtniszelltypen unterscheiden (Pitcher et al., 2002).

SIVmac239 und SIVmac251 benötigen zur Infektion von T-Zellen den Korezeptor CD195 (Viollet et al., 2006; Nishimura et al., 2004) und infizieren zunächst CD4 ${ }^{+}$T-Zellen, die diesen Rezeptor exprimieren (Veazey et al., 2000). Der SIV-Korezeptor $\mathrm{CD}_{195^{+}}$wird sehr stark von CD95-positiven Gedächtniszellen exprimiert, so dass diese Zellen in der akuten Phase der Infektion infiziert und zerstört werden (Mattapallil et al., 2005). Dieser Verlust ist bereits drei Tage nach Infektion im Blut und in mukosalen Geweben der Tiere nachweisbar (Li et al., 2005; Veazey et al., 1998). Eine Infektion mit einem chimären HI-/SI-Virus konnte durch Blockierung des CD195-Rezeptors inhibiert werden (Lederman et al., 2004).

Im DNA-Ad-Experiment war der Anteil der CD4 $4^{+} 195^{+}$T-Zellpopulation bei den Impflingen bis zur Woche 4 nach Infektion im Vergleich zu den Kontrollen signifikant erhöht. Durch die inversen Korrelationen wurde in diesem Experiment belegt, dass die $\mathrm{CD}^{+} 195^{+}$T-Lymphozyten bei hohen Virusbeladungen zerstört werden. Im VLP-Ad-Versuch gab es keine signifikanten Unterschiede zwischen Impflingen und Kontrollen. Hingegen war der Anteil der $\mathrm{CD}^{+} 195^{+}$T-Zellpopulation bei den Impflingen des aVLP-AdExperiments im gesamten Beobachtungszeitraum gegenüber den Kontrolltieren signifikant erhöht.

Mattapallil und Kollegen haben die Expression von CD195 auf den CD4 ${ }^{+}$ T-Lymphozyten in verschiedenen Geweben untersucht und konnten zeigen, dass die Veränderungen der CD4 $195^{+}$T-Zellpopulation nicht zur Vorhersage des Infektionsverlaufs verwendet werden kann (Mattapallil et al., 2005). Durch Untersuchung der CD195-Expression auf Basis der mRNA-Expression konnten 
sie zeigen, dass der Anteil von infizierten Zellen in CD195-negativen T-Zellen gleich hoch ist wie in CD195-positiven T-Zellen. Sie vermuten, dass eine geringe Expression von CD195 zwar für eine Infektion durch SIV ausreichend, diese Expression für die Messung im Durchflusszytometer jedoch zu gering ist. Die Ergebnisse der drei Versuchsreihen, die in den Impflingen einen konstanten oder erhöhten Anteil der $\mathrm{CD}^{+} 195^{+}$T-Lymphozyten im Blut zeigen, lassen vermuten, dass die Zellen vor einer Infektion geschützt waren. Es muss jedoch festgehalten werden, dass in dieser Arbeit nur die Blutlymphozyten untersucht wurden. In vielen Publikationen wurde gezeigt, dass es während der HIV bzw. SIV-Infektion zu einem andauernden Verlust der CD4 $195^{+}$T-Lymphozyten im gastrointestinalen Trakt kommt (Mehandru et al., 2007; Brenchley et al., 2004; Veazey et al., 1998). Um Aussagen über den Verlust von Lymphozyten in diesen Kompartimenten machen zu können, ist es unbedingt notwendig, zukünftig diese Gewebe im Verlauf der Infektion zu untersuchen.

\subsection{Die verschiedenen Gedächtniszellpopulationen bleiben in den Impflingen erhalten}

In dieser Arbeit wurde die Expression von CD95 auf den CD4 ${ }^{+}$T-Zellen untersucht, da dieser Marker im Menschen als Aktivierungs- und Gedächtnismarker beschrieben ist (Bahbouhi et al., 2004; Hamann et al., 1997). In dem DNA-Ad-Versuch blieb der Anteil der $\mathrm{CD}^{+}$Gedächtniszellen in den Impflingen in der akuten Phase der Infektion unverändert. In den Kontrolltieren kam es bereits in der zweiten Woche zu einem Verlust dieser Zellpopulation. Die Korrelationsanalysen bestätigen, dass diese Zellpopulation bei hoher Virusbeladung verloren geht.

Der Anteil der $\mathrm{CD}^{+} 95^{+}$T-Zellen blieb während des VLP-Ad-Versuchs in den Impflingen konstant, wohingegen der Anteil in den Kontrollen in den ersten Wochen signifikant auf die Hälfte der Präinfektionswerte sank. In dem aVLP-AdVersuch stieg der Anteil dieser Gedächtniszellpopulation in den Impflingen zunächst an und lag während des gesamten Beobachtungszeitraums im Bereich der Präinfektionswerte. In den Kontrollen sank der Anteil der $\mathrm{CD} 4^{+} 95^{+}$ T-Zellen dagegen bis zur Woche 2 auf etwa $60 \%$ ab und stieg im weiteren Verlauf der Infektion wieder auf etwa $75 \%$ an. 
Mattapallil und Kollegen beschreiben einen Verlust der $\mathrm{CD}^{+} 95^{+}$ T-Zellpopulation innerhalb der ersten 17 Tage nach Infektion mit SIVmac251 in acht Affen (Mattapallil et al., 2005). Im Gegensatz dazu und zu den Ergebnissen in dieser Arbeit berichten Viollet und Kollegen, dass die Infektion mit dem gleichen Virus zu keinen Veränderungen der $\mathrm{CD}^{+} 95^{+}$ T-Zellpopulation führte (Viollet et al., 2006).

Eine Erklärung für die unterschiedlichen Ergebnisse in Bezug auf die CD95Expression der CD4 ${ }^{+}$T-Lymphozyten könnte in der Herkunft der Versuchstiere in den verschiedenen Impfstudien liegen, da in der Studie von Viollet und Kollegen vier Rhesusaffen chinesischer Herkunft verwendet wurden. In der vorliegenden Arbeit wurde dagegen ausschließlich mit Tieren indischer Herkunft gearbeitet, wobei insgesamt 39 Tiere untersucht wurden.

Rhesusaffen chinesischen Ursprungs zeigen eine niedrigere Virusbeladung und einen verzögerten Krankheitsverlauf nach SIVmac239-Infektion (Ling et al., 2002; Trichel et al., 2002). Vergleichende Studien mit Tieren verschiedener Herkunft sind bisher noch selten, aber sie zeigen, dass der genetische Hintergrund der Versuchstiere einen Einfluss auf den Verlauf von Vakzineexperimenten haben kann (Stahl-Hennig et al., 2007; Marcondes et al., 2006).

Die Expression des Oberflächenantigens CD95 wird in Kombination mit CD28 in vielen Studien zur Unterscheidung von naiven $\left(\mathrm{CD}^{2} 5^{-2} 8^{+}\right)$, zentralen $\left(\mathrm{CD}^{+} 25^{+}\right)$und Effektorgedächtniszellen $\left(\mathrm{CD}^{+} 5^{+} 28^{-}\right)$verwendet (Acierno et al., 2006; Sun et al., 2005; Pitcher et al., 2002).

Funktionelle Untersuchungen zeigen, dass zentrale Gedächtniszellen vermehrt in Lymphknoten vorhanden sind, weniger Zytokine als die Effektorgedächtniszellen bilden, jedoch nach antigener Stimulation schnell proliferieren können. Die Effektorgedächtniszellen sind dagegen stärker im peripheren Gewebe zu finden und bilden nach antigener Stimulation rasch Zytokine (Sallusto et al., 2004; Sallusto et al., 1999).

In der vorliegenden Arbeit wurden die verschiedenen Gedächtniszellpopulationen in allen drei Versuchsreihen nach Belastungsinfektion untersucht. 
In der ersten Versuchsreihe war der Anteil der $\mathrm{CD}^{+}$zentralen Gedächtniszellen zwei Wochen nach Infektion in der „oralen Impfgruppe“ signifikant erhöht. Die Anteile der CD4 ${ }^{+}$Effektorgedächtniszellen waren zu diesem Zeitpunkt in den Kontrollen signifikant erhöht und korrelierten mit der Höhe der Virusbeladung.

Der Anstieg der $\mathrm{CD}^{+}$Effektorzellpopulation führte jedoch nicht zu einer Reduktion der Virusbeladung.

In den Impflingen stieg der Anteil der $\mathrm{CD}^{+}$zentralen Gedächtniszellen an und der Anteil der naiven Zellen nahm ab. Die $\mathrm{CD}^{+}$Effektorgedächtniszellen blieben nahezu unverändert.

Im Gegensatz dazu stieg in den Kontrolltieren der Anteil der CD8 ${ }^{+}$ Effektorgedächtniszellen zu Lasten der naiven Zellen stark an. Diese Veränderung der Gedächtniszellen kann möglicherweise durch die anamnestische Immunantwort der Impflinge und eine Primärantwort in den Kontrolltieren erklärt werden.

In dem VLP-Ad-Versuch zeigten sich keine Unterschiede in den Anteilen der $\mathrm{CD}^{+}$bzw. $\mathrm{CD}^{+}$zentralen Gedächtniszellen zwischen den Impflingen und den Kontrollen. Eine Erklärung hierfür liegt vermutlich in dem geringen Unterschied der Viruslasten zwischen den Impflingen und den Kontrolltieren in dieser Versuchsreihe.

In dem aVLP-Ad-Experiment war der Anteil der $\mathrm{CD}^{+}$zentralen Gedächtniszellen im Vergleich zu den Kontrollen bis zur vierten Woche nach Infektion erhöht. Bei den CD8 ${ }^{+}$T-Zellen waren die zentralen Gedächtniszellen zwei Wochen nach Infektion ebenfalls im Vergleich zu den Kontrollen signifikant erhöht. Diese Ergebnisse beruhen ebenso wie in der ersten Versuchsreihe auf dem Einfluss der Immunisierung.

Eine klare Aussage über die Ursachen von Veränderungen der zentralen und Effektorgedächtniszellen ist sehr schwierig, da bisher nur wenige Studien vorliegen, die Veränderungen dieser Populationen nach Infektion charakterisieren. Zusätzlich erschweren die verschiedenen Immunisierungsund Infektionsprotokolle einen direkten Vergleich der Studien.

In verschiedenen Experimenten wurden die Veränderungen von Gedächtniszellen nach Infektion mit SIV untersucht. Letvin und Kollegen zeigten, dass der Erhalt von $\mathrm{CD}^{+}$zentralen Gedächtniszellen mit einem längeren Überleben nach Belastungsinfektion verbunden war (Letvin et al., 
2006). In Tieren, die mit einem "DNA-Prime“ und Adeno- oder attenuierten Pockenvektoren immunisiert und anschließend mit SHIV 89.6P infiziert wurden, zeigten sich $\mathrm{CD}^{+}$zentrale Gedächtniszellen, die nach Gag-Stimulation IFNy (Acierno et al., 2006) und weitere Zytokine (Sun et al., 2006) bildeten. Gauduin und Kollegen konnten in Affen, die mehrere Jahre mit einem attenuierten Virus infiziert waren, eine $\mathrm{CD} 4^{+}$Effektorgedächtniszellpopulation nachweisen, die in diesen Tieren stärker ausgeprägt war als in Tieren, die neun bis zwölf Monate mit SIVmac239 infiziert waren (Gauduin et al., 2006).

Alle benannten Publikationen beschreiben nicht die Veränderungen von Gedächtniszellpopulationen im zeitlichen Verlauf der akuten Infektion, so dass ein direkter Vergleich mit den Ergebnissen der vorliegenden Arbeit nicht möglich ist.

Es lässt sich jedoch feststellen, dass es zwar in allen Tieren, die in dieser Arbeit beschrieben werden, zu einem Verlust der $\mathrm{CD} 4^{+}$T-Lymphozyten nach Infektion kam. Der Anteil der $\mathrm{CD}^{+}$Gedächtniszellpopulation blieb jedoch in den Impflingen aus der ersten und dritten Versuchsreihe erhalten, was klar impfbedingte Schutzeffekte darstellt.

In weiteren Versuchen wäre es wichtig, die Veränderungen der Gedächtnis-TLymphozyten in der akuten Phase der Infektion zu untersuchen und zu prüfen, ob diese Zellen auch in mukosalen Geweben wie zum Beispiel dem GALT erhalten bleiben.

\section{8 Übereinstimmende Ergebnisse beim Nachweis virusspezifischer T-Lymphozyten durch die ELISPOT- und die ICS-Technik}

Zytotoxische T-Lymphozyten verfügen über unterschiedliche Effektorfunktionen zur Eliminierung eines Virus. Die zugrunde liegenden Mechanismen beruhen auf der Sekretion von Zytokinen zur Aktivierung weiterer Immunzellen und der direkten Zerstörung infizierter Zellen durch zytotoxische Moleküle.

Im Jahr 1983 wurde die Technik des „Enzyme-linked Immunospot Assay“ (ELISPOT) zur Bestimmung von antikörpersezernierenden Zellen entwickelt (Czerkinsky et al., 1983; Sedgwick et al., 1983). Diese Methode wurde dann zur Detektion von zytokinsezernierenden Zellen weiterentwickelt (Czerkinsky et al., 1988). 
In dieser Arbeit wurde die ELISPOT-Technik verwendet, um nach Peptidstimulation IFNy-sezernierende T-Lymphozyten nachzuweisen.

Als ein weiterer funktioneller Test zur Analyse von antigenspezifischer Zytokinproduktion wurde die intrazelluläre Zytokinfärbung (ICS) verwendet. Bei dieser Methode wird im Gegensatz zum ELISPOT nicht das freigesetzte Zytokin gemessen, sondern die Zytokinfreisetzung wird durch Blockierung des Golgi-Apparates verhindert, so dass das akkumulierte Zytokin intrazellulär mit Hilfe von Fluorochrom-gekoppelten Antikörpern dargestellt werden kann.

Im Rhesusaffenmodell konnten Van der Meide und Kollegen zeigen, dass Affen-PBMC durch Stimulation mit Mitogenen oder rekombinanten Proteinen zur IFNy-Sekretion angeregt werden können (Van der Meide et al., 1995).

In der vorliegenden Arbeit wurde in der zweiten und dritten Versuchsreihe die ELISPOT-Technik mit der Methode des ICS verglichen. In dem VLP-AdVersuch wurde das polyfunktionale ICS mit den Zytokinen IFNy und IL2 etabliert und im aVLP-Ad-Versuch um das Zytokin TNFa erweitert.

Für den Vergleich mit den ELISPOT-Daten wurden die prozentualen Anteile der polyfunktionalen Zellpopulationen, die IFNy exprimieren, addiert und den Daten des ELISPOT gegenübergestellt.

In dieser Arbeit wurden die Ergebnisse des ICS erstmals über einen längeren Zeitraum mit den ELISPOT-Daten verglichen. Durch die Kombination beider Techniken ist es möglich, Aussagen über die Stärke einer Immunantwort und den Phänotyp der Zytokin-sezernierenden Zellen zu machen.

Die Ergebnisse der zweiten Versuchsreihe zeigten, dass in drei von vier Impflingen und in fünf von sieben Kontrolltieren mit beiden Methoden IFNYsezernierende Lymphozyten nach Belastungsinfektion nachweisbar waren und die Ergebnisse beider Techniken in den ersten vier Monaten nach Belastungsinfektion miteinander korrelierten.

In zwei der vier Impflinge erfolgte zwei Wochen nach Belastungsinfektion sowohl eine $\mathrm{CD}^{+}$als auch $\mathrm{CD}^{+}$vermittelte IFNy-Freisetzung. Des Weiteren war zu diesem Zeitpunkt der mittlere Anteil von $\mathrm{CD}^{+}{ }^{+}$und $\mathrm{CD}^{+}$Zytokinsezernierenden T-Zellen in den Impflingen im Vergleich zu den Kontrollen deutlich erhöht. 
Bei der dritten Versuchsreihe bestand über den gesamten Beobachtungszeitraum von 13 Wochen nach Belastungsinfektion eine Korrelation der ELISPOT-Daten mit den Ergebnissen des ICS. In allen Tieren war ein deutlicher Anstieg der IFNy-produzierenden T-Zellen am Tag 10 nach Infektion mit der ELISPOT-Technik und dem ICS nachweisbar.

Den größten Anteil an IFNy-sezernierenden Zellen bildeten in allen Tieren die $\mathrm{CD}^{+}$T-Lymphozyten. In den beiden Tieren mit den stärksten Antworten ließ sich zusätzlich eine deutliche CD4 ${ }^{+}$Antwort nachweisen. In der Woche 13 nach Belastungsinfektion lag in drei von vier Tieren sowohl eine virusspezifisch Zytokin-sezernierende CD4 ${ }^{+}$als auch $\mathrm{CD}^{+}$T-Zellpopulation vor.

In den Kontrolltieren waren dagegen am Tag 10 nach Infektion nahezu keine IFNy-Antworten messbar. Erst zum darauffolgenden Messzeitpunkt, vier Wochen nach Belastungsinfektion, war in drei von sechs Tieren eine Immunantwort nachweisbar, wobei nur in einem Tier eine deutliche CD4 ${ }^{+}$ Antwort messbar war. Zum Zeitpunkt Woche 13 nach Infektion zeigten fünf der sechs Kontrolltiere eine Immunantwort gegen Gag. In zwei Tieren war sowohl eine $\mathrm{CD}^{+}$als auch $\mathrm{CD}^{+}$Antwort, in zwei Tieren nur eine $\mathrm{CD}^{+}$Antwort messbar und in einem Tier überwog die CD4 ${ }^{+}$Antwort.

In der Literatur gibt es beim Vergleich der ELISPOT-Technik mit dem ICS unterschiedliche Ergebnisse. Karlsson und Kollegen beschreiben vergleichbare Ergebnisse zwischen ELISPOT und ICS, wobei die ELISPOT-Technik eine höhere Sensitivität bei geringen Immunantworten aufweist (Karlsson et al., 2003). Paher und Kollegen weisen der ICS-Technik eine höhere Sensitivität zu, wobei sie jedoch berichten, das Detektionslimit der jeweiligen Methode nicht ermittelt zu haben (Pahar et al., 2003). Beide Arbeitsgruppen ziehen das Fazit, dass es bei beiden Techniken Vor- und Nachteile gibt. So besteht ein Vorteil des ELISPOT darin, dass für diese Methode wenige Zellen benötigt werden und die Ergebnisse gut reproduzierbar sind. Ein Nachteil besteht darin, dass nur ein Zytokin detektiert werden kann, wobei es inzwischen auch die Entwicklung von Zwei-Farben-ELISPOTs gibt (Peretz et al., 2007).

Die ICS-Technik erlaubt dagegen die Phänotypisierung der Zellen bei gleichzeitiger Analyse von mehreren Zytokinen und Chemokinen.

Ein abschließender Vergleich beider Methoden ist nicht möglich, da beide Techniken sowohl Vor- als auch Nachteile aufweisen. Der ELISPOT zeigte in 
unseren Versuchen eine höhere Sensitivität im Vergleich zum ICS. Weiterhin ist der Zellbedarf für diese Technik geringer.

Wenn die Anstrengungen, die Methode des ICS besser zu standardisieren, Erfolg zeigen (Maecker et al., 2005) und es gelingt die Sensitivität zu erhöhen, überwiegen die Vorteile des ICS, da durch die Phänotypisierung der T-Zellen eine genauere Charakterisierung der Zytokin-sezernierenden Zellen möglich ist. Weiterhin wird zurzeit vermehrt die Analyse von polyfunktionalen Lymphozyten durchgeführt, was bisher nur mit der Technik des ICS möglich ist.

\subsection{Die Reduktion der Virusbeladung korreliert mit der vermehrten Bildung von IFNy durch polyfunktionale T-Lymphozyten}

Die Gesamtheit der T-Lymphozyten setzt sich aus sehr heterogenen Zellpopulationen zusammen. Obwohl durch Phänotypisierung zwischen verschiedenen Gedächtnis-T-Zellen oder naiven Zellen unterschieden werden kann, ist es bisher noch nicht gelungen, eine direkte Korrelation zwischen bestimmten Phänotypen und funktionellen Charakteristika zu finden. Daher müssen antigenspezifische T-Zellen funktionell charakterisiert werden, um ein entsprechendes Profil mit möglichen Schutzfunktionen zu korrelieren.

Die funktionelle Charakterisierung von T-Lymphozyten beschränkte sich zunächst auf die Messung von Zytokinen und hierbei insbesondere auf die Analyse der IFNy-Freisetzung (Beattie et al., 2004; Goulder et al., 2001). Andere Zytokine wie z.B. IL2 sind im Verlauf einer Virusinfektion ebenfalls von großer Bedeutung (Harari et al., 2005; Graziosi et al., 1996; Picker et al., 1995). Es konnte gezeigt werden, dass die HIV-Infektion in Individuen, deren CD8 ${ }^{+}$ T-Lymphozyten das Potential besitzen, sowohl IFNy als auch IL2 zu sezernieren, deutlich milder verläuft als in Individuen, deren Zellen nur IFNY oder IL2 sezernieren (Harari et al., 2004). Ebenso konnten in Patienten mit einer HIV-2-Infektion, die häufiger einen milderen Krankheitsverlauf aufweist, vermehrt doppelt-positive IFNy ${ }^{+} \mathrm{IL}^{+}{ }^{+} \mathrm{T}$-Zellen nachgewiesen werden (Duvall et al., 2006).

In der zweiten Versuchsreihe dieser Arbeit wurden daher mittels der intrazellulären Zytokinfärbung sowohl IFNy als auch IL2 gemessen. Es konnten jedoch in der akuten Phase der Infektion keine Unterschiede zwischen den 
Impflingen und den Kontrollen in Bezug auf eine polyfunktionale Zellpopulation detektiert werden.

Möglicherweise liegt die Ursache dafür in der geringen Immunogenität der VLPs in der zweiten Studie, da in der dritten Versuchsreihe ein deutlicher Unterschied zwischen Impflingen und Kontrollen in Bezug auf polyfunktionale T-Zellen bestand. In vergleichbaren Impfstoffstudien mit VLPs wurde nur der Anteil von IFNy-sezernierenden T-Zellen gemessen (Kuate et al., 2006; Montefiori et al., 2001), so dass ein Vergleich in Bezug auf Polyfunktionalität nur mit den Ergebnissen der dritten Versuchsreihe möglich ist.

In der dritten Versuchsreihe wurde das Zytokinspektrum um das Zytokin TNFa erweitert. Der simultane Nachweis von IFNy, IL2 und TNFa erhöht die Komplexität der Analyse erheblich, da sieben polyfunktionale Zellpopulationen messbar sind.

Mattapallil und Kollegen untersuchten die Veränderungen dieser Populationen in der akuten Phase der SIV-Infektion und konnten zeigen, dass sich die Anteile der $\mathrm{CD}^{+}$und $\mathrm{CD}^{+}$polyfunktionalen T-Zellen innerhalb weniger Tage ändern und sich das Zytokinspektrum in $\mathrm{CD}^{+}$T-Lymphozyten von überwiegend IL2-sezernierenden Zellen zum Zeitpunkt der Belastungsinfektion zu IFNy-sezernierenden Zellen vier Wochen nach Infektion verschiebt (Mattapallil et al., 2006).

Vergleichbare Ergebnisse lieferten auch die Analysen der dritten Versuchsreihe. In Übereinstimmung mit Mattapallil und Kollegen war die anamnestische Immunantwort mit einem Maximum der Zytokinbildung in den Impflingen früher als in den Kontrollen nachzuweisen. Im Gegensatz zu der publizierten Studie war der Anteil der Zytokin-positiven CD8 ${ }^{+}$T-Lymphozyten in der dritten Versuchsreihe deutlich ausgeprägter. Weiterhin war der Anteil der IFNy einfach-positiven $\mathrm{CD8}^{+} \mathrm{T}^{+}$-Lymphozyten deutlich höher als in der publizierten Studie. Ob dieser Unterschied in den unterschiedlichen Impfstoffkonstrukten begründet liegt, lässt sich aufgrund der verschiedenen Immunisierungsprotokolle nicht belegen.

Die Unterschiede zwischen den Impflingen und den Kontrollen des aVLP-AdVersuchs waren in Bezug auf die polyfunktionale CD4 ${ }^{+}$T-Zellpopulation nicht sehr ausgeprägt. Es war in beiden Gruppen ein Verlust von polyfunktionalen 
$\mathrm{CD}^{+}$T-Lymphozyten und eine Entwicklung von Zellen, die jeweils nur ein Zytokin bilden, nachzuweisen.

Sun und Kollegen konnten nach Infektion mit SIVmac251 keine antigenspezifischen $\mathrm{CD}^{+}{ }^{+} \mathrm{T}$-Lymphozyten detektieren. Zum Zeitpunkt der Peakvirämie verloren die CD4 ${ }^{+} \mathrm{T}$-Zellen jedoch ihre Fähigkeit, nach Stimulation mit Staphylococcus-Enterotoxin B Zytokine zu bilden (Sun et al., 2006).

Die Ergebnisse der eigenen Arbeit bestätigen publizierte Studien in der Annahme, dass es bereits im frühen Stadium der SIV-Infektion massive Veränderungen in den Zytokin-produzierenden T-Lymphozytenpopulationen gibt, die eine große Auswirkung auf den weiteren Verlauf der Infektion und den Erhalt von Gedächtniszellpopulationen haben können.

Aufgrund der technischen Entwicklung der Durchflusszytometrie können weitere zusätzliche Zellpopulationen untersucht werden. So wurden in einer HIV-Vakzinestudie von De Rosa und Kollegen zusätzlich zu den drei Zytokinen IFNy, IL2 und TNFa das Chemokin MIP-1 $\beta$ und das Zytokin IL4 untersucht (De Rosa et al., 2004). Interessanterweise waren in dieser Studie die CD4 ${ }^{+}$ T-Lymphozyten die komplexesten innerhalb der zu beobachtenden polyfunktionalen Zellpopulationen.

In einer weiteren Studie wurden die polyfunktionalen Lymphozytenpopulationen in einem Individuum nach Immunisierung mit Kanarienpockenvektoren und in zwei chronisch HIV-infizierten Individuen untersucht (Betts et al., 2005). In dieser Studie wurde neben den drei Zytokinen IFNy, IL2 und TNFa der Degranulationsmarker CD107 analysiert. Auch in dieser Untersuchung ließen sich eine Vielzahl von polyfunktionalen T-Zellsubpopulationen nachweisen.

Eine Gemeinsamkeit der beiden Studien liegt darin, dass der Nachweis einer einfach-positiven IFNy-Lymphozytenpopulation nach Stimulation mit Virusspezifischen Peptiden nicht als ein Indikator für eine protektive Immunantwort angesehen werden kann. Bisher gibt es jedoch noch keine weitergehende Definition für eine polyfunktionale T-Zellpopulation, die mit einer protektiven Vakzinierung korreliert.

Daher sind weitere Vakzinierungsstudien unter Einbeziehung der polyfunktionalen Analyse nötig, um die Bedeutung von T-Zellpopulationen für eine Impfstoff-vermittelte protektive T-Zellimmunität zu untersuchen. 


\subsection{In immunisierten Tieren bilden sich SIV-spezifische T-Lymphozyten schneller als in Kontrolltieren}

Tiere mit dem MamuA*01-MHC-Allel entwickeln nach SIV-Infektion eine immundominante Immunantwort gegen ein Gag-Peptid mit der Peptidsequenz CTPYDINQM (CM9 oder p11C; Allen et al., 1998). Dieses Peptid kann mit künstlichen MHC-I-Komplexen assoziiert und dieser Komplex über BiotinStreptavidin-Bindung mit einem Fluoreszenzfarbstoff gefärbt werden (Kuroda et al., 1998).

In dem aVLP-Ad-Versuch wurden T-Lymphozyten, die mit ihren T-Zellrezeptoren das CM9-Peptid binden können, von drei MamuA*01-positiven Tieren mit den Tetramer-Komplexen gefärbt. In Experimenten, in denen CD8 ${ }^{+}$ T-Zellen depletiert wurden, konnte gezeigt werden, dass Tetramer-positive $\mathrm{CD}^{+}$T-Lymphozyten für eine Reduktion der Virusbeladung notwendig sind (Schmitz et al., 1999).

Die Tetramer-Technik wurde für die vorliegende Arbeit erst während der laufenden Versuchsreihe etabliert, so dass für die Immunisierungsphase erst ab dem Zeitpunkt der Auffrischungsimmunisierung mit Adenoviruskonstrukten Ergebnisse vorlagen. Diese Ergebnisse geben daher den Anteil von Gagspezifischen $\mathrm{CD}^{+}{ }^{+} \mathrm{T}$-Zellen in den drei MamuA*01-positiven Tiere dieser dritten Versuchsreihe wieder.

Es zeigte sich, dass in einem der beiden Impflinge zwei Wochen nach der ersten Adenoimmunisierung 7,5\% Tetramer-positive $\mathrm{CD}^{+}{ }^{+}$T-Lymphozyten vorhanden waren. In dem zweiten Tier lag der Anteil dieser Zellen an allen CD8 $^{+}$T-Lymphozyten nur bei 0,4\%. Nach der zweiten Adenoimmunisierung ließ sich in beiden Impflingen nur eine geringe Tetramer-positive Population nachweisen.

Nach der Belastungsinfektion stieg der Anteil der Tetramer-positiven CD8 ${ }^{+}$ T-Zellen in beiden Impflingen innerhalb von 10 Tagen stark an und erreichte ein Maximum in der Woche 2 nach Infektion. In dem Kontrolltier war ein Anstieg erst ab der Woche 2 mit einem Maximum in der vierten Woche nach Infektion nachweisbar. Im weiteren Verlauf der Infektion sank der prozentuale Anteil der Tetramer-positiven T-Zellen in den Impflingen ab, stieg hingegen in dem Kontrolltier weiter an. 
In einer weiteren Analyse wurde die Expression des nukleären Proliferationsmarkers Ki67 untersucht. Die Expression dieses Markers war in den $\mathrm{CD}^{+}$T-Lymphozyten der Impflinge zehn Tage nach Infektion signifikant erhöht.

Diese Ergebnisse stimmen mit den Untersuchungen von Ueno und Kollegen überein, die in T-Zelllinien aus HIV-infizierten Menschen eine erhöhte Proliferationsfähigkeit von Tetramer-positiven Zellen nachweisen konnten (Ueno et al., 2004). Da in der dritten Versuchsreihe jedoch nur drei Tiere untersucht wurden, ist eine Korrelation der Tetramer-positiven T-Lymphozyten und der Ki67-Expression nicht aussagekräftig.

Aufgrund des starken Anstiegs der Tetramer-positiven $\mathrm{CD}^{+}{ }^{+}$T-Zellpopulation kann man jedoch postulieren, dass die Tetramer-positiven T-Zellen stark proliferierten und somit auch Ki67 exprimierten. Eine Kombination beider Färbungen könnte diese Annahme bestätigen.

Ergebnisse zum Anteil von Tetramer-positiven CD8 ${ }^{+}$T-Lymphozyten nach den DNA-Immunisierungen liegen in der dritten Versuchsreihe leider nicht vor, da die Technik zum Zeitpunkt der DNA-Immunisierungen noch nicht etabliert war. Verschiedene Studien haben jedoch gezeigt, dass es durch mehrmalige DNA-Immunisierungen möglich ist, in Makaken Anteile von 0,3\% bis $0,9 \%$ Tetramer-positiven CD8 ${ }^{+}$T-Lymphozyten im Blut zu induzieren (Hel et al., 2002; Allen et al., 2000). Beide Publikationen zeigten, dass durch weitere Immunisierung mit attenuiertem Vakziniavirus der Anteil auf $0,8 \%$ bis $20 \%$ Tetramer-positive $\mathrm{CD}^{+}$T-Lymphozyten erhöht werden konnte. Diese Größenordnung von Tetramer-positiven $\mathrm{CD}^{+}$T-Lymphozyten wurde in der vorliegenden Arbeit nach der ersten Adenoimmunisierung in den beiden immunisierten Tieren mit 0,4\% bzw. 7,5\% ebenfalls erreicht.

Weiterhin konnten Allen und Kollegen mit Hilfe der ICS-Technik zeigen, dass die induzierten Tetramer-positiven T-Zellen nach antigener Stimulation das Zytokin IFNy bilden (Allen et al., 2000). Diese Ergebnisse geben einen indirekten Hinweis auf die antivirale Funktionalität dieser Zellpopulation. Die Annahme, dass Tetramer-positive T-Zellen antiviral wirken können, wird durch die Korrelation zwischen einem hohen Anteil von Tetramer-positiven CD8 ${ }^{+}$ T-Lymphozyten und der Reduktion der viralen RNA im Blut von Versuchstieren bestätigt (Hel et al., 2002; Kuroda et al., 1999a). 
Für eine Korrelationsanalyse war die Anzahl der untersuchten MamuA*01positiven Tiere in der dritten Versuchsreihe nicht groß genug. Daher sollte ein engmaschiger Nachweis von Tetramer-positiven T-Zellen in weiteren Versuchen erfolgen, um eine ausreichend große Tieranzahl für zukünftige Analysen zu erhalten.

Acierno und Kollegen zeigten in einem "Prime-Boost"-Experiment mit dreifachem "DNA-Prime“ und einer Applikation von Adenoviruskonstrukten, dass Tetramer-positive CD8 ${ }^{+}$T-Lymphozyten aus dem Blut auch 75 Wochen nach SHIV-89.6P-Infektion in der Lage waren, IFNy zu sezernieren (Acierno et al., 2006). Für die chronische HIV-Infektion berichteten Shacklett und Kollegen, dass Tetramer-positive $\mathrm{CD}^{+} \quad$ T-Lymphozyten im Darm-assoziierten lymphatischen Gewebe (GALT) im Vergleich zum Blut erhöht sind und dort zur Immunabwehr beitragen (Shacklett et al., 2003).

In den Tieren der aVLP-Ad-Versuchsreihe wurden nach Belastungsinfektion parallel zum Blut auch in Darmbiopsien Tetramer-positive CD8 ${ }^{+} \mathrm{T}$-Lymphozyten nachgewiesen, wobei der gemessene prozentuale Anteil den Tetramer-Anteil im Blut nicht überstieg (T. Schultheiß, persönliche Mitteilung).

Um eine Aussage über die Fähigkeit der Tetramer-positiven $\mathrm{CD}^{+}$ T-Lymphozyten, auch in der chronischen Phase der Infektion IFNy zu sezernieren, machen zu können, sollte in Zukunft die Messung von polyfunktionalen T-Lymphozyten mit der Tetramerfärbung kombiniert werden.

Neben der Zytokinsekretion sollten auch weitere Parameter gemessen werden, um eine weitere funktionelle Charakterisierung der Tetramer-positiven Zellen zu ermöglichen. Betts und Kollegen konnten auf diese Weise nach Infektion mit dem Cytomegalievirus in Tetramer-positiven $\mathrm{CD}^{+}$T-Lymphozyten die Expression des Degranulationsmarkers CD107 nachweisen (Betts et al., 2003).

\subsection{Nachweis von polyfunktionalen und proliferierenden T-Zellen in Tieren mit reduzierter Virusbeladung}

In der ersten und zweiten Versuchsreihe war im Rahmen dieser Arbeit eine Untersuchung der Versuchstiere bis zur 76. Woche nach Belastungsinfektion möglich. Dabei stellte sich heraus, dass aus der Gesamtheit der Versuchstiere zehn Tiere in der Lage waren, die Virusbeladung im Blut sehr rasch nach Infektion zu kontrollieren. Bereits acht Wochen nach Infektion und über den 
gesamten weiteren Beobachtungszeitraum wiesen diese Tiere eine signifikante Reduktion der Virusbeladung im Vergleich zu den Tieren mit fortschreitender Immundefizienz auf. Daher werden diese Tiere im weiteren Verlauf als „Viruscontroller“ bezeichnet.

Von den zehn „Viruscontrollern“ trugen acht Tiere das MamuA*01-Allel. Vier der zehn Tiere stammten aus den Kontrollgruppen der beiden Versuchsreihen. Zwischen den geimpften Tieren und den Kontrolltieren, die sich zu „Viruscontrollern“ entwickelten, ließen sich bezüglich der untersuchten Parameter keine Unterschiede nachweisen.

Daher ist davon auszugehen, dass die Entwicklung zu „Viruscontrollern“ eher auf den genetischen MHC-Hintergrund der Tiere als auf die Immunisierung zurückzuführen ist (Mühl et al., 2002), was jedoch nicht die Entwicklung der beiden MamuA*01-negativen Tiere zu „Viruscontrollern“ erklärt.

Experimente durch andere Gruppen bestätigen die Ergebnisse, dass MamuA*01-positive Tiere die Viruslast schnell und langfristig reduzieren können (Mothe et al., 2003; O`Connor et al., 2003; Pal et al., 2002). Mögliche Ursachen hierfür sind die Entwicklung von virusspezifischen T-Lymphozyten, die insgesamt mehrere Epitope erkennen können (Allen et al., 2001) und in verschiedenen mukosalen Geweben vorkommen (Hel et al., 2002). Die Untersuchungen in dieser Arbeit konnten in allen MamuA*01-positiven „Viruscontrollern“ Tetramer-positive $\mathrm{CD}^{+}{ }^{+} \mathrm{T}$-Lymphozyten im Blut nachweisen. In ersten Untersuchungen in mukosalen Geweben konnten in diesen Tieren ebenfalls Tetramer-positive T-Zellen gemessen werden (T.Schultheiß, persönliche Mitteilung).

Sharpe und Kollegen berichten über langzeitinfizierte MamuA*01-positive Rhesusaffen, die im Blut ebenfalls Tetramer-positive $\mathrm{CD}^{+} \mathrm{T}$-Zellen aufwiesen, wobei die prozentualen Anteile in diesen Tieren geringer waren als in der vorliegenden Arbeit (Sharpe et al., 2004).

Neben der Analyse der Tetramer-positiven T-Lymphozyten wurde die Proliferationsfähigkeit der Lymphozyten nach antigener Stimulation untersucht. Es zeigte sich, dass es in allen Tieren nach Stimulation der PBMC mit chemisch inaktiviertem Virus zur Proliferation von $\mathrm{CD}^{+}$und $\mathrm{CD} 8^{+} \mathrm{T}$-Zellen kam.

Gauduin und Kollegen konnten in $\mathrm{CD}^{+}$T-Lymphozyten von langzeitüberlebenden Tieren eine deutliche Proliferation nach Stimulation mit 
SIV-Peptiden nachweisen (Gauduin et al., 1999). Durch eine zweiwöchige in-vitro-Expansion von Tetramer-positiven Zellen aus chronisch infizierten Makaken konnte ein starker Anstieg von Tetramer-positiven $\mathrm{CD}^{+}$ T-Lymphozyten nach antigener Stimulation nachgewiesen werden (Kuroda et al., 1999b).

In der vorliegenden Arbeit wurde die Proliferationsfähigkeit der Tetramer-positiven T-Zellen nicht bestimmt sodass sich keine direkte Aussage über den prozentualen Anteil der Tetramer-positiven T-Lymphozyten an den proliferierenden Zellen machen läßt. Da jedoch die T-Zellen der beiden MamuA*01-negativen Tiere ebenfalls hohe Proliferationswerte aufwiesen, ist zu vermuten, dass auch andere T-Zellen zur Proliferation angeregt werden.

Neben der Fähigkeit zur Proliferation ist die Bildung von Zytokinen eine bedeutende Funktion von T-Lymphozyten. In der vorliegenden Arbeit war im Blut von neun der zehn "Viruscontroller" die Bildung von Zytokinen durch polyfunktionale $\mathrm{CD} 8^{+} \mathrm{T}$-Zellen nach Gag-Stimulation nachweisbar.

Shankar und Kollegen untersuchten den Anteil von Gag- und Pol-spezifischen Tetramer-positiven und IFNy-positiven T-Zellen in HIV-infizierten Menschen (Shankar et al., 2000). In neun untersuchten, chronisch HIV-infizierten Menschen konnten $0,1 \%$ bis $1,1 \%$ Tetramer-positive $\mathrm{CD}^{+}$T-Lymphozyten nachgewiesen werden. In sieben Individuen zeigten weniger als $25 \%$ dieser Tetramer-positiven Zellen eine IFNy-Produktion. In zwei Individuen waren mehr als $50 \%$ der Tetramer-positiven T-Zellen auch IFNy-positiv. Diese beiden Individuen wiesen als einzige keine klinischen Symptome auf und hatten stabile CD4 ${ }^{+}$T-Zellzahlen.

Moniuszko und Kollegen konnten eine Korrelation zwischen der TNFa-Produktion und dem Anteil der Tetramer-positiven T-Zellen in SIVmac251-infizierten Makaken nachweisen (Moniuszko et al., 2005). Im Gegensatz dazu stehen die Ergebnisse von Hel und Kollegen, die eine Reduktion der Zytokinsekretion nach SIVmac251-Infektion in Tetramerpositiven T-Zellen gefunden haben (Hel et al., 2002).

Petrovas und Kollegen untersuchten in Tetramer-positiven $\mathrm{CD}^{+} \mathrm{T}$-Zellen die Expression von IFNy, TNFa und IL2 im Zeitraum von acht bis zwölf Wochen nach Infektion mit SIVmac251 (Petrovas et al., 2007). Sie konnten nachweisen, dass die Tetramer-positiven $\mathrm{CD}^{+}$T-Zellen hauptsächlich IFNy und TNFa 
produzieren. Eine Analyse von polyfunktionalen Zellen wurde nicht durchgeführt.

In neun HIV-infizierten Viruscontrollern untersuchten Betts und Kollegen die Funktionalität von $\mathrm{CD}^{+}$T-Lymphozyten (Betts et al., 2006). Die „Viruscontroller“ in der publizierten Studie wiesen einen erhöhten Anteil von polyfunktionalen T-Zellen im Vergleich zu den „Nicht-Controllern“ auf.

Diese Ergebnisse stimmen mit den Ergebnissen der vorliegenden Arbeit überein.

\subsection{Die Rolle der CD4 ${ }^{+}$T-Lymphozyten in der chronischen Infektion}

Die CD4 ${ }^{+}$T-Helferzellen spielen eine wichtige Rolle in der Erhaltung einer effektiven Immunität gegen verschiedene virale Infektionen. Die Proliferation und Zytokinsekretion von CD4 ${ }^{+}$T-Zellen unterstützt die zytotoxische Aktivität von CTL (Matloubian et a., 1994). Eine Depletion von CD4 ${ }^{+}$T-Zellen in Mäusen, die mit dem lymphozytären Choriomeningitis-Virus (LCMV) infiziert wurden, führte in der chronischen Phase zu einem Verlust der CD8 ${ }^{+}$CTL-Aktivität und damit zu einer persistierenden Virusbeladung (Battegay et al., 1994; Von Herrath et al., 1996).

In chronisch HIV-infizierten Menschen ist in Individuen, die ohne Therapie eine geringe Virusbeladung aufweisen, eine Proliferation von CD4 ${ }^{+}$T-Lymphozyten nach Stimulation zu messen. In infizierten Menschen mit hoher Virusbeladung ist eine solche Funktion nicht nachweisbar (Rosenberg et al., 1997). Dieser funktionelle Verlust kann mit der massiven Depletion von CD4 ${ }^{+}$T-Zellen im Darm in der akuten Phase der Infektion erklärt werden (Mehandru et al., 2007; Li et al.; 2005; Veazey et al., 1998). Da dieser Verlust von CD4 ${ }^{+}$T-Helferzellen nicht vollständig ersetzt werden kann, resultiert daraus vermutlich in der chronischen Phase der Infektion eine Reduktion der CTL-Aktivität.

In den "Viruscontrollern" in dieser Arbeit konnte in neun von zehn Tieren eine deutliche $\mathrm{CD}^{+}{ }^{+}$T-Zellproliferation nach Stimulation mit chemisch inaktiviertem Virus nachgewiesen werden. In zwei dieser sechs Tiere war zudem eine polyfunktionale $\mathrm{CD} 4^{+}$Population nachweisbar.

Eine funktionelle IFNy ${ }^{+} \mathrm{CD}^{+}$T-Population wurde in Langzeitüberlebenden nachgewiesen (Kawada et al., 2007). Daher ist es interessant zu überprüfen, 
welche Tiere die Viruslast über einen noch längeren Zeitraum als 72 Wochen kontrollieren können.

\subsection{Abschließende Bewertung und Ausblick}

Die natürliche Immunanwort gegen HIV führt trotz Induktion von virus-spezifischen T-Zellen und starken humoralen Antworten nicht zu einer Eliminierung des Virus. HIV besitzt eine Vielzahl von Mechanismen, um einer Immunantwort zu entkommen. Hierzu zählen die hohe genetische Variabilität, die eine Entwicklung von „Escape“-Mutanten ermöglicht, sowie eine Glykanhülle, die vor neutralisierenden Antikörpern gut schützt. Zusätzlich kann HIV die Expression der MHC-Klasse-I-Moleküle auf infizierten Zellen reduzieren und sich dadurch vor dem Angriff von Immunzellen schützen. Das entscheidende Charakteristikum einer HIV-Infektion liegt jedoch in der Zerstörung von CD4 ${ }^{+}$T-Zellen und damit in der fortschreitenden Zerstörung des Immunsystems des infizierten Organismus.

Die Entwicklung eines protektiven Impfstoffs stellt die Forschung aus den genannten Gründen vor eine große Herausforderung.

Die vorliegende Arbeit trägt einen Teil zur Untersuchung von T-Zell-basierten Impfstoffen im Rhesusaffenmodell bei. Es wurden drei verschiedene heterologe „Prime-Boost“-Immunisierungsprotokolle auf ihre Schutzwirkung vor SIV-Infektion untersucht.

Zusammenfassend lässt sich feststellen, dass keines der drei Protokolle einen dauerhaften Schutz vor SIV-Infektion vermitteln konnte. Dennoch führten alle drei Protokolle zu einer Reduktion der Virusbeladung in der akuten Phase der Infektion. $\mathrm{Ob}$ es bereits durch diese Reduktion der Virusbeladung zu einem Schutz vor der massiven Depletion von mukosalen T-Lymphozyten kam, konnte im Rahmen dieser Arbeit nicht untersucht werden.

Die Untersuchung von polyfunktionalen T-Lymphozyten, deren Nachweis in dieser Arbeit etabliert wurde, ermöglicht es jedoch, in zukünftigen Untersuchungen verstärkt T-Lymphozytenpopulationen zu charakterisieren, die möglicherweise mit dem Schutz vor SIV-Infektion korrelieren. Wünschenswert wäre es, wenn diese Technik zur funktionellen Charakterisierung von mukosalen Geweben beiträgt, um den Verlauf in der frühen Phase der SIV-Infektion noch genauer zu verstehen. Zur Untersuchung dieser 
Fragestellung wird auch in Zukunft das Rhesusaffenmodell von großer Bedeutung sein, da nur in einem Tiermodell die Möglichkeit besteht, den Infektionszeitpunkt und die Infektionsroute zu bestimmen. 


\section{Zusammenfassung}

Die HIV-Infektion und die daraus resultierende AIDS-Erkrankung sind eine globale Herausforderung für die Menschheit. Für präklinische Studien zur Entwicklung eines Impfstoffes gegen diese Virusinfektion und für entsprechende Pathogenesestudien repräsentiert die Infektion von Makaken mit dem Affenimmundefizienzvirus (SIV) das wichtigste Tiermodell.

In der vorliegenden Arbeit wurden in diesem Tiermodell drei „Prime-Boost“Immunisierungsprotokolle, die hinsichtlich der Vektorkombinationen und Applikationsrouten variierten, auf ihre Immunogenität und Wirksamkeit gegenüber einer SIV-Infektion untersucht. Ein besonderer Schwerpunkt lag auf dem Vergleich der differenzierenden ICS-Technik zum Nachweis virusspezifischer T-Zellimmunantworten mit der bislang verwendeten ELISPOTTechnik. Weiterhin wurden verschiedene T-Zellpopulationen des Blutes und ihre Veränderungen nach SIV-Exposition mit der polychromatischen Durchflusszytometrie charakterisiert.

Keine der Immunisierungsstrategien schützte die Impflinge vor einer SIV-Infektion, allerdings war ihre Viruslast in der akuten Infektionsphase im Vergleich zu Kontrolltieren zehnfach reduziert und es kam nicht zu einem infektionsbedingten Verlust von Gedächtnis-T-Zellen.

Im direkten Vergleich der mittels ELISPOT- und ICS-Technik erhobenen Daten der zweiten und dritten Versuchsreihe war in den Impflingen nach der Belastungsinfektion eine erhöhte IFNy-Freisetzung durch virusspezifische T-Lymphozyten im Gegensatz zu den Kontrolltieren zu beobachten. Weiterhin gelang es, sogenannte polyfunktionale T-Lymphozyten, die gleichzeitig mehrere Zytokine sezernieren, in Impflingen der dritten Versuchsreihe nach Belastungsinfektion nachzuweisen.

In chronisch SIV-infizierten Tieren, die langfristig eine sehr niedrige Viruslast aufwiesen, waren virusspezifisch proliferierende und polyfunktionale T-Zellen vorhanden, während diese in Tieren mit hoher Viruslast fehlten.

Die Ergebnisse der vorliegenden Arbeit ermöglichen es, in zukünftigen Modellstudien zur Prophylaxe und Pathogenese zelluläre Immunantworten differenzierter zu charakterisieren und dadurch potentielle Immunkorrelate aufzuzeigen. 


\section{Literaturverzeichnis}

1. Abate, G., J. Eslick, F. K. Newman, S. E. Frey, R. B. Belshe, T. P. Monath, and D. F. Hoft. 2005. Flow-cytometric detection of vacciniainduced memory effector CD4(+), CD8(+), and gamma delta TCR(+) T cells capable of antigen-specific expansion and effector functions. $J$ Infect Dis 192:1362-71.

2. Acierno, P. M., J. E. Schmitz, D. A. Gorgone, Y. Sun, S. Santra, M. S. Seaman, M. H. Newberg, J. R. Mascola, G. J. Nabel, D. Panicali, and N. L. Letvin. 2006. Preservation of functional virus-specific memory CD8+ T lymphocytes in vaccinated, simian human immunodeficiency virus-infected rhesus monkeys. J Immunol 176:5338-45.

3. Ahmed, R. K., G. Biberfeld, and R. Thorstensson. 2005. Innate immunity in experimental SIV infection and vaccination. Mol Immunol 42:251-8.

4. Alberts, B., D. Bray, K. Hopkin, A. Johnson, J. Lewis, M. Raff, K. Roberts, and P. Walter. 1998. Essential Cell Biology, 1st edition.

5. Allen, T. M., B. R. Mothe, J. Sidney, P. Jing, J. L. Dzuris, M. E. Liebl, T. U. Vogel, D. H. O'Connor, X. Wang, M. C. Wussow, J. A. Thomson, J. D. Altman, D. I. Watkins, and A. Sette. 2001. CD8(+) lymphocytes from simian immunodeficiency virus-infected rhesus macaques recognize 14 different epitopes bound by the major histocompatibility complex class I molecule mamu-A*01: implications for vaccine design and testing. J Virol 75:738-49.

6. Allen, T. M., J. Sidney, M. F. del Guercio, R. L. Glickman, G. L. Lensmeyer, D. A. Wiebe, R. DeMars, C. D. Pauza, R. P. Johnson, A. Sette, and D. I. Watkins. 1998. Characterization of the peptide binding motif of a rhesus $\mathrm{MHC}$ class I molecule (Mamu- $A^{*} 01$ ) that binds an immunodominant CTL epitope from simian immunodeficiency virus. J Immunol 160:6062-71.

7. Allen, T. M., T. U. Vogel, D. H. Fuller, B. R. Mothe, S. Steffen, J. E. Boyson, T. Shipley, J. Fuller, T. Hanke, A. Sette, J. D. Altman, B. Moss, A. J. McMichael, and D. I. Watkins. 2000. Induction of AIDS virus-specific CTL activity in fresh, unstimulated peripheral blood lymphocytes from rhesus macaques vaccinated with a DNA prime/modified vaccinia virus Ankara boost regimen. J Immunol 164:4968-78.

8. $\quad$ Altfeld, M., E. S. Rosenberg, R. Shankarappa, J. S. Mukherjee, F. M. Hecht, R. L. Eldridge, M. M. Addo, S. H. Poon, M. N. Phillips, G. K. Robbins, P. E. Sax, S. Boswell, J. O. Kahn, C. Brander, P. J. Goulder, J. A. Levy, J. I. Mullins, and B. D. Walker. 2001. Cellular immune responses and viral diversity in individuals treated during acute and early HIV-1 infection. J Exp Med 193:169-80.

9. Altman, J. D., P. A. Moss, P. J. Goulder, D. H. Barouch, M. G. McHeyzer-Williams, J. I. Bell, A. J. McMichael, and M. M. Davis. 1996. Phenotypic analysis of antigen-specific T lymphocytes. Science 274:94-6. 
10. Amara, R. R., K. Patel, G. Niedziela, P. Nigam, S. Sharma, S. I. Staprans, D. C. Montefiori, L. Chenareddi, J. G. Herndon, H. L. Robinson, H. M. McClure, and F. J. Novembre. 2005. A combination DNA and attenuated simian immunodeficiency virus vaccine strategy provides enhanced protection from simian/human immunodeficiency virus-induced disease. J Virol 79:15356-67.

11. Arthur, L. O., J. W. Bess, Jr., D. J. Waters, S. W. Pyle, J. C. Kelliher, P. L. Nara, K. Krohn, W. G. Robey, A. J. Langlois, R. C. Gallo, and et al. 1989. Challenge of chimpanzees (Pan troglodytes) immunized with human immunodeficiency virus envelope glycoprotein gp120. J Virol 63:5046-53.

12. Bahbouhi, B., A. Landay, and L. Al-Harthi. 2004. Dynamics of cytokine expression in HIV productively infected primary CD4+ T cells. Blood 103:4581-7.

13. Baig, J., D. B. Levy, P. F. McKay, J. E. Schmitz, S. Santra, R. A. Subbramanian, M. J. Kuroda, M. A. Lifton, D. A. Gorgone, L. S. Wyatt, B. Moss, Y. Huang, B. K. Chakrabarti, L. Xu, W. P. Kong, Z. Y. Yang, J. R. Mascola, G. J. Nabel, A. Carville, A. A. Lackner, R. S. Veazey, and N. L. Letvin. 2002. Elicitation of simian immunodeficiency virus-specific cytotoxic $T$ lymphocytes in mucosal compartments of rhesus monkeys by systemic vaccination. J Virol 76:11484-90.

14. Barouch, D. H., J. Kunstman, M. J. Kuroda, J. E. Schmitz, S. Santra, F. W. Peyerl, G. R. Krivulka, K. Beaudry, M. A. Lifton, D. A. Gorgone, D. C. Montefiori, M. G. Lewis, S. M. Wolinsky, and N. L. Letvin. 2002. Eventual AIDS vaccine failure in a rhesus monkey by viral escape from cytotoxic T lymphocytes. Nature 415:335-9.

15. Barre-Sinoussi, F., J. C. Chermann, F. Rey, M. T. Nugeyre, S. Chamaret, J. Gruest, C. Dauguet, C. Axler-Blin, F. Vezinet-Brun, C. Rouzioux, W. Rozenbaum, and L. Montagnier. 1983. Isolation of a Tlymphotropic retrovirus from a patient at risk for acquired immune deficiency syndrome (AIDS). Science 220:868-71.

16. Battegay, M., D. Moskophidis, A. Rahemtulla, H. Hengartner, T. W. Mak, and R. M. Zinkernagel. 1994. Enhanced establishment of a virus carrier state in adult CD4+ T-cell-deficient mice. J Virol 68:4700-4.

17. Baumgarth, N., and M. Roederer. 2000. A practical approach to multicolor flow cytometry for immunophenotyping. J Immunol Methods 243:77-97.

18. Beattie, T., R. Kaul, T. Rostron, T. Dong, P. Easterbrook, W. Jaoko, J. Kimani, F. Plummer, A. McMichael, and S. Rowland-Jones. 2004. Screening for HIV-specific T-cell responses using overlapping 15-mer peptide pools or optimized epitopes. Aids 18:1595-8.

19. Belyakov, I. M., D. Isakov, Q. Zhu, A. Dzutsev, and J. A. Berzofsky. 2007. A novel functional CTL avidity/activity compartmentalization to the site of mucosal immunization contributes to protection of macaques against simian/human immunodeficiency viral depletion of mucosal CD4+ T cells. J Immunol 178:7211-21.

20. Berger, E. A. 1998. HIV entry and tropism. When one receptor is not enough. Adv Exp Med Biol 452:151-7. 
21. Betts, M. R., J. M. Brenchley, D. A. Price, S. C. De Rosa, D. C. Douek, M. Roederer, and R. A. Koup. 2003. Sensitive and viable identification of antigen-specific CD8+ T cells by a flow cytometric assay for degranulation. J Immunol Methods 281:65-78.

22. Betts, M. R., B. Exley, D. A. Price, A. Bansal, Z. T. Camacho, V. Teaberry, S. M. West, D. R. Ambrozak, G. Tomaras, M. Roederer, J. M. Kilby, J. Tartaglia, R. Belshe, F. Gao, D. C. Douek, K. J. Weinhold, R. A. Koup, P. Goepfert, and G. Ferrari. 2005. Characterization of functional and phenotypic changes in anti-Gag vaccine-induced $\mathrm{T}$ cell responses and their role in protection after HIV-1 infection. Proc Natl Acad Sci U S A 102:4512-7.

23. Betts, M. R., M. C. Nason, S. M. West, S. C. De Rosa, S. A. Migueles, J. Abraham, M. M. Lederman, J. M. Benito, P. A. Goepfert, M.

Connors, M. Roederer, and R. A. Koup. 2006. HIV nonprogressors preferentially maintain highly functional HIV-specific CD8+ T-cells. Blood.

24. Bjorndal, A., H. Deng, M. Jansson, J. R. Fiore, C. Colognesi, A. Karlsson, J. Albert, G. Scarlatti, D. R. Littman, and E. M. Fenyo. 1997. Coreceptor usage of primary human immunodeficiency virus type 1 isolates varies according to biological phenotype. J Virol 71:7478-87.

25. Bleul, C. C., L. Wu, J. A. Hoxie, T. A. Springer, and C. R. Mackay. 1997. The HIV coreceptors CXCR4 and CCR5 are differentially expressed and regulated on human T lymphocytes. Proc Natl Acad Sci U S A 94:1925-30.

26. Borrow, P., H. Lewicki, B. H. Hahn, G. M. Shaw, and M. B. Oldstone. 1994. Virus-specific CD8+ cytotoxic T-lymphocyte activity associated with control of viremia in primary human immunodeficiency virus type 1 infection. J Virol 68:6103-10.

27. Brenchley, J. M., T. W. Schacker, L. E. Ruff, D. A. Price, J. H. Taylor, G. J. Beilman, P. L. Nguyen, A. Khoruts, M. Larson, A. T. Haase, and D. C. Douek. 2004. CD4+ T cell depletion during all stages of HIV disease occurs predominantly in the gastrointestinal tract. J Exp Med 200:749-59.

28. Calarota, S. A., M. Otero, K. Hermanstayne, M. Lewis, M. Rosati, B. K. Felber, G. N. Pavlakis, J. D. Boyer, and D. B. Weiner. 2003. Use of interleukin 15 to enhance interferon-gamma production by antigenspecific stimulated lymphocytes from rhesus macaques. J Immunol Methods 279:55-67.

29. Casimiro, D. R., F. Wang, W. A. Schleif, X. Liang, Z. Q. Zhang, T. W. Tobery, M. E. Davies, A. B. McDermott, D. H. O'Connor, A. Fridman, A. Bagchi, L. G. Tussey, A. J. Bett, A. C. Finnefrock, T. M. Fu, A. Tang, K. A. Wilson, M. Chen, H. C. Perry, G. J. Heidecker, D. C. Freed, A. Carella, K. S. Punt, K. J. Sykes, L. Huang, V. I. Ausensi, M. Bachinsky, U. Sadasivan-Nair, D. I. Watkins, E. A. Emini, and J. W. Shiver. 2005. Attenuation of simian immunodeficiency virus SIVmac239 infection by prophylactic immunization with dna and recombinant adenoviral vaccine vectors expressing Gag. J Virol 79:15547-55.

30. Catalfamo, M., T. Karpova, J. McNally, S. V. Costes, S. J. Lockett, E. Bos, P. J. Peters, and P. A. Henkart. 2004. Human CD8+ T cells store RANTES in a unique secretory compartment and release it rapidly after TcR stimulation. Immunity 20:219-30. 
31. Champagne, P., G. S. Ogg, A. S. King, C. Knabenhans, K. Ellefsen, M. Nobile, V. Appay, G. P. Rizzardi, S. Fleury, M. Lipp, R. Forster, S. Rowland-Jones, R. P. Sekaly, A. J. McMichael, and G. Pantaleo. 2001. Skewed maturation of memory HIV-specific CD8 T lymphocytes. Nature 410:106-11.

32. Chow, S.-C., Liu, J-P. 2002. Design and Analysis of Clinical Trials: Concepts and Methodologies. Wiley, 2nd edition.

33. Clavel, F., D. Guetard, F. Brun-Vezinet, S. Chamaret, M. A. Rey, M. O. Santos-Ferreira, A. G. Laurent, C. Dauguet, C. Katlama, C. Rouzioux, and et al. 1986. Isolation of a new human retrovirus from West African patients with AIDS. Science 233:343-6.

34. Coffin, J., A. Haase, J. A. Levy, L. Montagnier, S. Oroszlan, N. Teich, H. Temin, K. Toyoshima, H. Varmus, P. Vogt, and et al. 1986. What to call the AIDS virus? Nature 321:10.

35. Cohen, E. A., G. Dehni, J. G. Sodroski, and W. A. Haseltine. 1990. Human immunodeficiency virus vpr product is a virion-associated regulatory protein. J Virol 64:3097-9.

36. Czerkinsky, C., G. Andersson, H. P. Ekre, L. A. Nilsson, L. Klareskog, and O. Ouchterlony. 1988. Reverse ELISPOT assay for clonal analysis of cytokine production. I. Enumeration of gammainterferon-secreting cells. J Immunol Methods 110:29-36.

37. Czerkinsky, C. C., L. A. Nilsson, H. Nygren, O. Ouchterlony, and A. Tarkowski. 1983. A solid-phase enzyme-linked immunospot (ELISPOT) assay for enumeration of specific antibody-secreting cells. J Immunol Methods 65:109-21.

38. Dalgleish, A. G., P. C. Beverley, P. R. Clapham, D. H. Crawford, M. F. Greaves, and R. A. Weiss. 1984. The CD4 (T4) antigen is an essential component of the receptor for the AIDS retrovirus. Nature 312:763-7.

39. Daniel, M. D., F. Kirchhoff, S. C. Czajak, P. K. Sehgal, and R. C. Desrosiers. 1992. Protective effects of a live attenuated SIV vaccine with a deletion in the nef gene. Science 258:1938-41.

40. Daniel, M. D., N. L. Letvin, N. W. King, M. Kannagi, P. K. Sehgal, R. D. Hunt, P. J. Kanki, M. Essex, and R. C. Desrosiers. 1985. Isolation of T-cell tropic HTLV-III-like retrovirus from macaques. Science 228:1201-4.

41. Daniel, M. D., N. L. Letvin, P. K. Sehgal, G. Hunsmann, D. K. Schmidt, N. W. King, and R. C. Desrosiers. 1987. Long-term persistent infection of macaque monkeys with the simian immunodeficiency virus. $J$ Gen Virol 68 ( Pt 12):3183-9.

42. Davies, J. F., 2nd, Z. Hostomska, Z. Hostomsky, S. R. Jordan, and D. A. Matthews. 1991. Crystal structure of the ribonuclease $\mathrm{H}$ domain of HIV-1 reverse transcriptase. Science 252:88-95.

43. De Rosa, S. C., L. A. Herzenberg, L. A. Herzenberg, and M.

Roederer. 2001. 11-color, 13-parameter flow cytometry: identification of human naive $\mathrm{T}$ cells by phenotype, function, and T-cell receptor diversity. Nat Med 7:245-8.

44. De Rosa, S. C., F. X. Lu, J. Yu, S. P. Perfetto, J. Falloon, S. Moser, T. G. Evans, R. Koup, C. J. Miller, and M. Roederer. 2004. Vaccination in humans generates broad T cell cytokine responses. J Immunol 173:5372-80. 
45. Deml, L., R. Schirmbeck, J. Reimann, H. Wolf, and R. Wagner. 1997. Recombinant human immunodeficiency Pr55gag virus-like particles presenting chimeric envelope glycoproteins induce cytotoxic T-cells and neutralizing antibodies. Virology 235:26-39.

46. Desrosiers, R. C. 1995. Non-human primate models for AIDS vaccines. Aids 9 Suppl A:S137-41.

47. Desrosiers, R. C. 2004. Prospects for an AIDS vaccine. Nat Med 10:221-3.

48. Desrosiers, R. C., M. S. Wyand, T. Kodama, D. J. Ringler, L. O. Arthur, P. K. Sehgal, N. L. Letvin, N. W. King, and M. D. Daniel. 1989. Vaccine protection against simian immunodeficiency virus infection. Proc Natl Acad Sci U S A 86:6353-7.

49. Dittmer, U., W. Luke, C. Stahl-Hennig, C. Coulibaly, H. Petry, W. Bodemer, G. Hunsmann, and G. Voss. 1994. Early helper T-cell dysfunction in simian immunodeficiency virus but not in human immunodeficiency virus type-2-infected macaques. J Med Primatol 23:298-303.

50. Doherty, T. M., R. A. Seder, and A. Sher. 1996. Induction and regulation of IL-15 expression in murine macrophages. J Immunol 156:735-41.

51. Donahoe, S. M., W. J. Moretto, R. V. Samuel, K. J. Metzner, P. A. Marx, T. Hanke, R. I. Connor, and D. F. Nixon. 2000. Direct measurement of CD8+ T cell responses in macaques infected with simian immunodeficiency virus. Virology 272:347-56.

52. Douek, D. C., J. M. Brenchley, M. R. Betts, D. R. Ambrozak, B. J. Hill, Y. Okamoto, J. P. Casazza, J. Kuruppu, K. Kunstman, S. Wolinsky, Z. Grossman, M. Dybul, A. Oxenius, D. A. Price, M. Connors, and R. A. Koup. 2002. HIV preferentially infects HIV-specific CD4+ T cells. Nature 417:95-8.

53. Duerr, A., J. N. Wasserheit, and L. Corey. 2006. HIV vaccines: new frontiers in vaccine development. Clin Infect Dis 43:500-11.

54. Duvall, M. G., A. Jaye, T. Dong, J. M. Brenchley, A. S. Alabi, D. J. Jeffries, M. van der Sande, T. O. Togun, S. J. McConkey, D. C. Douek, A. J. McMichael, H. C. Whittle, R. A. Koup, and S. L. Rowland-Jones. 2006. Maintenance of HIV-specific CD4+ T cell help distinguishes HIV-2 from HIV-1 infection. J Immunol 176:6973-81.

55. Evans, D. T., J. E. Bricker, H. B. Sanford, S. Lang, A. Carville, B. A. Richardson, M. Piatak, Jr., J. D. Lifson, K. G. Mansfield, and R. C. Desrosiers. 2005. Immunization of macaques with single-cycle simian immunodeficiency virus (SIV) stimulates diverse virus-specific immune responses and reduces viral loads after challenge with SIVmac239. J Virol 79:7707-20.

56. Fehniger, T. A., G. Herbein, H. Yu, M. I. Para, Z. P. Bernstein, W. A. O'Brien, and M. A. Caligiuri. 1998. Natural killer cells from HIV-1+ patients produce $\mathrm{C}-\mathrm{C}$ chemokines and inhibit HIV-1 infection. J Immunol 161:6433-8.

57. Finkel, T. H., G. Tudor-Williams, N. K. Banda, M. F. Cotton, T. Curiel, C. Monks, T. W. Baba, R. M. Ruprecht, and A. Kupfer. 1995. Apoptosis occurs predominantly in bystander cells and not in productively infected cells of HIV- and SIV-infected lymph nodes. Nat Med 1:129-34. 
58. Freed, E. O., E. L. Delwart, G. L. Buchschacher, Jr., and A. T. Panganiban. 1992. A mutation in the human immunodeficiency virus type 1 transmembrane glycoprotein gp41 dominantly interferes with fusion and infectivity. Proc Natl Acad Sci U S A 89:70-4.

59. Fultz, P. N., H. M. McClure, D. C. Anderson, R. B. Swenson, R. Anand, and A. Srinivasan. 1986. Isolation of a T-lymphotropic retrovirus from naturally infected sooty mangabey monkeys (Cercocebus atys). Proc Natl Acad Sci U S A 83:5286-90.

60. Gauduin, M. C., R. L. Glickman, S. Ahmad, T. Yilma, and R. P. Johnson. 1999. Immunization with live attenuated simian immunodeficiency virus induces strong type $1 \mathrm{~T}$ helper responses and beta-chemokine production. Proc Natl Acad Sci U S A 96:14031-6.

61. Gauduin, M. C., P. W. Parren, R. Weir, C. F. Barbas, D. R. Burton, and R. A. Koup. 1997. Passive immunization with a human monoclonal antibody protects hu-PBL-SCID mice against challenge by primary isolates of HIV-1. Nat Med 3:1389-93.

62. Gauduin, M. C., Y. Yu, A. Barabasz, A. Carville, M. Piatak, J. D. Lifson, R. C. Desrosiers, and R. P. Johnson. 2006. Induction of a virus-specific effector-memory CD4+ T cell response by attenuated SIV infection. J Exp Med 203:2661-72.

63. Gelderblom, H., H. Reupke, T. Winkel, R. Kunze, and G. Pauli. 1987. $\mathrm{MHC}$-antigens: constituents of the envelopes of human and simian immunodeficiency viruses. Z Naturforsch [C] 42:1328-34.

64. Gelderblom, H. R. 1991. Assembly and morphology of HIV: potential effect of structure on viral function. Aids 5:617-37.

65. Gerdes, J., H. Lemke, H. Baisch, H. H. Wacker, U. Schwab, and H. Stein. 1984. Cell cycle analysis of a cell proliferation-associated human nuclear antigen defined by the monoclonal antibody Ki-67. J Immunol 133:1710-5.

66. Gottlieb, M. S., R. Schroff, H. M. Schanker, J. D. Weisman, P. T. Fan, R. A. Wolf, and A. Saxon. 1981. Pneumocystis carinii pneumonia and mucosal candidiasis in previously healthy homosexual men: evidence of a new acquired cellular immunodeficiency. N Engl J Med 305:1425-31.

67. Gottlinger, H. G., J. G. Sodroski, and W. A. Haseltine. 1989. Role of capsid precursor processing and myristoylation in morphogenesis and infectivity of human immunodeficiency virus type 1. Proc Natl Acad Sci U S A 86:5781-5.

68. Goulder, P. J., M. M. Addo, M. A. Altfeld, E. S. Rosenberg, Y. Tang, U. Govender, N. Mngqundaniso, K. Annamalai, T. U. Vogel, M. Hammond, M. Bunce, H. M. Coovadia, and B. D. Walker. 2001. Rapid definition of five novel HLA-A*3002-restricted human immunodeficiency virus-specific cytotoxic T-lymphocyte epitopes by elispot and intracellular cytokine staining assays. J Virol 75:1339-47.

69. Graziosi, C., K. R. Gantt, M. Vaccarezza, J. F. Demarest, M. Daucher, M. S. Saag, G. M. Shaw, T. C. Quinn, O. J. Cohen, C. C. Welbon, G. Pantaleo, and A. S. Fauci. 1996. Kinetics of cytokine expression during primary human immunodeficiency virus type 1 infection. Proc Natl Acad Sci U S A 93:4386-91.

70. Grossman, Z., M. Meier-Schellersheim, W. E. Paul, and L. J. Picker. 2006. Pathogenesis of HIV infection: what the virus spares is as important as what it destroys. Nat Med 12:289-95. 
71. Gundlach, B. R., S. Reiprich, S. Sopper, R. E. Means, U. Dittmer, K. Matz-Rensing, C. Stahl-Hennig, and K. Uberla. 1998. Env-independent protection induced by live, attenuated simian immunodeficiency virus vaccines. J Virol 72:7846-51.

72. Hahn, B. H., G. M. Shaw, K. M. De Cock, and P. M. Sharp. 2000. AIDS as a zoonosis: scientific and public health implications. Science 287:60714.

73. Hamann, D., P. A. Baars, M. H. Rep, B. Hooibrink, S. R. KerkhofGarde, M. R. Klein, and R. A. van Lier. 1997. Phenotypic and functional separation of memory and effector human CD8+ T cells. J Exp Med 186:1407-18.

74. Harari, A., S. Petitpierre, F. Vallelian, and G. Pantaleo. 2004. Skewed representation of functionally distinct populations of virus-specific CD4 T cells in HIV-1-infected subjects with progressive disease: changes after antiretroviral therapy. Blood 103:966-72.

75. Harari, A., F. Vallelian, P. R. Meylan, and G. Pantaleo. 2005. Functional heterogeneity of memory CD4 T cell responses in different conditions of antigen exposure and persistence. J Immunol 174:1037-45.

76. Hartmann, G., A. Marschner, P. R. Viveros, C. Stahl-Hennig, M. Eisenblatter, Y. S. Suh, S. Endres, K. Tenner-Racz, K. Uberla, P. Racz, R. M. Steinman, and R. Ignatius. 2005. CpG oligonucleotides induce strong humoral but only weak CD4+ T cell responses to protein antigens in rhesus macaques in vivo. Vaccine 23:3310-7.

77. Hel, Z., J. Nacsa, E. Tryniszewska, W. P. Tsai, R. W. Parks, D. C. Montefiori, B. K. Felber, J. Tartaglia, G. N. Pavlakis, and G. Franchini. 2002. Containment of simian immunodeficiency virus infection in vaccinated macaques: correlation with the magnitude of virus-specific pre- and postchallenge CD4+ and CD8+ T cell responses. J Immunol 169:4778-87.

78. Hel, Z., W. P. Tsai, E. Tryniszewska, J. Nacsa, P. D. Markham, M. G. Lewis, G. N. Pavlakis, B. K. Felber, J. Tartaglia, and G. Franchini. 2006. Improved vaccine protection from simian AIDS by the addition of nonstructural simian immunodeficiency virus genes. J Immunol 176:8596.

79. Ho, D. D., A. U. Neumann, A. S. Perelson, W. Chen, J. M. Leonard, and M. Markowitz. 1995. Rapid turnover of plasma virions and CD4 lymphocytes in HIV-1 infection. Nature 373:123-6.

80. Horton, H., T. U. Vogel, D. K. Carter, K. Vielhuber, D. H. Fuller, T. Shipley, J. T. Fuller, K. J. Kunstman, G. Sutter, D. C. Montefiori, V. Erfle, R. C. Desrosiers, N. Wilson, L. J. Picker, S. M. Wolinsky, C. Wang, D. B. Allison, and D. I. Watkins. 2002. Immunization of rhesus macaques with a DNA prime/modified vaccinia virus Ankara boost regimen induces broad simian immunodeficiency virus (SIV)-specific Tcell responses and reduces initial viral replication but does not prevent disease progression following challenge with pathogenic SIVmac239. J Virol 76:7187-202.

81. Hu, S. L. 2005. Non-human primate models for AIDS vaccine research. Curr Drug Targets Infect Disord 5:193-201. 
82. Iyasere, C., J. C. Tilton, A. J. Johnson, S. Younes, B. Yassine-Diab, R. P. Sekaly, W. W. Kwok, S. A. Migueles, A. C. Laborico, W. L. Shupert, C. W. Hallahan, R. T. Davey, Jr., M. Dybul, S. Vogel, J. Metcalf, and M. Connors. 2003. Diminished proliferation of human immunodeficiency virus-specific CD4+ T cells is associated with diminished interleukin-2 (IL-2) production and is recovered by exogenous IL-2. J Virol 77:10900-9.

83. Jakob, T., P. S. Walker, A. M. Krieg, E. von Stebut, M. C. Udey, and J. C. Vogel. 1999. Bacterial DNA and CpG-containing oligodeoxynucleotides activate cutaneous dendritic cells and induce IL12 production: implications for the augmentation of Th1 responses. Int Arch Allergy Immunol 118:457-61.

84. Jin, X., D. E. Bauer, S. E. Tuttleton, S. Lewin, A. Gettie, J. Blanchard, C. E. Irwin, J. T. Safrit, J. Mittler, L. Weinberger, L. G. Kostrikis, L. Zhang, A. S. Perelson, and D. D. Ho. 1999. Dramatic rise in plasma viremia after CD8(+) T cell depletion in simian immunodeficiency virusinfected macaques. J Exp Med 189:991-8.

85. Joag, S. V., Z. Li, L. Foresman, E. B. Stephens, L. J. Zhao, I. Adany, D. M. Pinson, H. M. McClure, and O. Narayan. 1996. Chimeric simian/human immunodeficiency virus that causes progressive loss of CD4+ T cells and AIDS in pig-tailed macaques. J Virol 70:3189-97.

86. Johnson, B. K., G. A. Stone, M. S. Godec, D. M. Asher, D. C. Gajdusek, and C. J. Gibbs, Jr. 1993. Long-term observations of human immunodeficiency virus-infected chimpanzees. AIDS Res Hum Retroviruses 9:375-8.

87. Johnson, R. P., J. D. Lifson, S. C. Czajak, K. S. Cole, K. H. Manson, R. Glickman, J. Yang, D. C. Montefiori, R. Montelaro, M. S. Wyand, and R. C. Desrosiers. 1999. Highly attenuated vaccine strains of simian immunodeficiency virus protect against vaginal challenge: inverse relationship of degree of protection with level of attenuation. J Virol 73:4952-61.

88. Jordan, H. L., M. J. Kuroda, J. E. Schmitz, T. Steenbeke, M. A. Forman, and N. L. Letvin. 1999. Detection of simian immunodeficiency virus Gag-specific CD8(+) T lymphocytes in semen of chronically infected rhesus monkeys by cell staining with a tetrameric major histocompatibility complex class I-peptide complex. J Virol 73:4508-12.

89. Kang, S. M., Q. Yao, L. Guo, and R. W. Compans. 2003. Mucosal immunization with virus-like particles of simian immunodeficiency virus conjugated with cholera toxin subunit B. J Virol 77:9823-30.

90. Kanki, P. J., F. Barin, S. M'Boup, J. S. Allan, J. L. Romet-Lemonne, R. Marlink, M. F. McLane, T. H. Lee, B. Arbeille, F. Denis, and et al. 1986. New human T-lymphotropic retrovirus related to simian Tlymphotropic virus type III (STLV-IIIAGM). Science 232:238-43.

91. Karlsson, A. C., J. N. Martin, S. R. Younger, B. M. Bredt, L. Epling, R. Ronquillo, A. Varma, S. G. Deeks, J. M. McCune, D. F. Nixon, and E. Sinclair. 2003. Comparison of the ELISPOT and cytokine flow cytometry assays for the enumeration of antigen-specific T cells. J Immunol Methods 283:141-53. 
92. Kawada, M., T. Tsukamoto, H. Yamamoto, A. Takeda, H. Igarashi, D. I. Watkins, and T. Matano. 2007. Long-term control of simian immunodeficiency virus replication with central memory CD4+ T-cell preservation after nonsterile protection by a cytotoxic T-lymphocytebased vaccine. J Virol 81:5202-11.

93. Kneitz, C., T. Kerkau, J. Muller, C. Coulibaly, C. Stahl-Hennig, G. Hunsmann, T. Hunig, and A. Schimpl. 1993. Early phenotypic and functional alterations in lymphocytes from simian immunodeficiency virus infected macaques. Vet Immunol Immunopathol 36:239-55.

94. Kuate, S., C. Stahl-Hennig, H. Stoiber, G. Nchinda, A. Floto, M. Franz, U. Sauermann, S. Bredl, L. Deml, R. Ignatius, S. Norley, P. Racz, K. Tenner-Racz, R. M. Steinman, R. Wagner, and K. Uberla. 2006. Immunogenicity and efficacy of immunodeficiency virus-like particles pseudotyped with the $\mathrm{G}$ protein of vesicular stomatitis virus. Virology 351:133-44.

95. Kuate, S., C. Stahl-Hennig, P. ten Haaft, J. Heeney, and K. Uberla. 2003. Single-cycle immunodeficiency viruses provide strategies for uncoupling in vivo expression levels from viral replicative capacity and for mimicking live-attenuated SIV vaccines. Virology 313:653-62.

96. Kulaga, H., T. Folks, R. Rutledge, M. E. Truckenmiller, E. Gugel, and T. J. Kindt. 1989. Infection of rabbits with human immunodeficiency virus 1. A small animal model for acquired immunodeficiency syndrome. J Exp Med 169:321-6.

97. Kumar, A., W. Weiss, J. A. Tine, S. L. Hoffman, and W. O. Rogers. 2001. ELISPOT assay for detection of peptide specific interferon-gamma secreting cells in rhesus macaques. J Immunol Methods 247:49-60.

98. Kuroda, M. J., J. E. Schmitz, D. H. Barouch, A. Craiu, T. M. Allen, A. Sette, D. I. Watkins, M. A. Forman, and N. L. Letvin. 1998. Analysis of Gag-specific cytotoxic T lymphocytes in simian immunodeficiency virusinfected rhesus monkeys by cell staining with a tetrameric major histocompatibility complex class I-peptide complex. J Exp Med 187:1373-81.

99. Kuroda, M. J., J. E. Schmitz, W. A. Charini, C. E. Nickerson, M. A. Lifton, C. I. Lord, M. A. Forman, and N. L. Letvin. 1999b. Emergence of CTL coincides with clearance of virus during primary simian immunodeficiency virus infection in rhesus monkeys. J Immunol 162:5127-33.

100. Kuroda, M. J., J. E. Schmitz, W. A. Charini, C. E. Nickerson, C. I. Lord, M. A. Forman, and N. L. Letvin. 1999a. Comparative analysis of cytotoxic $\mathrm{T}$ lymphocytes in lymph nodes and peripheral blood of simian immunodeficiency virus-infected rhesus monkeys. J Virol 73:1573-9.

101. Kutzler, M. A., T. M. Robinson, M. A. Chattergoon, D. K. Choo, A. Y. Choo, P. Y. Choe, M. P. Ramanathan, R. Parkinson, S. Kudchodkar, Y. Tamura, M. Sidhu, V. Roopchand, J. J. Kim, G. N. Pavlakis, B. K. Felber, T. A. Waldmann, J. D. Boyer, and D. B. Weiner. 2005. Coimmunization with an optimized IL-15 plasmid results in enhanced function and longevity of CD8 T cells that are partially independent of CD4 T cell help. J Immunol 175:112-23. 
102. Kwong, P. D., R. Wyatt, J. Robinson, R. W. Sweet, J. Sodroski, and W. A. Hendrickson. 1998. Structure of an HIV gp120 envelope glycoprotein in complex with the CD4 receptor and a neutralizing human antibody. Nature 393:648-59.

103. Lathey, J. L., R. D. Pratt, and S. A. Spector. 1997. Appearance of autologous neutralizing antibody correlates with reduction in virus load and phenotype switch during primary infection with human immunodeficiency virus type 1. J Infect Dis 175:231-2.

104. Le Grand, R., G. Vogt, B. Vaslin, P. Roques, F. Theodoro, A. M. Aubertin, and D. Dormont. 1992. Specific and non-specific immunity and protection of macaques against SIV infection. Vaccine 10:873-9.

105. Leavitt, A. D., R. B. Rose, and H. E. Varmus. 1992. Both substrate and target oligonucleotide sequences affect in vitro integration mediated by human immunodeficiency virus type 1 integrase protein produced in Saccharomyces cerevisiae. J Virol 66:2359-68.

106. Lederman, M. M., R. S. Veazey, R. Offord, D. E. Mosier, J. Dufour, M. Mefford, M. Piatak, Jr., J. D. Lifson, J. R. Salkowitz, B. Rodriguez, A. Blauvelt, and O. Hartley. 2004. Prevention of vaginal SHIV transmission in rhesus macaques through inhibition of CCR5. Science 306:485-7.

107. Lehner, T., R. Brookes, C. Panagiotidi, L. Tao, L. S. Klavinskis, J. Walker, P. Walker, R. Ward, L. Hussain, J. H. Gearing, and et al. 1993. T- and B-cell functions and epitope expression in nonhuman primates immunized with simian immunodeficiency virus antigen by the rectal route. Proc Natl Acad Sci U S A 90:8638-42.

108. Letvin, N. L., M. D. Daniel, P. K. Sehgal, R. C. Desrosiers, R. D. Hunt, L. M. Waldron, J. J. MacKey, D. K. Schmidt, L. V. Chalifoux, and N. W. King. 1985. Induction of AIDS-like disease in macaque monkeys with T-cell tropic retrovirus STLV-III. Science 230:71-3.

109. Letvin, N. L., and N. W. King. 1990. Immunologic and pathologic manifestations of the infection of rhesus monkeys with simian immunodeficiency virus of macaques. J Acquir Immune Defic Syndr 3:1023-40.

110. Letvin, N. L., J. R. Mascola, Y. Sun, D. A. Gorgone, A. P. Buzby, L. Xu, Z. Y. Yang, B. Chakrabarti, S. S. Rao, J. E. Schmitz, D. C. Montefiori, B. R. Barker, F. L. Bookstein, and G. J. Nabel. 2006. Preserved CD4+ central memory T cells and survival in vaccinated SIVchallenged monkeys. Science 312:1530-3.

111. Letvin, N. L., J. E. Schmitz, H. L. Jordan, A. Seth, V. M. Hirsch, K. A. Reimann, and M. J. Kuroda. 1999. Cytotoxic T lymphocytes specific for the simian immunodeficiency virus. Immunol Rev 170:127-34.

112. Li, Q., L. Duan, J. D. Estes, Z. M. Ma, T. Rourke, Y. Wang, C. Reilly, J. Carlis, C. J. Miller, and A. T. Haase. 2005. Peak SIV replication in resting memory CD4+ T cells depletes gut lamina propria CD4+ T cells. Nature 434:1148-52. 
113. Lifson, J. D., J. L. Rossio, M. Piatak, Jr., J. Bess, Jr., E. Chertova, D. K. Schneider, V. J. Coalter, B. Poore, R. F. Kiser, R. J. Imming, A. J. Scarzello, L. E. Henderson, W. G. Alvord, V. M. Hirsch, R. E. Benveniste, and L. O. Arthur. 2004. Evaluation of the safety, immunogenicity, and protective efficacy of whole inactivated simian immunodeficiency virus (SIV) vaccines with conformationally and functionally intact envelope glycoproteins. AIDS Res Hum Retroviruses 20:772-87.

114. Ling, B., R. S. Veazey, A. Luckay, C. Penedo, K. Xu, J. D. Lifson, and P. A. Marx. 2002. SIV(mac) pathogenesis in rhesus macaques of Chinese and Indian origin compared with primary HIV infections in humans. Aids 16:1489-96.

115. Liu, H., X. Wu, M. Newman, G. M. Shaw, B. H. Hahn, and J. C. Kappes. 1995. The Vif protein of human and simian immunodeficiency viruses is packaged into virions and associates with viral core structures. J Virol 69:7630-8.

116. Lusso, P., P. D. Markham, A. Ranki, P. Earl, B. Moss, F. Dorner, R. C. Gallo, and K. J. Krohn. 1988. Cell-mediated immune response toward viral envelope and core antigens in gibbon apes (Hylobates lar) chronically infected with human immunodeficiency virus-1. J Immunol 141:2467-73.

117. Maecker, H. T., A. Rinfret, P. D'Souza, J. Darden, E. Roig, C. Landry, P. Hayes, J. Birungi, O. Anzala, M. Garcia, A. Harari, I. Frank, R. Baydo, M. Baker, J. Holbrook, J. Ottinger, L. Lamoreaux, C. L. Epling, E. Sinclair, M. A. Suni, K. Punt, S. Calarota, S. El-Bahi, G. Alter, H. Maila, E. Kuta, J. Cox, C. Gray, M. Altfeld, N. Nougarede, J. Boyer, L. Tussey, T. Tobery, B. Bredt, M. Roederer, R. Koup, V. C. Maino, K. Weinhold, G. Pantaleo, J. Gilmour, H. Horton, and R. P. Sekaly. 2005. Standardization of cytokine flow cytometry assays. BMC Immunol 6:13.

118. Makedonas, G., and M. R. Betts. 2006. Polyfunctional analysis of human t cell responses: importance in vaccine immunogenicity and natural infection. Springer Semin Immunopathol 28:209-19.

119. Makitalo, B., P. Lundholm, J. Hinkula, C. Nilsson, K. Karlen, A. Morner, G. Sutter, V. Erfle, J. L. Heeney, B. Wahren, G. Biberfeld, and R. Thorstensson. 2004. Enhanced cellular immunity and systemic control of SHIV infection by combined parenteral and mucosal administration of a DNA prime MVA boost vaccine regimen. J Gen Virol 85:2407-19.

120. Marcondes, M. C., M. C. Penedo, C. Lanigan, D. Hall, D. D. Watry, M. Zandonatti, and H. S. Fox. 2006. Simian immunodeficiency virusinduced CD4+ T cell deficits in cytokine secretion profile are dependent on monkey origin. Viral Immunol 19:679-89.

121. Margolis, L. B., S. Glushakova, J. C. Grivel, and P. M. Murphy. 1998. Blockade of CC chemokine receptor 5 (CCR5)-tropic human immunodeficiency virus-1 replication in human lymphoid tissue by CC chemokines. J Clin Invest 101:1876-80. 
122. Mascola, J. R., G. Stiegler, T. C. VanCott, H. Katinger, C. B. Carpenter, C. E. Hanson, H. Beary, D. Hayes, S. S. Frankel, D. L. Birx, and M. G. Lewis. 2000. Protection of macaques against vaginal transmission of a pathogenic HIV-1/SIV chimeric virus by passive infusion of neutralizing antibodies. Nat Med 6:207-10.

123. Masur, H., M. A. Michelis, J. B. Greene, I. Onorato, R. A. Stouwe, R. S. Holzman, G. Wormser, L. Brettman, M. Lange, H. W. Murray, and S. Cunningham-Rundles. 1981. An outbreak of community-acquired Pneumocystis carinii pneumonia: initial manifestation of cellular immune dysfunction. N Engl J Med 305:1431-8.

124. Matloubian, M., R. J. Concepcion, and R. Ahmed. 1994. CD4+ T cells are required to sustain $\mathrm{CD} 8+$ cytotoxic $\mathrm{T}$-cell responses during chronic viral infection. J Virol 68:8056-63.

125. Mattapallil, J. J., D. C. Douek, A. Buckler-White, D. Montefiori, N. L. Letvin, G. J. Nabel, and M. Roederer. 2006. Vaccination preserves CD4 memory T cells during acute simian immunodeficiency virus challenge. J Exp Med.

126. Mattapallil, J. J., D. C. Douek, B. Hill, Y. Nishimura, M. Martin, and M. Roederer. 2005. Massive infection and loss of memory CD4+ T cells in multiple tissues during acute SIV infection. Nature 434:1093-7.

127. Mehandru, S., M. A. Poles, K. Tenner-Racz, V. Manuelli, P. JeanPierre, P. Lopez, A. Shet, A. Low, H. Mohri, D. Boden, P. Racz, and M. Markowitz. 2007. Mechanisms of gastrointestinal CD4+ T-cell depletion during acute and early human immunodeficiency virus type 1 infection. J Virol 81:599-612.

128. Mellors, J. W., A. Munoz, J. V. Giorgi, J. B. Margolick, C. J. Tassoni, P. Gupta, L. A. Kingsley, J. A. Todd, A. J. Saah, R. Detels, J. P. Phair, and C. R. Rinaldo, Jr. 1997. Plasma viral load and CD4+ lymphocytes as prognostic markers of HIV-1 infection. Ann Intern Med 126:946-54.

129. Meyaard, L., S. A. Otto, I. P. Keet, M. T. Roos, and F. Miedema. 1994. Programmed death of T cells in human immunodeficiency virus infection. No correlation with progression to disease. J Clin Invest 93:982-8.

130. Miller, M. D., H. Yamamoto, A. L. Hughes, D. I. Watkins, and N. L. Letvin. 1991. Definition of an epitope and MHC class I molecule recognized by gag-specific cytotoxic $T$ lymphocytes in SIVmac-infected rhesus monkeys. J Immunol 147:320-9.

131. Moniuszko, M., D. Bogdan, R. Pal, D. Venzon, L. Stevceva, J. Nacsa, E. Tryniszewska, Y. Edghill-Smith, S. M. Wolinsky, and G. Franchini. 2005. Correlation between viral RNA levels but not immune responses in plasma and tissues of macaques with long-standing SIVmac251 infection. Virology 333:159-68.

132. Montefiori, D. C., J. T. Safrit, S. L. Lydy, A. P. Barry, M. Bilska, H. T. Vo, M. Klein, J. Tartaglia, H. L. Robinson, and B. Rovinski. 2001. Induction of neutralizing antibodies and gag-specific cellular immune responses to an R5 primary isolate of human immunodeficiency virus type 1 in rhesus macaques. J Virol 75:5879-90. 
133. Moore, J. P., Y. Cao, L. Qing, Q. J. Sattentau, J. Pyati, R. Koduri, J. Robinson, C. F. Barbas, 3rd, D. R. Burton, and D. D. Ho. 1995.

Primary isolates of human immunodeficiency virus type 1 are relatively resistant to neutralization by monoclonal antibodies to gp120, and their neutralization is not predicted by studies with monomeric gp120. J Virol 69:101-9.

134. Mothe, B. R., H. Horton, D. K. Carter, T. M. Allen, M. E. Liebl, P. Skinner, T. U. Vogel, S. Fuenger, K. Vielhuber, W. Rehrauer, N. Wilson, G. Franchini, J. D. Altman, A. Haase, L. J. Picker, D. B. Allison, and D. I. Watkins. 2002. Dominance of CD8 responses specific for epitopes bound by a single major histocompatibility complex class I molecule during the acute phase of viral infection. J Virol 76:875-84.

135. Mothe, B. R., J. Weinfurter, C. Wang, W. Rehrauer, N. Wilson, T. M. Allen, D. B. Allison, and D. I. Watkins. 2003. Expression of the major histocompatibility complex class I molecule Mamu-A*01 is associated with control of simian immunodeficiency virus SIVmac239 replication. J Virol 77:2736-40.

136. Muhl, T., M. Krawczak, P. Ten Haaft, G. Hunsmann, and U. Sauermann. 2002. MHC class I alleles influence set-point viral load and survival time in simian immunodeficiency virus-infected rhesus monkeys. J Immunol 169:3438-46.

137. Murphy, F. A., Kingsbury, D.W. . 1990. Virus taxonomy. In B.N. Fields: Virology 2.Auflage.

138. Musso, T., L. Calosso, M. Zucca, M. Millesimo, D. Ravarino, M. Giovarelli, F. Malavasi, A. N. Ponzi, R. Paus, and S. Bulfone-Paus. 1999. Human monocytes constitutively express membrane-bound, biologically active, and interferon-gamma-upregulated interleukin-15. Blood 93:3531-9.

139. Nara, P. L., W. G. Robey, L. O. Arthur, D. M. Asher, A. V. Wolff, C. J. Gibbs, Jr., D. C. Gajdusek, and P. J. Fischinger. 1987. Persistent infection of chimpanzees with human immunodeficiency virus: serological responses and properties of reisolated viruses. J Virol 61:3173-80.

140. Narayan, O., and J. E. Clements. 1989. Biology and pathogenesis of lentiviruses. J Gen Virol 70 ( Pt 7):1617-39.

141. Neeson, P., J. Boyer, S. Kumar, M. G. Lewis, L. Mattias, R. Veazey, D. Weiner, and Y. Paterson. 2006. A DNA prime-oral Listeria boost vaccine in rhesus macaques induces a SIV-specific CD8 T cell mucosal response characterized by high levels of alpha4beta7 integrin and an effector memory phenotype. Virology 354:299-315.

142. Negri, D. R., S. Baroncelli, S. Catone, A. Comini, Z. Michelini, M. T. Maggiorella, L. Sernicola, F. Crostarosa, R. Belli, M. G. Mancini, S. Farcomeni, Z. Fagrouch, M. Ciccozzi, S. Boros, P. Liljestrom, S. Norley, J. Heeney, and F. Titti. 2004. Protective efficacy of a multicomponent vector vaccine in cynomolgus monkeys after intrarectal simian immunodeficiency virus challenge. J Gen Virol 85:1191-201.

143. Neutra, M. R., and P. A. Kozlowski. 2006. Mucosal vaccines: the promise and the challenge. Nat Rev Immunol 6:148-58. 
144. Nishimura, Y., T. Igarashi, O. K. Donau, A. Buckler-White, C. Buckler, B. A. Lafont, R. M. Goeken, S. Goldstein, V. M. Hirsch, and M. A. Martin. 2004. Highly pathogenic SHIVs and SIVs target different CD4+ T cell subsets in rhesus monkeys, explaining their divergent clinical courses. Proc Natl Acad Sci U S A 101:12324-9.

145. Notka, F., C. Stahl-Hennig, U. Dittmer, H. Wolf, and R. Wagner. 1999. Accelerated clearance of SHIV in rhesus monkeys by virus-like particle vaccines is dependent on induction of neutralizing antibodies. Vaccine 18:291-301.

146. Ochsenbein, A. F., D. D. Pinschewer, S. Sierro, E. Horvath, H. Hengartner, and R. M. Zinkernagel. 2000. Protective long-term antibody memory by antigen-driven and $\mathrm{T}$ help-dependent differentiation of long-lived memory B cells to short-lived plasma cells independent of secondary lymphoid organs. Proc Natl Acad Sci U S A 97:13263-8.

147. O'Connor, D. H., B. R. Mothe, J. T. Weinfurter, S. Fuenger, W. M. Rehrauer, P. Jing, R. R. Rudersdorf, M. E. Liebl, K. Krebs, J. Vasquez, E. Dodds, J. Loffredo, S. Martin, A. B. McDermott, T. M. Allen, C. Wang, G. G. Doxiadis, D. C. Montefiori, A. Hughes, D. R. Burton, D. B. Allison, S. M. Wolinsky, R. Bontrop, L. J. Picker, and D. I. Watkins. 2003. Major histocompatibility complex class I alleles associated with slow simian immunodeficiency virus disease progression bind epitopes recognized by dominant acute-phase cytotoxic-Tlymphocyte responses. J Virol 77:9029-40.

148. Pahar, B., J. Li, T. Rourke, C. J. Miller, and M. B. McChesney. 2003. Detection of antigen-specific $\mathrm{T}$ cell interferon gamma expression by ELISPOT and cytokine flow cytometry assays in rhesus macaques. $\mathrm{J}$ Immunol Methods 282:103-15.

149. Pal, R., D. Venzon, N. L. Letvin, S. Santra, D. C. Montefiori, N. R. Miller, E. Tryniszewska, M. G. Lewis, T. C. VanCott, V. Hirsch, R. Woodward, A. Gibson, M. Grace, E. Dobratz, P. D. Markham, Z. Hel, J. Nacsa, M. Klein, J. Tartaglia, and G. Franchini. 2002. ALVAC-SIVgag-pol-env-based vaccination and macaque major histocompatibility complex class I $\left(A^{*} 01\right)$ delay simian immunodeficiency virus SIVmacinduced immunodeficiency. J Virol 76:292-302.

150. Palella, F. J., Jr., K. M. Delaney, A. C. Moorman, M. O. Loveless, J. Fuhrer, G. A. Satten, D. J. Aschman, and S. D. Holmberg. 1998. Declining morbidity and mortality among patients with advanced human immunodeficiency virus infection. HIV Outpatient Study Investigators. N Engl J Med 338:853-60.

151. Paliard, X., Y. Liu, R. Wagner, H. Wolf, J. Baenziger, and C. M. Walker. 2000. Priming of strong, broad, and long-lived HIV type 1 p55gag-specific CD8+ cytotoxic T cells after administration of a virus-like particle vaccine in rhesus macaques. AIDS Res Hum Retroviruses 16:273-82.

152. Pantophlet, R., and D. R. Burton. 2006. GP120: target for neutralizing HIV-1 antibodies. Annu Rev Immunol 24:739-69. 
153. Patterson, L. J., N. Malkevitch, D. Venzon, J. Pinczewski, V. R. Gomez-Roman, L. Wang, V. S. Kalyanaraman, P. D. Markham, F. A. Robey, and M. Robert-Guroff. 2004. Protection against mucosal simian immunodeficiency virus SIV(mac251) challenge by using replicating adenovirus-SIV multigene vaccine priming and subunit boosting. J Virol 78:2212-21.

154. Peeters, M., C. Honore, T. Huet, L. Bedjabaga, S. Ossari, P. Bussi, R. W. Cooper, and E. Delaporte. 1989. Isolation and partial characterization of an HIV-related virus occurring naturally in chimpanzees in Gabon. Aids 3:625-30.

155. Peretz, Y., M. L. Ndongala, S. Boulet, M. R. Boulassel, D. Rouleau, P. Cote, D. Longpre, J. P. Routy, J. Falutz, C. Tremblay, C. M. Tsoukas, R. P. Sekaly, and N. F. Bernard. 2007. Functional T cell subsets contribute differentially to HIV peptide-specific responses within infected individuals: Correlation of these functional T cell subsets with markers of disease progression. Clin Immunol.

156. Persidsky, Y., H. S. Nottet, V. G. Sasseville, L. G. Epstein, and H. E. Gendelman. 1995. The development of animal model systems for HIV-1 encephalitis and its associated dementia. J Neurovirol 1:229-43.

157. Petrovas, C., D. A. Price, J. Mattapallil, D. R. Ambrozak, C. Geldmacher, V. Cecchinato, M. Vaccari, E. Tryniszewska, E. Gostick, M. Roederer, D. C. Douek, S. H. Morgan, S. J. Davis, G. Franchini, and R. A. Koup. 2007. SIV-specific CD8+T-cells express high levels of PD1 and cytokines but have impaired proliferative capacity in acute and chronic SIVmac251 infection. Blood.

158. Pfeffer, K. 2003. Biological functions of tumor necrosis factor cytokines and their receptors. Cytokine Growth Factor Rev 14:185-91.

159. Phillips, A. N. 1996. Reduction of HIV concentration during acute infection: independence from a specific immune response. Science 271:497-9.

160. Picker, L. J., S. I. Hagen, R. Lum, E. F. Reed-Inderbitzin, L. M. Daly, A. W. Sylwester, J. M. Walker, D. C. Siess, M. Piatak, Jr., C. Wang, D. B. Allison, V. C. Maino, J. D. Lifson, T. Kodama, and M. K. Axthelm. 2004. Insufficient production and tissue delivery of CD4+ memory T cells in rapidly progressive simian immunodeficiency virus infection. J Exp Med 200:1299-314.

161. Picker, L. J., E. F. Reed-Inderbitzin, S. I. Hagen, J. B. Edgar, S. G. Hansen, A. Legasse, S. Planer, M. Piatak, Jr., J. D. Lifson, V. C. Maino, M. K. Axthelm, and F. Villinger. 2006. IL-15 induces CD4 effector memory $T$ cell production and tissue emigration in nonhuman primates. J Clin Invest 116:1514-24.

162. Picker, L. J., M. K. Singh, Z. Zdraveski, J. R. Treer, S. L. Waldrop, P. R. Bergstresser, and V. C. Maino. 1995. Direct demonstration of cytokine synthesis heterogeneity among human memory/effector $\mathrm{T}$ cells by flow cytometry. Blood 86:1408-19.

163. Picker, L. J., and D. I. Watkins. 2005. HIV pathogenesis: the first cut is the deepest. Nat Immunol 6:430-2.

164. Pitcher, C. J., S. I. Hagen, J. M. Walker, R. Lum, B. L. Mitchell, V. C. Maino, M. K. Axthelm, and L. J. Picker. 2002. Development and homeostasis of T cell memory in rhesus macaque. J Immunol 168:29-43. 
165. Pitcher, C. J., C. Quittner, D. M. Peterson, M. Connors, R. A. Koup, V. C. Maino, and L. J. Picker. 1999. HIV-1-specific CD4+ T cells are detectable in most individuals with active HIV-1 infection, but decline with prolonged viral suppression. Nat Med 5:518-25.

166. Pope, M., and A. T. Haase. 2003. Transmission, acute HIV-1 infection and the quest for strategies to prevent infection. Nat Med 9:847-52.

167. Richman, D. D., T. Wrin, S. J. Little, and C. J. Petropoulos. 2003. Rapid evolution of the neutralizing antibody response to HIV type 1 infection. Proc Natl Acad Sci U S A 100:4144-9.

168. Rosati, M., A. von Gegerfelt, P. Roth, C. Alicea, A. Valentin, M. Robert-Guroff, D. Venzon, D. C. Montefiori, P. Markham, B. K. Felber, and G. N. Pavlakis. 2005. DNA vaccines expressing different forms of simian immunodeficiency virus antigens decrease viremia upon SIVmac251 challenge. J Virol 79:8480-92.

169. Rosenberg, E. S., J. M. Billingsley, A. M. Caliendo, S. L. Boswell, P. E. Sax, S. A. Kalams, and B. D. Walker. 1997. Vigorous HIV-1-specific CD4+ T cell responses associated with control of viremia. Science 278:1447-50.

170. Sacha, J. B., C. Chung, E. G. Rakasz, S. P. Spencer, A. K. Jonas, A. T. Bean, W. Lee, B. J. Burwitz, J. J. Stephany, J. T. Loffredo, D. B. Allison, S. Adnan, A. Hoji, N. A. Wilson, T. C. Friedrich, J. D. Lifson, O. O. Yang, and D. I. Watkins. 2007. Gag-specific CD8+ T lymphocytes recognize infected cells before AIDS-virus integration and viral protein expression. J Immunol 178:2746-54.

171. Sakaguchi, K., N. Zambrano, E. T. Baldwin, B. A. Shapiro, J. W. Erickson, J. G. Omichinski, G. M. Clore, A. M. Gronenborn, and E. Appella. 1993. Identification of a binding site for the human immunodeficiency virus type 1 nucleocapsid protein. Proc Natl Acad Sci U S A 90:5219-23.

172. Sallusto, F., J. Geginat, and A. Lanzavecchia. 2004. Central memory and effector memory $T$ cell subsets: function, generation, and maintenance. Annu Rev Immunol 22:745-63.

173. Sallusto, F., D. Lenig, R. Forster, M. Lipp, and A. Lanzavecchia. 1999. Two subsets of memory T lymphocytes with distinct homing potentials and effector functions. Nature 401:708-12.

174. Sammons, M. L., E. L. Stephen, H. B. Levy, S. Baron, and D. E. Hilmas. 1977. Interferon induction in cynomolgus and rhesus monkey after repeated doses of a modified polyriboinosinic-polyribocytidylic acid complex. Antimicrob Agents Chemother 11:80-3.

175. Santiago, M. L., C. M. Rodenburg, S. Kamenya, F. Bibollet-Ruche, F. Gao, E. Bailes, S. Meleth, S. J. Soong, J. M. Kilby, Z. Moldoveanu, B. Fahey, M. N. Muller, A. Ayouba, E. Nerrienet, H. M. McClure, J. L. Heeney, A. E. Pusey, D. A. Collins, C. Boesch, R. W. Wrangham, J. Goodall, P. M. Sharp, G. M. Shaw, and B. H. Hahn. 2002. SIVcpz in wild chimpanzees. Science 295:465.

176. Schmitz, J. E., M. J. Kuroda, S. Santra, V. G. Sasseville, M. A. Simon, M. A. Lifton, P. Racz, K. Tenner-Racz, M. Dalesandro, B. J. Scallon, J. Ghrayeb, M. A. Forman, D. C. Montefiori, E. P. Rieber, N. L. Letvin, and K. A. Reimann. 1999. Control of viremia in simian immunodeficiency virus infection by CD8+ lymphocytes. Science 283:857-60. 
177. Schroder, K., P. J. Hertzog, T. Ravasi, and D. A. Hume. 2004. Interferon-gamma: an overview of signals, mechanisms and functions. J Leukoc Biol 75:163-89.

178. Sedgwick, J. D., and P. G. Holt. 1983. Kinetics and distribution of antigen-specific IgE-secreting cells during the primary antibody response in the rat. J Exp Med 157:2178-83.

179. Shacklett, B. L., C. A. Cox, J. K. Sandberg, N. H. Stollman, M. A. Jacobson, and D. F. Nixon. 2003. Trafficking of human immunodeficiency virus type 1-specific CD8+ T cells to gut-associated lymphoid tissue during chronic infection. J Virol 77:5621-31.

180. Shankar, P., M. Russo, B. Harnisch, M. Patterson, P. Skolnik, and J. Lieberman. 2000. Impaired function of circulating HIV-specific CD8(+) T cells in chronic human immunodeficiency virus infection. Blood 96:3094101.

181. Sharpe, S. A., A. Cope, S. Dowall, N. Berry, C. Ham, J. L. Heeney, D. Hopkins, L. Easterbrook, M. Dennis, N. Almond, and M. Cranage. 2004. Macaques infected long-term with attenuated simian immunodeficiency virus (SIVmac) remain resistant to wild-type challenge, despite declining cytotoxic $T$ lymphocyte responses to an immunodominant epitope. J Gen Virol 85:2591-602.

182. Shiver, J. W., T. M. Fu, L. Chen, D. R. Casimiro, M. E. Davies, R. K. Evans, Z. Q. Zhang, A. J. Simon, W. L. Trigona, S. A. Dubey, L. Huang, V. A. Harris, R. S. Long, X. Liang, L. Handt, W. A. Schleif, L. Zhu, D. C. Freed, N. V. Persaud, L. Guan, K. S. Punt, A. Tang, M. Chen, K. A. Wilson, K. B. Collins, G. J. Heidecker, V. R. Fernandez, H. C. Perry, J. G. Joyce, K. M. Grimm, J. C. Cook, P. M. Keller, D. S. Kresock, H. Mach, R. D. Troutman, L. A. Isopi, D. M. Williams, Z. Xu, K. E. Bohannon, D. B. Volkin, D. C. Montefiori, A. Miura, G. R. Krivulka, M. A. Lifton, M. J. Kuroda, J. E. Schmitz, N. L. Letvin, M. J. Caulfield, A. J. Bett, R. Youil, D. C. Kaslow, and E. A. Emini. 2002. Replication-incompetent adenoviral vaccine vector elicits effective antiimmunodeficiency-virus immunity. Nature 415:331-5.

183. Siegal, F. P., C. Lopez, G. S. Hammer, A. E. Brown, S. J. Kornfeld, J. Gold, J. Hassett, S. Z. Hirschman, C. Cunningham-Rundles, B. R. Adelsberg, and et al. 1981. Severe acquired immunodeficiency in male homosexuals, manifested by chronic perianal ulcerative herpes simplex lesions. N Engl J Med 305:1439-44.

184. Someya, K., Y. Ami, T. Nakasone, Y. Izumi, K. Matsuo, S. Horibata, K. Q. Xin, H. Yamamoto, K. Okuda, N. Yamamoto, and M. Honda. 2006. Induction of positive cellular and humoral immune responses by a prime-boost vaccine encoded with simian immunodeficiency virus gag/pol. J Immunol 176:1784-95.

185. Song, K., R. L. Rabin, B. J. Hill, S. C. De Rosa, S. P. Perfetto, H. H. Zhang, J. F. Foley, J. S. Reiner, J. Liu, J. J. Mattapallil, D. C. Douek, M. Roederer, and J. M. Farber. 2005. Characterization of subsets of CD4+ memory $T$ cells reveals early branched pathways of $T$ cell differentiation in humans. Proc Natl Acad Sci U S A 102:7916-21. 
186. Sopper, S., D. Nierwetberg, A. Halbach, U. Sauer, C. Scheller, C. Stahl-Hennig, K. Matz-Rensing, F. Schafer, T. Schneider, V. ter Meulen, and J. G. Muller. 2003. Impact of simian immunodeficiency virus (SIV) infection on lymphocyte numbers and T-cell turnover in different organs of rhesus monkeys. Blood 101:1213-9.

187. Stahl-Hennig, C., R. M. Steinman, P. Ten Haaft, K. Uberla, N. Stolte, S. Saeland, K. Tenner-Racz, and P. Racz. 2002. The simian immunodeficiency virus deltaNef vaccine, after application to the tonsils of Rhesus macaques, replicates primarily within CD4(+) T cells and elicits a local perforin-positive CD8(+) T-cell response. J Virol 76:688-96.

188. Stahl-Hennig, C., R. M. Steinman, K. Tenner-Racz, M. Pope, N. Stolte, K. Matz-Rensing, G. Grobschupff, B. Raschdorff, G. Hunsmann, and P. Racz. 1999. Rapid infection of oral mucosalassociated lymphoid tissue with simian immunodeficiency virus. Science 285:1261-5.

189. Stahl-Hennig, C., Y. S. Suh, K. S. Park, U. Sauermann, K. S. Kim, S. Ahn, M. Franz, R. Schulte, N. Stolte-Leeb, G. Hunsmann, and Y. C. Sung. 2007. Immunogenicity of a DNA prime and recombinant adenovirus boost regime significantly varies between rhesus macaques of Chinese and Indian origins. J Med Primatol 36:195-205.

190. Stahl-Hennig, C., G. Voss, S. Nick, H. Petry, D. Fuchs, H. Wachter, C. Coulibaly, W. Luke, and G. Hunsmann. 1992. Immunization with tween-ether-treated SIV adsorbed onto aluminum hydroxide protects monkeys against experimental SIV infection. Virology 186:588-96.

191. Suh, Y. S., K. S. Park, U. Sauermann, M. Franz, S. Norley, D. Wilfingseder, H. Stoiber, Z. Fagrouch, J. Heeney, G. Hunsmann, C. Stahl-Hennig, and Y. C. Sung. 2006. Reduction of viral loads by multigenic DNA priming and adenovirus boosting in the SIVmacmacaque model. Vaccine 24:1811-20.

192. Sun, J. C., M. A. Williams, and M. J. Bevan. 2004. CD4+ T cells are required for the maintenance, not programming, of memory CD8+ T cells after acute infection. Nat Immunol 5:927-33.

193. Sun, Y., J. E. Schmitz, P. M. Acierno, S. Santra, R. A. Subbramanian, D. H. Barouch, D. A. Gorgone, M. A. Lifton, K. R. Beaudry, K. Manson, V. Philippon, L. Xu, H. T. Maecker, J. R. Mascola, D. Panicali, G. J. Nabel, and N. L. Letvin. 2005. Dysfunction of simian immunodeficiency virus/simian human immunodeficiency virus-induced IL-2 expression by central memory CD4+ T Iymphocytes. J Immunol 174:4753-60.

194. Sun, Y., J. E. Schmitz, A. P. Buzby, B. R. Barker, S. S. Rao, L. Xu, Z. Y. Yang, J. R. Mascola, G. J. Nabel, and N. L. Letvin. 2006. Virusspecific cellular immune correlates of survival in vaccinated monkeys after simian immunodeficiency virus challenge. J Virol 80:10950-6.

195. Tanaka, K., and M. Kasahara. 1998. The MHC class I ligand-generating system: roles of immunoproteasomes and the interferon-gammainducible proteasome activator PA28. Immunol Rev 163:161-76. 
196. Teleshova, N., J. Kenney, J. Jones, J. Marshall, G. Van Nest, J. Dufour, R. Bohm, J. D. Lifson, A. Gettie, and M. Pope. 2004. CpG-C immunostimulatory oligodeoxyribonucleotide activation of plasmacytoid dendritic cells in rhesus macaques to augment the activation of IFNgamma-secreting simian immunodeficiency virus-specific $T$ cells. J Immunol 173:1647-57.

197. Tenner-Racz, K., C. Stahl Hennig, K. Uberla, H. Stoiber, R. Ignatius, J. Heeney, R. M. Steinman, and P. Racz. 2004. Early protection against pathogenic virus infection at a mucosal challenge site after vaccination with attenuated simian immunodeficiency virus. Proc Natl Acad Sci U S A 101:3017-22.

198. Thorner, A. R., A. A. Lemckert, J. Goudsmit, D. M. Lynch, B. A. Ewald, M. Denholtz, M. J. Havenga, and D. H. Barouch. 2006. Immunogenicity of heterologous recombinant adenovirus prime-boost vaccine regimens is enhanced by circumventing vector cross-reactivity. $\mathrm{J}$ Virol 80:12009-16.

199. Trichel, A. M., P. A. Rajakumar, and M. Murphey-Corb. 2002. Species-specific variation in SIV disease progression between Chinese and Indian subspecies of rhesus macaque. J Med Primatol 31:171-8.

200. Tsujimoto, H., R. W. Cooper, T. Kodama, M. Fukasawa, T. Miura, Y. Ohta, K. Ishikawa, M. Nakai, E. Frost, G. E. Roelants, and et al. 1988. Isolation and characterization of simian immunodeficiency virus from mandrills in Africa and its relationship to other human and simian immunodeficiency viruses. J Virol 62:4044-50.

201. Tyler, D. S., S. D. Stanley, C. A. Nastala, A. A. Austin, J. A. Bartlett, K. C. Stine, H. K. Lyerly, D. P. Bolognesi, and K. J. Weinhold. 1990. Alterations in antibody-dependent cellular cytotoxicity during the course of HIV-1 infection. Humoral and cellular defects. J Immunol 144:3375-84.

202. Ueno, T., H. Tomiyama, M. Fujiwara, S. Oka, and M. Takiguchi. 2004. Functionally impaired HIV-specific CD8 T cells show high affinity TCRligand interactions. J Immunol 173:5451-7.

203. UNAIDS. 2006. AIDS Epidemic Update : Special Report on HIVIAIDS: December 2006. WHO Library Cataloguing-in-Publication Data.

204. van der Meide, P. H., R. J. Groenestein, M. C. de Labie, J. Heeney, P. Pala, and M. Slaoui. 1995. Enumeration of lymphokine-secreting cells as a quantitative measure for cellular immune responses in rhesus macaques. J Med Primatol 24:271-81.

205. VandeWoude, S., and C. Apetrei. 2006. Going wild: lessons from naturally occurring T-lymphotropic lentiviruses. Clin Microbiol Rev 19:728-62.

206. Veazey, R. S., M. DeMaria, L. V. Chalifoux, D. E. Shvetz, D. R. Pauley, H. L. Knight, M. Rosenzweig, R. P. Johnson, R. C. Desrosiers, and A. A. Lackner. 1998. Gastrointestinal tract as a major site of CD4+ T cell depletion and viral replication in SIV infection. Science 280:427-31.

207. Veazey, R. S., K. G. Mansfield, I. C. Tham, A. C. Carville, D. E. Shvetz, A. E. Forand, and A. A. Lackner. 2000. Dynamics of CCR5 expression by CD4(+) T cells in lymphoid tissues during simian immunodeficiency virus infection. J Virol 74:11001-7. 
208. Viollet, L., V. Monceaux, F. Petit, R. Ho Tsong Fang, M. C. Cumont, B. Hurtrel, and J. Estaquier. 2006. Death of CD4+ T cells from lymph nodes during primary SIVmac251 infection predicts the rate of AIDS progression. J Immunol 177:6685-94.

209. von Herrath, M. G., M. Yokoyama, J. Dockter, M. B. Oldstone, and J. L. Whitton. 1996. CD4-deficient mice have reduced levels of memory cytotoxic T lymphocytes after immunization and show diminished resistance to subsequent virus challenge. J Virol 70:1072-9.

210. Wagner, L., O. O. Yang, E. A. Garcia-Zepeda, Y. Ge, S. A. Kalams, B. D. Walker, M. S. Pasternack, and A. D. Luster. 1998. Beta-chemokines are released from HIV-1-specific cytolytic T-cell granules complexed to proteoglycans. Nature 391:908-11.

211. Wagner, R., L. Deml, R. Schirmbeck, M. Niedrig, J. Reimann, and H. Wolf. 1996. Construction, expression, and immunogenicity of chimeric HIV-1 virus-like particles. Virology 220:128-40.

212. Wang, W. K., M. Y. Chen, C. Y. Chuang, K. T. Jeang, and L. M. Huang. 2000. Molecular biology of human immunodeficiency virus type 1. J Microbiol Immunol Infect 33:131-40.

213. Watson, A., J. Ranchalis, B. Travis, J. McClure, W. Sutton, P. R. Johnson, S. L. Hu, and N. L. Haigwood. 1997. Plasma viremia in macaques infected with simian immunodeficiency virus: plasma viral load early in infection predicts survival. J Virol 71:284-90.

214. Wherry, E. J., and R. Ahmed. 2004. Memory CD8 T-cell differentiation during viral infection. J Virol 78:5535-45.

215. Wilson, N. A., J. Reed, G. S. Napoe, S. Piaskowski, A. Szymanski, J. Furlott, E. J. Gonzalez, L. J. Yant, N. J. Maness, G. E. May, T. Soma, M. R. Reynolds, E. Rakasz, R. Rudersdorf, A. B. McDermott, D. H. O'Connor, T. C. Friedrich, D. B. Allison, A. Patki, L. J. Picker, D. R. Burton, J. Lin, L. Huang, D. Patel, G. Heindecker, J. Fan, M. Citron, M. Horton, F. Wang, X. Liang, J. W. Shiver, D. R. Casimiro, and D. I. Watkins. 2006. Vaccine-induced cellular immune responses reduce plasma viral concentrations after repeated low-dose challenge with pathogenic simian immunodeficiency virus SIVmac239. J Virol 80:587585.

216. Yamamoto, H., M. Kawada, A. Takeda, H. Igarashi, and T. Matano. 2007. Post-infection immunodeficiency virus control by neutralizing antibodies. PLoS ONE 2:e540.

217. Yang, O. O., S. A. Kalams, A. Trocha, H. Cao, A. Luster, R. P. Johnson, and B. D. Walker. 1997. Suppression of human immunodeficiency virus type 1 replication by CD8+ cells: evidence for HLA class I-restricted triggering of cytolytic and noncytolytic mechanisms. J Virol 71:3120-8.

218. Younes, S. A., B. Yassine-Diab, A. R. Dumont, M. R. Boulassel, Z. Grossman, J. P. Routy, and R. P. Sekaly. 2003. HIV-1 viremia prevents the establishment of interleukin 2-producing HIV-specific memory CD4+ T cells endowed with proliferative capacity. J Exp Med 198:1909-22.

219. Zhang, Z. Q., S. W. Wietgrefe, Q. Li, M. D. Shore, L. Duan, C. Reilly, J. D. Lifson, and A. T. Haase. 2004. Roles of substrate availability and infection of resting and activated CD4+ T cells in transmission and acute simian immunodeficiency virus infection. Proc Natl Acad Sci U S A 101:5640-5. 


\section{Anhang}

\section{Abbildungsverzeichnis}

Abb. 1.1: Aufbau des SIV-Genoms.............................................. 5

Abb. 1.2: Schematische Darstellung des HIV-Replikationszyklus ..............6 6

Abb. 1.3: Vergleich der konventionellen Sicht des SIV-Infektionsverlaufs mit dem neuen Modell ........................................................... 7

Abb. 1.4: Veränderungen der T-Zellpopulationen, der Virämie und der Immunaktivierung nach SIV-Infektion..................................... 8

Abb. 2.1: Schematische Darstellung der drei Versuchsreihen.....................27

Abb. 3.1: Anzahl IFNy-sezernierender Zellen im Zeitraum der „Prime- und Boost"-Immunisierungen nach Gag-Stimulation

Abb. 3.2: Anzahl IFNy-sezernierender Zellen im Zeitraum der „Prime- und Boost"-Immunisierungen nach p26-Stimulation

Abb 3.3: Anzahl der viralen RNA-Kopien pro Milliliter Blutplasma im Zeitverlauf nach Belastungsinfektion

Abb. 3.4: Kaplan-Meier-Darstellung des Anteils der überlebenden Tiere der ersten Versuchsreihe nach Belastungsinfektion

Abb. 3.5: Anteil der CD4 ${ }^{+}$T-Lymphozyten an den Gesamtlymphozyten nach Belastungsinfektion

Abb. 3.6: Anteil der CD $195^{+}$T-Lymphozyten an den CD4 ${ }^{+}$T-Lymphozyten nach Belastungsinfektion

Abb. 3.7: Korrelation der Plasma-RNA mit der Expression von CD195 auf den $\mathrm{CD}^{+}$T-Lymphozyten

Abb. 3.8: Anteil der CD95 ${ }^{+}$T-Lymphozyten an den CD4 ${ }^{+}$T-Lymphozyten nach Belastungsinfektion

Abb. 3.9: Korrelation der Plasma-RNA mit der Expression von CD95 auf den $\mathrm{CD}^{+} \mathrm{T}$-Lymphozyten

Abb. 3.10: Anteil der $\mathrm{CD}^{+} 5^{+} 28^{+}$T-Lymphozyten (TCM) und der $\mathrm{CD}^{+} 5^{+} 28^{-}$T-Lymphozyten (TEM) an den CD4 ${ }^{+}$T-Lymphozyten nach Belastungsinfektion

Abb. 3.11: Korrelation der Plasma-RNA mit dem Anteil der CD4 ${ }^{+} \mathrm{TCM}^{-}$ und $\mathrm{CD} 4^{+}$TEM

Abb. 3.12: Anteil der CD95 ${ }^{+} 28^{+}$(TCM), der CD95 ${ }^{+} 28^{-}$(TEM) und der naiven T-Lymphozyten an den $\mathrm{CD}^{+} \mathrm{T}$-Zellen im Zeitverlauf und in der Woche 2 im Blut der Versuchstiere

Abb. 3.13: Anzahl IFNy-sezernierender PBMC in den drei Versuchsgruppen nach Gag-Stimulation im Zeitraum nach Belastungsinfektion 
Abb. 3.14: Anzahl IFNy-sezernierender PBMC in den drei Versuchsgruppen nach p26-Stimulation im Zeitraum nach Belastungsinfektion 60

Abb. 3.15: Anzahl IFNy-sezernierender Zellen in der Impfgruppe (A) und den Kontrolltieren (B) im Zeitraum der „Prime- und Boost“Immunisierungen nach Gag-Stimulation

Abb 3.16: Anzahl der viralen RNA-Kopien pro Milliliter Blutplasma im Zeitverlauf nach Belastungsinfektion

Abb. 3.17: Kaplan-Meier-Darstellung des Anteils der überlebenden Tiere der zweiten Versuchsreihe nach Belastungsinfektion

Abb. 3.18: Anteil der CD4 ${ }^{+}$T-Lymphozyten an den Gesamtlymphozyten im Blut der Versuchstiere nach Belastungsinfektion.

Abb. 3.19: Anteil der CD4 ${ }^{+} 195^{+}$T-Lymphozyten an den

Gesamtlymphozyten im Blut der Versuchstiere nach

Belastungsinfektion

Abb. 3.20: Anteil der CD4 ${ }^{+} 95^{+}$T-Lymphozyten an den

Gesamtlymphozyten im Blut der Versuchstiere nach

Belastungsinfektion

Abb. 3.21: Anteil der zentralen Gedächtniszellen (TCM) und der Effektorgedächtniszellen (TEM) im Blut der Versuchstiere nach Belastungsinfektion

Abb. 3.22: Vergleich der mittleren Anzahl der IFNy-sezernierenden Zellen in der Impfgruppe und den Kontrollen nach Gag-Stimulation zum Zeitpunkt der Belastungsinfektion.

Abb. 3.23: Anzahl IFNy-sezernierender Zellen in der Impfgruppe (A) und den Kontrolltieren (B) nach Gag-Stimulation im Zeitraum nach Belastungsinfektion

Abb. 3.24: Vergleich der ELISPOT- und ICS-Ergebnisse nach Gag-Stimulation in den Impflingen nach Belastungsinfektion in der zweiten Versuchsreihe.

Abb. 3.25: Vergleich der ELISPOT- und ICS-Ergebnisse nach Gag-Stimulation in den Kontrollen nach Belastungsinfektion in der zweiten Versuchsreihe

Abb. 3.26: Vergleich der ELISPOT- und ICS-Ergebnisse nach Gag-Stimulation im Zeitverlauf nach Belastungsinfektion in der zweiten Versuchsreihe

Abb. 3.27: Gemittelter Anteil an Zytokin-einfach positiven und polyfunktionalen $\mathrm{CD}^{+}$und $\mathrm{CD}^{+}{ }^{\mathrm{T}}$-Lymphozyten nach GagStimulation zwei Wochen nach Belastungsinfektion in der zweiten Versuchsreihe

Abb 3.28: Anzahl der viralen RNA-Kopien pro Milliliter Blutplasma im Zeitverlauf nach Belastungsinfektion in den viruskontrollierenden Tieren 
Abb 3.29: Anzahl der viralen RNA-Kopien pro Milliliter Blutplasma im Zeitverlauf nach Belastungsinfektion in den nichtviruskontrollierenden Tieren ....

Abb. 3.30: Mittlere Anzahl von viralen RNA-Kopien pro Milliliter Blutplasma im Zeitverlauf nach Belastungsinfektion in den viruskontrollierenden Tieren und den Tieren mit hoher Viruslast 78

Abb. 3.31: Prozentualer Anteil von proliferierenden GedächtnisT-Lymphozyten nach antigenspezifischer Stimulation in den Viruscontrollern in der chronischen Phase der Belastungsinfektion

Abb. 3.32: Prozentualer Anteil von proliferierenden T-Lymphozyten nach antigenspezifischer Stimulation in nicht-infizierten Kontrolltieren

Abb. 3.33: Polyfunktionale T-Lymphozyten nach Gag-Stimulation in den Viruscontrollern 62 bis 74 Wochen nach

Belastungsinfektion

Abb. 3.34: Polyfunktionale T-Lymphozyten nach SEB-Stimulation in den Viruscontrollern 62 bis 74 Wochen nach Belastungsinfektion

Abb. 3.35: Polyfunktionale T-Lymphozyten nach SEB-Stimulation in den Non-Controllern 62 bis 74 Wochen nach Belastungsinfektion

Abb. 3.36: Prozentualer Anteil der CM9-Tetramer ${ }^{+} \mathrm{CD}^{+}{ }^{\text {T-Lymphozyten..... } 84}$

Abb. 3.37: Anzahl IFNy-sezernierender Zellen in der Impfgruppe (A) und den Kontrolltieren (B) im Zeitraum der „Prime- und Boost“Immunisierungen nach Gag-Stimulation

Abb 3.38: Anzahl der viralen RNA-Kopien pro Milliliter Blutplasma im Zeitverlauf nach Belastungsinfektion

Abb. 3.39: Anteil der CD4 ${ }^{+}$T-Lymphozyten an den Gesamtlymphozyten im Blut der Versuchstiere nach Belastungsinfektion.

Abb. 3.40: Anteil der CD4 ${ }^{+} 195^{+}$T-Lymphozyten an den Gesamtlymphozyten im Zeitverlauf im Blut der Versuchstiere nach Belastungsinfektion

Abb. 3.41: Anteil der CD4 ${ }^{+} 95^{+}$T-Lymphozyten an den Gesamtlymphozyten im Zeitverlauf im Blut der Versuchstiere nach Belastungsinfektion

Abb. 3.42: Anteil der $\mathrm{CD}^{+} 95^{+} 28^{+}$und der $\mathrm{CD}^{+} 95^{+} 28^{+}$T-Lymphozyten an den Gesamtlymphozyten im Zeitverlauf im Blut der Versuchstiere nach Belastungsinfektion.

Abb. 3.43: Anteil IFNy-sezernierender PBMC in den zwei Versuchsgruppen nach Gag-Stimulation in der dritten Versuchsreihe

Abb. 3.44: Vergleich der ELISPOT- und ICS-Ergebnisse der Impflinge nach Gag-Stimulation im Zeitverlauf nach Belastungsinfektion in der dritten Versuchsreihe 
Abb. 3.45: Vergleich der ELISPOT- und ICS-Ergebnisse der Kontrollen nach Gag-Stimulation im Zeitverlauf nach Belastungsinfektion in der dritten Versuchsreihe

Abb. 3.46: Vergleich der medianen ELISPOT- und ICS-Ergebnisse nach Gag-Stimulation im Zeitverlauf nach Belastungsinfektion in der dritten Versuchsreihe

Abb. 3.47: Polyfunktionale CD4 ${ }^{+}$T-Lymphozyten nach Gag-Stimulation in den Impflingen und Kontrollen der dritten Versuchsreihe nach Belastungsinfektion

Abb. 3.48: Polyfunktionale CD8 ${ }^{+}$T-Lymphozyten nach Gag-Stimulation in den Impflingen und Kontrollen der dritten Versuchsreihe nach Belastungsinfektion 102

Abb. 3.49: Expression von Ki67 in den T-Lymphozyten im Zeitverlauf in den Impflingen und Kontrollen... 103

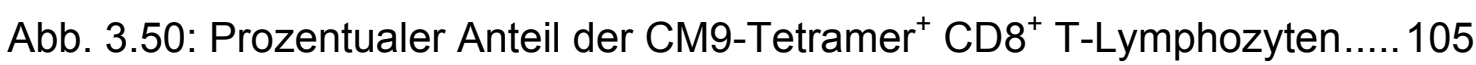

Abb. 3.51: Absolute Anzahl der CM9-Tetramer ${ }^{+}$CD8 $^{+}$T-Lymphozyten 105 


\section{Tabellenverzeichnis}

Tab. 2.1: Übersicht über die verwendeten Fluoreszenzfarbstoffe, ihre Absorptions- und Emissionsmaxima und die zur Messung im Durchflusszytometer verwendeten Filter und Laser

Tab. 2.2: Übersicht über die verwendeten murinen anti-humanen Antikörper

Tab. 2.3: Übersicht über die verwendeten Zellkulturmedien, Puffer und Medienzusätze

Tab. 2.4: Zuordnungsnummer und Peptidsequenzen der 22 Peptide des p26-Peptidpools

Tab. 2.5: Zuordnungsnummer und Peptidsequenzen der 16 Peptide des Gag-Peptidpools 22

Tab. 2.6: Peptidsequenz des Gag CM9-Peptids 22

Tab. 2.7: Beschreibung des HCV-Peptidpools mit den entsprechenden Peptidsequenzen und dem Reinheitsgrad. 22

Tab. 2.8: Sequenzen der verwendeten Primer und der Taqman-Sonde ......23

Tab. 2.9: Immunisierungsschema der ersten Versuchsreihe (DNA-Adeno)

Tab. 2.10: Immunisierungsschema der zweiten Versuchsreihe (VLP-Adeno) 26

Tab. 2.11: Immunisierungsschema der dritten Versuchsreihe (aVLP-Adeno) 26

Tab. 2.12: Übersicht über die verwendeten Kombinationen der jeweiligen Antikörper-Fluorochrom-Konjugate (Tab. 2.2) zur Charakterisierung der T-Zellen.

Tab. 2.13: Übersicht über die Kombination der verwendeten Antikörper-Fluorochrom-Konjugate (Tab. 2.2) für die intrazelluläre Zytokinfärbung ............................................................... 33

Tab. 2.14: Reaktionsansatz für die RT-PCR …....................................... 36

Tab. 2.15: PCR-Bedingungen für die RT-PCR .................................... 36

Tab. 3.1: Ergebnisse des ELISPOT und des Proliferationstests in den zehn viruskontrollierenden Tieren

Tab. 3.2: Ergebnisse der CM9-Tetramerfärbung und des ICS in den zehn viruskontrollierenden Tieren 


\section{Publikationsverzeichnis}

\section{Publikationen mit persönlicher Beteiligung}

Suh YS, Ki Park KS, Sauermann U, Kim KS, Ahn SS, Franz M, Schulte R, Wilfingseder D, Stoiber H, Überla K, Hunsmann G, Stahl-Hennig C, Sung YC

Protection of AIDS-related Diseases by Multigenic DNA and Recombinant Adenovirus Vaccination in Macaques Challenged with a Lethal Dose of SIVmac239 (eingereicht beim Journal of Virology)

Stahl-Hennig, C., Y. S. Suh, K. S. Park, U. Sauermann, K. S. Kim, S. Ahn, M. Franz, R. Schulte, N. Stolte-Leeb, G. Hunsmann, and Y. C. Sung. 2007. Immunogenicity of a DNA prime and recombinant adenovirus boost regime significantly varies between rhesus macaques of Chinese and Indian origins. J Med Primatol 36:195-205.

\section{Vorträge (international)}

Reiner Schulte; Multicolour flow cytometry allows monitoring of immunological parameters in SIV vaccine experiment;

Movement as prevention and health - Modulation of free radicals concentration, Konferenz der Universität Rom - Tor Vergata, September 25-27, 2006, Rom, Italien

Reiner Schulte, Sieghart Sopper, You-Suk Suh, Kwang Son Kim, Youl Soung Sung, Ulrike Sauermann, Gerhard Hunsmann, Christiane Stahl-Hennig; Preservation of central memory T cell subsets after SIVmac239 challenge following a DNA prime and adenoviral boost vaccination regime; AIDS Vaccine06, $5^{\text {th }}$ International AIDS VACCINE Conference, August 29 September 1, 2006, Amsterdam, Niederlande

Reiner Schulte, Sieghart Sopper, Gerhard Hunsmann, Christiane Stahl-Hennig Multicolour flow cytometry for the monitoring of T-cell physiology in SIV vaccine experiments;

Korea-Germany AIDS Symposium \& Workshop, Februar 8-9, 2006 POSTTECH Biotech Center, Pohang, Republik Korea

\section{Vorträge (national)}

Reiner Schulte, Paris Sidiropoulos, Christiane Stahl-Hennig, Gerhard Hunsmann, Sieghart Sopper Multicolour flow cytometry allows monitoring of immunological parameters 1. Congress of the European Federation for Primatology (9. Tagung der Gesellschaft für Primatologie), Göttingen 


\section{Posterbeiträge}

Reiner Schulte, Sieghart Sopper, Ulrike Sauermann, Gerhard Hunsmann and Christiane Stahl-Hennig

Polyfunctional $\mathrm{CD} 4^{+} \mathrm{T}$-cell responses and proliferation of $\mathrm{CD} 4^{+}$memory $\mathrm{T}$-cells in long-term SIV-infected macaques

Jahrestagung der Deutschen Gesellschaft für Virologie, September 2007, Nürnberg

Reiner Schulte, Sieghart Sopper, Gerhard Hunsmann and Christiane StahlHennig

Multicolour flow cytometry for the monitoring of T-cell physiology in long-term SIV-infected macaques

1. Congress of the European Federation for Primatology (9. Tagung der Gesellschaft für Primatologie), Göttingen

Reiner Schulte, Sieghart Sopper, Gerhard Hunsmann and Christiane StahlHennig

Flow-cytometric analysis of SIV-specific immune responses in long-term infected macaques

Jahrestagung der Deutschen Gesellschaft für Virologie, März 2005, Hannover 


\section{Danksagung}

Herrn Prof. Dr. H.-J. Fritz danke ich für die externe Betreuung der vorliegenden Arbeit und deren Vertretung im Fachbereich Biologie der Georg-AugustUniversität Göttingen.

Herrn Priv.-Doz. Dr. Sieghart Sopper danke ich für die Übernahme des Koreferates dieser Arbeit. Weiterhin danke ich inm für sein Interesse an der Arbeit und zahllose hilfreiche Unterstützungen und Diskussionen.

Herrn Prof. Dr. G. Hunsmann danke ich für die guten Arbeitsmöglichkeiten in der Abteilung Virologie und Immunologie am Deutschen Primatenzentrum und viele interessante Gespräche.

Mein besonderer Dank gilt Frau Dr. Christiane Stahl-Hennig für die Vergabe des Themas dieser Arbeit und für die Bereitstellung des Arbeitsplatzes in der Abteilung Virologie und Immunologie. Sie hat die Entwicklung der Arbeit stets mit großem Interesse verfolgt und durch viele fachkundige Anregungen und Hinweise maßgeblich zum Erfolg der Arbeit beigetragen. Ihre Diskussionsbereitschaft und Unterstützung waren für mich eine große Hilfe.

Mein Dank gilt außerdem Judith Hampe, Sandra Heine und Nicola Schwedhelm für ihre tatkräftige Unterstützung meiner praktischen Arbeiten im Labor.

Allen Kollegen aus der Abteilung für Virologie und Immunologie danke ich für das angenehme Arbeitsklima. Mein besonderer Dank gilt Dr. Monika Franz, Dr. Angela Brunke, Christina Dieter sowie Peter Müller, Thorsten Eggers, Henning Mascher und Gabriele Marschhausen.

Meiner Familie danke ich für die Unterstützung und liebevolle Begleitung meines bisherigen Werdeganges.

Meiner Frau Ina danke ich für ihre Liebe und Geduld sowie die Unterstützung bei der Fertigstellung dieser Arbeit. 


\title{
Lebenslauf
}

\author{
Reiner Schulte \\ geboren am 09. Januar 1978 in Arnsberg \\ Diplom-Biochemiker \\ Nationalität: deutsch
}

seit Januar 2004

Doktorand in der AG „Tiermodelle“ der Abteilung für

Virologie und Immunologie am Deutschen

Primatenzentrum $\mathrm{GmbH}$, Leibniz Institut für

Primatenforschung, Göttingen

$01 / 2002-12 / 2003$

Diplomarbeit

„Biochemische und zellbiologische Charakterisierung von Dexamethason enthaltenden Liposomen“

in der Nachwuchsgruppe Experimentelle

Rheumatologie am Klinikum der Friedrich-Schiller-

Universität Jena

10/1998 - 12/2003 Diplomstudiengang Biochemie / Molekularbiologie,

Friedrich-Schiller-Universität Jena
07/1997-04/1998 Ableistung des Grundwehrdienstes
09/1988 - 06/1997 Besuch des Städtischen Gymnasiums Sundern
Abschluss: Abitur

Göttingen, den 18.09.2007

Reiner Schulte 